\title{
A new approach to running style analysis using a pressure-sensitive insole device: a small step towards injury prevention
}

Citation for published version (APA):

Mann, R. M. (2015). A new approach to running style analysis using a pressure-sensitive insole device: a small step towards injury prevention. [Doctoral Thesis, Maastricht University]. Datawyse / Universitaire Pers Maastricht. https://doi.org/10.26481/dis.20150706rm

Document status and date:

Published: 01/01/2015

DOI:

10.26481/dis.20150706rm

Document Version:

Publisher's PDF, also known as Version of record

Please check the document version of this publication:

- A submitted manuscript is the version of the article upon submission and before peer-review. There can be important differences between the submitted version and the official published version of record.

People interested in the research are advised to contact the author for the final version of the publication, or visit the DOI to the publisher's website.

- The final author version and the galley proof are versions of the publication after peer review.

- The final published version features the final layout of the paper including the volume, issue and page numbers.

Link to publication

\footnotetext{
General rights rights.

- You may freely distribute the URL identifying the publication in the public portal. please follow below link for the End User Agreement:

www.umlib.nl/taverne-license

Take down policy

If you believe that this document breaches copyright please contact us at:

repository@maastrichtuniversity.nl

providing details and we will investigate your claim.
}

Copyright and moral rights for the publications made accessible in the public portal are retained by the authors and/or other copyright owners and it is a condition of accessing publications that users recognise and abide by the legal requirements associated with these

- Users may download and print one copy of any publication from the public portal for the purpose of private study or research.

- You may not further distribute the material or use it for any profit-making activity or commercial gain

If the publication is distributed under the terms of Article $25 \mathrm{fa}$ of the Dutch Copyright Act, indicated by the "Taverne" license above, 
The work presented in this thesis was supported by the Fond National de la Recherche, Luxembourg (ref : 1102562)

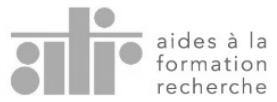

Fonds National de la

Recherche Luxembourg

ISBN 9789461594518 


\title{
A new approach to running style analysis using a pressure-sensitive insole device:
}

A small step towards injury prevention.

\author{
PROEFSCHRIFT \\ ter verkrijging van de graad van doctor aan de Universiteit Maastricht, \\ op gezag van de Rector Magnificus, Prof. Dr L.L.G Soete, \\ volgens het besluit van het College van Decanen, \\ in het openbaar te verdedigen \\ op maandag 6 juli 2015, om 14:00 uur \\ door \\ ROBERT MICHAEL MANN \\ Geboren te Luxemburg op 20 juni 1985
}

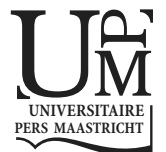




\section{Promotores}

Prof. dr. Matthijs Hesselink

Prof. dr. Daniel Theisen

Sports Medicine Research Laboratory,

Luxembourg Institute of Health

\section{Copromotores}

Dr Kenneth Meijer

Dr Laurent Malisoux

Sports Medicine Research Laboratory,

Luxembourg Institute of Health

\section{Beoordelingscommissie}

Prof. dr. Rob de Bie (chair)

Prof. dr. Lodewijk van Rhijn

Dr Fred Hartgens

Prof. dr. Jean-Benoît Morin

Dr Rasmus Nielsen

Université de Nice Sophia Antipolis, France

Aarhus University, Denmark 


\section{Contents}

$\begin{array}{ll}\text { List of Abbreviations } & 6\end{array}$

$\begin{array}{lll}\text { Chapter } 1 & \text { General introduction } & 7\end{array}$

Chapter 2 Reliability and Validity of Pressure and Temporal

Parameters Recorded Using a Pressure-sensitive Insole during Running.

Chapter 3 Can the Runalyser Reliably Measure Vertical Loading Rate?

Chapter 4 Association of Previous Injury and Speed with Running Style and Stride-to-stride Fluctuations.

Chapter 5 The Effect of Fatigue and Shoe Type on Running Biomechanics from Pressure Data.

Chapter 6 Can Parallel Use of Different Running Shoes Decrease Running related Injury Risk?

Chapter $7 \quad$ General discussion

Summary

Samenvatting

Valorisation

Acknowledgements

About the author 


\section{List of Abbreviations}

\begin{tabular}{ll} 
95\%Cl & 95\% confidence interval \\
a.u. & arbitrary unit \\
AFR & Aides à la Formation-Recherche \\
AT & Achilles tendinopathy \\
BMI & body mass index \\
CNER & Comité National d'Ethique de Recherche \\
CONV & Conventional running shoes \\
CV & Coefficient of variation \\
DF & duty factor \\
DFA & detrended fluctuation analysis \\
FC & foot contact \\
FFS & forefoot strike \\
FMM & foot mobility magnitude \\
FSA & footstrike angle \\
HABIT & habitual running style \\
HR & hazard ratio \\
ICC & intra-class correlation coefficient \\
MDC & minimal detectible change \\
MFS & midfoot strike \\
MIN & minimalistic running shoes \\
ms & milliseconds \\
Non-RFS & non rearfoot strike \\
PF & plantar fasciitis \\
PFP & patellofemoral pain \\
PRS & preferred running speed \\
RFS & rearfoot strike \\
RPE & rate of perceived exertion \\
RRI & running-related injury \\
SD & standard deviation \\
frequency $_{\text {fri }}$ & stride frequency \\
SI & strike index \\
$\mathrm{S}_{\text {length }}$ & stride length \\
$\mathrm{T}_{\text {contact }}$ & contact time \\
$\mathrm{T}_{\text {flight }}$ & flight time \\
TIPPS & Training and Injury Prevention Platform for Sports \\
TO & toe-off \\
TSF & tibial stress fracture \\
$\mathrm{T}_{\text {stride }}$ & stride time \\
VLR & vertical loading rate \\
& \\
\hline
\end{tabular}


Chapter 1

General introduction 


\section{The contemporary runner}

As a recreational and health-related activity, running has experienced a global surge in popularity as a result of the "running boom" in the early 1970s. A number of catalysts (originating from the United States) simultaneously contributed to this phenomenon which we are still experiencing today. Running shoes were suddenly much more commercially available, and the well-known running coach, Bill Bowerman introduced the first cushioned running shoe to the world in 1972, the "Moon Shoe", famously conceived using his wife's waffle iron. Further experimentation led to the "Waffle Trainer" released in 1974. Jim Fixx's book "The Complete Book of Running", as well as other literature such as "Jogging: A Physical Fitness Program for All Ages" by Bowerman and Dr Waldo Harris, and the popular magazine "Runner's World" also contributed to the sharp growth in running participation. World-famous athletes of the time such as Frank Shorter and Bill Rodgers managed to spark the appeal of running within the general population with their respective, 1972 Olympic and four-time Boston Marathon gold medals (Larson, 2012). Ever growing numbers of marathon participation illustrate this increase in running popularity. For example, 1981 saw 6,418 runners cross the finish line of the first edition of the London Marathon, and in 2003 this number had grown to 32,200 (Tunstall Pedoe, 2014). Yearly interest is still increasing, with 35,817 finishers registered in 2014 ("London Marathon Race Results 2014," 2014). Figure 1.1 shows the annual participation numbers of the Boston Marathon since its debut in 1897. The sudden, exponential rise in participants highlights this increased popularity of running around the early 1970s, and although it does not necessarily depict a sudden increase in people practicing running activity, it certainly suggests a change in behaviour of runners as of this era. In 1996 the organisers celebrated 100 years of the Boston Marathon, which was marked by a staggering 38,708 entrants (Association, 2014). This could be an example of a recent shift in runners participating in a marathon for primarily performance oriented goals to social and health-related goals. Winning is no longer the primary motivation to take part in a marathon. Indeed, it has been observed that the median time to complete a marathon has risen from 3h:32min in 1980 to $4 \mathrm{~h}: 16 \mathrm{~min}$ in 2008 for men, and from $4 \mathrm{~h}: 03 \mathrm{~min}$ to $4 \mathrm{~h}: 43 \mathrm{~min}$ for women (Macur, 2009). The gender-divide also reduced significantly with an increase in female marathon participation from $10.5 \%$ to $34 \%$ over a 20 year period reported in 2002 (Chorley et al., 2002). A shift in runner demographics and a gradual increase in popularity in recreational running has occurred, bringing with it an array of health consequences on at a population level. 


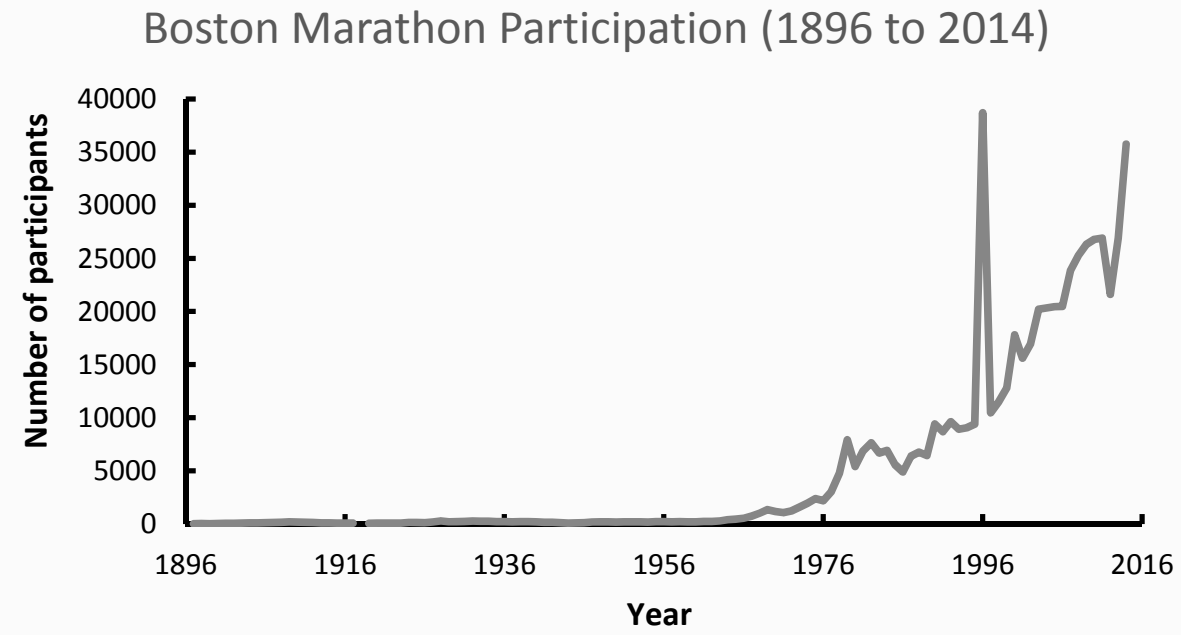

Figure 1.1. The number of entrants for each year of the marathon's existence. Curtesy of Boston Athletic Association and adapted from http://www.baa.org/races/boston-marathon/boston-marathonhistory/participation.aspx.

\section{Running-related injury incidence and definition}

Positive health benefits of regular running activity have been put forward. Running reduces the risk of cardiovascular disease, diabetes mellitus type II and hypercholesterolemia (Thompson et al., 2003) and increases aerobic fitness, skeletal muscle strength and bone density (Pedersen \& Saltin, 2006). Psychological benefits of running exercise such as combatting depression have also been suspected (Craft \& Perna, 2004). Despite these advantages, injury is a main cause of interruption and discontinuation of running activity (Sallis et al., 1990), and a fear of re-injury can dissuade former runners for example, from resuming their running participation (Sallis et al., 1992). In 1992, Van Mechelen reviewed the injury incidences of 10 prospective and retrospective studies of one year follow-up and reported an overall yearly incidence rate of $24-77 \%$, or $37-56 \%$ when restricted to cohorts of more than 500 recreational runners (van Mechelen, 1992). In 2007, injury incidence as a result of running was estimated at $19.4-79.3 \%$ for lower limb injuries, and $19.4-92.4 \%$ for all injuries (van Gent et al., 2007). It has been estimated that $50 \%$ of runners sustain a running-related injury (RRI) within a year, and at any given moment $25 \%$ of runners are injured (Fields et al., 2010). Indeed, a survey of 1049 recreational runners revealed that $22 \%$ started a marathon race with some form of musculoskeletal pain (Lopes et al., 2011). With the rapid increase in running participation as outlined above, it would 
appear that RRI incidences have not undergone any noticeable reduction over the last few decades (Jenkins \& Cauthon, 2011) despite extensive research in RRI risk factor identification and RRI prevention, and the relentless evolution of shoe technologies.

Table 1.1. Summary of prospective cohort studies reporting on RRI incidence.

\begin{tabular}{|c|c|c|c|c|}
\hline Study & Inclusion criteria & Cohort & Follow-up & $\begin{array}{l}\text { RRI incidence/rate of } \\
\text { incidence }\end{array}$ \\
\hline$\frac{\text { (Bovens et }}{\text { al., 1989) }}$ & $>20 y$ & $\begin{array}{l}73 \text { volunteers with } \\
\text { little or no running } \\
\text { experience }\end{array}$ & 18 months & $85 \%$ (62/73 runners) \\
\hline $\begin{array}{l}\text { (Taunton et } \\
\text { al., 2003) }\end{array}$ & $\begin{array}{l}\text { Recreational } \\
\text { runners interested } \\
\text { in completing } 10 \mathrm{~km} \\
\text { or improving race } \\
\text { time. }\end{array}$ & $\begin{array}{l}844 \text { recreational } \\
\text { runners }\end{array}$ & $\begin{array}{l}13 \text { weeks training } \\
\text { protocol of either } \\
\text { novice or } \\
\text { intermediate level }\end{array}$ & $\begin{array}{l}29.5 \%(249 / 844 \\
\text { runners) }\end{array}$ \\
\hline $\begin{array}{l}\text { (Lun et al., } \\
\text { 2004) }\end{array}$ & $\begin{array}{l}>18 \mathrm{y},>20 \mathrm{~km} / \text { week } \\
\text { running, no current } \\
\text { injury, }<4 x / \text { week } \\
\text { other axial loading } \\
\text { activities. }\end{array}$ & $\begin{array}{l}153 \text { recreational } \\
\text { runners (66 } \\
\text { dropouts). }\end{array}$ & 6 months & $79 \%$ (69/87 runners) \\
\hline $\begin{array}{l}\text { (Rauh et al., } \\
\underline{2006)}\end{array}$ & $\begin{array}{l}\text { Competitors in the } \\
1996 \text { cross-country } \\
\text { season in Seattle, } \\
\text { Washington. }\end{array}$ & $\begin{array}{l}421 \text { cross-country, } \\
\text { high school } \\
\text { runners }\end{array}$ & $\begin{array}{l}11 \text { weeks (the } 1996 \\
\text { cross-country } \\
\text { season) }\end{array}$ & $\begin{array}{l}17 / 1000 \text { athletic } \\
\text { events }\end{array}$ \\
\hline $\begin{array}{l}\frac{\text { (Van }}{\text { Middelkoop }} \\
\text { et al., 2008) }\end{array}$ & $\begin{array}{l}\text { Male, resident of } \\
\text { the Netherlands and } \\
\text { not competitive } \\
\text { with professional } \\
\text { runners. }\end{array}$ & $\begin{array}{l}694 \text { male runners } \\
\text { taking part in the } \\
2005 \text { Rotterdam } \\
\text { Marathon }\end{array}$ & $\begin{array}{l}\text { Questionnaire } 1 \\
\text { month before and } \\
\text { immediately after } \\
\text { marathon event. }\end{array}$ & $\begin{array}{l}28.1 \% \text { (195/694 } \\
\text { runners) reported } \\
\text { injury } 1 \text { month prior } \\
\text { to or during } \\
\text { marathon. }\end{array}$ \\
\hline $\begin{array}{l}\text { (Buist et al., } \\
\underline{2008)}\end{array}$ & $\begin{array}{l}\text { Healthy and } 18 \text { - } 65 \\
\text { years, no injury } \\
\text { previous } 3 \text { months, } \\
\text { no regular running } \\
\text { for previous } 12 \\
\text { months. }\end{array}$ & $\begin{array}{l}250 \text { graded training } \\
\text { programme, } 236 \\
\text { standard training } \\
\text { programme }\end{array}$ & $\begin{array}{l}\text { 13-week graded } \\
\text { training programme } \\
\text { for intervention } \\
\text { group and 8-week } \\
\text { standard training } \\
\text { programme for } \\
\text { controls. }\end{array}$ & $\begin{array}{l}20.8 \% \text { for graded } \\
\text { training programme } \\
\text { and } 20.3 \% \text { for } \\
\text { standard training } \\
\text { programme. }\end{array}$ \\
\hline $\begin{array}{l}\text { (Buist et al., } \\
\underline{2010)}\end{array}$ & $>18 y$ & $\begin{array}{l}629 \text { novice and } \\
\text { recreational } \\
\text { runners }\end{array}$ & $\begin{array}{l}\text { 8-week training } \\
\text { period }\end{array}$ & $\begin{array}{l}30.1 / 1000 \text { hours of } \\
\text { running }\end{array}$ \\
\hline $\begin{array}{l}\text { (Bredeweg, } \\
\text { Zijlstra, et al., } \\
\underline{2012)}\end{array}$ & $\begin{array}{l}\text { Healthy and } 18 \text { - } 65 \\
\text { years, no injury } \\
\text { previous } 3 \text { months, } \\
\text { no regular running } \\
\text { for previous } 12 \\
\text { months. }\end{array}$ & $\begin{array}{l}432 \text { novice runners } \\
\text { ( } 211 \\
\text { preconditioning } \\
\text { group, } 221 \text { control } \\
\text { group). }\end{array}$ & $\begin{array}{l}4 \text { weeks walking } \\
\text { and hopping } \\
\text { exercises for } \\
\text { preconditioning } \\
\text { group \& } 9 \text { weeks } \\
\text { running programme } \\
\text { for all runners. }\end{array}$ & $\begin{array}{l}15.2 \%(26 / 171) \text { in } \\
\text { preconditioning } \\
\text { group) and } 16.8 \% \\
(32 / 191) \text { in the } \\
\text { control group. }\end{array}$ \\
\hline
\end{tabular}




\begin{tabular}{|l|l|l|l|l|}
\hline$\frac{\text { (Nielsen et }}{\text { al., 2013) }}$ & $\begin{array}{l}\text { Healthy and 18 - 65 } \\
\text { years, no injury } \\
\text { previous 3 months, } \\
\text { no regular running } \\
\text { for previous 12 } \\
\text { months, }<4 \\
\text { hours/week other } \\
\text { axial loading } \\
\text { activities. }\end{array}$ & 12 months & $\begin{array}{l}27.2 \% \text { (252/927 } \\
\text { runners) }\end{array}$ \\
\hline $\begin{array}{l}\text { (Theisen et } \\
\text { al., 2013) }\end{array}$ & $\begin{array}{l}\text { Running at least } \\
1 x / \text { week for }>6 \text { of } \\
\text { the last 12 months }\end{array}$ & $\begin{array}{l}247 \text { recreational } \\
\text { runners }\end{array}$ & 5 months & $\begin{array}{l}12.1 / 1000 \text { hours of } \\
\text { running (69 RRIs } \\
\text { reported) }\end{array}$ \\
\hline \hline
\end{tabular}

A number of prospective cohort studies have emerged, reporting on RRI incidences and risk factors (table 1). Lun et al. (2004) reported that $79 \%$ of their 87 runners sustained a RRI during a 6-month period (Lun et al., 2004), which is one of the highest incidences listed. However, this study took into account all musculoskeletal symptoms of the lower extremities, either reducing or stopping normal training, as well as any recurrent injuries. They also reported a high dropout rate (66/153 runners) which they suspected to underestimate the RRI incidence. This study included a comparatively low participant number, limiting the analysis of specific RRIs. Since, studies have included much larger cohorts (Bredeweg, Zijlstra, et al., 2012; Buist et al., 2010; Buist et al., 2008; Nielsen et al., 2013; Rauh et al., 2006; Theisen et al., 2013; Van Middelkoop et al., 2008). Rauh et al. (2005) observed an overall RRI incidence rate of 17/1000 athletic exposures (any training session or competition where the athlete was at risk of injury) in a cohort of 421 competitive cross-country runners. Buist et al. (2008) reported an RRI incidence of $20.8 \%$ for novice runners undergoing a graded training programme and $20.3 \%$ for a standard training group over 13 weeks (Buist et al., 2008). They therefore concluded that a graded training programme (increasing intensity by a maximum of $10 \%$ each week) was no more effective in preventing RRIs in novice runners than a standard 8-week running programme. A multi-centric study using a 13week training programme and including 844 recreational runners reported a $29.5 \%$ injury rate (Taunton et al., 2003). A systematic review of 19 studies by Tonoli et al. (2010) revealed that out of cross country, marathon, competitive, recreational and novice runners, the latter presented the highest RRI incidence $(2.56 \%)$ and cross country runners the lowest $(0.1 \%)$ (Tonoli, 2010). From the handful of studies presented (table 1), it is evident that there are large discrepancies in inclusion criteria, cohort sizes and characteristics, observation periods and even in the methods used to report RRI incidence.

Defining RRI is subject to some debate, as many different definitions have been used, making comparison of results between studies challenging (Hoeberigs, 1992; Nielsen 
et al., 2012; Tonoli, 2010). No general consensus exists to define a RRI as yet. In many cases however, RRIs are characterised as any pain or physical complaint to the lower extremities or lower back region as a result of running activity, being of an overuse nature and resulting in an adaptation or cessation of running practice (Bovens et al., 1989; Buist et al., 2010; Buist et al., 2008). In most cases therefore, blisters, chafing, and suddenly occurring injuries such as ankle sprains, cuts and scrapes are excluded from this definition. Often the time-loss definition of injury is applied (Fuller et al., 2006; Junge et al., 2008), with researchers utilising various cut-offs for their analyses, ranging from an interruption or cessation of running activity of a minimum of one day (Bovens et al., 1989; Buist et al., 2010; Lun et al., 2004; Theisen et al., 2013; Van Middelkoop et al., 2008) to a minimum of one week (Bredeweg, Zijlstra, et al., 2012; Buist et al., 2007; Buist et al., 2008; Hreljac, 2005; Lysholm \& Wiklander, 1987). Some researchers have also employed severity classifications of RRI (Chorley et al., 2002; Daoud et al., 2012), based on the amount of time spent inactive or training a modified intensity due to pain. A pain definition in itself also exists and has been utilised (M. Ryan et al., 2014). Specific pathologies common among runners have been identified in the literature.

\section{Running-related injury types}

With regards to the most prevalent types of RRIs sustained, researchers have reported different findings. Buist et al. (2008) found $40 \%$ lower leg injuries, $37 \%$ knee injuries and $10 \%$ foot and ankle injuries (Buist et al., 2008), Bredeweg et al. (2013) found $41.2 \%$ knee injuries, $23.5 \%$ lower leg injuries and $12.1 \%$ foot and ankle injuries and Bovens et al. (1989) reported the most injured locations to be the knee and lower leg (25\% and $21 \%$ respectively) (Bovens et al., 1989; Bredeweg, Kluitenberg, et al., 2012). More specifically, Tonoli et al. (2010) reported the most diagnosed RRIs to be Achilles tendinopathy, iliotibial band friction syndrome and medial tibial stress syndrome (Tonoli, 2010). More recently, a review by Lopes et al. (2012) found medial tibial stress syndrome (13.6\% to $20.0 \%$ ), Achilles tendinopathy (9.1\% to $10.9 \%$ ) and plantar fasciitis (4.5\% to $17.5 \%$ ) to be the most commonly reported RRI incidences (Lopes et al., 2012). RRIs to the knee, lower leg and foot have been incorporated into studies looking at biomechanical risk factors. 


\section{Potential biomechanical risk factors}

Despite the multitude of research being conducted, we are still at the stage of hypothesis testing with regards to possible biomechanical risk factors of RRI. Table 1.2 provides an overview of the type of research that has been carried out over the years, and the results regarding associations between RRI and biomechanical factors.

Table 1.2. Overview of existing studies on biomechanics and most prevalent RRIs.

\begin{tabular}{|c|c|c|c|c|}
\hline Study & Inclusion criteria & Cohort & Design & Biomechanical risk factors \\
\hline \multicolumn{5}{|c|}{ Knee injuries } \\
\hline $\begin{array}{l}\text { (Duffey et al., } \\
2000)\end{array}$ & $\begin{array}{l}\geq 16 \mathrm{~km} / \text { week } \\
\text { running for }>1 \mathrm{y}\end{array}$ & $\begin{array}{l}70 \text { non-injured } \\
\text { control and } 99 \\
\text { anterior knee } \\
\text { pain recreational, } \\
\text { competitive } \\
\text { runners }\end{array}$ & $\begin{array}{l}\text { Retrospective, } \\
\text { cross-sectional }\end{array}$ & $\begin{array}{l}\text { Anterior knee pain associated } \\
\text { with higher arched feet, more } \\
\text { frequent shoe replacement, } \\
\text { less pronation through } 10 \% \text { of } \\
\text { stance and weak knee } \\
\text { extensors. }\end{array}$ \\
\hline $\begin{array}{l}\text { (Stefanyshyn } \\
\text { et al., 2006) }\end{array}$ & $\begin{array}{l}\text { No other injuries } \\
\text { during past } 3 \\
\text { months other } \\
\text { than PFP pain in } \\
\text { injured group }\end{array}$ & $\begin{array}{l}20 \text { PFP pain } \\
\text { sufferers vs } 20 \\
\text { controls } \\
140 \text { pain-free } \\
\text { runners }\end{array}$ & $\begin{array}{l}\text { Retrospective, } \\
\text { Case-control } \\
\text { and } \\
\text { prospective 6- } \\
\text { month follow- } \\
\text { up }\end{array}$ & $\begin{array}{l}6 \text { runners developed PFP pain } \\
\text { and displayed higher knee } \\
\text { abduction impulses than } 6 \\
\text { matched controls. }\end{array}$ \\
\hline $\begin{array}{l}\text { (Thijs et al., } \\
\text { 2007) }\end{array}$ & $\begin{array}{l}\text { No history of } \\
\text { knee or lower leg } \\
\text { complaints }\end{array}$ & $\begin{array}{l}84 \text { Military } \\
\text { recruits }\end{array}$ & $\begin{array}{l}\text { Prospective 6- } \\
\text { week follow- } \\
\text { up }\end{array}$ & $\begin{array}{l}\text { Barefoot walking pressure } \\
\text { patterns reveal those } \\
\text { developing PFP to have a less } \\
\text { pronated heelstrike and more } \\
\text { lateral foot rollover. }\end{array}$ \\
\hline $\begin{array}{l}\text { (Thijs et al., } \\
\text { 2008) }\end{array}$ & $\begin{array}{l}\text { No history of } \\
\text { lower limb } \\
\text { surgery, no } \\
\text { injuries to lower } \\
\text { limbs during last } \\
6 \text { months }\end{array}$ & $\begin{array}{l}102 \text { novice } \\
\text { runners }\end{array}$ & $\begin{array}{l}\text { Prospective } \\
\text { 10-week } \\
\text { follow-up }\end{array}$ & $\begin{array}{l}\text { Excessive shock during } \\
\text { heelstrike may increase risk of } \\
\text { PFP. }\end{array}$ \\
\hline $\begin{array}{l}\text { (Messier et } \\
\text { al., 2008) }\end{array}$ & $\begin{array}{l}20-55 \mathrm{y} \text {, injury- } \\
\text { free } \geq 1 \mathrm{y}, \\
\geq 16 \mathrm{~km} / \text { week } \\
\text { running }\end{array}$ & $\begin{array}{l}20 \text { non-injured } \\
\text { runners }\end{array}$ & Cross-sectional & $\begin{array}{l}\text { Larger knee joint loads } \\
\text { associated with poor hamstring } \\
\text { flexibility, greater body weight } \\
\text { and greater muscle strength. } \\
\text { Possible risk factors of knee } \\
\text { injury. }\end{array}$ \\
\hline $\begin{array}{l}\text { (Grau et al., } \\
\text { 2008) }\end{array}$ & $\begin{array}{l}\text { Healthy or } \\
\text { afflicted with } \\
\text { patellar } \\
\text { tendinopathy, } \\
\text { RFS, female }\end{array}$ & $\begin{array}{l}12 \text { female } \\
\text { runners patellar } \\
\text { tendinopathy } \\
\text { group, } 12 \\
\text { controls }\end{array}$ & $\begin{array}{l}\text { Matched case- } \\
\text { control }\end{array}$ & $\begin{array}{l}\text { Increased pronation velocity, } \\
\text { knee flexion velocity, hip } \\
\text { adduction, decreased hip } \\
\text { extension velocity and a lack of } \\
\text { joint coordination associated }\end{array}$ \\
\hline
\end{tabular}


runners

2009)
27 PFP runners vs 16 controls

no previous

traumatic

patellar

dislocation. with patellar tendinopathy from barefoot running analysis.

Retrospective, case-control
Some PFP patients might

experience greater joint

contact forces and stresses

than pain-free subjects.

\begin{tabular}{|c|c|c|c|c|}
\hline \multicolumn{5}{|c|}{ Stress fractures } \\
\hline $\begin{array}{l}\text { (Crossley et } \\
\text { al., 1999) }\end{array}$ & $\begin{array}{l}\text { Male, no history } \\
\text { of leg surgery or } \\
\text { trauma, currently } \\
\text { not injured, } \\
\text { rearfoot strikers }\end{array}$ & $\begin{array}{l}23 \text { runners with } \\
\text { history of tibioal } \\
\text { stress fracture vs } \\
\text { matched group of } \\
23 \text { controls }\end{array}$ & $\begin{array}{l}\text { Retrospective, } \\
\text { case-control }\end{array}$ & $\begin{array}{l}\text { TSF group had smaller tibial } \\
\text { cross-section area than control } \\
\text { group. }\end{array}$ \\
\hline $\begin{array}{l}\text { (Bennett et } \\
\text { al., 2001) }\end{array}$ & $\begin{array}{l}\text { Injured group if } \\
\text { metatarsal stress } \\
\text { fracture } \\
\text { symptoms. No } \\
\text { previous injury } \\
\text { requiring medical } \\
\text { attention or } \\
\text { orthotics. }\end{array}$ & $\begin{array}{l}125 \text { high school, } \\
\text { cross-country } \\
\text { runners }\end{array}$ & $\begin{array}{l}\text { Prospective 8- } \\
\text { week follow- } \\
\text { up }\end{array}$ & $\begin{array}{l}\text { Greater navicular drop and } \\
\text { being female associated with } \\
13 \text { female and } 2 \text { male runners } \\
\text { in injured group compared } \\
\text { with } 8 \text { females and } 13 \text { males in } \\
\text { randomly selected non-injured } \\
\text { group. }\end{array}$ \\
\hline $\begin{array}{l}\text { (Korpelainen } \\
\text { et al., 2001) }\end{array}$ & $\begin{array}{l}19 \text { long-distance } \\
\text { runners and } \\
\text { other athletes } \\
\text { with } \geq 3 \\
\text { diagnosed stress } \\
\text { fractures }\end{array}$ & $\begin{array}{l}31 \text { athletes (not } \\
\text { just runners }\end{array}$ & $\begin{array}{l}\text { Retrospective, } \\
\text { case-control }\end{array}$ & $\begin{array}{l}\text { High weekly training mileage, } \\
\text { leg-length inequality, high arch } \\
\text { and forefoot varus associated } \\
\text { with recurrent stress fractures. }\end{array}$ \\
\hline $\begin{array}{l}\text { (Milner, } \\
\text { Ferber, et al., } \\
\text { 2006) }\end{array}$ & $\begin{array}{l}18-45 \text { y female } \\
\text { runners, } \geq 32 \\
\text { km/week } \\
\text { running, not } \\
\text { currently injured }\end{array}$ & $\begin{array}{l}20 \text { female } \\
\text { runners with } \\
\text { history of TSF vs } \\
20 \text { controls }\end{array}$ & $\begin{array}{l}\text { Retrospective, } \\
\text { case-control }\end{array}$ & $\begin{array}{l}\text { History of TSF is associated } \\
\text { with higher VLR and peak tibial } \\
\text { shock. }\end{array}$ \\
\hline $\begin{array}{l}\text { (Pohl et al., } \\
\text { 2008) }\end{array}$ & $\begin{array}{l}18-45 \text { y female } \\
\text { runners, } \geq 32 \\
\text { km/week } \\
\text { running, not } \\
\text { currently injured }\end{array}$ & $\begin{array}{l}30 \text { female } \\
\text { runners with } \\
\text { history of TSF vs } \\
30 \text { controls }\end{array}$ & $\begin{array}{l}\text { Retrospective, } \\
\text { case-control }\end{array}$ & $\begin{array}{l}\text { Greater hip adduction, peak } \\
\text { rearfoot eversion and peak } \\
\text { absolute free moment } \\
\text { associated with a history of } \\
\text { TSF. }\end{array}$ \\
\hline \multicolumn{5}{|c|}{ Achilles tendinopathy } \\
\hline $\begin{array}{l}\text { (McCrory et } \\
\text { al., 1999) }\end{array}$ & $\begin{array}{l}\geq 16 \mathrm{~km} / \text { week } \\
\text { running for } 1 \mathrm{y} \text {, } \\
\text { not currently } \\
\text { injured }\end{array}$ & $\begin{array}{l}31 \text { AT runners vs } \\
58 \text { controls }\end{array}$ & $\begin{array}{l}\text { Retrospective, } \\
\text { case-control }\end{array}$ & $\begin{array}{l}\text { Plantar flexion peak torque, } \\
\text { touchdown angle and years of } \\
\text { running were significantly } \\
\text { different between groups. }\end{array}$ \\
\hline $\begin{array}{l}\text { (Van Ginckel } \\
\text { et al., 2009) }\end{array}$ & $\begin{array}{l}\text { No injury during } \\
\text { last year, no } \\
\text { other sports }\end{array}$ & $\begin{array}{l}129 \text { novice } \\
\text { runners }\end{array}$ & $\begin{array}{l}\text { Prospective } \\
\text { 10-week } \\
\text { follow-up }\end{array}$ & $\begin{array}{l}\text { Barefoot running over pressure } \\
\text { plate revealed a decrease in } \\
\text { total posterior-anterior } \\
\text { displacement of the centre of } \\
\text { force and a laterally directed } \\
\text { force distribution in forefoot at }\end{array}$ \\
\hline
\end{tabular}




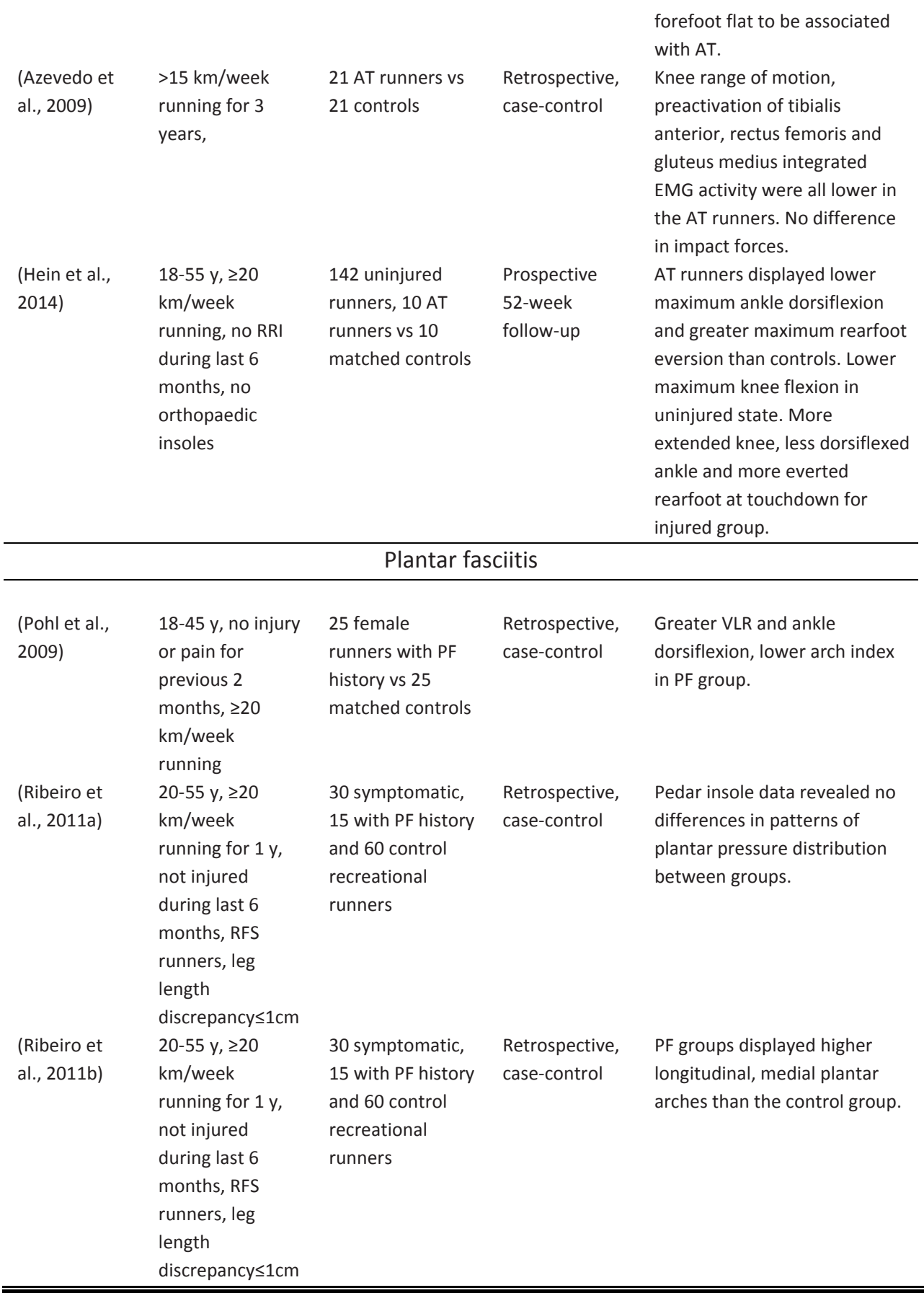

PFP=patellofemoral pain; TSF=tibial stress fracture; AT=Achilles tendinopathy; $P F=$ plantar fasciitis; VLR=vertical loading rate 
The purpose of table 1.2 is to highlight our current standpoint on research on biomechanical risk factors. First of all, in most cases, studies were of a retrospective design. This can only ever result in an association between risk factor and RRI being established, and not a causal effect. Even a prospective design cannot confirm a causal relationship if other potential confounders are not controlled for. Further, those prospective studies listed had rather short follow-up durations, generally lasting between six and 10 weeks. Only two studies reported sufficiently long follow-ups of six months (Stefanyshyn et al., 2006) and one year (Hein et al., 2014). Further, the sample sizes were not large enough to be able to put forward these findings as definitive risk factors. Rarely are more than 100 participants included in a biomechanical study, as biomechanical analyses are generally time-consuming, even though small sample sizes risk not being representative enough of the general population. With regards to the populations studied, we can see a large disparity in types of runners studied, ranging from cross-country high school athletes to military recruits to only female runners. Limiting analyses to one particular subgroup may provide information for that particular demographic, but results cannot be generalised to the general population of runners. In addition, the inclusion criteria for these studies vary greatly, although in most cases participants were confirmed recreational runners with a minimum weekly mileage. Finally, the findings of these studies suggest no consensus on definitive biomechanical risk factors. As well as varying study populations and designs, measurement protocols also differ greatly. Van Ginckel et al. (2009) used a barefoot running protocol for example, yet it has been shown that barefoot running is very different to shod running (De Wit et al., 2000; Hamill et al., 2011) making comparison of results with other studies difficult.

A few researchers have tried to summarize current findings for specific potential risk factors. A systematic review on risk factors of stress fractures revealed vertical loading rate $(V L R)$ to be associated with stress fractures $(p<0.05)$, although this was only the case in four of the eight studies reporting on VLR (Zadpoor \& Nikooyan, 2011). This association was not found for ground reaction force $(p=0.857)$. Another very recent systematic review concluded that abnormal biomechanics at the foot and tibia are perhaps less likely to be associated with iliotibial band syndrome, whereas a more proximal cause such as sagittal or frontal plane motion of the hip joint could be more predictive (Louw \& Deary, 2014). These conclusions do not pinpoint an exact cause of iliotibial band syndrome however, and can only serve as hypotheses for further studies. Hamill et al. (2008) modelled the strain of the iliotibial band during running and found greater strain and strain rate in a group of female runners developing iliotibial band syndrome compare to matched controls (Hamill et al., 2008). This result has not been repeated since, and remains to be confirmed. 
Foot structure has been speculated to play a role in RRI occurrence, and runners with high arched feet were found to have more leg stiffness and higher vertical loading rate than low arched runners (D. S. Williams, 3rd et al., 2004). Conflicting results have been reported when it comes to RRI. Williams et al. (2001) found that a low-arched group of runners reported general knee pain, patellar tendinitis and plantar fasciitis most frequently, whereas high-arched runners reported mainly plantar fasciitis, lateral knee pain and iliotibial band syndrome (D. S. Williams, 3rd et al., 2001). Contrarily, another study found no strong correlation between arch height and knee and ankle injuries in professional runners (Nakhaee et al., 2008). Static lower limb alignment has also been compared between injured and non-injured groups. Lun et al. (2004) found inconclusive evidence that static lower limb alignment was associated with RRI after a 6-month follow-up of 87 recreational runners (Lun et al., 2004). Rauh et al. (2005) found Q-angle of $\geq 20^{\circ}$ and recent previous injury to be predictors of RRI (Rauh et al., 2006).

Pronation, or excessive pronation and rearfoot eversion, have often been cited as a potential risk factor of RRI (R. T. H. Cheung \& Ng, 2007; Reed Ferber et al., 2009; Hintermann \& Nigg, 1998; McClay \& Manal, 1998). This is the combined eversion of the calcaneus and internal rotation of the talus, and it is accepted that a normal amount of pronation is necessary for impact attenuation during weight-bearing activities (Reed Ferber et al., 2009). However, a consensus of 'normal' and 'excessive' pronation definitions has yet to be reached. Indeed, Pohl et al. (2008) and Hein et al. (2014) found peak rearfoot eversion to be associated with Achilles tendinopathy and tibial stress fractures, respectively (table 1.2). Grau et al. (2008) found increased pronation velocity to be associated with patellar tendinopathy from barefoot analyses, yet Duffey et al. (2000) observed less pronation through first $10 \%$ of stance phase to be associated with anterior knee pain (table 1.2). In a recent, robust prospective study including 927 novice runners and a 1-year follow-up, Nielsen et al. (2013) found that pronators had a significantly reduced RRI risk compared to runners with a neutral foot type classification (Nielsen et al., 2013). Further studies of such design and more consistent results will help us better understand the associations between biomechanics and RRI.

Despite the increasing body of literature on running biomechanics over the last few decades, our understanding of biomechanical mechanisms of RRI remains poor (Hreljac, 2005). Current research has been unable to systematically reproduce and confirm findings of previous studies on potential biomechanical risk factors, and evidence-based research is severely lacking in this area. Large variation in cohorts, methodologies, RRI definitions and apparatus used between studies has contributed to this lack of conclusive evidence. In order to begin to develop sound hypotheses and work towards true risk factor identification, a rationale must be put forward, and robust and reliable measurement apparatus specifically designed to acquire data 
during running in the natural environment must be implemented. For now, biomechanical testing has been laboratory-based, and we must look to develop analysis tools which can be reliably implemented outside of the laboratory and in the natural running environment.

\section{Biomechanical mechanisms}

To begin with, an understanding of how RRIs of an overuse nature develop is paramount. The fundamental, underlying mechanism which explains this, is the response of biological tissue to repeated loading. Hreljac (2004) provides a simple yet comprehensive model of the stress-frequency relationship, and how it relates to injury occurrence (figure 1.2). The repetitive loading of the lower extremities can be tolerated up to a point, but when the accumulated stress reaches this point (the injury threshold), the risk of sustaining an injury becomes a reality. Figure 1.2 clearly shows the exponential relationship of high stress-low frequency or indeed low stress-high frequency model and how these relationships can overload a particular anatomical structure. Running is a repetitive activity, with runners experiencing between 500 and 1,200 foot-ground impacts per kilometer (Bartlett, 2012). This can mean in excess of 5,000 impacts per lower extremity during a $10 \mathrm{~km}$ run. Each step generates between 1.5 and 3 times body weight in collision forces in rearfoot strike (RFS) runners, occurring within the first $50 \mathrm{~ms}$ of stance phase (Lieberman et al., 2010).

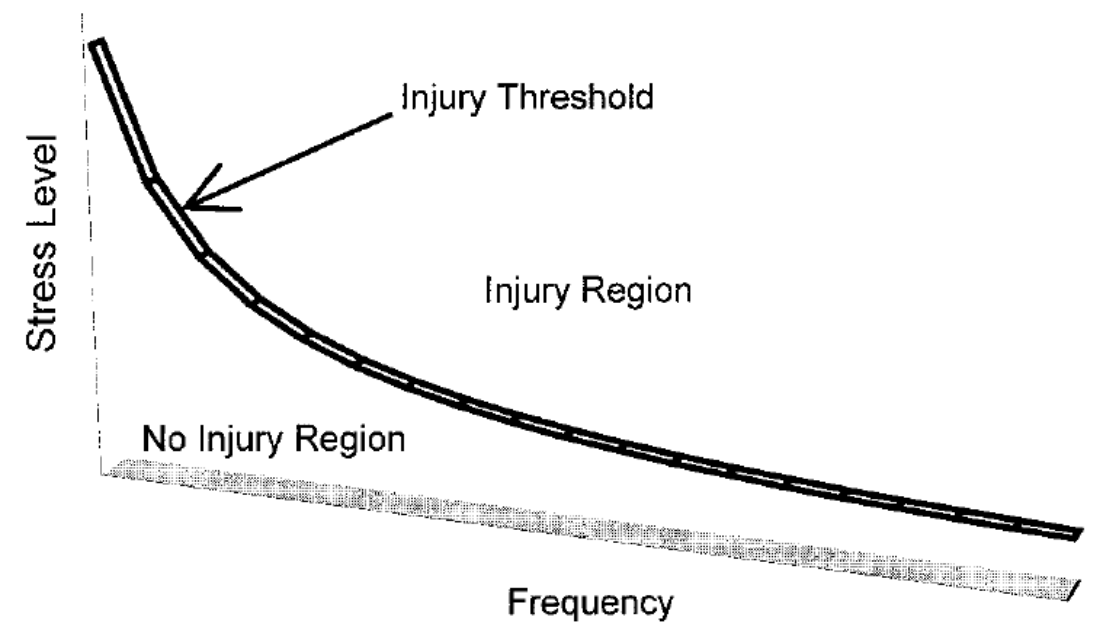

Figure 1.2. Fatigue curve showing the theoretical relationship between stress application and frequency, and the effect of these variables on overuse injury potential. Adapted from Hreljac (2004) (Hreljac, 2004). 
We have seen which types of overuse injuries are sustained by runners, all of them either involving the musculoskeletal system, joints, tendons or cartilage of the lower extremities. In the case of a metatarsal stress fracture for example, repeated force application to the bone without sufficient rest for bone regeneration reinforcement, will weaken it and make it more brittle over time. This eventually leads to micro fissures developing, which get bigger until pain is felt by the runner causing them to interrupt their habitual running activity. Sufficient rest for the structures to regenerate properly leads to positive adaptation, and a gradual strengthening and optimisation of the biological structures involved in running. However, finding the right balance between training and rest is unique to each individual. It is for this reason that a thorough understanding of how the biomechanics, training characteristics, and their interaction, should be established to be able to devise personalised prevention strategies to minimise the risk of injury among runners.

\section{Training errors}

From a training perspective, researchers have been able to put forward a handful of training errors with a little more certainty. A review by Van Mechelen (1992) summarised four etiological risk factors of RRI: “1) previous injury 2) lack of running experience 3) running to compete and 4) excessive weekly running distance" (van Mechelen, 1992). A retrospective study on 694 male runners confirmed more frequent competition participation [odds ratio 1.66; 95\% confidence interval (1.08-2.56)] and a history of RRIs [odds ratio 2.62; 95\% confidence interval (1.82-3.78)] to be associated with the occurrence of RRIs (Van Middelkoop et al., 2008). Injury during the previous 12 months was also identified as a risk factor by Theisen et al. (2013), with a hazard ratio of 1.735; 95\% confidence interval 1.037-2.902 (Theisen et al., 2013). This study also found no regular running during the previous 12 months, a higher body mass index (BMI) and running at subjectively higher intensities to increase RRI risk, and participation in other sports besides running to decrease the risk. Buist et al. (2010) also found that novice runners had a higher risk of sustaining a RRI than experienced runners. Finally, a recent systematic review highlighted previous injury as the main risk factor of RRI (Saragiotto et al., 2014). From this short synthesis, a definitive trend in findings of different research groups would suggest that previous injury and being a novice runner are two non-modifiable characteristics which should be taken into account when assessing the risk profile of a runner. The studies mentioned all included more than 250 runners and the review by Van Mechelen only included studies with $\geq 1$ year followup periods. This is in contrast to the previously presented research on biomechanics of running, where such large-scale, longitudinal studies remain to be conducted. 
Modifiable risk factors of overuse injuries have also been hypothesised. Those most often cited are an increase in running distance, an increase in training intensity and a too fast an increase in weekly training distance or intensity (Hreljac, 2005). These factors have been classed as training errors, as they result in the cumulated stresses to a structure outweighing the capacity for that structure to regenerate sufficiently (Hreljac, 2005). As previously explained, this is individual specific, and factors such as running distance and intensity should be adapted according to how much stress the individual runner can tolerate. However, a recent systematic review of 31 studies found no associations between training characteristics and RRI (Nielsen et al., 2012). These authors highlighted the urgent need for well designed, prospective studies on RRI risk factor identification. Sports injuries in general have been described as multifactorial (W. H. Meeuwisse et al., 2007) and RRIs are no exception (Marti et al., 1988). Taking this into account, it is important to have a global view of the potential modifiable and non-modifiable risk factors to be included in an eventual model of RRI. Table 1.3 presents those factors most likely to play a role in the occurrence of RRIs, and outlines whether or not they are intrinsic or extrinsic to the runner.

Table 1.3. Modifiable, non-modifiable, intrinsic and extrinsic potential risk factors of running-related injuries, adapted from Cameron (2010) (Cameron, 2010).

\begin{tabular}{lll}
\hline \hline & Modifiable & Non-modifiable \\
\hline Extrinsic & Environmental: & \\
& Meteorological conditions & \\
& Running surface & \\
& Footwear & \\
& Coaching/training characteristics & \\
\hline Intrinsic & Anatomical: & Anatomical: \\
& Running style & Q angle \\
& Foot pronation, FMM & Navicular drop \\
Body composition & Knee valgus \\
BMI & Postural alignment \\
& Generalized joint \\
& Neuromuscular: & hypermobility/laxity \\
Muscle strength & Hormonal: \\
Muscle activation patterns & Menstrual cycle \& hormone \\
Muscle fitness & concentrations \\
Physical fitness \& muscle fatigue & Demographic: \\
& Age \\
& Injury history \\
& Familial history \& genetics \\
\hline \hline & Sex \\
& Height \\
\hline
\end{tabular}

BMI: body mass index; FMM: foot mobility magnitude 
Table 1.3 does not include all potential risk factors (both training-related and biomechanical) hypothesised so far, but gives an idea of which types of factors must be controlled for, and which can be modified in future studies.

\section{Running-related injury model}

RRIs can affect runners of any experience level and performance level. The underlying mechanism is structural overload with repeated stress, and many of what are believed to be biomechanical risk factors of RRIs are not supported by robust, evidence-based studies. It is important that we understand how long a runner must be exposed to repetitive stress for it to result in an RRI. At the same time, measuring the frequency and nature of these loads during this time period will provide researchers with the information which has until now been lacking. This will aid in understanding the true interactions between biomechanics, running exposure and RRI. Measuring all these aspects would seem a logical next step in RRI research. Before doing so however, devising an appropriate model to study the relation between biomechanics, training characteristics and RRI is necessary.

Several contributing factors such as running experience, foot morphology, shoe type and running style may play a role when a runner experiences pain for the first time, and very often these factors are present long before the injury occurs. Due to this multifactorial nature of injuries, defining the underlying cause of an injury is extremely difficult. A cause can be a myriad of factors, or indeed a combination of many individual reasons. Runners cannot always be at their best; malnutrition, dehydration, inappropriate running surface, the type of shoe, too little sleep or mental and physical fatigue can all be potentially harmful to the runner. Ultimately, as has already been touched upon, what influences the direct cause of an overuse injury, is the movement itself, the act of running (Malisoux et al., 2014). For example, we can own shoes which do not fit or do not suit our morphology, but we need to run in them for the resulting movement patterns to create a problem. Malisoux et al. (2014) recently proposed a new model placing emphasis on the causal relationship between training characteristics and RRI (Malisoux et al., 2014). This model includes biomechanical and other intrinsic and extrinsic factors as effect modifiers. Running volume and frequency cannot explain the RRI occurrence on their own, therefore measuring and evaluating the role of these effect modifiers is important. 


\section{Assumed effect-}

measure modifiers

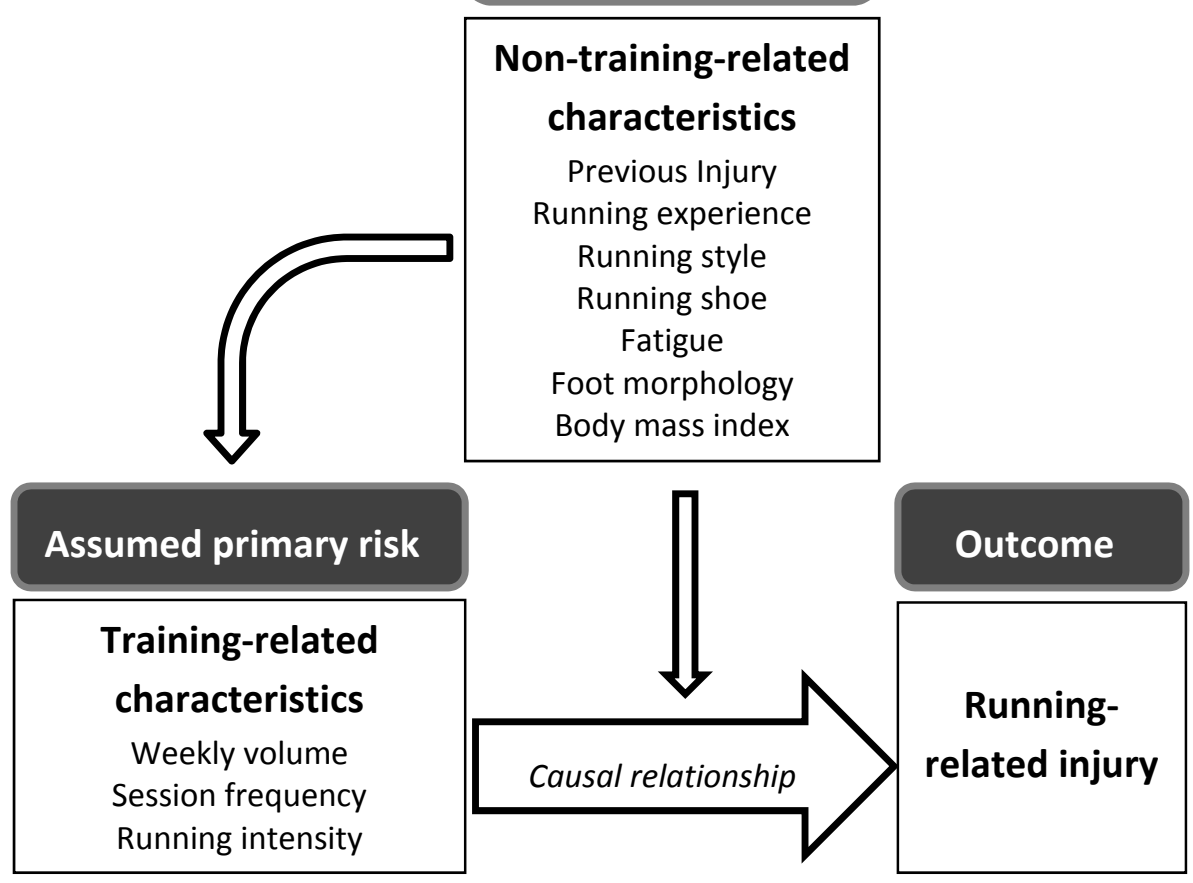

Figure 1.3. A running-related injury model adapted from Malisoux et al. (2014) (Malisoux et al., 2014). This model shows how biomechanical aspects are regarded as effect modifiers and how they interact with the primary risk factor, the act of running.

An early, linear model of sports injuries presented how intrinsic and extrinsic risk factors interact to provoke an injury in a susceptible athlete along with an inciting event (W.H. Meeuwisse, 1994). This model was later improved upon, to include the notion that inciting events can actually change an athlete's predisposition to injury (W. H. Meeuwisse et al., 2007). A dynamic, cyclical model was put forward, which also began to encompass the notion of causality (Rothman, 1976; Rothman \& Greenland, 2005). Yet none of these models are specific to RRI. The model proposed by Malisoux et al. (2014) puts the causal relationship between training characteristics and RRI at the centre, and acknowledges all other potential risk factors and biomechanical aspects as contributing effect modifiers. Thus, these effect modifiers influence the training load an individual can tolerate. As outlined above, our understanding of the running biomechanical variables studied so far and how these relate to RRI is poor, and 
we must consider an alternative approach. Therefore, this model highlights the need for continuous measurement to observe changes and fluctuations in running mechanics over time and how this relates to RRI, something which has not yet been attempted in running biomechanics. This is strongly related to the lack of appropriate measurement tools.

\section{Common practice and methodologies in biomechanical analysis}

Several different methods to observe how a runner is exposed to repetitive stress and structural overload exist. Running as a sporting or leisure activity is a fairly simple concept, but broken down into its many different mechanisms and movement chains, a comprehensive analysis can become extremely complex. It is for this reason that biomechanical analysis of running has gained much interest among researchers, sports physicians, coaches and athletes in recent years. Before being able to tackle the problem of RRIs on a multifactorial level, it is important to know in how far each individual factor can influence the runner. The foot is the sensory organ responsible for the interaction between the organism and the surrounding environment, the running surface. A repeated, unnatural interaction of the foot and running surface could develop weaknesses in the kinematic chain. Running is a repetitive activity, and this kinematic chain is only as strong as its weakest link; a constant mal-placement of the foot can lead to structural overload.

Force plates are the gold standard in measuring kinetics parameters such as ground reaction forces, vertical loading rates, force trajectories, and temporal parameters during the stance phase in running and are most commonly used in the measurement of these kinetic parameters (Rosenbaum \& Becker, 1997). They have the advantage of being able to accurately measure the aforementioned parameters at high sample rates (generally between 500 and $1000 \mathrm{~Hz}$ ). They are usually embedded into a runway between $10 \mathrm{~m}$ and $30 \mathrm{~m}$ long, flush with the running surface, and often disguised under an additional surface. The test subject runs from one end of the runway to the other, contacting the force plate with either the left or right foot, yet not specifically aiming for the force plate, as this can alter natural running gait (Abendroth-Smith, 1996). Although this force plate setup has been extensively used in biomechanical analyses (Azevedo et al., 2009; Duffey et al., 2000; R. Ferber et al., 2003; Milner, Davis, et al., 2006; Milner, Ferber, et al., 2006; Pohl et al., 2008; Stefanyshyn et al., 2006), it has been heavily criticised for only being able to measure a single step for each trial (Cavanagh et al., 1992; Dixon, 2008; Giandolini et al., 2014). To acquire several steps, several trials must be run. This creates the problem of continuity, as steps are not measured successively. Also, this setup is subject to much variability between trials, 
such as running speed and running style. Running trials are heavily dependent on the foot placement, and trials must be repeated if the foot does not entirely contact the force plate for example. Multiple measurements can be time consuming and can therefore induce unnecessary fatigue, which could introduce confounding. This drawback of repeating trials and potential altering of habitual running style due to a laboratory setting has often been cited (Dixon, 2008; Godi et al., 2014; Wiegerinck et al., 2009). One solution more recently introduced is the instrumented treadmill. This is a treadmill with either integrated force sensors or mounted on top of a force plate (Belli et al., 2001; Dierick et al., 2004; Verkerke et al., 1998). This allows for continuous measurement of multiple, consecutive steps, and ensures that running speed, elevation and running surface can be controlled. However, participants are still confined to a laboratory setting and often unable to be tested at their naturally undulating running speeds. They must be familiar with using a treadmill (Cavanagh et al., 1992; Dierick et al., 2004; Riley et al., 2008) if recorded data is to be considered reliable and representative of their habitual running style.

With accelerometers becoming more reliable, more compact and less costly, these devices are increasingly being used in biomechanical analyses of running. These devices, simply attached to bony anatomical structures to reduce artefacts due to skin vibrations, have been used to compare peak positive tibial accelerations between previously injured and non-injured, female runners (Miller et al., 2008; Pohl et al., 2008), to measure the reduction of this parameter with gait retraining (Crowell \& Davis, 2011), and has been put forward as an alternative measure of footstrike pattern which can be used in the field (Giandolini et al., 2014). However, these authors did acknowledge that this method could not accurately determine a FFS. Advantages of accelerometers are that they are lightweight, wireless and do not influence the natural running gait (Giandolini et al., 2014).

3D motion analysis systems are also often employed in biomechanical studies on running. This method has been particularly favoured when measuring rearfoot eversion (R. T. H. Cheung \& Ng, 2007; De Wit et al., 2000; Novacheck, 1998) and knee and ankle (Bonacci et al., 2014; Samaan et al., 2014; Shih et al., 2013) angles at footground contact for example. Smaller sample sizes are preferred (ranging from $n=8$ to $n=40$ ), as palpation and marker placement on the skin of the test subject is laborious and time-consuming. Estimating anthropometric data such as limb mass, centre of mass positioning, lever arms etc.) can lead to inaccurate analyses of 3D kinematics and joint moments. Depending on the protocol and equipment used, this preparatory process can last anywhere between 10 and 90 minutes (based on experience from our laboratory). Further, soft tissue vibrations during high impact activities such as running can cause measurement artefacts (Benoit et al., 2006; Lucchetti et al., 1998). Similarly, adhering markers to the running shoe directly has been found to overestimate 
rearfoot motion measurements (Butler et al., 2007; Stacoff et al., 2001). Combining a 3D kinematic camera system with a force plate or pressure mat allows for not only ground reaction forces and joint angles to be measured, but also for the calculation of internal work, individual joint loads, moment angles and joint torques. Such a setup can provide a lot of data, but is not practical for study designs including hundreds or even thousands of participants and foreseeing multiple acquisitions. Larger sample sizes require the biomechanical testing procedure to be as time-efficient as possible, and often only the kinetic measure is employed (Bredeweg, Kluitenberg, et al., 2012; Ghani Zadeh Hesar et al., 2009; Thijs et al., 2008; Van Ginckel et al., 2009).

In addition to force plates measuring ground reaction forces, the use of pressure instruments to capture plantar pressure patterns has become increasingly useful over the last few decades. Such devices have the added advantage of being able to measure localised pressure on the plantar area of the foot, not possible when using a force plate. This is said to be more relevant when conducting research on risk factors and pathologies (Rosenbaum \& Becker, 1997). Much work has been carried out using either pressure mats (De Cock et al., 2008; Thijs et al., 2008; Van Ginckel et al., 2009; Willems et al., 2012) or pressure insoles (Barnett et al., 2000; Fourchet et al., 2012; Hennig, 1995; Low \& Dixon, 2010; Tessutti et al., 2010) to observe these patterns during running. There is little difference in the information provided by both systems, with the centre of pressure (COP) and localised pressure magnitudes on the plantar aspect of the foot during the stance phase being of particular interest (De Cock et al., 2008; Hennig, 1995; Thijs et al., 2007; Willems et al., 2012). Pressure-sensitive insole devices cannot be used to measure barefoot running, and although information on the interaction between the foot and the ground can be relevant in specific research areas, of arguably greater interest is the interaction between the foot and the running shoe (Cavanagh et al., 1992; Dixon, 2008). Indeed, recent interest in the influence of types of running footwear on running biomechanics has grown (R. T. Cheung \& Ng, 2008; Logan et al., 2010; Wiegerinck et al., 2009; Willy \& Davis, 2014). Existing insole systems rely on external dataloggers which are worn by the runner on a waist belt and connected to the insole via cables which run down the leg, and can add up to $1.5 \mathrm{~kg}$ of surplus weight (Ribeiro et al., 2011b). These devices can have between 99 and 1000 individual sensors arranged in a matrix (Razak et al., 2012). However, often researchers define anatomical locations on the plantar foot, and group sensors of these locations together, as a form of data reduction (Bergstra et al., 2014; Martinez-Nova et al., 2007; Ribeiro et al., 2011b; Rosenbaum \& Becker, 1997; Wang et al., 2012). Generally, the more sensors a device employs, the greater the power consumption, the more electronic storage space is needed, and the greater the risk of reduced sampling rate. The need to develop a compact, robust insole-based research tool encompassing the benefits outlined above has been observed. 
A new measurement tool capable of quantifying running style and prolonged measurement is presented. The ensuing studies attempt to both contribute to the ever growing base of knowledge on the role footstrike pattern and spatiotemporal parameters play in various contexts and their relation to RRI, as well as laying the groundwork for future studies combining continuous biomechanical analyses of running with epidemiological study designs.

\section{Runalyser hardware description}

An obvious advantage of using an insole-based device is its portability and applicability to all running settings with running shoes. The insole goes where the runner goes, and provides a direct measure of the pressure patterns within the shoe. It also allows for consecutive data capture from all steps within an acquisition, providing valuable information on stride variability or running style adaptations to particular conditions for example. This means that the runner is not obliged to adjust running speed, foot placement and stride length as would be the case in conventional laboratory settings as outlined above.

The Runalyser is a pressure-sensitive insole device developed by TNO (Eindhoven, The Netherlands). It is specifically designed for biomechanical acquisition of gait parameters during running. It consists of a footpod unit containing an on-board microprocessor, an analog digital converter, an XBee-PRO signalling chip and a lithium ion battery (figure 1.4A). The footpod is connected to a $3 \mathrm{~mm}$ thick, flexible insole (Zephyr Technology, Ltd, Maryland, USA) available in three different sizes: small (EU3941.5), medium (EU42-44.5) and large (EU45-47). The insoles are constructed from 2 polyurethane foam layers, with a conductive fabric adhered to the outer surfaces (figure 1.4B). Flexible electronics printed on a plastic laminate substrate are sandwiched within the polyurethane foam layers. The printed electronics comprise silver connective traces which conduct signals from 8 printed carbon capacitive plates to a connector which is coupled to the footpod (figure $1.4 \mathrm{C}$ ). The polyurethane foam serves as a dielectric between the upper and lower conductive surfaces and the printed carbon plates. As pressure is applied to the insole, the foam compresses and the distance between the conductive surfaces and the carbon plates changes according to the amount of pressure applied. Since capacitance varies as a function of distance, the pressure applied to deform the foam can be translated into an analog electrical signal (Rosenbaum \& Becker, 1997). The left and right insoles are inserted into the running shoes and the corresponding footpods are connected and strapped to the lower leg, ensuring a minimal amount of discomfort for the runner (figure 1.4D). 
A

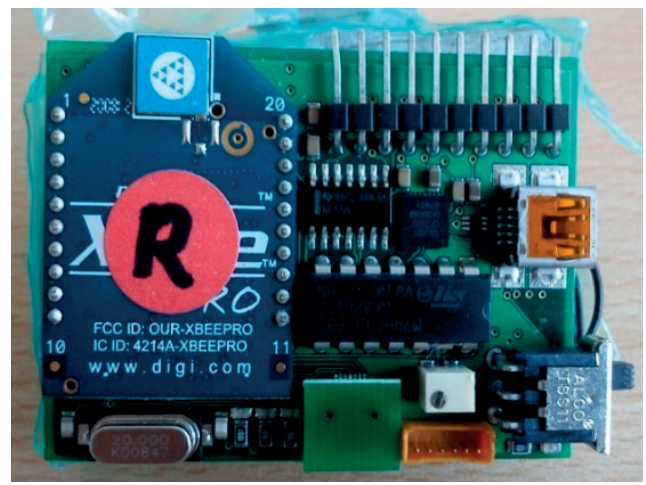

C

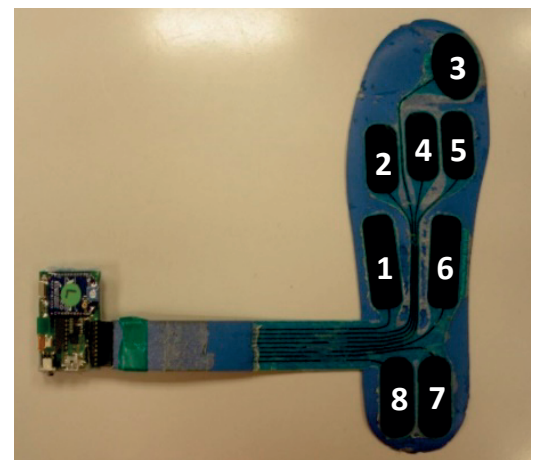

B

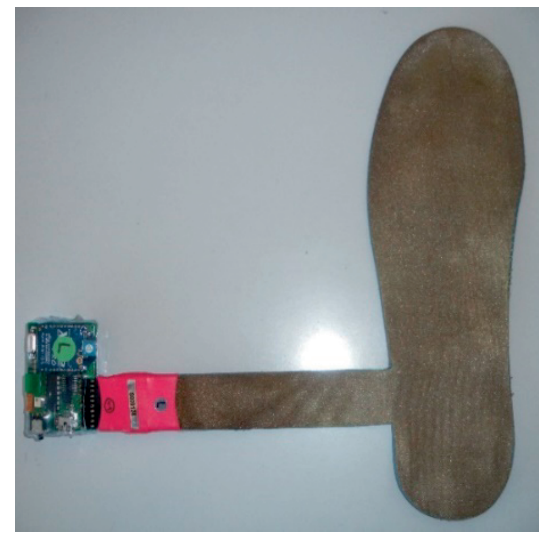

D

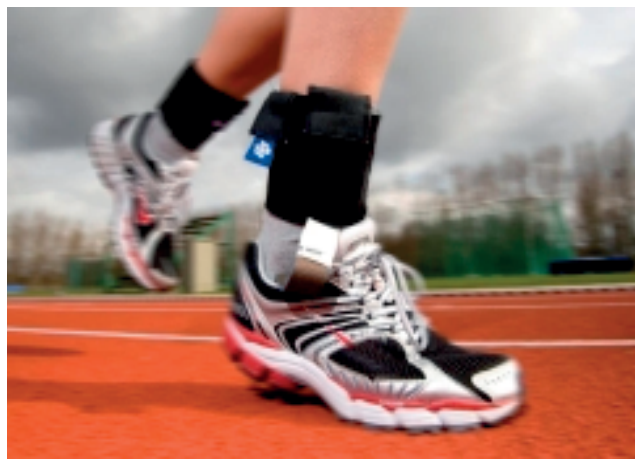

Figure 1.4. A) The footpod displaying the microprocessor, the analog-to-digital converter and the XBee-PRO signalling chip (the battery is located on the reverse side). B) shows an insole and its conductive fabric coating, connected to a footpod. C) Shows an insole with one layer of polyurethane foam removed, displaying the positioning of the eight sensors. D) Illustrates practical application of the Runalyser with the insole installed and the footpod strapped to the lower leg.

The acquisition electronics of the footpod accept eight input channels from the pressure sensitive regions of the insole. The signal is fed into the analog-to-digital converter to produce an output that can be processed by the on-board microprocessor. The signal is then transmitted wirelessly by the XBee-PRO 802.15.4 radio module to a receiving computer at a sample rate of $247.2 \mathrm{~Hz}$. The received data is stored in separate files for the left and right foot.

Custom built MATLAB (Mathworks Ltd., USA) algorithms are used to analyse the data. The Runalyser output is measured in arbitrary units for each of the eight sensors. After filtering the data using a $4^{\text {th }}$ order Butterworth filter, the centre of pressure in the 
mediolateral $(x)$ and anteroposterior $(y)$ directions are calculated, based on the signal magnitudes of each sensor, the position of the centre of each individual sensor in relation to the centre of the insole, and weighting factors of each sensor in relation to their surface area. From this we can trace the centre of pressure trajectory in relation to the insole, as well as calculate the strike index (SI). SI represents the initial contact point of the ground on the foot sole, expressed as a percentage of total sole length (figure 1.5).

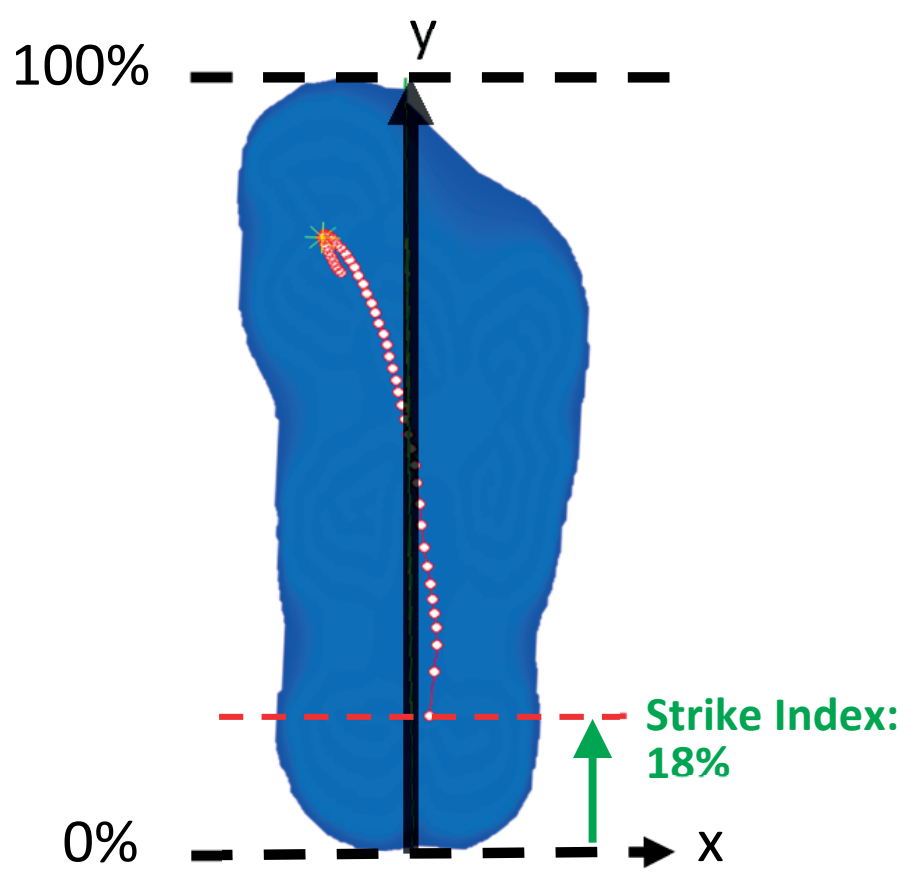

Figure 1.5. An example of how the strike index is calculated based on the initial contact point represented by the dashed, red line. The black arrow represents the total sole length (100\%), whereas the green arrow represents an $18 \%$ strike index in this case.

In order to be able to identify the initial contact point, we devised an algorithm to detect the moment of foot contact (FC) and the moment of toe-off (TO) based on the derivative of the raw data. This algorithm was optimised over time to be able to reliably detect all types of running styles. Figure 1.6 illustrates how we used the Runalyser data to calculate temporal parameters of running. Stride time $\left(T_{\text {stride }}\right)$ is calculated as the time difference between one foot contact and the next $\left(\mathrm{FC}_{2}-\mathrm{FC}_{1}\right)$. Contact time ( $\left.T_{\text {contact }}\right)$ was the time difference between FC and TO. Flight time $\left(T_{\text {flight }}\right)$ was the resulting difference when $T_{\text {contact }}$ was subtracted from $T_{\text {stride }}$. Further, we 
calculated the duty factor (DF), which is the percentage of time spent in contact with the ground ( $\left.\mathrm{T}_{\text {contact }} / \mathrm{T}_{\text {stride }} * 100\right)$, and in knowing the running speed we calculated the stride length $\left(S_{\text {length }}\right)$ by multiplying $T_{\text {stride }}$ by running speed. Finally, stride frequency is calculated by dividing running speed by $S_{\text {length }}$ (see chapter 2 for further details).

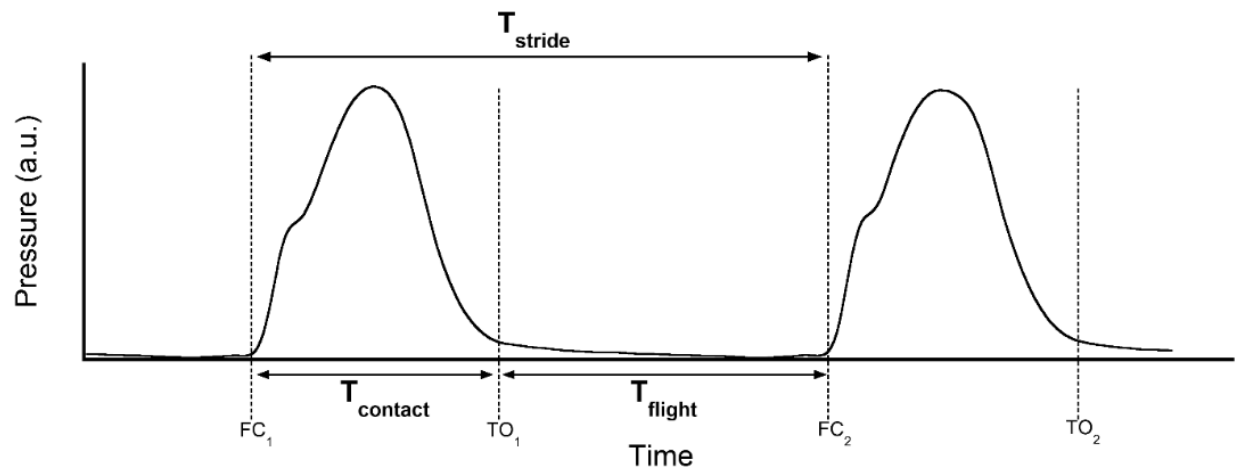

Figure 1.6. Example data as measured using the Runalyser to illustrate the definition of initial foot contact (FC) and toe-off (TO), and how this is used to measure stride time ( $\left.T_{\text {stride }}\right)$, contact time ( $\left.T_{\text {contact }}\right)$ and flight time $\left(\mathrm{T}_{\text {flight }}\right)$.

Having developed analysis algorithms to measure running strike pattern and spatiotemporal parameters, the first aim of this thesis was to test the reliability and validity of these measures, by comparing the Runalyser output to that of the gold standard, a force plate. As we were able to perform continuous acquisitions with the Runalyser, we employed an instrumented treadmill to base our analysis on multiple, consecutive steps, so as to improve the accuracy of our results.

We hypothesised that the Runalyser would be a valid and reliable tool when measuring strike index and spatiotemporal parameters (chapter 2).

\section{Running style}

Throughout this thesis, the term "running style" encompasses both the footstrike pattern (quantified using the $\mathrm{SI}$ ) and spatiotemporal parameters. Three types of footstrike pattern have been identified and are commonly used in running style research (figure 1.7). A rearfoot strike (RFS) is characterised as the posterior (heel) portion of the foot contacts the ground first, a midfoot strike (MFS) where the heel and the ball of the foot contact the ground simultaneously and a forefoot strike (FFS), 
where the anterior portion of the foot contacts the ground first, and the heel generally follows (Hasegawa et al., 2007; Larson, 2012; Lieberman et al., 2010). In 2010, an article appearing in Nature rekindled the debate on foot strike pattern within the scientific and running communities. Lieberman et al. (2010) demonstrated that striking the ground with the forefoot when barefoot, reduced the VLR seven-fold compared with striking the ground with the rearfoot (Lieberman et al., 2010). Hatala et al. (2013) confirmed that a FFS produced lower impact forces in comparison with a RFS (Hatala et al., 2013).

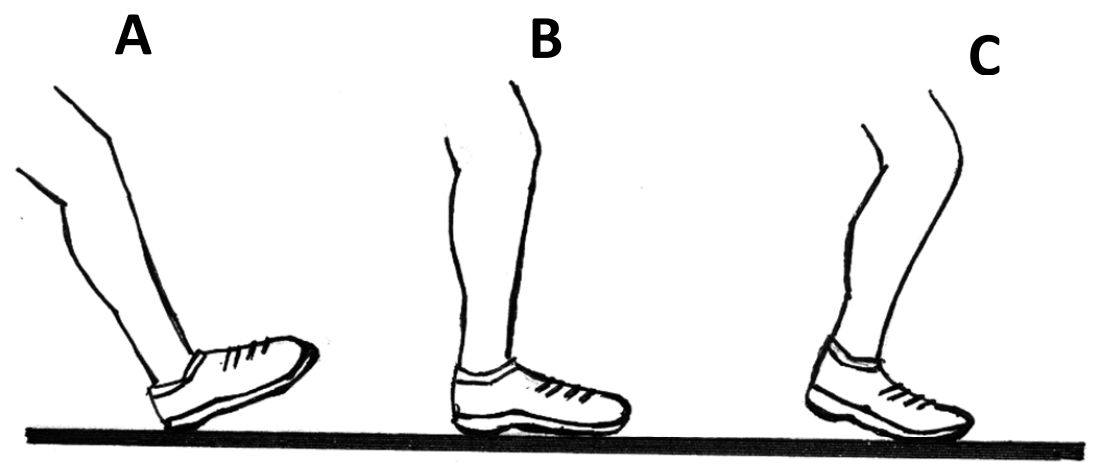

Figure 1.7. Examples of different running styles based on footstrike. A) Depicts a rearfoot strike, B) a midfoot strike and C) a forefoot strike running pattern. Illustrated by the author.

A recent study looking at possible interventions to reduce impact forces in runners, found that both encouraging a MFS in habitual RFS runners, and combining this with wearing racing flats and increasing the preferred stride frequency by $10 \%$, decreased the VLR by around $50 \%$ when compared to their normal running condition (Giandolini et al., 2012). However, wearing racing flats and reducing $S_{\text {frequency }}$ as stand-alone interventions did not significantly decrease VLR. These findings suggest that VLR is only significantly influenced by a change in strike pattern. As the VLR appears to be related to strike pattern and is a variable often analysed in biomechanical analyses, we aimed to further test the capabilities of the Runalyser, to see if it would be possible to accurately obtain a measure of VLR from its arbitrary output.

We hypothesised that the Runalyser would be able to provide an estimate of vertical loading rate, based on a comparison of data acquired using an instrumented treadmill (chapter 3).

Another factor thought to influence the running style is the running speed. This has been found to influence spatiotemporal parameters of running (Ogueta-Alday et al., 
2014; Padulo et al., 2012), yet the relation with SI and RRI has not yet been established. By testing our cohort of runners at five relative, submaximal running speeds, we aimed to identify differences in $\mathrm{SI}$ and confirm existing trends in spatiotemporal parameters.

\section{We hypothesised a decrease in strike index, contact time and stride time, and an increase in flight time, stride length and frequency with increasing running speed based on previous observations (chapter 4).}

Squadrone \& Galozzi (2009) observed that the SI was significantly higher in barefoot and minimalistic running shoe conditions compared with the conventional running shoe condition (Squadrone \& Gallozzi, 2009). The latter encouraged a RFS therefore, despite the cohort consisting of experienced barefoot runners.

Although this sudden interest in footstrike pattern among researchers is apparent, very few have looked at the relation with RRI. One study found that RFS runners were at a 2.6 times greater risk of sustaining a repetitive stress injury than FFS runners (Daoud et al., 2012). However, this study only included 52 elite cross-country runners, and reported many limitations in the protocol. Diebal et al. (2012) reported promising results when they retrained 10 chronic exertional compartment syndrome patients to run using a FFS, and found significantly reduced pain levels and improved running times (Diebal et al., 2012). FFS runners have been found to display lower patellofemoral stress and knee frontal plane moment than RFS runners, leading to speculation that FFS running could be protective against knee injuries (Kulmala et al., 2013). However, these authors also observed higher plantarflexor moment and Achilles tendon forces in FFS runners. This raises the question as to whether or not one footstrike pattern is more protective than another, and whether or not runners should adopt an alternative pattern to reduce the risk of RRI. Researchers have been successful in adapting the running style of habitual rear-foot strike runners to reduce VLR using various methods (Boyer et al., 2014; Crowell \& Davis, 2011; Diebal et al., 2012; Giandolini et al., 2013; D. S. Williams et al., 2000). Visual cues and verbal feedback during a 4-week intervention achieved greater effects than orthotic insole or shock absorbing shoe interventions (Crowell \& Davis, 2011). A similar 6-week, FFS retraining intervention resulted in reduced pain levels and increased running performance among military recruits (Diebal et al., 2012). The authors of these papers suggested that these adaptations are sustainable in the short (immediately afterwards) (D. S. Williams et al., 2000) and long (one month later) (Crowell \& Davis, 2011) term, and that adopting a forefoot strike, thereby lowering the VLR, is an effective way of reducing the risk of stress fractures (Crowell \& Davis, 2011) and reducing intramuscular pressure (Diebal et al., 2012). Although these studies were able to show biomechanical adaptation through gait retraining interventions, Bredeweg (2012) saw no difference in 
RRI incidence between a preconditioning, 4-week intervention group and control group (Bredeweg, Zijlstra, et al., 2012). The duration of the transitioning period needed is still being debated, and can be very individual-specific. However, the lack of prospective studies focusing on footstrike pattern and RRI incidence means that we still cannot be sure that gait retraining is a justified RRI prevention method. Only one recent study has reported on $S_{\text {length }}$ and its relation to patellofemoral joint stress (Willson et al., 2014). Once again, this study did not look at the causal relationship between PFP and $S_{\text {length, }}$, but did find a $31 \%$ increase in joint stress in the longer $S_{\text {length }}$ condition, and a $22 \%$ decrease in the shorter $S_{\text {length }}$ condition. Very few studies have included spatiotemporal parameters when trying to identify RRI risk factors. Using the Runalyser as a measurement tool, and taking foot type and morphology into account, we aimed to compare running style between a group of recreational runners having previously sustained a RRI, and a control group.

\section{We hypothesised that strike index and spatiotemporal parameters will be different between previously injured and non-injured runners (chapter 4).}

\section{Running shoes}

A factor which has been the subject of a number of studies recently is the running shoe itself. Historically, the running shoe industry has experienced many changes over the last four decades. Since the 1970s, Nike and other shoe manufacturers have been interlocked in a constant battle to design and produce "consumer products", shoes that consumers want to buy. Companies began introducing more advanced technology into their shoe design, such as anti-pronation wedges, longitudinal arch supports, motion control and stability mechanisms (Altman \& Davis, 2012; Lieberman, 2012; Rixe et al., 2012). The running shoe market exploded, with a choice of over 200 new shoe models on offer each season (Bartlett, 2012). Many specialist shoe shops now offer gait analyses to their clients, with the aim of "prescribing" the most appropriate running shoe for their foot structure and running style to reduce the risk of injury. However, as discussed above, the overall effectiveness of this remains to be established. A study employing a 13-week training programme randomly issued neutral, stability or motion-control shoes to 81 female runners with either neutral, pronated or highly pronated feet (M. B. Ryan et al., 2011). The number of missed training days due to pain using three visual analogue scale (VAS) items was recorded. Greater pain values were present when neutral foot type runners ran with a neutral shoe than with a stability shoe, and that in pronated foot type runners greater pain values were found for the stability shoe than the neutral shoe. The authors concluded 
that current shoe prescription methods may be flawed and even dangerous. Similarly, Knapik et al. (2010) assigned motion control, stability or cushioned shoes to military recruits depending on their plantar foot shape (low, medium or high arch respectively) (Knapik, Brosch, et al., 2010). A control group received stability shoes only, and after 6 weeks of training multivariate Cox regression analysis yielded little effect of prescribing or assigning running shoes, and a tendency toward a greater hazard ratio in the prescribed shoe group. These researchers published a meta-analysis of three similar studies of differing military cohorts and concluded that assigning these shoe types based on static plantar foot shape did not reduce RRI incidence as expected (Knapik, Trone, et al., 2010). A double blinded, randomised controlled trial by Theisen et al. (2013) tested the influence of soft vs hard midsoles (15\% hardness difference) of running shoes on RRI incidence in two groups of recreational runners over a 5-month period (Theisen et al., 2013). Shoe type was not found to be associated with RRI, with a hazard ratio of 0.92; 95\% confidence interval=0.57-1.48. Nielsen et al. (2013) found that novice runners with pronated feet were not at a higher risk of injury when running in a neutral running shoe (Nielsen et al., 2013).

Based on the current literature on running shoes and their relation to RRI, we must conclude that there is as yet no evidence to suggest that a particular type of shoe or integrated technology is preventative against injury. This observation is becoming widely recognised, and it is for this reason that alternatives to conventional running shoes are in high demand in the running community, and which the running market is ensuring great supply.

\section{Barefoot and minimalist running}

Such an alternative, is the minimalistic and barefoot running movement. When running barefoot, the natural shock-absorbing mechanism of the foot comes into play, as well as a combination of the elastic properties of the medial longitudinal arches. Greater knee flexion and plantarflexion of the foot lead to greater leg compliance at impact, allowing for this natural shock absorption (Lieberman et al., 2010). This is in essence due to the fact that striking the ground with the heel first while barefoot hurts (Robbins \& Hanna, 1987), and cannot be endured for prolonged periods of continuous running. Biomechanical comparisons of shod and barefoot running revealed that runners primarily use a MFS or FFS when barefoot, increase their ankle stiffness and reduce the VLR as a result of not using a RFS (Hamill et al., 2011). The majority of habitually shod runners running barefoot for the first time were found to significantly lower VLR due to FFS adaptation, although this was not the case for all runners (R. T. Cheung \& Rainbow, 2014). One study found higher VLRs in barefoot running compared 
to shod (De Wit et al., 2000). Guided visual and verbal instruction to adopt a FFS when barefoot also showed significant decreases in VLR in patients with manageable pain during treadmill running (Samaan et al., 2014). $T_{\text {contact }}, T_{\text {flight }}$ and $T_{\text {stride }}$ have been found to decrease when barefoot compared to shod (Divert et al., 2005). Step frequency was found to be higher and step length shorter in barefoot running (De Wit et al., 2000).

A relatively new concept to the running community, is running in minimalistic footwear. It has been shown that running in minimalistic shoes is biomechanically different to running barefoot (Bonacci et al., 2013). Minimalism is the most recent running shoe concept; in addition, shoes in general limit the proprioceptive abilities of the foot thereby reducing reactivity and stability of the concerned nerves and muscles. Regular use of stiff, bulky, conventional running footwear can lead to weak musculature in the feet and lower legs; arch supports and anti-pronation wedges may restrict natural running movements to an extent that the RRI risk is increased (Lieberman, 2012).

With these drawbacks of conventional running shoes being recognised, minimalistic running shoes have taken the running shoe market by storm during the last few years. Christopher McDougall's best-seller "Born to Run" invoked a huge amount of publicity for the minimalistic running shoe movement (McDougall, 2010). Surprisingly however, very few studies have looked at the effect of minimalistic running shoes on RRI. Anecdotal evidence of runners switching from conventional running shoes to minimalistic running shoes exists, reporting mainly metatarsal stress fractures (Cauthon et al., 2013; Salzler et al., 2012) and Achilles tendinopathy (Cauthon et al., 2013). Only one prospective study to date reported overall greater injury incidence with minimalistic shoe compared to conventional shoe use (M. Ryan et al., 2014). This study reported significantly more shin and calf pain when using the Vibram FiveFinger Bikila (a very minimalistic running shoe). In 2012, a lawsuit was filed against Vibram USA Inc. and Vibram FiveFingers LLC, because an exceedingly large portion of runners were sustaining overuse injuries as a result of running with these minimalistic shoes (Massachusetts, 2012). Vibram Inc. at the time, was claiming that running in their product would limit the risk of injury as it encourages a "natural running style". They failed to communicate that gradual acclimatisation to this type of running shoe could be necessary, as sudden changes can cause structural overload. It is now largely recognised that the transition duration must be adequate for the risk of injury to remain minimal (Rothschild, 2012). This period and strategy for adaptation has yet to be defined through further research (Altman \& Davis, 2012; Lieberman, 2012). It is also thought to vary from one runner to the other (Rixe et al., 2012). We therefore aimed to observe the influence of first-time minimalistic shoe use on strike pattern and spatiotemporal parameters in recreational runners using the Runalyser. Better understanding of how runners react to minimalistic running shoes, will provide 
valuable information for future interventions studying the effect of this type of shoe on RRI.

We hypothesised that first-time use of minimalistic running shoes will increase the strike index and decrease the stride length (chapter 5).

\section{Variability}

A concept which has not been studied in great depth, is the variability of running activity, and how variation ties in with RRI. Variability can be conceived on various levels, but is ultimately connected to the underlying mechanism of RRI presented throughout. As we have seen, the repetitive movement of running without sufficient rest for structural regeneration is what ultimately causes structural overload and overuse injuries. However, it has been thought that varying the otherwise repetitive loading of a specific structure, thereby dissipating the resulting stresses over additional structures, may reduce the risk of structural overload in general (Hamill et al., 2012; Meardon et al., 2011; Miller et al., 2008). Varying these loads between strides could reduce the risk of RRI. Associations of variability due to fatigue and iliotibial band syndrome have been tested (Miller et al., 2008). Less variability (expressed as standard deviation in this particular study) was found for thigh ab/adduction and foot in/eversion in previously injured runners, however the sample size was small (eight previously injured vs eight controls) and only seven consecutive steps were analysed at each acquisition using kinematics. Greater variability was found for knee flexion/extension and foot ab/adduction. Conclusive evidence that variability in running patterns is severely lacking, and to date, only one study has looked at the inter-stride variability of $T_{\text {stride, }}$ and compared this between nine previously injured runners, and nine controls (Meardon et al., 2011). These researchers used the coefficient of variation ( $\mathrm{CV}$, calculated as: standard deviation/mean) to measure interstride variability, and detrended fluctuation analysis (DFA) to measure stride-to-stride correlative patterns of $\mathrm{T}_{\text {stride. }}$ DFA is a technique which indicates in how far a stride is correlated with the ones previous (Jordan et al., 2006, 2007). Less correlation would suggest more randomness in a runner's stride-to-stride running pattern. Such analyses require prolonged sampling of a minimum of 60 consecutive steps (Dingwell \& Cusumano, 2010), which as we have seen, is often not feasible in a laboratory setting using runways and kinematics. The Runalyser is an optimal tool for prolonged acquisition. We therefore aimed to measure variability and correlative patterns of SI and spatiotemporal parameters in previously injured and non-injured runners (chapter 4). Additionally, we aimed to study the effect of running speed (chapter 4), shoe type 
and fatigue (chapter 5 ) on the variability and correlative patterns of these parameters, as this has previously not been done.

We hypothesised greater variability and more randomness in the running pattern of non-injured runners (chapter 4), when using a minimalistic running shoe for the first time, and after a prolonged running bout (chapter 5).

Another level of variability can relate to external, modifiable risk factors (table 1.3). We have seen that different types of running shoe exist, and are expected to influence running style in different ways. Indeed, studies comparing running in training shoes and racing flats (Wiegerinck et al., 2009) and new and worn shoes (Kong et al., 2009) have yielded differences in types and magnitudes of musculoskeletal stresses. Introducing such a variability through the use of different running shoes could be a way of reducing repetitive loading to isolated structures. At the inter-session level, alternating between multiple pairs of running shoes would introduce a variability in structural loading, but ensure that the accumulation of load to specific structures in consecutive sessions is reduced. A prospective cohort study, following 264 recreational runners for 22 weeks, sought to compare the RRI incidence between those using only one pair of running shoes, and those regularly alternating between multiple pairs.

We hypothesised a lower running-related injury incidence among runners alternating between multiple pairs of running shoes during a 22 week follow-up period (chapter 6). 


\section{Thesis outline}

The following work is a series of studies designed to lay the groundwork for further projects combining a newly developed, pressure-sensitive insole device with epidemiological study designs to be implemented in RRI. Chapter 2 presents the validation of the parameters measured using the Runalyser, and a new classification of footstrike pattern based on SI. Chapter 3 pushes the functionality of the Runalyser to its limits, as we attempt to obtain a valid and reliable measure of VLR using the Runalyser. Chapter 4 introduces post hoc analyses of variability and correlative patterns on Runalyser parameters, and aims to identify differences in these parameters and foot morphology, between previously injured and non-injured runners. In addition, changes in SI and spatiotemporal parameters, as well as their inter-stride variability and correlative patterns are observed as submaximal running speed is increased. Chapter 5 builds on the idea of running shoe type (extrinsic factor) and fatigue (intrinsic factor) influencing running style, and the Runalyser is used to measure any effects. Chapter 6 presents a prospective cohort study on the influence of variability, induced by concomitant, multiple running shoe use and the simultaneous practice of other sports besides running, on the RRI incidence. Finally, a general discussion of the findings is presented in chapter 7, along with suggestions for further research and an overall conclusion. 


\section{Summary of hypotheses}

We hypothesised that the Runalyser would be a valid and reliable tool when measuring strike index and spatiotemporal parameters (chapter 2).

We hypothesised that the Runalyser would be able to provide an estimate of vertical loading rate, based on a comparison of data acquired using an instrumented treadmill (chapter 3).

We hypothesised a decrease in strike index and contact time and stride time, and an increase in flight time, stride length and frequency with increasing running speed based on previous observations (chapter 4).

We hypothesised that strike index and spatiotemporal parameters will be different between previously injured and non-injured runners (chapter 4).

We hypothesised that first-time use of minimalistic running shoes will increase the strike index and decrease the stride length (chapter 5).

We hypothesised greater variability and more randomness in the running pattern of non-injured runners (chapter 4), when using a minimalistic running shoe for the first time, and after a prolonged running bout (chapter 5).

We hypothesised a lower running-related injury incidence among runners alternating between multiple pairs of running shoes during a 22 week follow-up period (chapter 6). 


\section{References}

Abendroth-Smith, J. (1996). Stride adjustments during a running approach toward a force plate. Res $Q$ Exerc Sport, 67(1), 97-101.

Altman, A. R., \& Davis, I. S. (2012). Barefoot running: biomechanics and implications for running injuries. Curr Sports Med Rep, 11(5), 244-250.

Association, B. A. (2014). Boston Marathon History: Participation. Retrieved 13/10/2014, 2014, from http://www.baa.org/races/boston-marathon/boston-marathon-history/participation.aspx

Azevedo, L. B., Lambert, M. I., Vaughan, C. L., O'Connor, C. M., \& Schwellnus, M. P. (2009). Biomechanical variables associated with Achilles tendinopathy in runners. Br J Sports Med, 43(4), 288-292.

Barnett, S., Cunningham, J. L., \& West, S. (2000). A comparison of vertical force and temporal parameters produced by an in-shoe pressure measuring system and a force platform. Clin Biomech (Bristol, Avon), 15(10), 781-785.

Bartlett, R. B., M. (2012). Sports Biomechanics: reducing injury risk and improving performance (2nd ed.). 711 Third Avenue, New York, NY 10017: Routledge.

Belli, A., Bui, P., Berger, A., Geyssant, A., \& Lacour, J. R. (2001). A treadmill ergometer for three-dimensional ground reaction forces measurement during walking. J Biomech, 34(1), 105-112.

Bennett, J. E., Reinking, M. F., Pluemer, B., Pentel, A., Seaton, M., \& Killian, C. (2001). Factors contributing to the development of medial tibial stress syndrome in high school runners. J Orthop Sports Phys Ther, 31(9), 504-510.

Benoit, D. L., Ramsey, D. K., Lamontagne, M., Xu, L., Wretenberg, P., \& Renstrom, P. (2006). Effect of skin movement artifact on knee kinematics during gait and cutting motions measured in vivo. Gait Posture, 24(2), 152-164.

Bergstra, S. A., Kluitenberg, B., Dekker, R., Bredeweg, S. W., Postema, K., Van den Heuvel, E. R., ... Sobhani, S. (2014). Running with a minimalist shoe increases plantar pressure in the forefoot region of healthy female runners. J Sci Med Sport

Besier, T. F., Fredericson, M., Gold, G. E., Beaupre, G. S., \& Delp, S. L. (2009). Knee muscle forces during walking and running in patellofemoral pain patients and pain-free controls. J Biomech, 42(7), 898-905.

Bonacci, J., Saunders, P. U., Hicks, A., Rantalainen, T., Vicenzino, B. G., \& Spratford, W. (2013). Running in a minimalist and lightweight shoe is not the same as running barefoot: a biomechanical study. $\mathrm{Br} J$ Sports Med, 47(6), 387-392.

Bonacci, J., Vicenzino, B., Spratford, W., \& Collins, P. (2014). Take your shoes off to reduce patellofemoral joint stress during running. Br J Sports Med, 48(6), 425-428.

Bovens, A. M., Janssen, G. M., Vermeer, H. G., Hoeberigs, J. H., Janssen, M. P., \& Verstappen, F. T. (1989). Occurrence of running injuries in adults following a supervised training program. Int J Sports Med, 10 Supp/ 3, S186-190.

Boyer, E. R., Rooney, B. D., \& Derrick, T. R. (2014). Rearfoot and midfoot or forefoot impacts in habitually shod runners. Med Sci Sports Exerc, 46(7), 1384-1391.

Bredeweg, S. W., Kluitenberg, B., Bessem, B., \& Buist, I. (2012). Differences in kinetic variables between injured and noninjured novice runners: A prospective cohort study. J Sci Med Sport

Bredeweg, S. W., Zijlstra, S., Bessem, B., \& Buist, I. (2012). The effectiveness of a preconditioning programme on preventing running-related injuries in novice runners: a randomised controlled trial. Br J Sports Med

Buist, I., Bredeweg, S. W., Bessem, B., van Mechelen, W., Lemmink, K. A., \& Diercks, R. L. (2010). Incidence and risk factors of running-related injuries during preparation for a 4-mile recreational running event. Br J Sports Med, 44(8), 598-604.

Buist, I., Bredeweg, S. W., Lemmink, K. A., Pepping, G. J., Zwerver, J., van Mechelen, W., \& Diercks, R. L. (2007). The GRONORUN study: is a graded training program for novice runners effective in preventing running related injuries? Design of a Randomized Controlled Trial. BMC Musculoskelet Disord, 8, 24.

Buist, I., Bredeweg, S. W., van Mechelen, W., Lemmink, K. A., Pepping, G. J., \& Diercks, R. L. (2008). No effect of a graded training program on the number of running-related injuries in novice runners: $a$ randomized controlled trial. Am J Sports Med, 36(1), 33-39.

Butler, R. J., Hamill, J., \& Davis, I. (2007). Effect of footwear on high and low arched runners' mechanics during a prolonged run. Gait Posture, 26(2), 219-225. 
Cameron, K. L. (2010). Commentary: Time for a paradigm shift in conceptualizing risk factors in sports injury research. J Athl Train, 45(1), 58-60.

Cauthon, D. J., Langer, P., \& Coniglione, T. C. (2013). Minimalist shoe injuries: three case reports. Foot (Edinb), 23(2-3), 100-103.

Cavanagh, P. R., Hewitt Jr, F. G., \& Perry, J. E. (1992). In-shoe plantar pressure measurement: a review. The Foot, 2(4), 185-194.

Cheung, R. T., \& Ng, G. Y. (2008). Influence of different footwear on force of landing during running. Phys Ther, 88(5), 620-628.

Cheung, R. T., \& Rainbow, M. J. (2014). Landing pattern and vertical loading rates during first attempt of barefoot running in habitual shod runners. Hum Mov Sci, 34, 120-127.

Cheung, R. T. H., \& Ng, G. Y. F. (2007). Efficacy of motion control shoes for reducing excessive rearfoot motion in fatigued runners. Physical Therapy in Sport, 8(2), 75-81.

Chorley, J. N., Cianca, J. C., Divine, J. G., \& Hew, T. D. (2002). Baseline injury risk factors for runners starting a marathon training program. Clin J Sport Med, 12(1), 18-23.

Craft, L. L., \& Perna, F. M. (2004). The Benefits of Exercise for the Clinically Depressed. Prim Care Companion J Clin Psychiatry, 6(3), 104-111.

Crossley, K., Bennell, K. L., Wrigley, T., \& Oakes, B. W. (1999). Ground reaction forces, bone characteristics, and tibial stress fracture in male runners. Med Sci Sports Exerc, 31(8), 1088-1093.

Crowell, H. P., \& Davis, I. S. (2011). Gait retraining to reduce lower extremity loading in runners. Clin Biomech (Bristol, Avon), 26(1), 78-83.

Daoud, A. I., Geissler, G. J., Wang, F., Saretsky, J., Daoud, Y. A., \& Lieberman, D. E. (2012). Foot strike and injury rates in endurance runners: a retrospective study. Med Sci Sports Exerc, 44(7), 1325-1334.

De Cock, A., Vanrenterghem, J., Willems, T., Witvrouw, E., \& De Clercq, D. (2008). The trajectory of the centre of pressure during barefoot running as a potential measure for foot function. Gait Posture, 27(4), 669-675.

De Wit, B., De Clercq, D., \& Aerts, P. (2000). Biomechanical analysis of the stance phase during barefoot and shod running. J Biomech, 33(3), 269-278.

Diebal, A. R., Gregory, R., Alitz, C., \& Gerber, J. P. (2012). Forefoot running improves pain and disability associated with chronic exertional compartment syndrome. Am J Sports Med, 40(5), 1060-1067.

Dierick, F., Penta, M., Renaut, D., \& Detrembleur, C. (2004). A force measuring treadmill in clinical gait analysis. Gait Posture, 20(3), 299-303.

Dingwell, J. B., \& Cusumano, J. P. (2010). Re-interpreting detrended fluctuation analyses of stride-to-stride variability in human walking. Gait Posture, 32(3), 348-353.

Divert, C., Mornieux, G., Baur, H., Mayer, F., \& Belli, A. (2005). Mechanical comparison of barefoot and shod running. Int J Sports Med, 26(7), 593-598.

Dixon, S. J. (2008). Use of pressure insoles to compare in-shoe loading for modern running shoes. Ergonomics, 51(10), 1503-1514.

Duffey, M. J., Martin, D. F., Cannon, D. W., Craven, T., \& Messier, S. P. (2000). Etiologic factors associated with anterior knee pain in distance runners. Med Sci Sports Exerc, 32(11), 1825-1832.

Ferber, R., Davis, I. M., \& Williams, D. S., 3rd. (2003). Gender differences in lower extremity mechanics during running. Clin Biomech (Bristol, Avon), 18(4), 350-357.

Ferber, R., Hreljac, A., \& Kendall, K. D. (2009). Suspected Mechanisms in the Cause of Overuse Running Injuries: A Clinical Review. Sports Health: A Multidisciplinary Approach, 1(3), 242-246.

Fields, K. B., Sykes, J. C., Walker, K. M., \& Jackson, J. C. (2010). Prevention of running injuries. Curr Sports Med Rep, 9(3), 176-182.

Fourchet, F., Kelly, L., Horobeanu, C., Loepelt, H., Taiar, R., \& Millet, G. P. (2012). Comparison of plantar pressure distribution in adolescent runners at low vs. high running velocity. Gait Posture, 35(4), 685687.

Fuller, C. W., Ekstrand, J., Junge, A., Andersen, T. E., Bahr, R., Dvorak, J., . . . Meeuwisse, W. H. (2006). Consensus statement on injury definitions and data collection procedures in studies of football (soccer) injuries. Clin J Sport Med, 16(2), 97-106.

Ghani Zadeh Hesar, N., Van Ginckel, A., Cools, A., Peersman, W., Roosen, P., De Clercq, D., \& Witvrouw, E. (2009). A prospective study on gait-related intrinsic risk factors for lower leg overuse injuries. $\mathrm{Br} J$ Sports Med, 43(13), 1057-1061. 
Giandolini, M., Arnal, P. J., Millet, G. Y., Peyrot, N., Samozino, P., Dubois, B., \& Morin, J. B. (2012). Impact reduction during running: efficiency of simple acute interventions in recreational runners. Eur J Appl Physiol

Giandolini, M., Horvais, N., Farges, Y., Samozino, P., \& Morin, J. B. (2013). Impact reduction through longterm intervention in recreational runners: midfoot strike pattern versus low-drop/low-heel height footwear. Eur J Appl Physiol, 113(8), 2077-2090.

Giandolini, M., Poupard, T., Gimenez, P., Horvais, N., Millet, G. Y., Morin, J. B., \& Samozino, P. (2014). A simple field method to identify foot strike pattern during running. J Biomech, 47(7), 1588-1593.

Godi, M., Turcato, A. M., Schieppati, M., \& Nardone, A. (2014). Test-retest reliability of an insole plantar pressure system to assess gait along linear and curved trajectories. J Neuroeng Rehabil, 11, 95.

Grau, S., Maiwald, C., Krauss, I., Axmann, D., Janssen, P., \& Horstmann, T. (2008). What are causes and treatment strategies for patellar-tendinopathy in female runners? J Biomech, 41(9), 2042-2046.

Hamill, J., Miller, R., Noehren, B., \& Davis, I. (2008). A prospective study of iliotibial band strain in runners. Clin Biomech (Bristol, Avon), 23(8), 1018-1025.

Hamill, J., Palmer, C., \& Van Emmerik, R. E. (2012). Coordinative variability and overuse injury. Sports Med Arthrosc Rehabil Ther Technol, 4(1), 45.

Hamill, J., Russell, E. M., Gruber, A. H., \& Miller, R. (2011). Impact characteristics in shod and barefoot running. Footwear Science, 3(1), 33-40.

Hasegawa, H., Yamauchi, T., \& Kraemer, W. J. (2007). Foot strike patterns of runners at the $15-\mathrm{km}$ point during an elite-level half marathon. J Strength Cond Res, 21(3), 888-893.

Hatala, K. G., Dingwall, H. L., Wunderlich, R. E., \& Richmond, B. G. (2013). Variation in Foot Strike Patterns during Running among Habitually Barefoot Populations. PLoS One, 8(1), e52548.

Hein, T., Janssen, P., Wagner-Fritz, U., Haupt, G., \& Grau, S. (2014). Prospective analysis of intrinsic and extrinsic risk factors on the development of Achilles tendon pain in runners. Scand J Med Sci Sports, 24(3), e201-e212.

Hennig, E. M., Milani, T. L. (1995). In-Shoe Pressure Distribution for Running in Various Types of Footwear. Journal of Applied Biomechanics, 11(3), 299-310.

Hintermann, B., \& Nigg, B. M. (1998). Pronation in runners. Implications for injuries. Sports Med, 26(3), 169176.

Hoeberigs, J. H. (1992). Factors related to the incidence of running injuries. A review. Sports Med, 13(6), 408422.

Hreljac, A. (2004). Impact and overuse injuries in runners. Med Sci Sports Exerc, 36(5), 845-849.

Hreljac, A. (2005). Etiology, prevention, and early intervention of overuse injuries in runners: a biomechanical perspective. Phys Med Rehabil Clin N Am, 16(3), 651-667, vi.

Jenkins, D. W., \& Cauthon, D. J. (2011). Barefoot running claims and controversies: a review of the literature. J Am Podiatr Med Assoc, 101(3), 231-246.

Jordan, K., Challis, J. H., \& Newell, K. M. (2006). Long range correlations in the stride interval of running. Gait Posture, 24(1), 120-125.

Jordan, K., Challis, J. H., \& Newell, K. M. (2007). Speed influences on the scaling behavior of gait cycle fluctuations during treadmill running. Hum Mov Sci, 26(1), 87-102.

Junge, A., Engebretsen, L., Alonso, J. M., Renstrom, P., Mountjoy, M., Aubry, M., \& Dvorak, J. (2008). Injury surveillance in multi-sport events: the International Olympic Committee approach. Br J Sports Med, 42(6), 413-421.

Knapik, J. J., Brosch, L. C., Venuto, M., Swedler, D. I., Bullock, S. H., Gaines, L. S., . . Jones, B. H. (2010). Effect on injuries of assigning shoes based on foot shape in air force basic training. Am J Prev Med, 38(1 Suppl), S197-211.

Knapik, J. J., Trone, D. W., Swedler, D. I., Villasenor, A., Bullock, S. H., Schmied, E., . . Jones, B. H. (2010). Injury reduction effectiveness of assigning running shoes based on plantar shape in Marine Corps basic training. Am J Sports Med, 38(9), 1759-1767.

Kong, P. W., Candelaria, N. G., \& Smith, D. R. (2009). Running in new and worn shoes: a comparison of three types of cushioning footwear. Br J Sports Med, 43(10), 745-749.

Korpelainen, R., Orava, S., Karpakka, J., Siira, P., \& Hulkko, A. (2001). Risk factors for recurrent stress fractures in athletes. Am J Sports Med, 29(3), 304-310.

Kulmala, J. P., Avela, J., Pasanen, K., \& Parkkari, J. (2013). Forefoot strikers exhibit lower running-induced knee loading than rearfoot strikers. Med Sci Sports Exerc, 45(12), 2306-2313. 
Larson, P. K., B. (2012). Tread Lightly: Form, Footwear, and the Quest for Injury-free Running. 307 West 36th Street, 11th Floor, New York, NY: Skyhorse Publishing, Inc.

Lieberman, D. E. (2012). What we can learn about running from barefoot running: an evolutionary medical perspective. Exerc Sport Sci Rev, 40(2), 63-72.

Lieberman, D. E., Venkadesan, M., Werbel, W. A., Daoud, A. I., D'Andrea, S., Davis, I. S., . . . Pitsiladis, Y. (2010). Foot strike patterns and collision forces in habitually barefoot versus shod runners. Nature, 463, 531-536.

Logan, S., Hunter, I., JT, J. T. H., Feland, J. B., \& Parcell, A. C. (2010). Ground reaction force differences between running shoes, racing flats, and distance spikes in runners. J Sports Sci Med, 9(1), 147-153.

London Marathon Race Results 2014. (2014). Retrieved 10/10/2014, 2014, from http://www.marathonguide.com/results/browse.cfm?MIDD=16140413

Lopes, A. D., Costa, L. O., Saragiotto, B. T., Yamato, T. P., Adami, F., \& Verhagen, E. (2011). Musculoskeletal pain is prevalent among recreational runners who are about to compete: an observational study of 1049 runners. J Physiother, 57(3), 179-182.

Lopes, A. D., Hespanhol Junior, L. C., Yeung, S. S., \& Costa, L. O. (2012). What are the main running-related musculoskeletal injuries? A Systematic Review. Sports Med, 42(10), 891-905.

Louw, M., \& Deary, C. (2014). The biomechanical variables involved in the aetiology of iliotibial band syndrome in distance runners - A systematic review of the literature. Phys Ther Sport, 15(1), 64-75.

Low, D. C., \& Dixon, S. J. (2010). Footscan pressure insoles: accuracy and reliability of force and pressure measurements in running. Gait Posture, 32(4), 664-666.

Lucchetti, L., Cappozzo, A., Cappello, A., \& Della Croce, U. (1998). Skin movement artefact assessment and compensation in the estimation of knee-joint kinematics. J Biomech, 31(11), 977-984.

Lun, V., Meeuwisse, W. H., Stergiou, P., \& Stefanyshyn, D. (2004). Relation between running injury and static lower limb alignment in recreational runners. Br J Sports Med, 38(5), 576-580.

Lysholm, J., \& Wiklander, J. (1987). Injuries in runners. Am J Sports Med, 15(2), 168-171.

Macur, J. (2009). Plodders Have a Place, but Is It in a Marathon? Retrieved 06.01.2015, 2015, from http://www.nytimes.com/2009/10/23/sports/23marathon.html?pagewanted=all\&_r=0

Malisoux, L., Nielsen, R. O., Urhausen, A., \& Theisen, D. (2014). A step towards understanding the mechanisms of running-related injuries. J Sci Med Sport

Marti, B., Vader, J. P., Minder, C. E., \& Abelin, T. (1988). On the epidemiology of running injuries. The 1984 Bern Grand-Prix study. Am J Sports Med, 16(3), 285-294.

Martinez-Nova, A., Cuevas-Garcia, J. C., Pascual-Huerta, J., \& Sanchez-Rodriguez, R. (2007). BioFoot ${ }^{\circledR}$ in-shoe system: Normal values and assessment of the reliability and repeatability. The Foot, 17(4), 190-196.

Massachusetts, U. S. D. C. f. t. D. o. (2012). Vibram Inc. Lawsuit. 2012, from http://www.universalhub.com/files/vibram-complaint.pdf

McClay, I., \& Manal, K. (1998). A comparison of three-dimensional lower extremity kinematics during running between excessive pronators and normals. Clin Biomech (Bristol, Avon), 13(3), 195-203.

McCrory, J. L., Martin, D. F., Lowery, R. B., Cannon, D. W., Curl, W. W., Read, H. M., Jr., . . Messier, S. P. (1999). Etiologic factors associated with Achilles tendinitis in runners. Med Sci Sports Exerc, 31(10), 1374-1381.

McDougall, C. (2010). Born to Run: The hidden tribe, the ultra-runners and the greatest race the world has never known. Great Britain: Profile Books Ltd.

Meardon, S. A., Hamill, J., \& Derrick, T. R. (2011). Running injury and stride time variability over a prolonged run. Gait Posture, 33(1), 36-40.

Meeuwisse, W. H. (1994). Assessing Causation in Sport Injury: A Multifactorial Model. Clin J Sport Med, 4(3), 166-170.

Meeuwisse, W. H., Tyreman, H., Hagel, B., \& Emery, C. (2007). A dynamic model of etiology in sport injury: the recursive nature of risk and causation. Clin J Sport Med, 17(3), 215-219.

Messier, S. P., Legault, C., Schoenlank, C. R., Newman, J. J., Martin, D. F., \& DeVita, P. (2008). Risk factors and mechanisms of knee injury in runners. Med Sci Sports Exerc, 40(11), 1873-1879.

Miller, R. H., Meardon, S. A., Derrick, T. R., \& Gillette, J. C. (2008). Continuous relative phase variability during an exhaustive run in runners with a history of iliotibial band syndrome. J Appl Biomech, 24(3), 262-270.

Milner, C. E., Davis, I. S., \& Hamill, J. (2006). Free moment as a predictor of tibial stress fracture in distance runners. J Biomech, 39(15), 2819-2825.

Milner, C. E., Ferber, R., Pollard, C. D., Hamill, J., \& Davis, I. S. (2006). Biomechanical factors associated with tibial stress fracture in female runners. Med Sci Sports Exerc, 38(2), 323-328. 
Nakhaee, Z., Rahimi, A., Abaee, M., Rezasoltani, A., \& Kalantari, K. K. (2008). The relationship between the height of the medial longitudinal arch (MLA) and the ankle and knee injuries in professional runners. Foot (Edinb), 18(2), 84-90.

Nielsen, R. O., Buist, I., Parner, E. T., Nohr, E. A., Sorensen, H., Lind, M., \& Rasmussen, S. (2013). Foot pronation is not associated with increased injury risk in novice runners wearing a neutral shoe: a 1year prospective cohort study. Br J Sports Med

Nielsen, R. O., Buist, I., Sorensen, H., Lind, M., \& Rasmussen, S. (2012). Training errors and running related injuries: a systematic review. Int J Sports Phys Ther, $7(1), 58-75$.

Novacheck, T. F. (1998). The biomechanics of running. Gait Posture, 7(1), 77-95.

Ogueta-Alday, A., Rodriguez-Marroyo, J. A., \& Garcia-Lopez, J. (2014). Rearfoot striking runners are more economical than midfoot strikers. Med Sci Sports Exerc, 46(3), 580-585.

Padulo, J., Annino, G., Migliaccio, G. M., D'Ottavio, S., \& Tihanyi, J. (2012). Kinematics of running at different slopes and speeds. J Strength Cond Res, 26(5), 1331-1339.

Pedersen, B. K., \& Saltin, B. (2006). Evidence for prescribing exercise as therapy in chronic disease. Scand J Med Sci Sports, 16 Suppl 1, 3-63.

Pohl, M. B., Hamill, J., \& Davis, I. S. (2009). Biomechanical and anatomic factors associated with a history of plantar fasciitis in female runners. Clin J Sport Med, 19(5), 372-376.

Pohl, M. B., Mullineaux, D. R., Milner, C. E., Hamill, J., \& Davis, I. S. (2008). Biomechanical predictors of retrospective tibial stress fractures in runners. J Biomech, 41(6), 1160-1165.

Rauh, M. J., Koepsell, T. D., Rivara, F. P., Margherita, A. J., \& Rice, S. G. (2006). Epidemiology of musculoskeletal injuries among high school cross-country runners. Am J Epidemiol, 163(2), 151-159.

Razak, A. H., Zayegh, A., Begg, R. K., \& Wahab, Y. (2012). Foot plantar pressure measurement system: a review. Sensors (Basel), 12(7), 9884-9912.

Ribeiro, A. P., Trombini-Souza, F., Tessutti, V., Rodrigues Lima, F., Sacco Ide, C., \& Joao, S. M. (2011a). Rearfoot alignment and medial longitudinal arch configurations of runners with symptoms and histories of plantar fasciitis. Clinics (Sao Paulo), 66(6), 1027-1033.

Ribeiro, A. P., Trombini-Souza, F., Tessutti, V. D., Lima, F. R., Joao, S. M., \& Sacco, I. C. (2011b). The effects of plantar fasciitis and pain on plantar pressure distribution of recreational runners. Clin Biomech (Bristol, Avon), 26(2), 194-199.

Riley, P. O., Dicharry, J., Franz, J., Della Croce, U., Wilder, R. P., \& Kerrigan, D. C. (2008). A kinematics and kinetic comparison of overground and treadmill running. Med Sci Sports Exerc, 40(6), 1093-1100.

Rixe, J. A., Gallo, R. A., \& Silvis, M. L. (2012). The barefoot debate: can minimalist shoes reduce runningrelated injuries? Curr Sports Med Rep, 11(3), 160-165.

Robbins, S. E., \& Hanna, A. M. (1987). Running-related injury prevention through barefoot adaptations. Med Sci Sports Exerc, 19(2), 148-156.

Rosenbaum, D., \& Becker, H. P. (1997). Plantar pressure distribution measurements. Technical background and clinical applications. Foot and Ankle Surgery, 3(1), 1-14.

Rothman, K. J. (1976). Causes. Am J Epidemiol, 104(6), 587-592.

Rothman, K. J., \& Greenland, S. (2005). Causation and causal inference in epidemiology. Am J Public Health, 95 Suppl 1, S144-150.

Rothschild, C. (2012). Running Barefoot or in Minimalist Shoes: Evidence or Conjecture? National Strength and Conditioning Association, 34(2), 8-16.

Ryan, M., Elashi, M., Newsham-West, R., \& Taunton, J. (2014). Examining injury risk and pain perception in runners using minimalist footwear. Br J Sports Med, 48(16), 1257-1262.

Ryan, M. B., Valiant, G. A., McDonald, K., \& Taunton, J. E. (2011). The effect of three different levels of footwear stability on pain outcomes in women runners: a randomised control trial. Br J Sports Med, 45(9), 715-721.

Sallis, J. F., Hovell, M. F., \& Hofstetter, C. R. (1992). Predictors of adoption and maintenance of vigorous physical activity in men and women. Prev Med, 21(2), 237-251.

Sallis, J. F., Hovell, M. F., Hofstetter, C. R., Elder, J. P., Faucher, P., Spry, V. M., . . Hackley, M. (1990). Lifetime history of relapse from exercise. Addict Behav, 15(6), 573-579.

Salzler, M. J., Bluman, E. M., Noonan, S., Chiodo, C. P., \& de Asla, R. J. (2012). Injuries observed in minimalist runners. Foot Ankle Int, 33(4), 262-266.

Samaan, C. D., Rainbow, M. J., \& Davis, I. S. (2014). Reduction in ground reaction force variables with instructed barefoot running. Journal of Sport and Health Science, 3(2), 143-151. 
Saragiotto, B. T., Yamato, T. P., Hespanhol Junior, L. C., Rainbow, M. J., Davis, I. S., \& Lopes, A. D. (2014). What are the main risk factors for running-related injuries? Sports Med, 44(8), 1153-1163.

Shih, Y., Lin, K. L., \& Shiang, T. Y. (2013). Is the foot striking pattern more important than barefoot or shod conditions in running? Gait Posture, 38(3), 490-494.

Squadrone, R., \& Gallozzi, C. (2009). Biomechanical and physiological comparison of barefoot and two shod conditions in experienced barefoot runners. J Sports Med Phys Fitness, 49(1), 6-13.

Stacoff, A., Reinschmidt, C., Nigg, B. M., Van Den Bogert, A. J., Lundberg, A., Denoth, J., \& Stussi, E. (2001). Effects of shoe sole construction on skeletal motion during running. Med Sci Sports Exerc, 33(2), 311319.

Stefanyshyn, D. J., Stergiou, P., Lun, V. M., Meeuwisse, W. H., \& Worobets, J. T. (2006). Knee angular impulse as a predictor of patellofemoral pain in runners. Am J Sports Med, 34(11), 1844-1851.

Taunton, J. E., Ryan, M. B., Clement, D. B., McKenzie, D. C., Lloyd-Smith, D. R., \& Zumbo, B. D. (2003). A prospective study of running injuries: the Vancouver Sun Run "In Training" clinics. Br J Sports Med, $37(3), 239-244$.

Tessutti, V., Trombini-Souza, F., Ribeiro, A. P., Nunes, A. L., \& Sacco, I. d. C. N. (2010). In-shoe plantar pressure distribution during running on natural grass and asphalt in recreational runners. Journal of Science and Medicine in Sport, 13(1), 151-155.

Theisen, D., Malisoux, L., Genin, J., Delattre, N., Seil, R., \& Urhausen, A. (2013). Influence of midsole hardness of standard cushioned shoes on running-related injury risk: a double-blind randomised controlled trial. Br J Sports Med, doi:10.1136/bjsports-2013-092613.

Thijs, Y., De Clercq, D., Roosen, P., \& Witvrouw, E. (2008). Gait-related intrinsic risk factors for patellofemoral pain in novice recreational runners. $\mathrm{Br} J$ Sports Med, published online 8 Apr 2008, doi:2010.1136/bjsm.2008.046649.

Thijs, Y., Van Tiggelen, D., Roosen, P., De Clercq, D., \& Witvrouw, E. (2007). A prospective study on gaitrelated intrinsic risk factors for patellofemoral pain. Clin J Sport Med, 17(6), 437-445.

Thompson, P. D., Buchner, D., Pina, I. L., Balady, G. J., Williams, M. A., Marcus, B. H., . . . Metabolism Subcommittee on Physical, A. (2003). Exercise and physical activity in the prevention and treatment of atherosclerotic cardiovascular disease: a statement from the Council on Clinical Cardiology (Subcommittee on Exercise, Rehabilitation, and Prevention) and the Council on Nutrition, Physical Activity, and Metabolism (Subcommittee on Physical Activity). Circulation, 107(24), 3109-3116.

Tonoli, C., Cumps, E., Aerts, I., Verhagen, E., Meeusen, R. (2010). Incidence, Risk Factors and Prevention of Running Related Injuries in Long-distance Running: a Systematical Review. Sport \& Geneeskunde(5), 12-18.

Tunstall Pedoe, D. (2014). London Marathon: what we know about the incidence of injury, illness and death in the London Marathon. 2014, from http://www.pponline.co.uk/encyc/london-marathon-what-weknow-about-the-incidence-of-injury-illness-and-death-in-the-london-marathon-881\#

van Gent, R. N., Siem, D., van Middelkoop, M., van Os, A. G., Bierma-Zeinstra, S. M., \& Koes, B. W. (2007). Incidence and determinants of lower extremity running injuries in long distance runners: a systematic review. Br J Sports Med, 41(8), 469-480; discussion 480.

Van Ginckel, A., Thijs, Y., Hesar, N. G., Mahieu, N., De Clercq, D., Roosen, P., \& Witvrouw, E. (2009). Intrinsic gait-related risk factors for Achilles tendinopathy in novice runners: a prospective study. Gait Posture, 29(3), 387-391.

van Mechelen, W. (1992). Running injuries. A review of the epidemiological literature. Sports Med, 14(5), 320-335.

Van Middelkoop, M., Kolkman, J., Van Ochten, J., Bierma-Zeinstra, S. M., \& Koes, B. W. (2008). Risk factors for lower extremity injuries among male marathon runners. Scand J Med Sci Sports, 18(6), 691-697.

Verkerke, G. J., Ament, W., Wierenga, R., \& Rakhorst, G. (1998). Measuring changes in step parameters during an exhausting running exercise. Gait Posture, 8(1), 37-42.

Wang, L., Hong, Y., Li, J. X., \& Zhou, J. H. (2012). Comparison of plantar loads during running on different overground surfaces. Res Sports Med, 20(2), 75-85.

Wiegerinck, J. I., Boyd, J., Yoder, J. C., Abbey, A. N., Nunley, J. A., \& Queen, R. M. (2009). Differences in plantar loading between training shoes and racing flats at a self-selected running speed. Gait Posture, 29(3), 514-519.

Willems, T. M., De Ridder, R., \& Roosen, P. (2012). The effect of a long-distance run on plantar pressure distribution during running. Gait Posture, 35(3), 405-409. 
Williams, D. S., 3rd, Davis, I. M., Scholz, J. P., Hamill, J., \& Buchanan, T. S. (2004). High-arched runners exhibit increased leg stiffness compared to low-arched runners. Gait Posture, 19(3), 263-269.

Williams, D. S., 3rd, McClay, I. S., \& Hamill, J. (2001). Arch structure and injury patterns in runners. Clin Biomech (Bristol, Avon), 16(4), 341-347.

Williams, D. S., McClay, I. S., \& Manal, K. T. (2000). lower extremity mechanics in a converted forefoot strike pattern in runners. Jounal of Applied Biomechanics, 16(2), 210-218.

Willson, J. D., Sharpee, R., Meardon, S. A., \& Kernozek, T. W. (2014). Effects of step length on patellofemoral joint stress in female runners with and without patellofemoral pain. Clin Biomech (Bristol, Avon), 29(3), 243-247.

Willy, R. W., \& Davis, I. S. (2014). Kinematic and kinetic comparison of running in standard and minimalist shoes. Med Sci Sports Exerc, 46(2), 318-323.

Zadpoor, A. A., \& Nikooyan, A. A. (2011). The relationship between lower-extremity stress fractures and the ground reaction force: a systematic review. Clin Biomech (Bristol, Avon), 26(1), 23-28. 


\section{Chapter 2}

\section{Reliability and Validity of Pressure and Temporal Parameters Recorded Using a Pressure- sensitive Insole during Running.}

Robert Mann, Laurent Malisoux, Roman Brunner, Paul Gette, Axel Urhausen, Andrew Statham, Kenneth Meijer and Daniel Theisen

Gait \& Posture, 2014. 39; 455-459. 


\section{Abstract}

Running biomechanics has received increasing interest in recent literature on runningrelated injuries, calling for new, portable methods for large-scale measurements. Our aims were to define running strike pattern based on output of a new pressuresensitive measurement device, the Runalyser, and to test its validity regarding temporal parameters describing running gait. Furthermore, reliability of the Runalyser measurements was evaluated, as well as its ability to discriminate different running styles. 31 healthy participants $(30.3 \pm 7.4$ years, $1.78 \pm 0.10 \mathrm{~m}$ and $74.1 \pm 12.1 \mathrm{~kg}$ ) were involved in the different study parts. 11 participants were instructed to use a rearfoot (RFS), midfoot (MFS) and forefoot (FFS) strike pattern while running on a treadmill. Strike pattern was subsequently defined using a linear regression $\left(R^{2}=0.89\right)$ between foot strike angle, as determined by motion analysis $(1000 \mathrm{~Hz})$, and strike index (SI, point of contact on the foot sole, as a percentage of foot sole length), as measured by the Runalyser. MFS was defined by the $95 \%$ confidence interval of the intercept ( $\mathrm{SI}=43.9$ 49.1\%). High agreement (overall mean difference 1.2\%) was found between stance time, flight time, stride time and duty factor as determined by the Runalyser and a force-measuring treadmill ( $n=16$ participants). Measurements of the two devices were highly correlated $(R \geq 0.80)$ and not significantly different. Test-retest intra-class correlation coefficients for all parameters were $\geq 0.94$ ( $n=14$ participants). Significant differences $(p<0.05)$ between FFS, RFS and habitual running were detected regarding SI, stance time and stride time ( $n=24$ participants). The Runalyser is suitable for, and easily applicable in large-scale studies on running biomechanics.

\section{Key words}

Strike index, foot strike pattern, biomechanics 


\section{Introduction}

Biomechanics of human running has recently received new interest within the area of running-related injuries (Lieberman et al., 2010). One aspect which is being rigorously discussed is the role of foot strike pattern in injury incidence (Altman \& Davis, 2012a; Jenkins \& Cauthon, 2011; Lieberman, 2012; Lieberman et al., 2010). It has been suggested that a forefoot strike (FFS) running pattern could have a protective effect against certain running-related injuries, through greater leg compliance upon foot contact with the ground, reduced stride length and thereby reduced vertical loading rate (Lieberman et al., 2010). Another study (Squadrone \& Gallozzi, 2009) attributed a shorter contact time ( $\left.T_{\text {contact }}\right)$ and increased step frequency to FFS running compared to a rear-foot strike (RFS), highlighting the relevance of evaluating both temporal parameters and foot strike pattern when studying risk factors of injuries.

Foot strike pattern has previously been quantified by using strike index (SI) as a measure (Altman \& Davis, 2012b; Cavanagh \& Lafortune, 1980). SI is defined as the point of contact on the foot sole with the running surface, expressed as a percentage of total sole length (Cavanagh \& Lafortune, 1980). Previous studies (Altman \& Davis, 2012b; Cavanagh \& Lafortune, 1980) divided the foot sole into equal thirds to represent RFS, mid-foot strike (MFS) and FFS patterns, respectively. However, on no occasion has SI been compared to the actual foot strike angle (FSA) to determine a representative classification of foot strike pattern.

Temporal parameters are typically studied using motion analysis systems, force plates and pressure mats. Runners are therefore rarely tested in their habitual setting and required to perform several trials along a runway (Forner Cordero et al., 2004; Savelberg \& de Lange, 1999). These measured steps are subject to high variability, can be time consuming to acquire and analyse (Divert et al., 2005), and may perhaps not always yield representative data of the participant's true running style. Treadmills with built-in force plates solve the problem of multiple trials, but are costly and therefore rarely available in a clinical setting.

An alternative method, one which overcomes the drawback of isolating steps and confining testing to the laboratory, is to use a pressure sensitive insole. The Runalyser by TNO (Eindhoven, The Netherlands), as the name suggests, comprises such an insole developed specifically to analyse pressure patterns and temporal parameters at the foot-ground contact during running. However, this system is at the prototype stage of development, and needs to be tested for validity and reliability. Therefore, the aims of this study were four-fold. Firstly, to devise a valid definition of strike pattern by comparing the SI using the Runalyser to the actual FSA. Secondly, to validate temporal parameters by comparing Runalyser data to that acquired using an instrumented treadmill measuring ground reaction forces. The third aim was to test the reliability of 
the output of the Runalyser using a test-retest approach. Additionally, a descriptive analysis of variables measured using the Runalyser for different foot strike patterns is provided.

\section{Methods}

\section{Participants}

A total of 31 participants ( 24 male and 7 female) were recruited. Mean $\pm S D$ age, height and weight were $30.3 \pm 7.4$ years, $1.78 \pm 0.10 \mathrm{~m}$ and $74.1 \pm 12.1 \mathrm{~kg}$, respectively. Subsets of this initial sample constituted the cohorts of the individual study parts. They were all free of injury at the time of testing, were accustomed to running on a treadmill and provided written informed consent prior to inclusion. This research was approved by the National Research Ethics Committee.

\section{The Runalyser}

Participants were equipped with the Runalyser consisting of an insole ( $3 \mathrm{~mm}$ thick) and a microprocessor clipped to the lateral aspect of the shoe. The microprocessor acquires and transmits real-time pressure data wirelessly to a nearby computer at a rate of $247 \mathrm{~Hz}$ for the left and right foot separately. The insole comprises eight capacitive sensors (Rosenbaum \& Becker, 1997) distributed as follows: medial heel, lateral heel, medial mid-foot, lateral mid-foot, first metatarsal head, second metatarsal head, fourth metatarsal head and the hallux (Hennig, 1995). Insoles are available in small, medium and large sizes. They were positioned on top of the original running shoe insole, thus ensuring direct contact with the foot. Due to the dimensions of the pressure sensors, the insole has a SI sensitive zone between $12.5 \%$ at the heel and $86.3 \%$ at the toe (see figure 2.1). In knowing the distances of the sensors relative to each other and to the centre of the insole, the centre of pressure location, and thus the SI can be calculated. Temporal parameters were established based on the curve representing the sum of all sensors and its first-grade derivative. Foot contact was defined as the moment when the first-grade derivative diverged from the zeroline, while the original curve remained below a certain threshold. Toe-off was determined by the moment when the first-grade derivative converged from a negative value towards the zeroline, with the original curve below a certain threshold. The thresholds for foot contact and toe-off were defined based on preliminary testing. $T_{\text {contact }}$ was taken as the time between foot contact and toe-off for each step, stride time $\left(T_{\text {stride }}\right)$ was the time from one foot contact to the next for the same foot, and flight time $\left(T_{\text {flight }}\right)$ 
the difference between $T_{\text {stride }}$ and $T_{\text {contact }}$. The duty factor (DF) was obtained by dividing $T_{\text {contact }}$ by $T_{\text {stride. }}$. Runalyser data were filtered using a 4th order, lowpass Butterworth filter. The cut-off frequency varied between 49 and $51 \mathrm{~Hz}$ depending on the insole specific noise frequency determined for each individual acquisition based on a FastFourier Transform. All Runalyser recordings lasted for a minimum of 30 seconds and were done simultaneously with other measurement devices (see below) to analyse the exact same running strides.

\section{SI validation}

11 participants took part in the SI validation study by running on a treadmill (Woodway PPS70 plus, USA) at a $0^{\circ}$ slope and a mean self-selected running speed of $3.03 \pm 1.04$ $\mathrm{m} / \mathrm{s}$ (range 2.78-3.33 m/s). A motion analysis system (CODAmotion, Charnwood Dynamics, UK) was used to calculate the FSA of the sole of the running shoe with the surface of the treadmill. All tests were performed using a single shoe model of appropriate size, equipped with markers at the most posterior aspect of the calcaneus and the $1^{\text {st }}$ and $5^{\text {th }}$ metatarsophalangeal joint. The marker at the calcaneus and a virtual marker midway between the $1^{\text {st }}$ and $5^{\text {th }}$ metatarsophalangeal joint markers constituted the foot reference line. Three further markers were placed on the treadmill, at the same height as the running surface, to provide the ground reference plane. Marker positions were acquired at $1000 \mathrm{~Hz}$ using three CX1 cameras placed at the front and either side of the treadmill. FSA was determined at foot contact, as derived from the Runalyser data which were synchronised with the kinematic recordings. FSA was defined as the difference between the $3 \mathrm{D}$ angle of the foot reference line at foot contact and the one determined during a static, standing acquisition for each participant. A positive FSA-value signified a RFS, and a negative value a FFS. After a 2-minute warm-up, the participants were instructed to adopt a FFS, MFS and RFS pattern successively, each for approximately 2 minutes. A FFS was described to them as making initial contact with the ground with the front portion of the foot or the toes; a MFS was described as landing with the sole of the foot parallel to the treadmill surface (heel and ball of the foot contacting the running surface simultaneously); a RFS was described as the heel of the foot making initial contact with the ground, and the foot subsequently rolling forward towards toe-off (Hasegawa et al., 2007; Hayes \& Caplan, 2012; Larson et al., 2011; Lieberman et al., 2010). Data acquisition took place after the first minute to ensure that the requested running style was understood and fully adopted. Data were also acquired during the initial warm-up phase, without the participants' knowledge, so as to evaluate their habitual running style for subsequent classification. An average of $42 \pm 5$ steps were recorded per trial. Only data of the right foot were used for analysis of this study part. 


\section{Temporal parameter validation}

16 participants were included in the validation study of temporal parameters of the Runalyser. They ran at a self-selected running speed of $3.19 \pm 0.25 \mathrm{~m} / \mathrm{s}$ (range 2.79-3.33 $\mathrm{m} / \mathrm{s}$ ) in the same conditions as for the previous study part. This was done on a treadmill (Mercury LT med, HP Cosmos, Germany) instrumented with four 3D straingauge force transducers measuring ground reaction forces. The instrumented treadmill has been previously validated (Dierick et al., 2004). The strain gauges were calibrated prior to testing. Ground reaction forces were acquired at $1000 \mathrm{~Hz}$, and the data were filtered using a 4th order, lowpass Butterworth filter at $50.05 \mathrm{~Hz}$. A similar algorithm as described above for the Runalyser was used to detect foot contact and toe-off, and all temporal parameters were calculated in exactly the same manner. For each participant, an average of $76 \pm 13$ steps recorded during the habitual running condition was used to compare the two instruments. Left or right foot data were randomly selected for each participant.

\section{Runalyser reliability}

To test the reliability of the $\mathrm{SI}$ and temporal parameters as measured using the Runalyser, 14 participants ran on a treadmill (Woodway XELG 90, USA) using their habitual running style on two separate occasions (at least 24 hours apart), under exactly the same conditions. The mean self-selected running speed was $2.5 \pm 0.5 \mathrm{~m} / \mathrm{s}$, and an average of $73 \pm 15$ steps per participant per foot were recorded. Left or right foot data were randomly selected for each participant for the analysis.

\section{Data analyses and statistics}

To compare the SI with FSA and devise a classification of running strike pattern according to $\mathrm{SI}$, a least squares linear regression with $\mathrm{SI}$ as the dependent variable was performed. The upper and lower boundaries of the $95 \%$ confidence interval $(95 \% \mathrm{Cl})$ of the $y$-intercept was used to determine the MFS condition. Temporal parameters as measured by the Runalyser and instrumented treadmill were analysed using BlandAltman plots (Bland \& Altman, 1986), correlations and paired sample T-tests. Reliability was tested by performing a one-way repeated measures analysis of variance (one-way RM ANOVA) on the test-retest data of the habitual running condition. From this we calculated the intra-class correlation coefficient (ICC) and minimal detectible change (MDC) for $\mathrm{SI}$ and temporal parameters data using the standard error of the measurement (SEM) (Weir, 2005): MDC $=1.96 *$ SEM * V2. Finally, Runalyser data of all variables collected for 24 participants having performed a RFS, FFS and habitual 
running were compared using a one-way RM ANOVA with the post hoc Bonferroni correction. Custom-built programmes in MATLAB (Mathworks Inc., USA) were used for data treatment, and all statistical analyses were performed using SPSS for Windows version 20. Statistical significance was accepted as $p<0.05$.

\section{Results}

SI values across the different running styles analysed in the first study part ranged between $13.4 \%$ and $65.6 \%$, while FSA ranged between $31.7^{\circ}$ and $-16.6^{\circ}$ (figure 2.1 ). The two variables had a strong $\left(R^{2}=0.89\right)$ linear relationship. The dashed lines in figure 2.1 illustrate the theoretical boundaries of the different foot strike pattern classifications represented by our approach. The SI window for a MFS (the $95 \% \mathrm{Cl}$ of the intercept of the SI-FSA relationship) running condition was calculated as [43.9, 49.1]. SI values above $49.1 \%$ were taken to be FFS, and values below $43.9 \%$ to be RFS. According to our definition, none of the participants adopted a true MFS, even when instructed to do so.

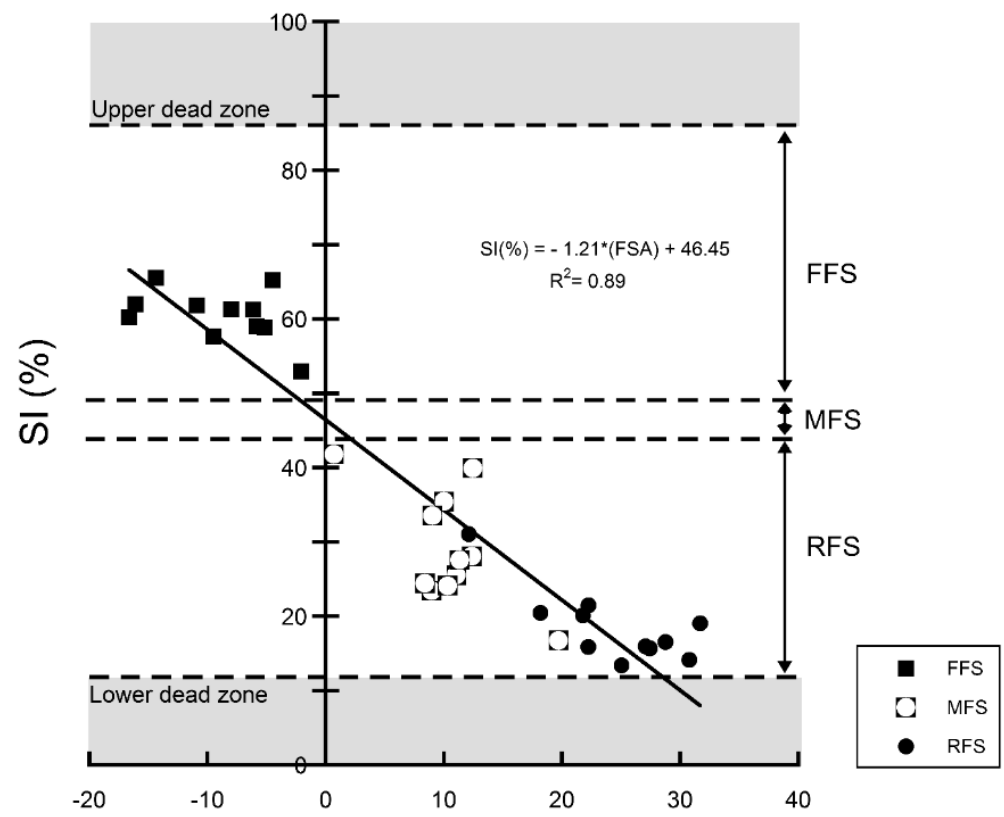

$\operatorname{FSA}\left({ }^{\circ}\right)$

Figure 2.1. A linear regression model depicting the correlation between SI and FSA for the three different running conditions ( $\mathrm{n}=11$ participants). 
Figure 2.2 depicts Bland-Altman plots of temporal parameters for habitual running as measured using the instrumented treadmill and Runalyser. Overall, the results of the two measuring devices showed no systematic error and narrow limits of agreement, representing $11.2 \%, 5.9 \%, 0.3 \%$ and $12.1 \%$ of the overall mean of both systems for $T_{\text {contact }}, T_{\text {flight }}, T_{\text {stride }}$ and DF, respectively. In addition, temporal parameters measured by the two devices were not significantly different and were highly correlated $(0.90,0.98$, 0.99 and 0.80 , respectively).

A

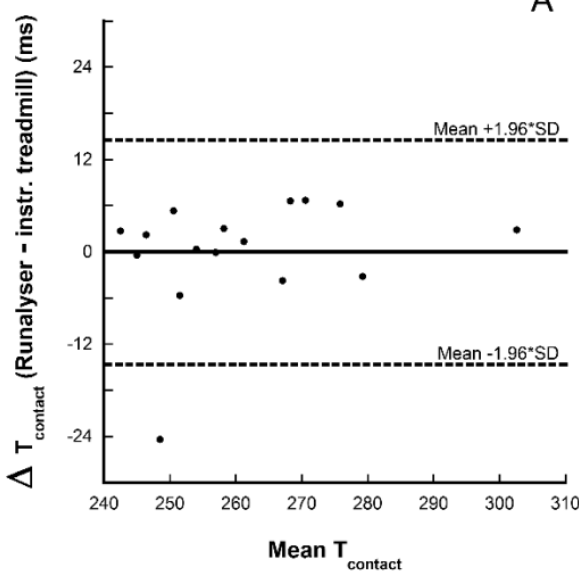

C

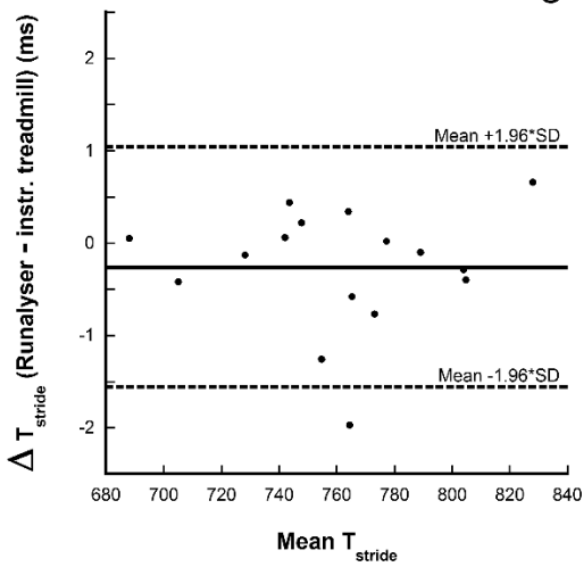

B

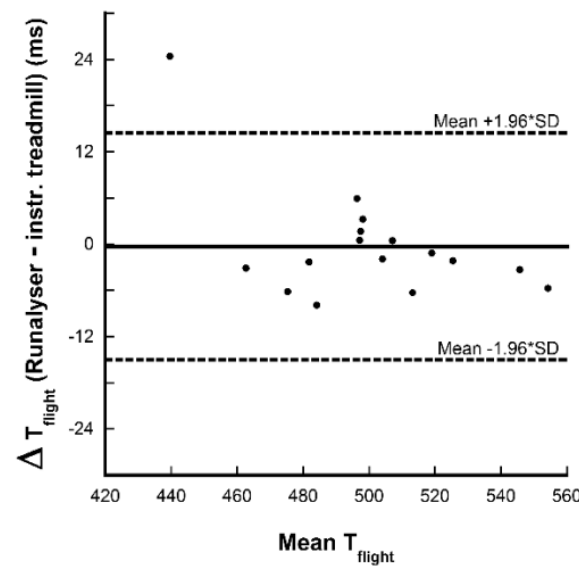

D

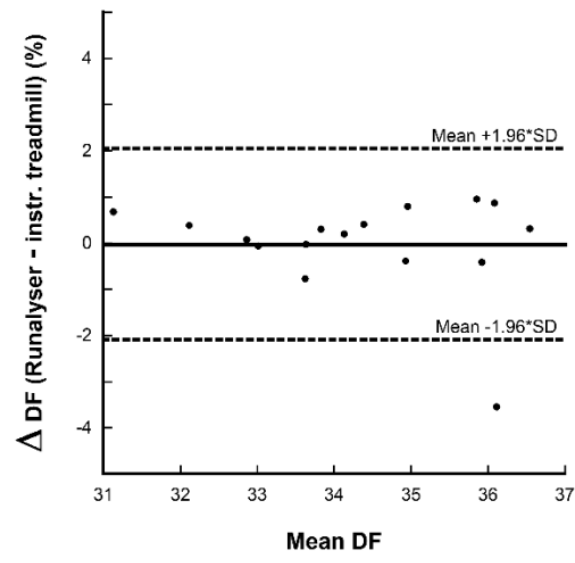

Figure 2.2. Bland Altman plots for stance time (A), flight time (B), stride time (C) and duty factor (D). $n=16$ participants. 
The results of the reliability testing of all Runalyser variables are presented in table 2.1. The ICCs for all five variables were high, ranging from 0.94 to 0.97 . SI yielded a MDC of 4.9\%, whereas for temporal parameters it ranged from $16.4 \mathrm{~ms}$ ( $\left.T_{\text {contact }}\right)$ to $29.2 \mathrm{~ms}$ $\left(T_{\text {flight }}\right)$.

Table 2.1. Reliability of variables measured using the Runalyser (test-retest design, $n=14$ participants)

\begin{tabular}{|c|c|c|c|c|c|}
\hline & SI (\%) & Tcontact (ms) & Tflight (ms) & Tstride (ms) & DF (\%) \\
\hline Mean(士SD)Test & $25.0( \pm 10.5)$ & $295( \pm 36)$ & $490( \pm 46)$ & $785( \pm 54)$ & $37.6( \pm 4.0)$ \\
\hline Mean( \pm SD)Retest & $25.2( \pm 10.5)$ & $298( \pm 37)$ & $485( \pm 50)$ & $783( \pm 54)$ & $38.1( \pm 4.3)$ \\
\hline $\mathbf{R 2}$ & 0.94 & 0.95 & 0.89 & 0.96 & 0.89 \\
\hline ICC & 0.97 & 0.97 & 0.95 & 0.97 & 0.94 \\
\hline MDC & 4.9 & 16.4 & 29.2 & 24.5 & 2.7 \\
\hline
\end{tabular}

A descriptive analysis of the different running styles is summarised in table 2.2. The SI obtained during habitual running revealed that all participants were RFS runners according to our definition. $\mathrm{SI}, \mathrm{T}_{\text {contact }}$ and $\mathrm{T}_{\text {stride }}$ displayed overall significant differences between running styles. This was not the case for $\mathrm{T}_{\text {flight }}$ and $\mathrm{DF}$, for which effect size was low. RFS and habitual running were not significantly different. FFS yielded a significantly higher SI compared to both RFS and habitual running, while $\mathrm{T}_{\text {contact }}$ was significantly lower than the two other styles. $\mathrm{T}_{\text {stride }}$ was significantly lower in FFS compared to RFS.

Table 2.2. Mean $( \pm S D)$ of variables measured using the Runalyser in the different running conditions ( $n=24$ participants).

\begin{tabular}{lllllll}
\hline & HABIT & FFS & RFS & p-value & Power & Effect size \\
\hline SI (\%) & $19.68( \pm 6.19)^{*}$ & $57.57( \pm 6.09)$ & $17.83( \pm 4.07)^{*}$ & $<0.001$ & 1.000 & 0.952 \\
$\begin{array}{l}\text { Tcontact } \\
\text { (ms) }\end{array}$ & $263( \pm 27)^{*}$ & $255( \pm 23)$ & $267( \pm 29)^{*}$ & 0.002 & 0.911 & 0.27 \\
Tflight (ms) & $485( \pm 33)$ & $478( \pm 44)$ & $487( \pm 41)$ & 0.310 & 0.250 & 0.05 \\
Tstride (ms) & $748( \pm 43)$ & $733( \pm 51)$ & $753( \pm 50)^{*}$ & 0.017 & 0.740 & 0.16 \\
DF (\%) & $35.21( \pm 2.55)$ & $34.83( \pm 2.55)$ & $35.47( \pm 2.79)$ & 0.109 & 0.447 & 0.09 \\
\hline \hline
\end{tabular}

\footnotetext{
* significantly different to FFS; HABIT = habitual running style.
} 


\section{Discussion}

The Runalyser was found to be a valid and reliable instrument to assess foot strike pattern and temporal parameters during running, based on foot sole pressure measurements. We propose $\mathrm{SI}$ as a continuous scale of measurement and provide a classification reference of foot strike pattern validated against actual FSA measurements. This classification builds on earlier work by Cavanagh and Lafortune (Cavanagh \& Lafortune, 1980) who divided the foot into three sections of equal length, respectively defining a RFS, MFS and FFS. Although a clear-cut definition, it is arbitrarily determined and may lack precision in the study of different running strike patterns. On the other hand, classifications based on video analyses can be used on a large scale, but are less accurate and may overestimate the proportion of MFS runners (Hasegawa et al., 2007; Larson et al., 2011). Indeed, our approach suggests that there is only a very small SI window (between 43.9 and $49.1 \%$ ) for MFS when taking a $0^{\circ}$ FSA as the definition of this strike pattern. This narrow margin can be explained by the fact that there is only one way in which the foot can contact the ground in a true MFS condition (heel and ball of the foot striking the ground simultaneously), while there are many variations possible when using a FFS or RFS pattern (Larson et al., 2011). In addition, when instructed to use a MFS, none of our participants achieved a true MFS according to our SI definition, with some even reporting discomfort. Using the SI as a continuous measure has the advantage of allowing a more in-depth analysis of running strike pattern, independently of the classification used.

Analysis of the Bland-Altman plots reveals that there is good agreement between Runalyser and instrumented treadmill data for temporal parameters (figure 2.2). On average the difference between the two measurement systems was consistently close to zero. Limits of agreement for $\mathrm{T}_{\text {stride }}$ (figure $2.2 \mathrm{C}$ ) were $3 \mathrm{~ms}$ apart, implying that the Runalyser is extremely accurate when detecting the initial contact point of each step. Limits of agreement for $\mathrm{T}_{\text {contact }}$ (figure 2.2A) and $\mathrm{T}_{\text {flight }}$ (figure 2.2B) were larger (29 and $30 \mathrm{~ms}$, respectively) illustrating somewhat less accuracy of the Runalyser in detecting the toe-off moment. This is also reflected in the DF (figure 2.2D) where limits of agreement were $4.2 \%$ apart. A previous study comparing pressure insole data to force plate data during walking found overall mean differences of $1.8 \%$ for temporal parameters (Barnett et al., 2000), which is comparable to our findings of $\sim 1.2 \%$.

Runalyser measurements were found to be highly reproducible. The MDCs reported describe a difference in Runalyser measurements that can be considered a true change, for example when comparing two groups of runners or when learning to adopt a different running style. A MDC of $4.9 \%$ for SI allows researchers to detect changes in running strike pattern within and between running style classifications. 
As demonstrated by the results in table 2.2, the Runalyser was able to discriminate different running styles. $\mathrm{SI}$ is a clear indicator of running strike pattern, as highlighted by the significant differences between FFS, RFS and habitual running. Our data suggest that when shifting from a RFS to a FFS, a runner is likely to shorten $\mathrm{T}_{\text {stride }}$ by decreasing $\mathrm{T}_{\text {contact }}$, while keeping $\mathrm{T}_{\text {flight }}$ more or less constant. These observations are consistent with a previous investigation showing that $T_{\text {contact, }}$ but not $T_{\text {flight, }}$, was significantly shorter during barefoot compared to shod running, the former inducing greater ankle plantar flexion at foot contact (De Wit et al., 2000). Another study (Diebal et al., 2012) found that $T_{\text {contact }}$ was significantly reduced after six weeks of FFS running training in individuals with exertional compartment syndrome. In line with this, Hasegawa et al. (Hasegawa et al., 2007) found that elite long-distance runners adopting a FFS displayed shorter $\mathrm{T}_{\text {contact }}$ than their RFS counterparts.

Some limitations need to be considered when using the Runalyser. The number of sensors within the insole is limited. An increased number would provide a higher spatial resolution and could result in greater precision when determining the centre of pressure location. In the present context, however, the Runalyser provides sufficient accuracy for the concerned variables and has the advantage of remaining highly portable. The sensors are positioned directly beneath prominent anatomical structures of the foot, but no sensor is present at the $2^{\text {nd }}$ to $5^{\text {th }}$ phalanges. Slight variations in $\mathrm{T}_{\text {contact }}$ and $\mathrm{T}_{\text {flight, }}$ as observed in figure 2.2, may be attributed to this. Of particular interest in this respect, are the results of a lightweight participant $(47.5 \mathrm{~kg})$ for whom $\mathrm{T}_{\text {contact }}$ and $\mathrm{T}_{\text {flight }}$ were under- and overestimated, respectively. This suggests that our algorithm to detect toe-off is slightly less accurate for very lightweight runners. However, this does not affect $\mathrm{T}_{\text {stride }}$ or SI measurements.

To conclude, this study provides a reference to classify different running styles and suggests $\mathrm{SI}$ as a continuous measurement when using the Runalyser. Our results demonstrate that the device is valid and reliable when measuring temporal parameters. A main advantage is its ability to record large numbers of consecutive steps, needed to achieve representative data on running style (Divert et al., 2005; Kluitenberg et al., 2012). The Runalyser was designed for overground (as well as outdoor) use, meaning a treadmill is not necessary for continuous measurement. Its portability and ease of application make it an interesting tool for large-scale analyses of running gait. Pressure insoles such as the Runalyser provide valuable information for researchers, clinicians, podiatrists, athletes and coaches, and can provide real-time feedback in the athlete's habitual setting to help improve performance and prevent injury. 


\section{Acknowledgments}

The present study was financially supported by the National Research Fund, Luxembourg (AFR Robert Mann: ref.1102562). Thanks goes to Dr Marc Hoppenbrauwer of TNO, Eindhoven, The Netherlands for his technical support, the research team of the Physiology and Biomechanics of Locomotion Unit, Université Catholique de Louvain, Belgium for the use of their instrumented treadmill and to the study participants for their valuable contribution. 


\section{References}

Altman, A. R., \& Davis, I. S. (2012a). Barefoot running: biomechanics and implications for running injuries. Curr Sports Med Rep, 11(5), 244-250.

Altman, A. R., \& Davis, I. S. (2012b). A kinematic method for footstrike pattern detection in barefoot and shod runners. Gait Posture, 35(2), 298-300.

Barnett, S., Cunningham, J. L., \& West, S. (2000). A comparison of vertical force and temporal parameters produced by an in-shoe pressure measuring system and a force platform. Clin Biomech (Bristol, Avon), 15(10), 781-785.

Bland, J. M., \& Altman, D. G. (1986). Statistical methods for assessing agreement between two methods of clinical measurement. Lancet, 1(8476), 307-310.

Cavanagh, P. R., \& Lafortune, M. A. (1980). Ground reaction forces in distance running. J Biomech, 13(5), 397-406.

De Wit, B., De Clercq, D., \& Aerts, P. (2000). Biomechanical analysis of the stance phase during barefoot and shod running. J Biomech, 33(3), 269-278.

Diebal, A. R., Gregory, R., Alitz, C., \& Gerber, J. P. (2012). Forefoot running improves pain and disability associated with chronic exertional compartment syndrome. Am J Sports Med, 40(5), 1060-1067.

Dierick, F., Penta, M., Renaut, D., \& Detrembleur, C. (2004). A force measuring treadmill in clinical gait analysis. Gait Posture, 20(3), 299-303.

Divert, C., Mornieux, G., Baur, H., Mayer, F., \& Belli, A. (2005). Mechanical comparison of barefoot and shod running. Int J Sports Med, 26(7), 593-598.

Forner Cordero, A., Koopman, H. J. F. M., \& van der Helm, F. C. T. (2004). Use of pressure insoles to calculate the complete ground reaction forces. Journal of Biomechanics, 37(9), 1427-1432.

Hasegawa, H., Yamauchi, T., \& Kraemer, W. J. (2007). Foot strike patterns of runners at the 15-km point during an elite-level half marathon. J Strength Cond Res, 21(3), 888-893.

Hayes, P., \& Caplan, N. (2012). Foot strike patterns and ground contact times during high-calibre middledistance races. J Sports Sci, 30(12), 1275-1283.

Hennig, E. M., Milani, T. L. (1995). In-Shoe Pressure Distribution for Running in Various Types of Footwear. Journal of Applied Biomechanics, 11(3), 299-310.

Jenkins, D. W., \& Cauthon, D. J. (2011). Barefoot running claims and controversies: a review of the literature. J Am Podiatr Med Assoc, 101(3), 231-246.

Kluitenberg, B., Bredeweg, S. W., Zijlstra, S., Zijlstra, W., \& Buist, I. (2012). Comparison of vertical ground reaction forces during overground and treadmill running. A validation study. BMC Musculoskelet Disord, 13, 235.

Larson, P., Higgins, E., Kaminski, J., Decker, T., Preble, J., Lyons, D., . . . Normile, A. (2011). Foot strike patterns of recreational and sub-elite runners in a long-distance road race. J Sports Sci, 29(15), 16651673.

Lieberman, D. E. (2012). What we can learn about running from barefoot running: an evolutionary medical perspective. Exerc Sport Sci Rev, 40(2), 63-72.

Lieberman, D. E., Venkadesan, M., Werbel, W. A., Daoud, A. I., D'Andrea, S., Davis, I. S., . . . Pitsiladis, Y. (2010). Foot strike patterns and collision forces in habitually barefoot versus shod runners. Nature, $463,531-536$.

Rosenbaum, D., \& Becker, H. P. (1997). Plantar pressure distribution measurements. Technical background and clinical applications. Foot and Ankle Surgery, 3(1), 1-14.

Savelberg, H. H., \& de Lange, A. L. (1999). novel Award Third Prize Paper. Assessment of the horizontal,foreaft component of the ground reaction force from insole pressure patterns by using artificial neural networks. Clin Biomech (Bristol, Avon), 14(8), 585-592.

Squadrone, R., \& Gallozzi, C. (2009). Biomechanical and physiological comparison of barefoot and two shod conditions in experienced barefoot runners. J Sports Med Phys Fitness, 49(1), 6-13.

Weir, J. P. (2005). Quantifying test-retest reliability using the intraclass correlation coefficient and the SEM. J Strength Cond Res, 19(1), 231-240. 


\section{Chapter 3}

\section{Can the Runalyser Reliably Measure Vertical Loading Rate?}

Unpublished observations. 


\section{Abstract}

Vertical loading rate (VLR) has been found to be related to stress fractures in running, as well as to vary according to the type of running style. Attempts to use pressuresensitive insole devices to measure ground reaction forces accurately have previously been carried out. Advantages of using insoles are continuous measurement of consecutive steps and no restrictions in foot placement. We aimed to compare VLR measurements of the Runalyser with those of an instrumented treadmill. 16 runners were measured using both devices simultaneously while running with their habitual running style, a FFS and a RFS. Regression analysis revealed no correlation of VLR between the two devices. We confirmed a FFS to display lower VLR than a RFS running style. 


\section{Background}

Vertical loading rate (VLR) of the vertical ground reaction forces during running has featured heavily in biomechanical research in running (Azevedo et al., 2009; Crowell \& Davis, 2011; Daoud et al., 2012; Diebal et al., 2012; Hobara et al., 2012; Kulmala et al., 2013; Lieberman et al., 2010). A meta-analysis conducted in 2011 of 13 studies revealed that overall, VLR was significantly higher in runners sustaining lower extremity stress fractures compared to controls (Zadpoor \& Nikooyan, 2011). However these researchers did not find any evidence that the magnitude of ground reaction forces between groups was any different. VLR has also been found to relate to the running style, with several researchers reporting reduced VLR when runners use a FFS compared to a RFS running style (Boyer et al., 2014; Goss \& Gross, 2012; Lieberman et al., 2010). In general, the VLR is calculated as follows:

$$
\operatorname{VLR}\left(\mathrm{BWs}^{-1}\right)=\frac{\Delta \text { force }(\mathrm{BW})}{\Delta \text { time }(\mathrm{s})}
$$

The global definition of VLR used by the aforementioned study is: "the slope of the initial part of the vertical ground reaction force-time curve (between the footstrike and the vertical impact peak)", p.24 (Zadpoor \& Nikooyan, 2011). Various methods to define this section of the curve have been used. One study used $25 \mathrm{~ms}$ of the stance time as a cut-off to measure VLR (Arendse et al., 2004) (figure 3.1A). Lieberman et al. (2010) measured VLR from $200 \mathrm{~N}$ to $90 \%$ of the impact transient (the initial peak in the force-time curve representing initial heel contact) or $6.2 \pm 3.7 \%$ of the stance phase when no impact transient was detected (often the case in forefoot strikers) (Lieberman et al., 2010). The most commonly used method is outlined by Milner et al. (2008), and uses $20 \%$ and $80 \%$ of the time from foot contact to the impact transient peak (Milner et al., 2006) (figure 3.1B). This portion of the curve was chosen by these authors as it is generally the most linear. Using this reasoning, we identified the inflexion point of the initial loading of the force-time curve using the derivative of the acquired data, and defined VLR as the slope of the regression line between +2 and -2 data points from this inflexion point (figure 3.1C). This definition is based on exhaustive preliminary testing, and these data point limits were found to produce the most reliable and repeatable results when testing multiple subjects. Depending on the running style and speed, this portion of the curve may be limited to a minimum of 10 data points due to the $\mathbf{2 4 7 . 2}$ $\mathrm{Hz}$ sampling rate of the Runalyser, therefore including five data points in the analysis ensured that a representative measure of VLR was performed. In addition, this method did not depend on an impact transient being present, and could be consistently utilised for all different running styles. 

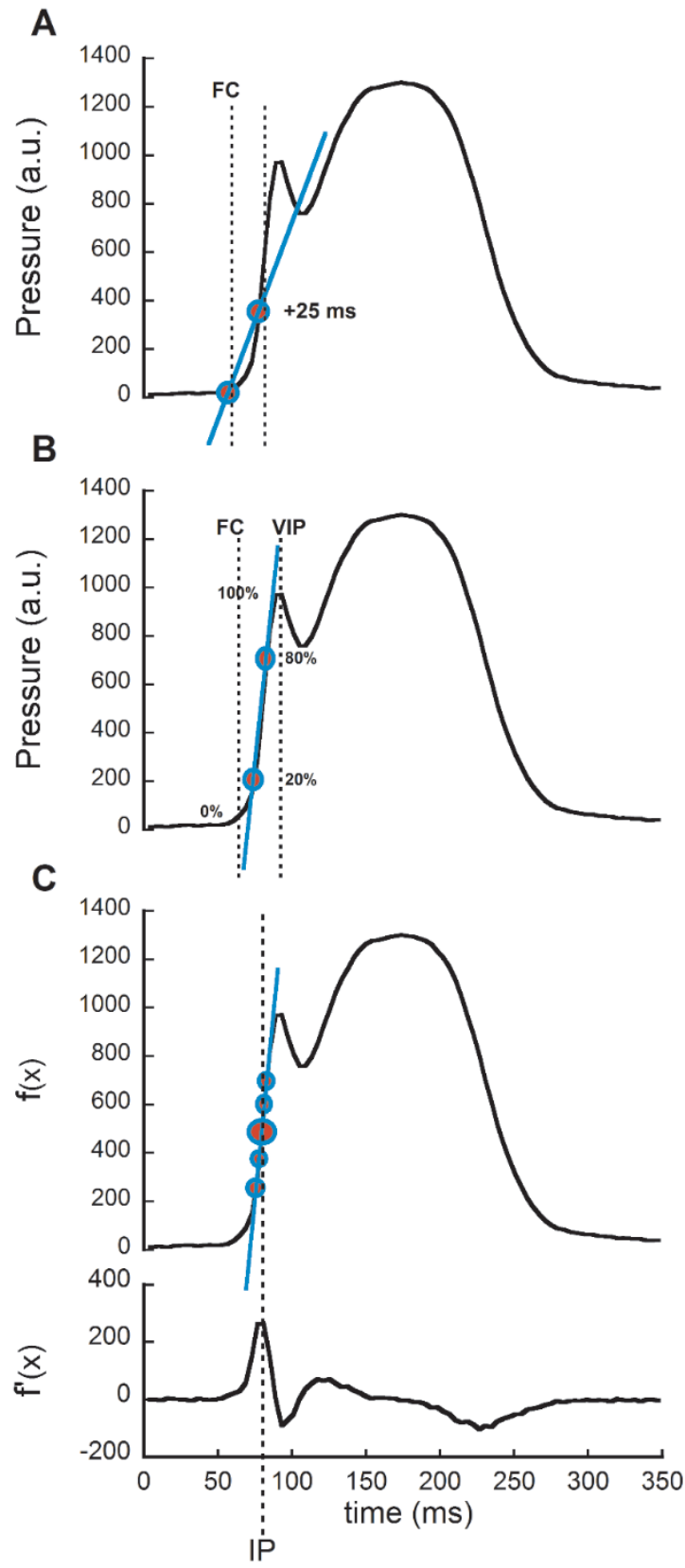

Figure 3.1. Examples of vertical loading rate (VLR) definitions of various studies depicted using pressure (arbitrary units, a.u.) curves as measured using the Runalyser. A) shows the method by Arendse et al. (2004) utilising a standardised 25 ms cut-off point. B) shows the method by Milner et al. (2008) using the $20 \%$ and $80 \%$ cut-off points between foot contact (FC) and the vertical impact peak (VIP). C) illustrates our method using the inflexion point (IP) located using the derived data $\left(f^{\prime}(x)\right)$ and calculating the regression line through +2 and -2 data points. The blue line represents the slope calculated, and thus the VLR. 
Previously, researchers have compared the ground reaction forces measured by pressure insole devices and force plates. One study found similarities in temporal parameters and peak forces (Barnett et al., 2000), and another reported good estimations of ground reaction forces using insoles (Fong et al., 2008). Another reported inaccuracies in ground reaction forces of the pressure insole, particularly at the beginning and at the end of stance phase (Forner Cordero et al., 2004). However, these authors pointed out that no foot placement constraints and continuous measurement of consecutive steps are advantages of pressure insole use over force plates. It is for this reason that we wished to find out if we could use the Runalyser to measure the VLR during running. We aimed to compare the VLR as measured using the Runalyser to that of the gold standard, an instrumented treadmill, hypothesising a linear relationship between the arbitrary units of the Runalyser and the Newton magnitudes of the instrumented treadmill. Additionally, we wanted to assess the magnitudes of VLR in a habitual, RFS, and FFS running style. We hypothesised the FFS running condition to yield an overall lower VLR than the RFS condition based on observations previously reported.

\section{Methods}

13 male and 3 female participants $(29.8 \pm 6.1 \mathrm{y}, 1.80 \pm 0.11 \mathrm{~m}$ and $72.1 \pm 11.5 \mathrm{~kg}$ ) were equipped with the Runalyser and a standard, conventional running shoe, and ran at either $10 \mathrm{~km} / \mathrm{h}$ or $12 \mathrm{~km} / \mathrm{h}$ on an instrumented treadmill (Mercury LT med, HP Cosmos, Germany) previously described in chapter 2 (Dierick et al., 2004) acquiring at $1000 \mathrm{~Hz}$. Subjects were instructed to stamp with distinguishable force for the first step of the right foot as the treadmill belt accelerated from standstill, to ensure accurate synchronisation of the force and pressure data. After 2 minutes of habitual running, participants ran for 2 minutes with each of the three running styles in the following order: habitual running style, FFS, RFS. The first minute served as a familiarisation period and the second minute in each condition was used for the analysis. VLR in a.u./ms and $\mathrm{N} / \mathrm{ms}$ were later calculated for Runalyser and instrumented treadmill data respectively. Left and right foot data were averaged (figure 3.2). Due to artefacts in the acquisitions, the following data was not retained: FFS data of the left foot for one participant, habitual running data for the right foot for 2 participants and both the FFS and RFS data for both feet for 3 participants. When available, good data for the other foot was used. A regression analysis was performed to test the correlation between the Runalyser VLR and that of the instrumented treadmill (figure 3.2). One-way repeated measures analysis of variance with the Bonferroni post hoc analysis were 
performed to observe any differences in VLR between running styles for the two measurement systems. Significance was accepted at $p<0.05$.

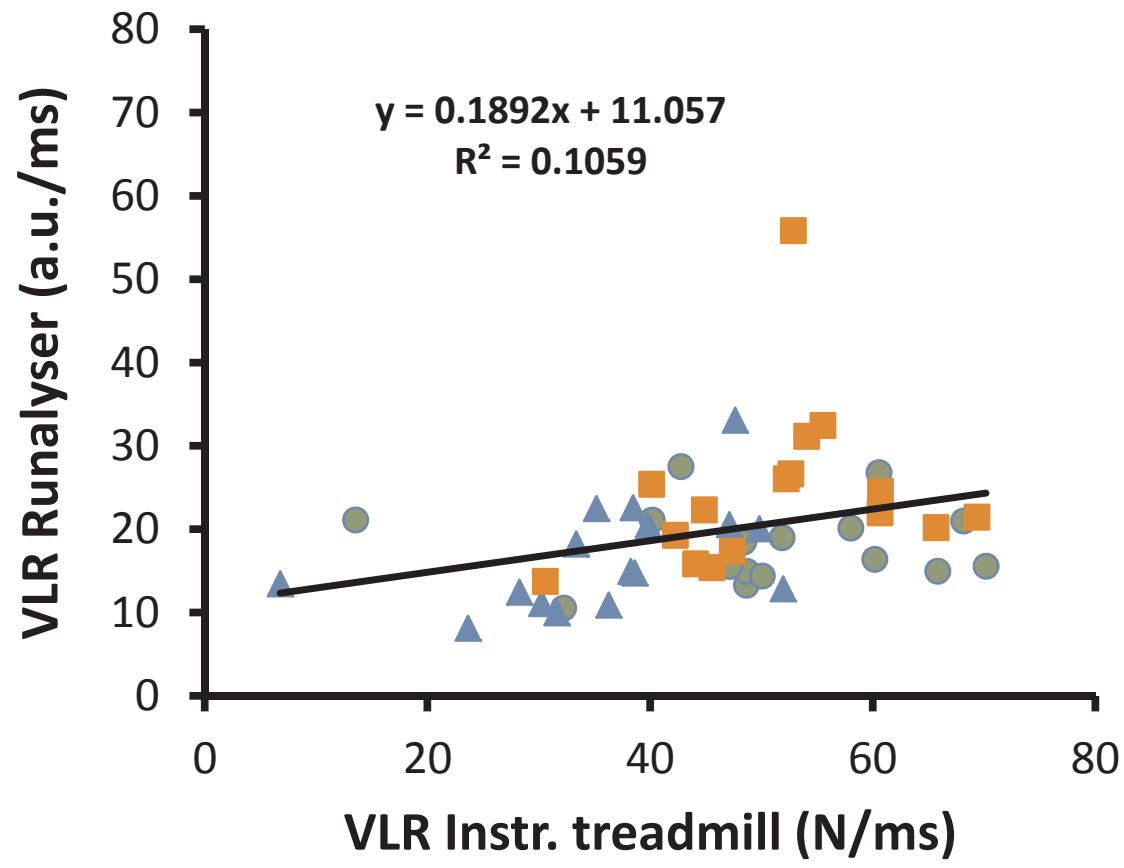

Figure 3.2. VLR values for the instrumented treadmill vs the Runalyser data. $\bigcirc=$ habitual running style, $\Delta=F F S$ and $\square=R F S$. The solid line is the regression line of all three running styles together.

\section{Results and discussion}

A first glance at the data in figure 3.2 indicates that there is no correlation between the gold standard measure of VLR and the Runalyser measure. We did not observe any correlation between the two measures overall, with $\mathrm{R}^{2}=0.11$. We also noticed a large disparity in values between insoles used, meaning that each insole would require calibration. The most likely explanation for this finding relates to the properties of the foam layers. Polyurethane foam is a viscoelastic material, which means it is not as reactive as a solid force plate for example. The associated lag in response time when the foam is compressed, means that there is a delay in the signal when compared to the instrumented treadmill. Chapter 2 demonstrated that by comparing these two devices, temporal parameters could ultimately be measured very accurately using the 
Runalyser. However, as VLR is by definition a rate of loading, this delay in the signal resulted in incomparable data between the two measurement systems. In addition, over time and with repeated deformation due to impact forces and exposure to sweat and other natural elements, the elasticity of the foam is subject to change and the insole itself to gradual degradation, factors which would influence signal amplitudes and VLR. As the temporal parameters are not dependent on amplitudes of the Runalyser raw data output, but on algorithms based on the derived data, these parameters are much less influenced by insole degradation. SI relies on the positioning of the sensors within the insole which remains fixed. Depending on frequency and conditions of use, the properties of each insole are different therefore, meaning that in order to measure amplitudes and VLRs consistently, frequent and rigorous calibration of the insoles would be required on a regular basis. Finally, the dead space between sensors on the insole could result in a loss of information when compared to the force data. When the foot contacts the treadmill, all the force applied is measured, whereas with the Runalyser, only the pressure applied by those parts of the foot which come into contact with the sensors is measured (figure 1.4).

Table 3.1. Mean $\pm S D$ values for 16 test subjects and results of a one-way repeated measures analysis of variance.

\begin{tabular}{lllll}
\hline \hline & HABIT & FFS & RFS & $p$-value \\
\hline Runalyser (a.u./ms) & $18.19 \pm 4.66$ & $16.64 \pm 6.40$ & $24.37 \pm 9.96^{*}$ & 0.001 \\
Instr. Treadmill (N/ms) & $50.39 \pm 14.32$ & $36.06 \pm 11.15^{\#}$ & $51.14 \pm 10.06^{*}$ & $<0.001$ \\
\hline \hline
\end{tabular}

$\mathrm{HABIT}=$ habitual running style; FFS=forefoot strike; RFS=rearfoot strike. ${ }^{*}=$ significantly different to HABIT and FFS. "=significantly different to HABIT.

With regards to our second hypothesis, table 3.1 clearly shows that differences in instrumented treadmill VLR were present between running styles overall, and a RFS displayed a significantly higher VLR than a FFS. This confirms the findings of previous studies. In addition, we found the VLR of the habitual running style to not differ significantly from the RFS running style. The opposite was true for the Runalyser VLR, as well as no difference being found between the VLRs in the habitual and FFS running conditions. The Runalyser displayed a relatively lower VLR for the habitual running style compared to the instrumented treadmill. It would seem that consciously altering the position of the foot from habitual running to RFS running made a large difference in Runalyser VLR but none at all in instrumented treadmill VLR. These participants were a subset of those described in chapter 2 , and all runners were confirmed to be habitual RFS runners (table 2.2) based on the SI. Therefore, making the conscious 
effort to strike the ground with a pronounced RFS may have invoked an altered sensor activation, yet unrelated to the actual rate of loading. The fact that $\mathrm{SI}$ did not differ between habitual running and RFS running (table 2.2) further illustrates that the Runalyser is not adapted to measuring rates of loading.

In conclusion, the Runalyser is not a reliable tool to measure VLR in its current state, and significant hardware alterations must be undertaken before such a comparison is repeated. We confirmed VLR to decrease when runners are instructed to adopt a FFS pattern, compared to a RFS and their habitual running style. 


\section{References}

Arendse, R. E., Noakes, T. D., Azevedo, L. B., Romanov, N., Schwellnus, M. P., \& Fletcher, G. (2004). Reduced eccentric loading of the knee with the pose running method. Med Sci Sports Exerc, 36(2), 272-277.

Azevedo, L. B., Lambert, M. I., Vaughan, C. L., O'Connor, C. M., \& Schwellnus, M. P. (2009). Biomechanical variables associated with Achilles tendinopathy in runners. Br J Sports Med, 43(4), 288-292.

Barnett, S., Cunningham, J. L., \& West, S. (2000). A comparison of vertical force and temporal parameters produced by an in-shoe pressure measuring system and a force platform. Clin Biomech (Bristol, Avon), 15(10), 781-785.

Boyer, E. R., Rooney, B. D., \& Derrick, T. R. (2014). Rearfoot and midfoot or forefoot impacts in habitually shod runners. Med Sci Sports Exerc, 46(7), 1384-1391.

Crowell, H. P., \& Davis, I. S. (2011). Gait retraining to reduce lower extremity loading in runners. Clin Biomech (Bristol, Avon), 26(1), 78-83.

Daoud, A. I., Geissler, G. J., Wang, F., Saretsky, J., Daoud, Y. A., \& Lieberman, D. E. (2012). Foot strike and injury rates in endurance runners: a retrospective study. Med Sci Sports Exerc, 44(7), 1325-1334.

Diebal, A. R., Gregory, R., Alitz, C., \& Gerber, J. P. (2012). Forefoot running improves pain and disability associated with chronic exertional compartment syndrome. Am J Sports Med, 40(5), 1060-1067.

Dierick, F., Penta, M., Renaut, D., \& Detrembleur, C. (2004). A force measuring treadmill in clinical gait analysis. Gait Posture, 20(3), 299-303.

Fong, D. T., Chan, Y. Y., Hong, Y., Yung, P. S., Fung, K. Y., \& Chan, K. M. (2008). Estimating the complete ground reaction forces with pressure insoles in walking. J Biomech, 41(11), 2597-2601.

Forner Cordero, A., Koopman, H. J. F. M., \& van der Helm, F. C. T. (2004). Use of pressure insoles to calculate the complete ground reaction forces. Journal of Biomechanics, 37(9), 1427-1432.

Goss, D. L., \& Gross, M. T. (2012). A review of mechanics and injury trends among various running styles. US Army Med Dep J, 62-71.

Hobara, H., Sato, T., Sakaguchi, M., Sato, T., \& Nakazawa, K. (2012). Step frequency and lower extremity loading during running. Int J Sports Med, 33(4), 310-313.

Kulmala, J. P., Avela, J., Pasanen, K., \& Parkkari, J. (2013). Forefoot strikers exhibit lower running-induced knee loading than rearfoot strikers. Med Sci Sports Exerc, 45(12), 2306-2313.

Lieberman, D. E., Venkadesan, M., Werbel, W. A., Daoud, A. I., D'Andrea, S., Davis, I. S., . . . Pitsiladis, Y. (2010). Foot strike patterns and collision forces in habitually barefoot versus shod runners. Nature, 463, 531-536.

Milner, C. E., Ferber, R., Pollard, C. D., Hamill, J., \& Davis, I. S. (2006). Biomechanical factors associated with tibial stress fracture in female runners. Med Sci Sports Exerc, 38(2), 323-328.

Zadpoor, A. A., \& Nikooyan, A. A. (2011). The relationship between lower-extremity stress fractures and the ground reaction force: a systematic review. Clin Biomech (Bristol, Avon), 26(1), 23-28. 



\section{Chapter 4}

\section{Association of Previous Injury and Speed with Running Style and Stride-to-stride Fluctuations.}

Robert Mann, Laurent Malisoux, Christian Nührenbörger, Axel Urhausen, Kenneth Meijer and Daniel Theisen

Scan J Med Sci Sports, 2014, in press. 


\section{Abstract}

Running-related injuries remain problematic among recreational runners. We evaluated the association between having sustained a recent running-related injury and speed, and the strike index (a measure of footstrike pattern, SI) and spatiotemporal parameters of running. 44 previously injured and 46 previously uninjured runners underwent treadmill running at 80,90,100, 110 and $120 \%$ of their preferred running speed. Participants wore a pressure insole device to measure SI, temporal parameters and stride length $\left(S_{\text {length }}\right)$ and frequency $\left(S_{\text {frequency }}\right)$ over 2-minute intervals. Coefficient of variation and detrended fluctuation analysis provided information on stride-to-stride variability and correlative patterns. Linear mixed models were used to compare differences between groups and changes with speed. Previously injured runners displayed significantly higher stride-to-stride correlations of $S I$ than controls $(p=0.046)$. As speed increased, $S I$, contact time $\left(T_{\text {contact }}\right)$, stride time $\left(T_{\text {stride }}\right)$ and duty factor $(D F)$ decreased $(p<0.001)$, whereas flight time $\left(T_{\text {flight }}\right), S_{\text {length }}$ and $S_{\text {frequency }}$ increased $(p<0.001)$. Stride-to-stride variability decreased significantly for $S I$, $T_{\text {contact, }}, T_{\text {flight }}$ and DF $(p \leq 0.005)$, as did correlative patterns for $T_{\text {contact }}, T_{\text {stride, }} D F, S_{\text {length }}$ and $S_{\text {frequency }}(p \leq 0.044)$. Previous running-related injury was associated with less strideto-stride randomness of footstrike pattern. Overall, runners became more pronounced rearfoot strikers as running speed increased.

\section{Key words}

Strike index, running biomechanics, running-related injury, detrended fluctuation analysis 


\section{Introduction}

Running as a recreational activity has boomed over the last few decades, and despite an increased interest in running-related injury (RRI) research, no decrease in RRI incidence has been observed (van Gent et al., 2007). With ever evolving barefoot and minimalistic shoe design and technology, runners, coaches, clinicians and researchers are heatedly debating which shoe types and foot strike patterns are most likely to reduce the risk of RRI. Hypotheses linking footstrike patterns to specific RRIs have emerged in recent years with one retrospective study (Daoud et al., 2012) finding that high level, cross-country runners using a forefoot strike (FFS) were 2.6 times less likely to sustain a RRI compared to rearfoot strike (RFS) runners. Another study (case series) retraining 10 chronic exertional compartment syndrome patients to run with a FFS reported significantly reduced pain when running for up to one year after the intervention (Diebal et al., 2012). Lower patellofemoral stress and knee frontal plane moment in FFS runners has been observed (Kulmala et al., 2013). On the other hand, another study (Almonroeder et al., 2013) witnessed an 11\% increase in Achilles tendon impulse per step in non-RFS runners, thereby speculating an elevated risk of Achilles tendinopathy.

The strike index $(\mathrm{SI})$ is a direct measure of running strike pattern (Cavanagh \& Lafortune, 1980). It represents the initial contact point on the foot sole with the ground, expressed as a percentage of total sole length and has been used to distinguish between RFS, FFS and midfoot strike (MFS) running (Cavanagh \& Lafortune, 1980; Mann et al., 2014; Squadrone \& Gallozzi, 2009). A recent study comparing spatiotemporal parameters of RFS and MFS runners questioned whether foot strike patterns remain the same at increasing, sub-maximal running speeds (Ogueta-Alday et al., 2014). This study found significant changes in contact time ( $\left.T_{\text {contact }}\right)$, flight time $\left(\mathrm{T}_{\text {flight }}\right)$, step length and step rate with increased running speed. Similarly, Padulo et al. (2012) observed overall changes in temporal parameters in groups of elite runners and amateur runners over various running speeds. Cluster analysis on the effect of running speed on the foot strike angle revealed three types of runners: those who consistently FFS, those who consistently RFS and those who transition from a RFS to a flatter foot strike angle at higher running speeds (Forrester \& Townend, 2014). However, the SI has not yet been anaylsed in this context, and neither has its association with RRI.

Long-range correlations between strides of the stride time ( $\left.T_{\text {stride }}\right)$ (Jordan et al., 2006) as well as stride length ( $\left.S_{\text {length }}\right), T_{\text {contact }}$ and force measurements (Jordan et al., 2007) have recently been analysed using detrended fluctuation analysis (DFA) at various running speeds. Previous studies have used DFA to distinguish between normal and pathological gait, and in children and the elderly (Hausdorff, 2007). One study looked at DFA in a group of trained distance runners compared with non-runners for $\mathrm{T}_{\text {stride }}$ and 
found a tendency towards weaker long-range correlations in the trained distance runners (Nakayama et al., 2010). SI and spatiotemporal parameters, as well as DFA at different running speeds have not yet been compared between previously injured and non-injured runners.

The aim of this retrospective, case-control study was to investigate the differences in SI, spatiotemporal parameters and stride-to-stride variability and correlative patterns between previously injured and uninjured runners. Based on the findings of Daoud et al. (2012) and Diebal et al. (2012), we hypothesized the injured group to display a more RFS running style. We also aimed to observe overall changes in running patterns as the running speed increased. Based on preliminary, unpublished observations, we hypothesised an overall decrease in SI with increased running speed.

\section{Methods}

\section{Participants}

A power calculation, based on an expected difference (minimal detectible change) of $4 \%$ SI and its standard deviation from a previous study (Mann et al., 2014), estimated each group to require 40 participants. All participants were recruited from a cohort of a previous study on RRI incidence (Malisoux et al., 2013) and the general population of Luxembourg. Participants were included in the study if they had no performanceimpeding conditions or pain due to injury at the time of testing, were comfortable with treadmill running, performed regular running for at least six of the previous 12 months, did not use orthopaedic insoles and were 18 years or older. The cohort was divided into two sub-groups based on whether or not participants had sustained at least one RRI but no other running impeding injury during the previous 12 months. RRI was defined as a physical pain or complaint altering or interrupting running activity for at least one week, affecting the lower extremities and progressive in nature. All participants provided informed consent, were made aware of the study procedures, provided information on running and injury history and were screened for cardiovascular risk factors using a standardised exercise aptitude questionnaire prior to testing. The study was approved by the National Research Ethics Committee of Luxembourg (ref: 201101/04).

\section{Instrumentation and protocol}

Leg length measurements were performed in a supine position from the anterior iliac crest to the medial malleoli for both legs (Duffey et al., 2000; Taunton et al., 2002) 
using a standardised anthropometric calliper. Foot type was assessed using podoscopic footprints and classified as either normal, flat-footed, flat-footed and pronated, higharched or high-arched and supinated by an orthopaedic surgeon specialising in the foot (Razeghi \& Batt, 2002). The foot mobility magnitude (FMM) was assessed according to the procedure described by McPoil et al. (2009) using a custom built measuring device. This measurement is based on highly reproducible values (ICC $\geq 0.97$ ) (McPoil et al., 2009) and is strongly suggested as a complementary measure when assessing foot type and posture (Cornwall \& McPoil, 2011).

The Runalyser (TNO, Eindhoven, The Netherlands) is a pressure-sensitive insole system which measures pressure- and time-related variables at foot-ground contact during running. The flexible insole component ( $3 \mathrm{~mm}$ thick), available in three sizes: small (EU 38-41), medium (EU 41.5-44.5) and large ( $\geq$ EU 45) is placed on top of the existing insole of both running shoes, thus allowing direct contact with the feet. The insoles are connected to microprocessors which are strapped to the lower leg of the runner, and transmit real-time pressure data (acquired at $247 \mathrm{~Hz}$ ) wirelessly to a nearby PC. Reliability and validity of this device has been published previously (Mann et al., 2014). The preferred running speed (PRS) was determined on a treadmill (Woodway $\mathrm{GmbH}$, Weil am Rhein, PPS70 Plus, Germany). The procedure was similar to that of Jordan et al. (2006) whereby the speed was gradually increased during a first trial until the participant felt they were running at their PRS. After a short rest this speed was increased by $1.0 \mathrm{~km} / \mathrm{h}$ in a second trial and then gradually decreased until the participant again felt they had reached their PRS. If a difference greater than $0.4 \mathrm{~km} / \mathrm{h}$ was detected between these two trials then the first trial was repeated. An average was taken to be the true PRS and participants were blinded to the running speed throughout. Subsequently, 5 intervals were run for $2 \mathrm{~min}$ at $80,90,100,110$ and $120 \%$ of the PRS (in that order to avoid the influence of fatigue at slower running speeds and to identify any potential turning points in running style). The intensity was measured using the 15-point Borg scale at the end of each 2-minute acquisition. If a participant indicated a score of 17 or more at any point the remaining trials were not performed.

\section{Data processing}

Custom-built MATLAB (Mathworks Inc., Natick, MA, USA) algorithms were used to analyse Runalyser data. $\mathrm{SI}, \mathrm{T}_{\text {contact }}, \mathrm{T}_{\text {flight }}$ and $\mathrm{T}_{\text {stride }}$ were measured, and the duty factor $\left(T_{\text {contact }} / T_{\text {stride }} * 100, D F\right)$, and $S_{\text {length }}\left(T_{\text {stride }} *\right.$ running speed) and frequency (running speed/S $S_{\text {length }}, S_{\text {frequency }}$ ) were calculated. Running speed was determined using the treadmill display. Data for the injured limb was retained for analysis in the RRI group, and a random selection of left or right limb data was analysed for the injury-free runners. DFA was performed on all Runalyser parameters for the full 2 minutes of each 
acquisition using the previously described method (Jordan et al., 2006; Peng et al., 1993), as was the coefficient of variation (CV). Two minutes of data acquisition have been used previously for DFA analysis of walking in elderly with and without higherlevel gait disorder (Herman et al., 2005). This provided us with an average time series of $161 \pm 12$ strides, which is more than the suggested minimum of 64 data samples (Dingwell \& Cusumano, 2010). DFA calculates a scaling exponent $\alpha$, providing information on the presence and strength of stride-to-stride correlative patterns during a time series (Peng et al., 1993). An $\alpha$ of 0.5 suggests no correlation between strides, i.e. a particular stride is not dependent on any of the preceding strides. An $\alpha>0.5$ suggests that long-range correlations are present, i.e. there is a certain dependency of a stride on those previous, and an $\alpha<0.5$ suggests the presence of anticorrelations, for example a shorter stride is more likely to follow a longer stride (Dingwell \& Cusumano, 2010; Jordan et al., 2006, 2007; Jordan \& Newell, 2008). We suffered data loss from the CV and DFA for one participant at $90 \%$ PRS, for one participant at $100 \%$ PRS and seven participants at $120 \%$ PRS (less than two minutes of analysable data - see supplementary data).

\section{Statistics}

Independent sample t-tests were performed to identify any significant descriptive, anthropometric and training differences between the two groups, and a Pearson $\chi^{2}$ test to compare foot types of both groups. Mean and standard deviation (SD) was calculated for all steps of each 2-minute acquisition. We used a linear mixed model, which overcomes the problem of missing data, entering "group" and "relative speed" as fixed effects and "subjects" as random slopes and intercepts to analyse group differences for SI, spatiotemporal parameters, CV and the scaling exponent $\alpha$ of DFA values over all five speeds. Several mixed models were run and, based on the best model fit (Bamia et al., 2013) according to Schwarz's Bayesian Criterion (BIC) and the least degrees of freedom used using the main outcome variable, SI, an autoregressive structure model was selected to analyse all variables. We confirmed runners to either increase, decrease or not change their SI as running speed increased by way of a linear regression analysis. A positive slope significantly deviating from 0 (95\% confidence interval) characterised the runner as a SI-increaser, no significant change characterised them as a runner not changing their SI and a negative slope characterised them as a runner decreasing their SI with increasing running speed. The proportions of previously injured runners in these three groups were compared using a Pearson $\chi^{2}$ analysis. Statistical analyses were carried out in SPSS (IBM, Armonk, New York, USA) for Windows version 20. Statistical significance was accepted as $p<0.05$. 


\section{Results}

Table 4.1 summarises the demographics, anthropometrics and running characteristics of the two groups. No differences were identified, except that the injured group had significantly fewer months of running during the previous 12 months compared to the control group, accounting for the time lost due to the RRI. PRS was similar between groups.

Table 4.1. Descriptives, anthropometry and training characteristics of the RRI and control group.

\begin{tabular}{|c|c|c|c|}
\hline & $\begin{array}{l}\text { RRI group } \\
(n=44)\end{array}$ & $\begin{array}{l}\text { Control group } \\
(n=46)\end{array}$ & $p$ \\
\hline Sex (male) & $33(75 \%)$ & $33(71.7 \%)$ & \\
\hline Age (y) & $40 \pm 10$ & $42 \pm 8$ & 0.207 \\
\hline Height (m) & $1.76 \pm 0.08$ & $1.77 \pm 0.07$ & 0.583 \\
\hline Weight (kg) & $70 \pm 9$ & $73 \pm 9$ & 0.140 \\
\hline BMI (kg/m2) & $22.6 \pm 2.1$ & $23.2 \pm 2.5$ & 0.172 \\
\hline Running experience (years) & $10.9 \pm 9.2$ & $11.4 \pm 9.0$ & 0.802 \\
\hline Average number of session/week & $2.9 \pm 1.1$ & $2.8 \pm 1.3$ & 0.585 \\
\hline Average session duration (min) & $61.6 \pm 16.0$ & $60.5 \pm 14.4$ & 0.735 \\
\hline Preferred running speed $(\mathrm{km} / \mathrm{h})$ & $10.8 \pm 1.4$ & $10.5 \pm 1.5$ & 0.315 \\
\hline Total mileage last 12 months (km) & $1285 \pm 890$ & $1478 \pm 1054$ & 0.351 \\
\hline Months run of last 12 months & $10.3 \pm 2.5$ & $11.4 \pm 1.7$ & 0.021 \\
\hline FMM (cm) & $1.27 \pm 0.28$ & $1.19 \pm 0.35$ & 0.283 \\
\hline FMM left-right difference (cm) & $0.26 \pm 0.19$ & $0.23 \pm 0.20$ & 0.388 \\
\hline Leg length left-right difference $(\mathrm{cm})$ & $0.59 \pm 0.41$ & $0.55 \pm 0.31$ & 0.596 \\
\hline Foot type: & & & \\
\hline normal & $29(65.9 \%)$ & $29(63.0 \%)$ & \multirow{4}{*}{0.581} \\
\hline flat foot & 0 & $2(4.3 \%)$ & \\
\hline high arch and supinated & $12(27.3 \%)$ & $12(26.1 \%)$ & \\
\hline high arch & $3(6.8 \%)$ & $3(6.5 \%)$ & \\
\hline
\end{tabular}

BMI: Body mass index. FMM: Foot mobility magnitude of injured side or randomly selected for the control group; Values are mean \pm SD.

RRIs were to the lower leg $(n=15,34 \%)$, the knee $(n=14,32 \%)$, the thigh $(n=6,14 \%)$, the foot $(n=6,14 \%)$ and the hip ( $n=3,7 \%) .55 \%$ of RRIs affected the tendons $(n=24), 23 \%$ involved the muscles $(n=10)$ and $11 \%$ were bony injuries $(n=5)$. 
Two runners indicated a RPE $\geq 17$ at the end of the $110 \%$ interval and therefore did not run the last interval. Overall values (across all speeds of both groups) of the variables

A

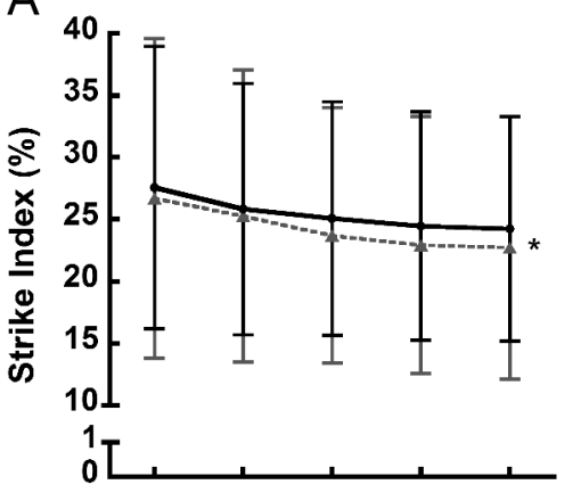

C
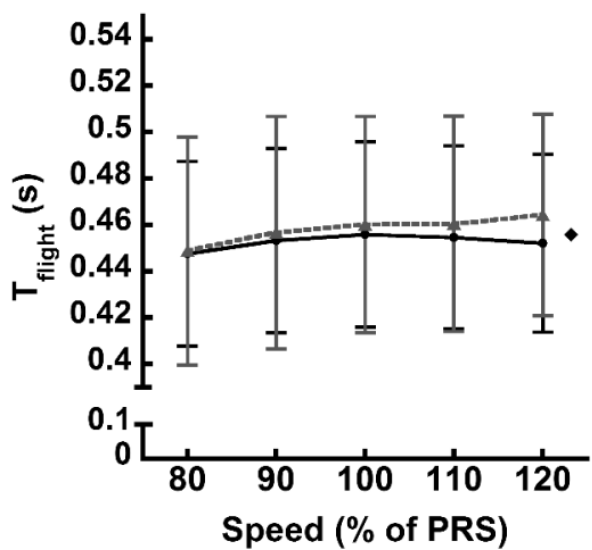

B

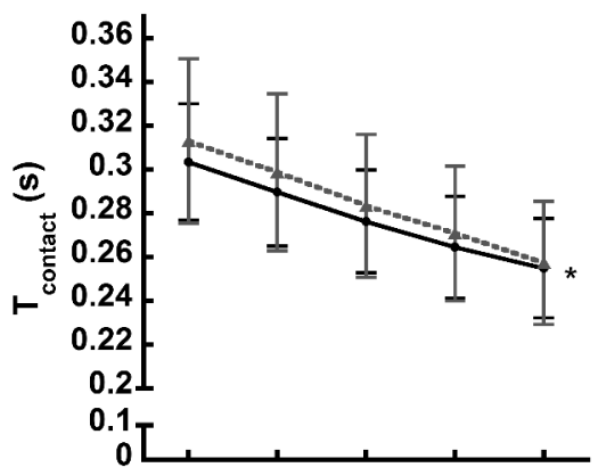

$\mathrm{D}$

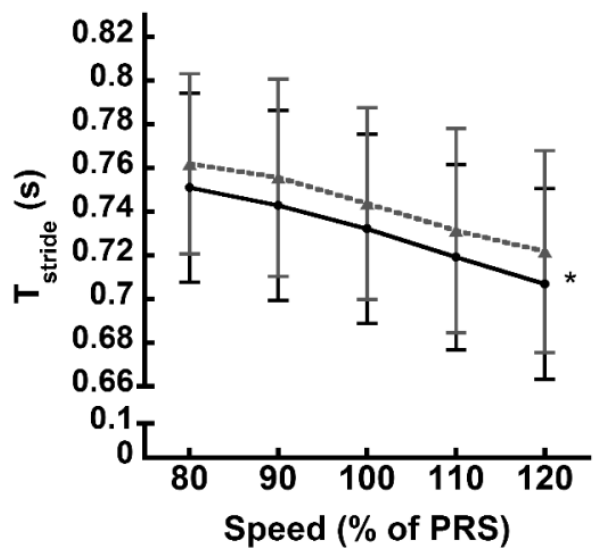

measured were as follows: SI $(24.8 \pm 10.5 \%), T_{\text {contact }}(0.281 \pm 0.079 \mathrm{~s}), \mathrm{T}_{\text {flight }}(0.455 \pm 0.043$ s), $T_{\text {stride }}(0.737 \pm 0.044 \mathrm{~s}), \mathrm{DF}(38.2 \pm 3.8 \%), \mathrm{S}_{\text {length }}(2.181 \pm 0.317 \mathrm{~m})$ and $\mathrm{S}_{\text {frequency }}(81.8 \pm 4.9$ strides/min). Figure 4.1 depicts the raw data for $\mathrm{SI}, \mathrm{T}_{\text {contact }}, \mathrm{T}_{\text {flight }}$ and $\mathrm{T}_{\text {stride. }}$. A complete dataset of all variables measured and calculated is available as supplementary data.

Figure 4.1. Mean and standard deviation of strike index (A), contact time (B), flight time (C) and stride time (D) by group (RRI=solid black line) and relative running speed. PRS=preferred running speed. *significant overall decrease with increasing running speed. significant overall increase with increasing running speed.

CV was not significantly different between groups for $\mathrm{SI}, \mathrm{T}_{\text {contact }}, \mathrm{T}_{\text {flight }}, \mathrm{T}_{\text {stride }}$ (figure 4.2), $D F, S_{\text {length }}$ and $S_{\text {frequency }}$ (see supplementary data). The $\alpha$ of DFA for SI was found to be marginally but significantly different $(p=0.046)$ between the RRI group (on average 
$0.75 \pm 0.15$ ) and the control group (on average $0.71 \pm 0.14$ ) (figure $4.3 \mathrm{~A}$ ). The $\alpha$ of all other variables did not differ significantly (figure 4.3 and supplementary data).
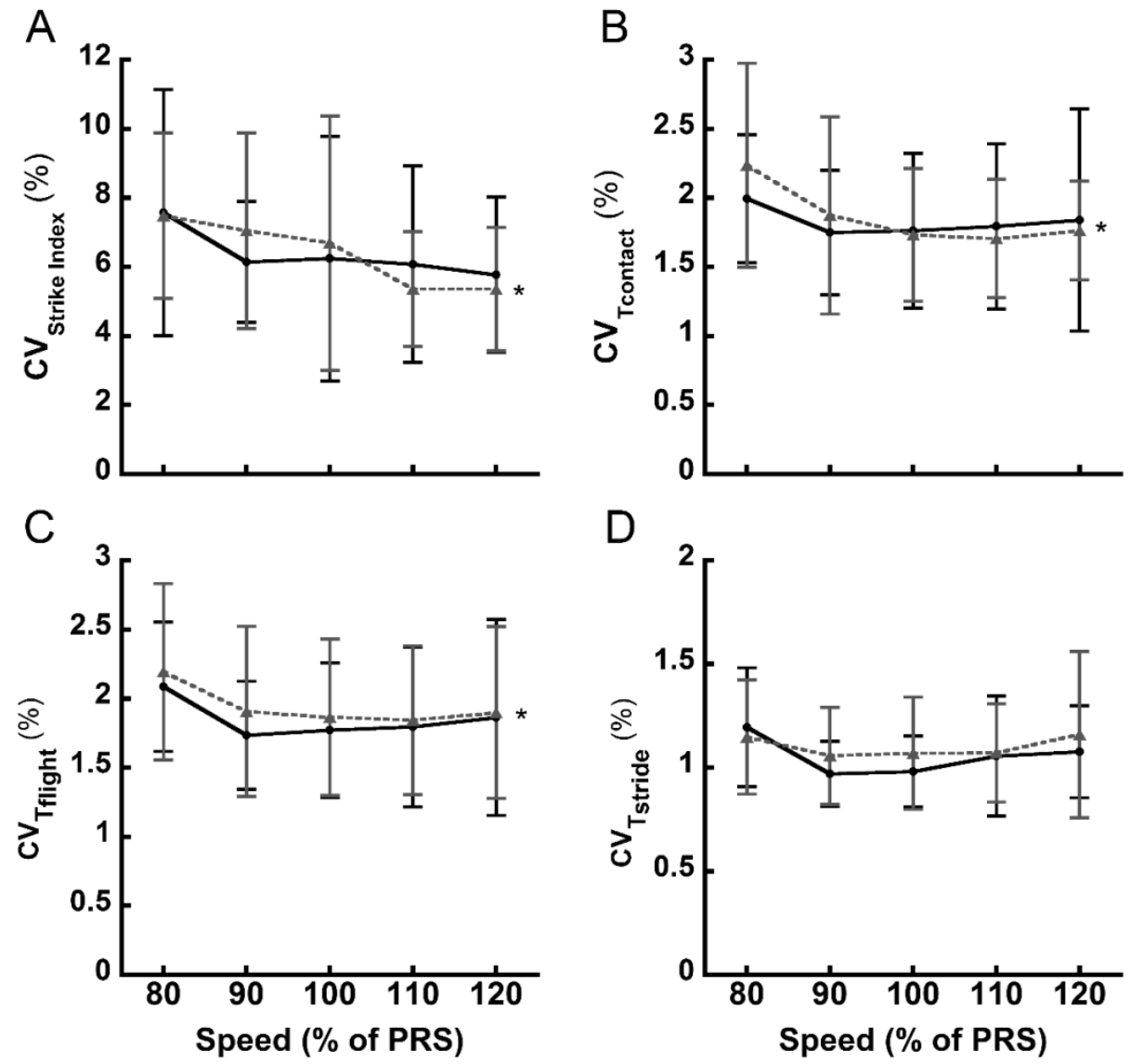

Figure 4.2. Mean and standard deviation of the CV of strike index (A), contact time (B), flight time (C) and stride time (D) by group (RRI=solid black line) and relative running speed. *Significant overall change with increasing running speed.

Increasing the running speed had a significant effect on the variables measured (figures 4.1-4.3). Overall, $\mathrm{SI}, \mathrm{T}_{\text {contact, }} \mathrm{T}_{\text {stride }}$ and $\mathrm{DF}$ all decreased with increasing running speed. $\mathrm{T}_{\text {flight }}$ significantly increased, as did $\mathrm{S}_{\text {length }}$ and $\mathrm{S}_{\text {frequency. }}$ In fact, $\mathrm{S}_{\text {length }}$ increased overall from $1.800 \pm 0.260$ to $2.548 \pm 0.363 \mathrm{~m} \mathrm{(29.5 \% )}$ from the slowest to the fastest running speed, whereas $S_{\text {frequency }}$ only increased from $79.6 \pm 4.5$ to $84.3 \pm 5.3$ strides $/ \mathrm{min}$ 
(5.6\%). Further, decreases in CV for SI, $\mathrm{T}_{\text {contact }}, \mathrm{T}_{\text {flight }}$ and DF were observed. The $\alpha$ also varied significantly according to running speed with overall decreased $\alpha$ for $T_{\text {contact, }}$
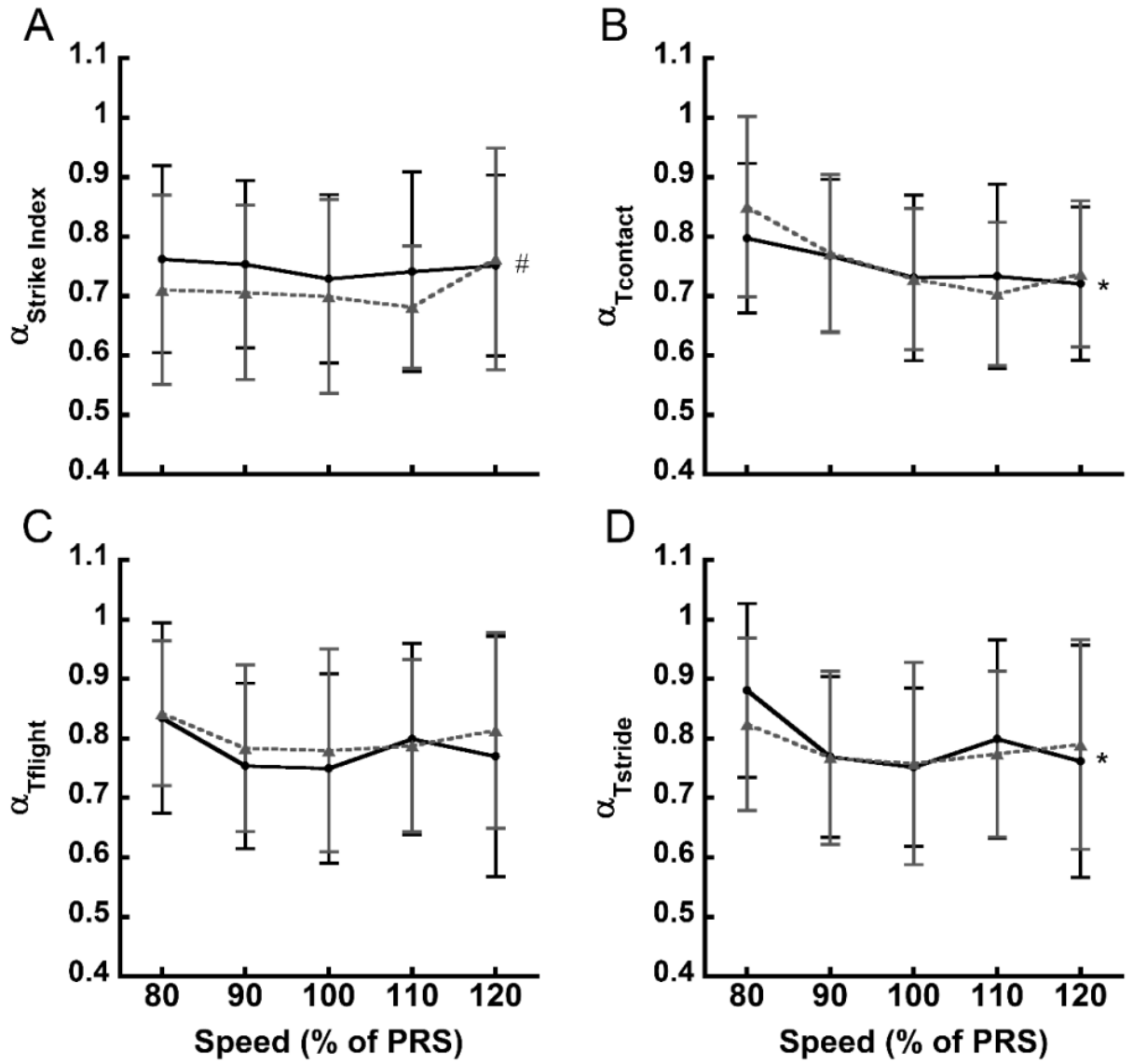

$\mathrm{T}_{\text {stride }}$ (figure 4.3), DF, $\mathrm{S}_{\text {length }}$ and $\mathrm{S}_{\text {frequency }}$ (supplementary data).

Figure 4.3. Mean and standard deviation of the $\alpha$ of strike index (A), contact time (B), flight time (C) and stride time (D) by group (RRI=solid black line) and relative running speed. The $\alpha$ indicates the strength of inter-stride correlative patterns, with a value of 0.5 signifying white noise or randomness between strides, and higher values signifying the presence of correlative patterns. *significant overall change in $\alpha$ with increasing running speed. \#significant overall difference between the RRI and control group.

Of the previously injured runners, 19 (43.2\%) decreased their SI, 24 (54.5\%) did not significantly change their SI and 1 (2.3\%) runner increased their SI as running speed increased. In the control group, 21 (45.7\%) runners decreased, 20 (43.5\%) did not 
significantly change and 5 (10.9\%) increased their SI with increased running speed. Overall, $40 \%$ of runners decreased their $\mathrm{SI}, 44 \%$ did not change their $\mathrm{SI}$ and $6 \%$ increased their SI as running speed increased. No significant differences in these three types of runners were found between groups $(p=0.214) .6 .7 \%$ of the total cohort were found to adopt a FFS or MFS running style, and the remaining $93.3 \%$ a RFS running style at the PRS.

\section{Discussion}

The main purpose of the study was to identify differences in running style and running parameters between runners having sustained a RRI during the previous 12 months and runners who had not sustained any injuries. The majority of variables tested did not differ significantly between groups. However, the $\alpha$ of SI was significantly lower in the control group compared to the RRI group, implying that there was a greater degree of randomness in the footstrike pattern (SI) among the control runners. However, the difference between groups is not large and we cannot deduce a causal relationship from this finding.

Although speculative, a plausible explanation for a reduced $\alpha$ in the control group could be a protective mechanism by neuromuscular processes to reduce repetitive loading (precursor to overload injuries) of the same structures. In other words, it could be possible that those runners predisposed to avoiding injury may do so by allowing for more flexibility in their footstrike pattern (SI), to accommodate a less "risky" running style. An organism less capable of adapting to the environment and maintaining a repetitive movement has been thought to have an increased risk of overloading specific structures or tissues (Hamill et al., 2012). For example, a FFS increases loading of the Achilles tendon and gastrocnemius (Almonroeder et al., 2013; Shih et al., 2013), whereas a RFS generates higher forces in the knee (Kulmala et al., 2013). Varying one's strike pattern could reduce the risk of the overload threshold (Hreljac, 2004) of specific physiological structures being reached. However, additional research is needed to further understand the role random and correlated footstrike patterns may play in overloading these structures.

The $\alpha$ of SI has not previously been investigated within the context of RRI, although one study (Meardon et al., 2011) looked at the behaviour of the $\alpha$ of $\mathrm{T}_{\text {stride }}$ in previously injured and uninjured runners. In contrast to our findings (no difference in the $\alpha$ of $\mathrm{T}_{\text {stride }}$ between groups) and their expectations, their RRI group displayed more randomness than the control group ( $\alpha=0.79$ and 0.96 for the RRI and control group, respectively). Overall our values of $\alpha$ for $T_{\text {stride }}$ were lower than those found by 
Meardon et al. (2011), but in line with other studies (Herman et al., 2005; Jordan et al., 2007).

To the authors' best knowledge, this is the first study to use the SI measure, and test its association with RRI. In most cases the strike pattern is determined visually using video camera footage (Daoud et al., 2012; Larson et al., 2011) or the footstrike angle (Forrester \& Townend, 2014; Kulmala et al., 2013). Pressure insoles provide a valid alternative, allowing for continuous measure of footstrike pattern. It must be noted that the majority of runners (93.3\%) habitually ran with a RFS, and the $6.7 \%$ MFS and FFS runners is not far off the 5.2\% MFS and FFS runners reported previously in a larger yet similar population of recreational runners (Larson et al., 2011). We found no significant association between RRI and runners who decreased their SI with increasing running speed and those who did not. A much higher proportion of runners decreased their SI (44.4\%) than those who increased SI (6.7\%), leading to an overall significant decrease in SI (figure 4.1A).

The overall decrease in $\mathrm{T}_{\text {contact }}$ and increase in $\mathrm{T}_{\text {flight }}$ (figure 4.1), $\mathrm{S}_{\text {length }}$ and $\mathrm{S}_{\text {frequency }}$ with increasing running speed has been previously shown (Ogueta-Alday et al., 2014; Padulo et al., 2012). We observed a significant decrease in $T_{\text {stride }}$ as well, despite the increase in $\mathrm{T}_{\text {flight }}$ (figure 4.1). This shows that $\mathrm{T}_{\text {contact }}$ is greatly influenced by running speed, also confirmed by an overall reduction in DF of $\sim 5 \%$. We also observed a dramatic increase in $S_{\text {length }}$ of $29.5 \%$. Compared to an overall $S_{\text {frequency }}$ increase of $5.6 \%$, these results are in accordance with the observation that recreational runners tend to rely more heavily on increasing their $S_{\text {length }}$ rather than $S_{\text {frequency }}$ to increase their running speed (Chapman et al., 2012). Studies have shown that reduced $S_{\text {length }}$ diminishes impact forces at landing (Derrick et al., 1998) and increased $S_{\text {frequency }}$ reduces joint forces and loading (Heiderscheit et al., 2011; Hobara et al., 2012; Lenhart et al., 2014), and these authors suggest increasing $S_{\text {frequency }}$ (indirectly decreasing $S_{\text {length }}$ ) as a way of preventing or treating RRIs. We did not find any differences between groups for $S_{\text {length }}$ and $S_{\text {frequency. }}$. Combining the use of lower limb kinematics and $\mathrm{SI}$ measure to explore the interaction of $\mathrm{SI}, \mathrm{S}_{\text {length }}$ and $\mathrm{S}_{\text {frequency }}$ and its relation to RRI would provide more insight into this aspect of running as well as help to clarify the currently poorly understood concept of "overstriding" (Youngren, 2005).

As running speed increased, there was a significant linear decrease in the stride-tostride variability (CV) of SI for all participants overall (figure 4.2A). Jordan et al, (2007) found significant linear decreases in the CV of $T_{\text {contact, }} T_{\text {stride }}$ and $S_{\text {length }}$ with increasing running speed. The present study also yielded significant decreases for $T_{\text {contact }}, T_{\text {flight }}$ (figure $4.2 \mathrm{~B}$ and $4.2 \mathrm{C}$ ) and DF, especially from the 80 to $90 \%$ running speed intervals. This shows that at slower than normal running speeds, runners display larger stride-tostride variability, which is reduced when running at the PRS or above. Taken together, these observations could suggest that at slower running speeds runners have more 
freedom to make subtle changes in their strike pattern and timing, and at faster running speeds more conformity between strides is established. This general decrease in stride-to-stride variability at faster running speeds could induce a risk of RRI, as the organism is subjected to more regular and elevated internal forces, the musculoskeletal system is more likely to be overloaded. Alternatively, Nakayama et al, 2010 compared CV of $\mathrm{T}_{\text {stride }}$ in trained runners and non-runners and found significantly less variability in the trained runners at 80,100 and $120 \%$ running speeds. They postulated that this difference was a by-product of training for improved running economy. We did not find any differences in CV between the RRI and control group for any of the variables measured.

The interpretation of the $\alpha$ of DFA remains elusive in the running literature (Dingwell \& Cusumano, 2010). Recent emphasis has been placed on the notion of persistent and anti-persistent correlations (Terrier \& Deriaz, 2012). Persistent long-range correlations represent greater statistical likelihood of a stride being similar to those previous (an $\alpha>0.5$ ), whereas anti-persistent correlations represent greater statistical likelihood of a stride being different to its predecessor (an $\alpha<0.5$ ). An $\alpha$ of 0.5 represents white noise or no correlations whatsoever. Studies looking at the effect of running speed on the $\alpha$ of $\mathrm{T}_{\text {stride }}$ have identified a U-shaped curve, showing that the least persistence (lowest $\alpha$ value) occurs at the PRS (Jordan et al., 2007; Jordan \& Newell, 2008). Our data which is based on 90 runners compared to the relatively low numbers (e.g. $n=8$ ) studied previously, did not yield such obvious trends, although some significant changes with no clear pattern were found (figure 4.3).

This study is not without its limitations, the main one being its retrospective design. We cannot, therefore, determine whether or not the lower value of $\alpha$ for SI in the RRI group, is a cause or a result of the previously sustained RRI. Furthermore, the clinical value of our findings cannot be quantified at this stage, as the differences in the $\alpha$ of SI, although significant, were found to be quite small. A possible reason for the lack of other associations between parameters and RRI is likely related to the fact that we did not focus on a specific injury type or pathology.

To conclude, our first hypothesis was confirmed in part with previously uninjured runners displaying significantly more randomness in their stride-to-stride footstrike pattern (SI) than their previously injured counterparts. No other group differences were found. Further study is warranted to shed light on the clinical relevance of the lower $\alpha$ value in previously uninjured runners. We confirmed our second hypothesis by detecting an overall significant decrease in SI with increasing running speed, although the majority of runners displayed a stable SI. Our results on the behaviour of spatiotemporal parameters with increasing running speed are comparable to those previously recorded. 


\section{Perspective}

Other than significantly more randomness of the footstrike pattern observed in the control group, the findings of this retrospective study show no other association between injury history and $\mathrm{Sl}$, spatiotemporal parameters and the CV and $\alpha$ of DFA of these variables. This supports the need for studies focusing on specific RRI pathologies and using prospective designs with sufficiently high participant numbers to further investigate the relationship between these parameters and RRI. Our findings being comparable to what has previously been observed as running speed increases, confirms the use of pressure insoles to detect these changes. With ever-advancing insole technology it should be possible for researchers to acquire in-field data within the runner's natural running environment in the near future. Such tools should be considered for future research, as they are capable of prolonged acquisition and do not interfere with the runner's gait pattern or running behaviour.

\section{Acknowledgements}

The current research was financially supported by a grant from the National Research Fund of Luxembourg to the first author (AFR ref. number: 1102562). The authors wish to thank Dr Marc Hoppenbrouwers and Dr Andy Statham from TNO, Eindhoven for providing the measurement device and technical support. Thanks also go to Roman Brunner and Paul Gette of the Sports Medicine Research Laboratory for help with data processing, to Thierry Windal for help with data collection and to Dr Nicolien van Giffen for the foot analysis. 


\section{References}

Almonroeder, T., Willson, J. D., \& Kernozek, T. W. (2013). The effect of foot strike pattern on achilles tendon load during running. Ann Biomed Eng, 41(8), 1758-1766.

Bamia, C., White, I. R., \& Kenward, M. G. (2013). Some consequences of assuming simple patterns for the treatment effect over time in a linear mixed model. Stat Med, 32(15), 2585-2594.

Cavanagh, P. R., \& Lafortune, M. A. (1980). Ground reaction forces in distance running. J Biomech, 13(5), 397-406.

Chapman, R. F., Laymon, A. S., Wilhite, D. P., McKenzie, J. M., Tanner, D. A., \& Stager, J. M. (2012). Ground contact time as an indicator of metabolic cost in elite distance runners. Med Sci Sports Exerc, 44(5), 917-925.

Cornwall, M. W., \& McPoil, T. G. (2011). Relationship between static foot posture and foot mobility. J Foot Ankle Res, $4,4$.

Daoud, A. I., Geissler, G. J., Wang, F., Saretsky, J., Daoud, Y. A., \& Lieberman, D. E. (2012). Foot strike and injury rates in endurance runners: a retrospective study. Med Sci Sports Exerc, 44(7), 1325-1334.

Derrick, T. R., Hamill, J., \& Caldwell, G. E. (1998). Energy absorption of impacts during running at various stride lengths. Med Sci Sports Exerc, 30(1), 128-135.

Diebal, A. R., Gregory, R., Alitz, C., \& Gerber, J. P. (2012). Forefoot running improves pain and disability associated with chronic exertional compartment syndrome. Am J Sports Med, 40(5), 1060-1067.

Dingwell, J. B., \& Cusumano, J. P. (2010). Re-interpreting detrended fluctuation analyses of stride-to-stride variability in human walking. Gait Posture, 32(3), 348-353.

Duffey, M. J., Martin, D. F., Cannon, D. W., Craven, T., \& Messier, S. P. (2000). Etiologic factors associated with anterior knee pain in distance runners. Med Sci Sports Exerc, 32(11), 1825-1832.

Forrester, S. E., \& Townend, J. (2014). The effect of running velocity on footstrike angle - A curve-clustering approach. Gait Posture, http: //dx.doi.org/10.1016/j.gaitpost .2014.1008.1004.

Hamill, J., Palmer, C., \& Van Emmerik, R. E. (2012). Coordinative variability and overuse injury. Sports Med Arthrosc Rehabil Ther Technol, 4(1), 45.

Hausdorff, J. M. (2007). Gait dynamics, fractals and falls: finding meaning in the stride-to-stride fluctuations of human walking. Hum Mov Sci, 26(4), 555-589.

Heiderscheit, B. C., Chumanov, E. S., Michalski, M. P., Wille, C. M., \& Ryan, M. B. (2011). Effects of Step Rate Manipulation on Joint Mechanics during Running. Med Sci Sports Exerc, 43(2), 296-302.

Herman, T., Giladi, N., Gurevich, T., \& Hausdorff, J. M. (2005). Gait instability and fractal dynamics of older adults with a "cautious" gait: why do certain older adults walk fearfully? Gait Posture, 21(2), 178-185.

Hobara, H., Sato, T., Sakaguchi, M., Sato, T., \& Nakazawa, K. (2012). Step frequency and lower extremity loading during running. Int J Sports Med, 33(4), 310-313.

Hreljac, A. (2004). Impact and overuse injuries in runners. Med Sci Sports Exerc, 36(5), 845-849.

Jordan, K., Challis, J. H., \& Newell, K. M. (2006). Long range correlations in the stride interval of running. Gait Posture, 24(1), 120-125.

Jordan, K., Challis, J. H., \& Newell, K. M. (2007). Speed influences on the scaling behavior of gait cycle fluctuations during treadmill running. Hum Mov Sci, 26(1), 87-102.

Jordan, K., \& Newell, K. M. (2008). The structure of variability in human walking and running is speeddependent. Exerc Sport Sci Rev, 36(4), 200-204.

Kulmala, J. P., Avela, J., Pasanen, K., \& Parkkari, J. (2013). Forefoot strikers exhibit lower running-induced knee loading than rearfoot strikers. Med Sci Sports Exerc, 45(12), 2306-2313.

Larson, P., Higgins, E., Kaminski, J., Decker, T., Preble, J., Lyons, D., . . . Normile, A. (2011). Foot strike patterns of recreational and sub-elite runners in a long-distance road race. J Sports Sci, 29(15), 16651673.

Lenhart, R. L., Thelen, D. G., Wille, C. M., Chumanov, E. S., \& Heiderscheit, B. C. (2014). Increasing running step rate reduces patellofemoral joint forces. Med Sci Sports Exerc, 46(3), 557-564.

Malisoux, L., Ramesh, J., Mann, R., Seil, R., Urhausen, A., \& Theisen, D. (2013). Can parallel use of different running shoes decrease running-related injury risk? Scand J Med Sci Sports, doi: 10.1111/sms.12154.

Mann, R., Malisoux, L., Brunner, R., Gette, P., Urhausen, A., Statham, A., . . . Theisen, D. (2014). Reliability and validity of pressure and temporal parameters recorded using a pressure-sensitive insole during running. Gait Posture, 39(1), 455-459. 
McPoil, T. G., Vicenzino, B., Cornwall, M. W., Collins, N., \& Warren, M. (2009). Reliability and normative values for the foot mobility magnitude: a composite measure of vertical and medial-lateral mobility of the midfoot. J Foot Ankle Res, 2, 6.

Meardon, S. A., Hamill, J., \& Derrick, T. R. (2011). Running injury and stride time variability over a prolonged run. Gait Posture, 33(1), 36-40.

Nakayama, Y., Kudo, K., \& Ohtsuki, T. (2010). Variability and fluctuation in running gait cycle of trained runners and non-runners. Gait Posture, 31(3), 331-335.

Ogueta-Alday, A., Rodriguez-Marroyo, J. A., \& Garcia-Lopez, J. (2014). Rearfoot striking runners are more economical than midfoot strikers. Med Sci Sports Exerc, 46(3), 580-585.

Padulo, J., Annino, G., Migliaccio, G. M., D'Ottavio, S., \& Tihanyi, J. (2012). Kinematics of running at different slopes and speeds. J Strength Cond Res, 26(5), 1331-1339.

Peng, C. K., Mietus, J., Hausdorff, J. M., Havlin, S., Stanley, H. E., \& Goldberger, A. L. (1993). Long-range anticorrelations and non-Gaussian behavior of the heartbeat. Phys Rev Lett, 70(9), 1343-1346.

Razeghi, M., \& Batt, M. E. (2002). Foot type classification: a critical review of current methods. Gait Posture, 15(3), 282-291.

Shih, Y., Lin, K. L., \& Shiang, T. Y. (2013). Is the foot striking pattern more important than barefoot or shod conditions in running? Gait Posture, 38(3), 490-494.

Squadrone, R., \& Gallozzi, C. (2009). Biomechanical and physiological comparison of barefoot and two shod conditions in experienced barefoot runners. J Sports Med Phys Fitness, 49(1), 6-13.

Taunton, J. E., Ryan, M. B., Clement, D. B., McKenzie, D. C., Lloyd-Smith, D. R., \& Zumbo, B. D. (2002). A retrospective case-control analysis of 2002 running injuries. Br J Sports Med, 36(2), 95-101.

Terrier, P., \& Deriaz, O. (2012). Persistent and anti-persistent pattern in stride-to-stride variability of treadmill walking: influence of rhythmic auditory cueing. Hum Mov Sci, 31(6), 1585-1597.

van Gent, R. N., Siem, D., van Middelkoop, M., van Os, A. G., Bierma-Zeinstra, S. M., \& Koes, B. W. (2007). Incidence and determinants of lower extremity running injuries in long distance runners: a systematic review. Br J Sports Med, 41(8), 469-480; discussion 480.

Youngren, J. (2005). Improving Stride Mechanics. In K. Beck (Ed.) Run Strong (pp. 8-24). Champaign, IL: Human Kinetics, Inc. 
Supplementary data 


\begin{tabular}{|c|c|c|c|c|c|c|c|c|c|c|c|c|c|c|c|c|}
\hline \multirow{3}{*}{. } & Q & $\begin{array}{l}\vec{\Delta} \\
\dot{0}\end{array}$ & & & 宮 & & $\begin{array}{l}-1 \\
\stackrel{8}{0} \\
\dot{v}\end{array}$ & & $\begin{array}{l}\vec{\Delta} \\
\dot{0} \\
\dot{v}\end{array}$ & & $\begin{array}{l}-1 \\
\dot{0} \\
\dot{v}\end{array}$ & & $\begin{array}{l}-1 \\
\stackrel{8}{0} \\
\dot{0}\end{array}$ & & $\begin{array}{l}\overrightarrow{0} \\
\dot{0} \\
\dot{v}\end{array}$ & \\
\hline & 山् & $\begin{array}{l}\Delta \\
0 \\
0\end{array}$ & & & 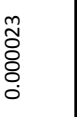 & & 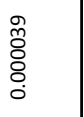 & & 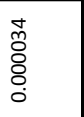 & & $\begin{array}{l}\tilde{m} \\
0 \\
0 \\
0\end{array}$ & & $\begin{array}{l}\infty \\
\stackrel{1}{0} \\
0 \\
0\end{array}$ & & $\begin{array}{l}\text { O̊ } \\
\text { O̊ } \\
0\end{array}$ & \\
\hline & مـ & $\begin{array}{l}\text { t. } \\
\text { Oे } \\
\text { i. }\end{array}$ & & & $\begin{array}{l}\text { so } \\
\vdots \\
\vdots\end{array}$ & & $\begin{array}{l}\text { ป̃ } \\
\text { ठ̊ } \\
0\end{array}$ & & 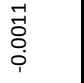 & & 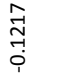 & & $\begin{array}{l}\hat{\infty} \\
\stackrel{0}{0} \\
0\end{array}$ & & 궁 & \\
\hline \multirow{3}{*}{ 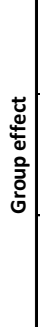 } & 2 & $\begin{array}{l}\overrightarrow{00} \\
\stackrel{\leftrightarrow}{0}\end{array}$ & & & 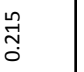 & & 令 & & 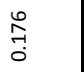 & & $\begin{array}{l}\text { ్ֻర } \\
\stackrel{0}{0}\end{array}$ & & $\begin{array}{l}\stackrel{\leftrightarrow}{\infty} \\
0 \\
0\end{array}$ & & 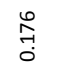 & \\
\hline & 山् & $\stackrel{m}{o}$ & & & ֻ̊ & & $\begin{array}{l}\infty \\
\stackrel{\infty}{0} \\
\stackrel{0}{0}\end{array}$ & & $\begin{array}{l}\text { oे } \\
\text { ¿ }\end{array}$ & & $\begin{array}{l}\stackrel{\Omega}{\Omega} \\
\stackrel{1}{i} \\
0\end{array}$ & & $\begin{array}{l}\infty \\
\stackrel{0}{0} \\
\stackrel{0}{0} \\
0\end{array}$ & & 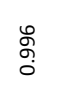 & \\
\hline & مـ & \multicolumn{2}{|l|}{$\stackrel{\text { I }}{\rightarrow}$} & \multicolumn{2}{|c|}{$\begin{array}{l}\hat{o} \\
\text { i }\end{array}$} & \multicolumn{2}{|r|}{$\begin{array}{l}\text { \& } \\
\stackrel{0}{0} \\
0 \\
i\end{array}$} & \multicolumn{2}{|r|}{ 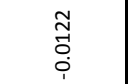 } & \multicolumn{2}{|r|}{ 尽 } & \multicolumn{2}{|r|}{$\begin{array}{l}0 \\
\stackrel{0}{0} \\
0 \\
0\end{array}$} & \multicolumn{3}{|c|}{ 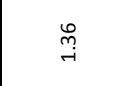 } \\
\hline ذ్తి & 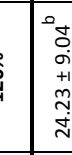 & 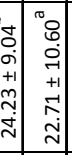 & 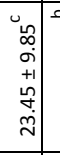 & 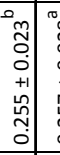 & 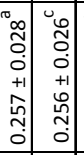 & 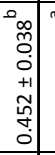 & 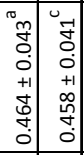 & \begin{tabular}{l|l|} 
& \\
& \\
0 \\
0 \\
0 \\
+1 \\
0 \\
0 \\
0 \\
0 \\
\end{tabular} & 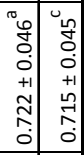 & 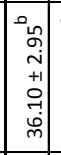 & 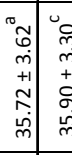 & 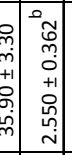 & 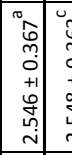 & 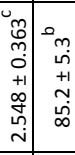 & 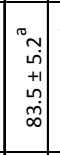 & $\begin{array}{c}u_{m} \\
i \\
+ \\
+1 \\
m \\
\dot{\infty} \\
\dot{D}\end{array}$ \\
\hline ذ్ & \begin{tabular}{l}
$\tilde{N}$ \\
$o$ \\
+1 \\
\multirow{f}{f}{} \\
$\dot{\sim}$
\end{tabular} & 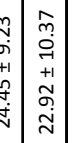 & \begin{tabular}{l|l}
$\vec{D}$ & \\
$\sigma$ & \\
+1 & \\
$\omega$ & \\
$\tilde{\nu}$ &
\end{tabular} & 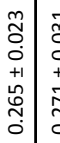 & 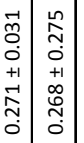 & 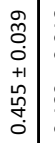 & \begin{tabular}{l|l}
0 & 0 \\
0 & 0 \\
0 & 0 \\
0 & 0 \\
+1 & +1 \\
0 & 1 \\
0 & 0 \\
0 & $f$ \\
0 & 0
\end{tabular} & 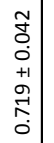 & 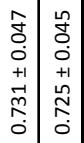 & 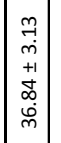 & $\begin{array}{l}2 \\
\dot{+} \\
+1 \\
+1 \\
o \\
\dot{m} \\
\dot{m}\end{array}$ & 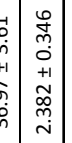 & 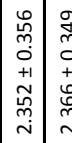 & 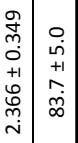 & \begin{tabular}{l|} 
\\
\multirow{n}{*}{} \\
+1 \\
+1 \\
$\dot{\Delta}$ \\
$\infty$ \\
\end{tabular} & $\begin{array}{l}\overrightarrow{-1} \\
\dot{n} \\
+1 \\
0 \\
\ddot{\infty} \\
\infty\end{array}$ \\
\hline ذ్తి & $\begin{array}{l}\tilde{q} \\
\sigma \\
+1 \\
+ \\
\dot{\alpha} \\
\dot{\sim}\end{array}$ & 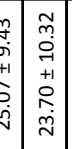 & $\begin{array}{l}\infty \\
\infty \\
\sigma \\
+1 \\
\hat{n} \\
\stackrel{m}{\dot{d}}\end{array}$ & 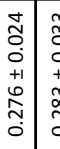 & 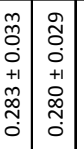 & 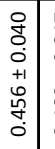 & 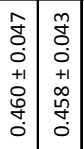 & \begin{tabular}{l|l} 
& \\
0 \\
0 \\
0 \\
+1 \\
$\tilde{N}$ \\
$\tilde{n}$ \\
0
\end{tabular} & 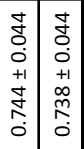 & \begin{tabular}{|l|}
$\tilde{7}$ \\
$\dot{m}$ \\
+1 \\
$\stackrel{2}{2}$ \\
$\hat{\dot{m}}$ \\
\end{tabular} & $\begin{array}{l}m \\
m \\
\dot{p} \\
+1 \\
\stackrel{-1}{7} \\
\infty \\
m\end{array}$ & 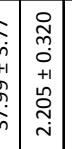 & 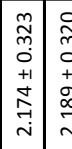 & 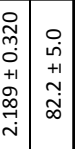 & \begin{tabular}{c|}
$\hat{\dot{t}}$ \\
+1 \\
0 \\
$\dot{\dot{H}}$ \\
\end{tabular} & $\begin{array}{c}\sigma \\
\dot{+} \\
+1 \\
\omega \\
\dot{j} \\
\infty\end{array}$ \\
\hline ڤें & 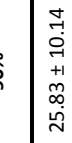 & 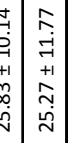 & 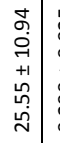 & 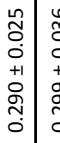 & 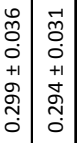 & $\begin{array}{l}0 \\
0 \\
0 \\
0 \\
+1 \\
n \\
\tilde{f} \\
0 \\
0\end{array}$ & 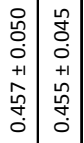 & 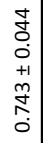 & 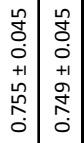 & 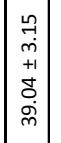 & 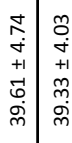 & 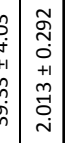 & 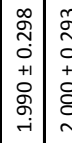 & 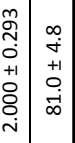 & $\begin{array}{l}r \\
\dot{f} \\
+1 \\
\hat{\sigma} \\
\dot{r}\end{array}$ & $\begin{array}{l}\infty \\
\dot{+} \\
+1 \\
+ \\
\dot{0} \\
\dot{\infty}\end{array}$ \\
\hline ذें & 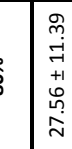 & 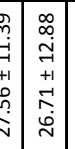 & 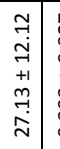 & 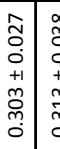 & 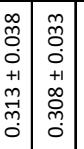 & \begin{tabular}{l|l}
$g$ \\
0 \\
0 \\
0 \\
+1 \\
$o$ \\
$o$ \\
\multirow{J}{0}{} \\
0
\end{tabular} & \begin{tabular}{l|l}
$g$ & \multicolumn{2}{c}{} \\
0 & 0 \\
0 & 0 \\
0 & 0 \\
+1 & + \\
$o$ & 0 \\
$f$ & $f$ \\
0 & 0 \\
\end{tabular} & 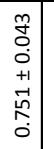 & 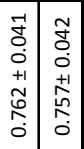 & \begin{tabular}{|c|}
$\vec{m}$ \\
$\tilde{m}$ \\
+1 \\
$o$ \\
$\dot{q}$ \\
$\dot{q}$ \\
\end{tabular} & 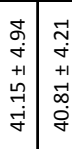 & 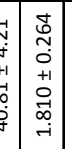 & 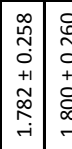 & 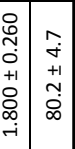 & \begin{tabular}{|c|}
$\mathcal{N}$ \\
$\stackrel{+}{+}$ \\
+1 \\
$\dot{+}$ \\
$\dot{T}$ \\
\end{tabular} & 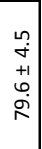 \\
\hline$=$ & F & $\mathscr{f}$ & \&: & 7 & \begin{tabular}{l|l|}
8 & 8
\end{tabular} & $F$ & \& 8 & \& & : 8 & $F$ & $\mathscr{f}$ & 7 & $\mathscr{f}$ & \begin{tabular}{l|l} 
& 8
\end{tabular} & $f$ & 8 \\
\hline ⿳亠े冖े & $\bar{\alpha}$ & 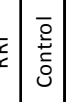 & 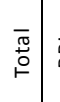 & $\bar{\alpha}$ & 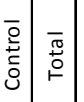 & $\bar{\propto}$ & 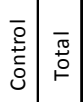 & $\bar{\alpha}$ & 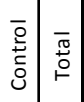 & $\bar{\alpha}$ & $\begin{array}{l}\overline{0} \\
\stackrel{0}{+} \\
\dot{0} \\
0\end{array}$ & $\overline{\frac{\alpha}{\propto}}$ & 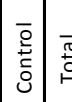 & $\begin{array}{l}\overline{\underline{g}} \\
\stackrel{0}{\circ} \\
\vdash\end{array}$ & \begin{tabular}{|l|} 
\\
\\
0 \\
0 \\
0 \\
0
\end{tabular} & 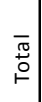 \\
\hline $\begin{array}{l}\frac{0}{0} \\
\frac{0}{9} \\
\frac{70}{7}\end{array}$ & & $\bar{n}$ & & & 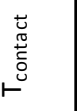 & & & & 总 & & 㟔 & & 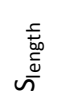 & & 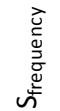 & \\
\hline$\frac{\frac{n}{n}}{\frac{3}{\pi}}$ & & & & & & & & & $\frac{d}{4}$ & & & & & & & \\
\hline
\end{tabular}




\begin{tabular}{|c|c|c|c|c|c|c|c|c|c|c|c|c|c|c|c|c|c|}
\hline \multirow{3}{*}{ 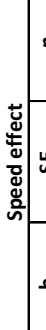 } & \multicolumn{3}{|c|}{$\begin{array}{l}\overrightarrow{0} \\
\dot{0} \\
\dot{v}\end{array}$} & \multicolumn{2}{|c|}{$\begin{array}{l}\vec{\Delta} \\
0 \\
\dot{v}\end{array}$} & \multicolumn{2}{|r|}{$\begin{array}{l}\overrightarrow{0} \\
\text { Oे } \\
\text { v }\end{array}$} & \multicolumn{3}{|c|}{ 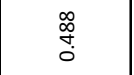 } & \multicolumn{2}{|c|}{ 茴 } & \multicolumn{2}{|c|}{$\begin{array}{l}\infty \\
\stackrel{\infty}{0} \\
0\end{array}$} & \multicolumn{3}{|c|}{\begin{tabular}{l} 
ơ \\
\multirow{0}{*}{}
\end{tabular}} \\
\hline & & $\begin{array}{l}\hat{O} \\
\stackrel{0}{0} \\
0\end{array}$ & & & స్̃̄ & & \begin{tabular}{l}
\multirow{Z}{*}{} \\
$\stackrel{0}{0}$ \\
0
\end{tabular} & & $\begin{array}{l}0 \\
\stackrel{0}{0} \\
0 \\
0\end{array}$ & & $\begin{array}{l}m \\
0 \\
0\end{array}$ & & & 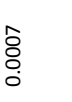 & & $\begin{array}{l}\hat{\circ} \\
\text { ठ } \\
\text {. }\end{array}$ & \\
\hline & & $\begin{array}{l}\stackrel{0}{0} \\
\dot{0} \\
\text { i. }\end{array}$ & & & 范 & & 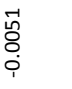 & & $\begin{array}{l}\text { n̊ } \\
0 \\
0 \\
\end{array}$ & & $\begin{array}{l}\text { ồ } \\
\text { ò } \\
\text { in }\end{array}$ & & & 足 & & $\begin{array}{l}n \\
0 \\
0 \\
i\end{array}$ & \\
\hline 2 & & $\begin{array}{c}\infty \\
\stackrel{\infty}{0} \\
0\end{array}$ & & & 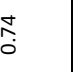 & & $\begin{array}{c}\text { 芯 } \\
\text { o. }\end{array}$ & & 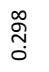 & & $\stackrel{\infty}{\stackrel{\infty}{a}}$ & & & ֶֻ & & 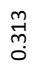 & \\
\hline & & 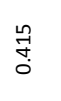 & & & & & 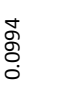 & & $\begin{array}{l}\overrightarrow{\mathcal{Z}} \\
\stackrel{\text { Oे }}{0}\end{array}$ & & 㟔 & & & $\begin{array}{l}\overrightarrow{\tilde{S}} \\
0 \\
0\end{array}$ & & $\begin{array}{l}\text { Iี } \\
\text { Oे } \\
0\end{array}$ & \\
\hline 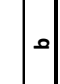 & & $\begin{array}{l}\overrightarrow{0} \\
00 \\
0 \\
i\end{array}$ & & & 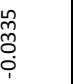 & & 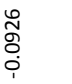 & & 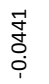 & & 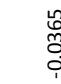 & & & 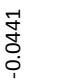 & & 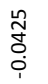 & \\
\hline ذ્స్ & 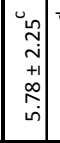 & 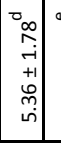 & 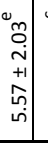 & 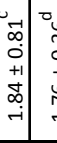 & 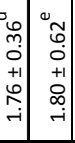 & \begin{tabular}{l|l}
0 & \multicolumn{1}{r}{} \\
0 & \\
0 & \\
+1 & \\
0 & \\
0 & \\
-1 &
\end{tabular} & 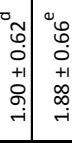 & \begin{tabular}{c}
0 \\
\multirow{N}{*}{} \\
0 \\
+1 \\
0 \\
0 \\
-1
\end{tabular} & 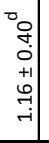 & 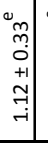 & 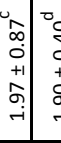 & 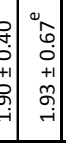 & 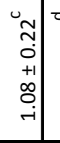 & 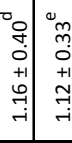 & $\mid$\begin{tabular}{c}
0 \\
\multirow{N}{*}{} \\
0 \\
+1 \\
0 \\
0 \\
- \\
-1
\end{tabular} & 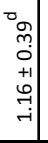 & 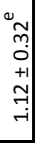 \\
\hline ذ্ট్తి & 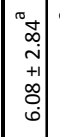 & 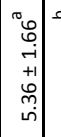 & 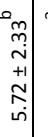 & 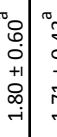 & 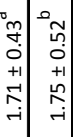 & \begin{tabular}{c|c} 
& \\
$\infty$ & 0 \\
0 & \\
0 & \\
+1 & \\
0 & \\
$-i$ &
\end{tabular} & 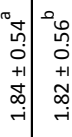 & 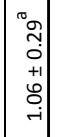 & 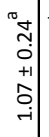 & \begin{tabular}{l|}
0 \\
$\sim$ \\
0 \\
+1 \\
+1 \\
0 \\
-1
\end{tabular} & 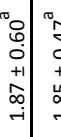 & 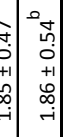 & 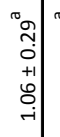 & 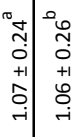 & 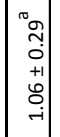 & 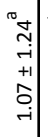 & 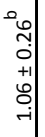 \\
\hline ذి ఫે & 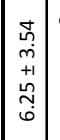 & $\left|\begin{array}{c}0 \\
0 \\
0 \\
0 \\
+1 \\
0 \\
0 \\
0 \\
0\end{array}\right|$ & $\begin{array}{l}0 \\
0 \\
\dot{m} \\
+1 \\
+1 \\
f \\
0\end{array}$ & 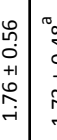 & 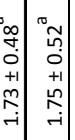 & \begin{tabular}{l|l}
$g$ & 0 \\
0 & \\
+1 & \\
& \\
$-i$ &
\end{tabular} & 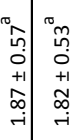 & $\mid$\begin{tabular}{c|}
1 \\
0 \\
0 \\
+1 \\
0 \\
$o$ \\
0 \\
0
\end{tabular} & 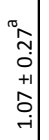 & 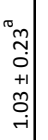 & 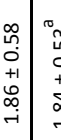 & 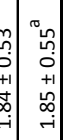 & \begin{tabular}{l|l}
7 & \\
0 \\
0 \\
+1 \\
$\infty$ \\
$o$ \\
0
\end{tabular} & 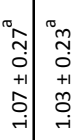 & $\begin{array}{l}7 \\
7 \\
0 \\
+1 \\
\infty \\
0 \\
0 \\
0\end{array}$ & 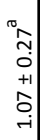 & $\begin{array}{c}\widetilde{n} \\
\\
0 \\
+1 \\
\tilde{+1} \\
\tilde{-} \\
-1\end{array}$ \\
\hline ถัँ & 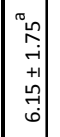 & 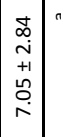 & 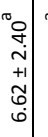 & 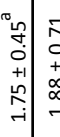 & 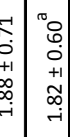 & 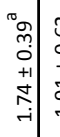 & 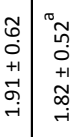 & $\mid$\begin{tabular}{c|}
0 \\
0 \\
-1 \\
0 \\
+1 \\
+1 \\
0 \\
0
\end{tabular} & 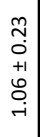 & 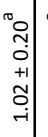 & 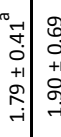 & 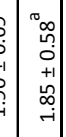 & $\begin{array}{c}0 . \\
0 \\
0 \\
0 \\
+1 \\
\vdots \\
0 \\
0\end{array}$ & 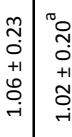 & $\mid \begin{array}{c}0 \\
0 \\
0 \\
0 \\
+1 \\
0 \\
0 \\
0\end{array}$ & $\begin{array}{l}\tilde{D} \\
0 \\
+1 \\
\varnothing \\
\varnothing \\
\dot{r}\end{array}$ & 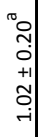 \\
\hline ذి๋ & $\begin{array}{l}\stackrel{0}{L} \\
\stackrel{n}{n} \\
+1 \\
\stackrel{+}{n} \\
\end{array}$ & 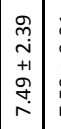 & 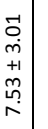 & 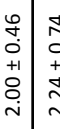 & 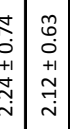 & 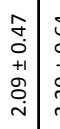 & 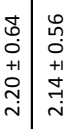 & 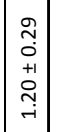 & 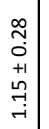 & 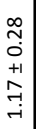 & 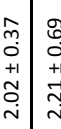 & 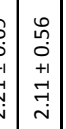 & \begin{tabular}{c|c}
$\stackrel{2}{2}$ \\
0 \\
+1 \\
+1 \\
$\stackrel{\sim}{+}$ \\
-1
\end{tabular} & 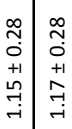 & 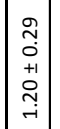 & 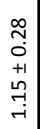 & 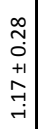 \\
\hline$=$ & 8 & $q$ & ৪ & 8 & 6 \& & 8 & ச & 7 & 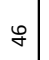 & ৪ & \& & ৪ & 8 & 8 & F & \& & 8 \\
\hline 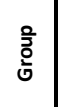 & $\bar{\propto}$ & 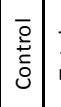 & 哭 & $\bar{\alpha}$ & 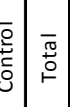 & $\overline{\widetilde{q}}$ & 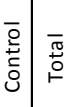 & $\bar{\propto}$ & 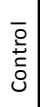 & $\begin{array}{l}\bar{\pi} \\
\stackrel{0}{0} \\
\circ\end{array}$ & \begin{tabular}{l|l}
$\bar{\alpha}$ & $\bar{g}$ \\
$\propto$ & \\
$\vdots$
\end{tabular} & 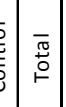 & $\bar{c}$ & 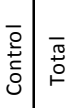 & $\bar{c}$ & $\begin{array}{l}\overline{0} \\
\stackrel{0}{0} \\
0 \\
0\end{array}$ & $\begin{array}{l}\bar{\Phi} \\
\stackrel{D}{\circ} \\
\stackrel{\circ}{\circ}\end{array}$ \\
\hline $\begin{array}{l}\frac{0}{\frac{0}{0}} \\
\frac{0}{50} \\
\frac{5}{5}\end{array}$ & & $\bar{n}$ & & & $\underset{\widetilde{J}}{\mathbb{J}}$ & & 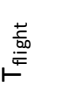 & & 总 & & 㟧 & & & 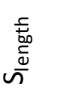 & & 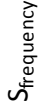 & \\
\hline$\frac{\frac{n}{n}}{\frac{n}{20}}$ & & & & & & & & & z & & & & & & & & \\
\hline
\end{tabular}




\begin{tabular}{|c|c|c|c|c|c|c|c|c|c|c|c|c|c|c|c|c|c|c|c|}
\hline \multirow{3}{*}{ 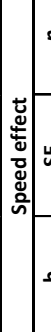 } & \multicolumn{3}{|c|}{$\begin{array}{l}\text { ̊̊ } \\
\text { م }\end{array}$} & \multicolumn{3}{|c|}{$\begin{array}{l}\overrightarrow{8} \\
\dot{0}\end{array}$} & \multicolumn{2}{|c|}{ 晩 } & \multicolumn{3}{|c|}{$\stackrel{\text { : }}{\circ}$} & \multicolumn{2}{|c|}{$\begin{array}{l}\text { J } \\
0 \\
0\end{array}$} & \multicolumn{3}{|c|}{ o̊ } & \multicolumn{3}{|c|}{ 亗 } \\
\hline & & 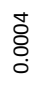 & & & $\begin{array}{l}\text { Oे } \\
\text { ¿. }\end{array}$ & & & مِّ & & 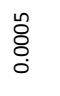 & & 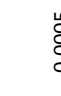 & & & 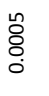 & & & 岁 & \\
\hline & & 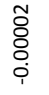 & & & 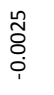 & & & $\begin{array}{l}\text { ồ } \\
\text { in }\end{array}$ & & 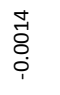 & & $\varliminf_{0}$ & & & 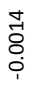 & & & 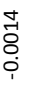 & \\
\hline$=$ & & $\begin{array}{l}\text { ơ } \\
0 \\
0\end{array}$ & & & $\begin{array}{l}\tilde{0} \\
0 \\
0\end{array}$ & & & 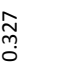 & & 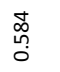 & & $\frac{\pi}{2}$ & ș & & $\begin{array}{l}\text { 总 } \\
\text { on }\end{array}$ & & & 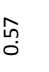 & \\
\hline 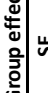 & & 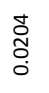 & & & \begin{tabular}{l}
\multirow{0}{0}{} \\
$\stackrel{0}{0}$ \\
0
\end{tabular} & & & סֶ & & 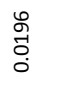 & & 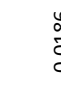 & & & 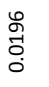 & & & 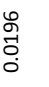 & \\
\hline . & & $\begin{array}{l}\tilde{J} \\
0 \\
0\end{array}$ & & & $\begin{array}{l}\text { ô } \\
\hat{8} \\
0 \\
1\end{array}$ & & & $\begin{array}{l}\hat{\sigma} \\
\text { ò } \\
\\
\end{array}$ & & $\begin{array}{l}\text { o̊ } \\
\text { O. } \\
0\end{array}$ & & L & & & $\begin{array}{l}\infty \\
\stackrel{0}{0} \\
0 \\
0\end{array}$ & & & 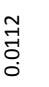 & \\
\hline ఫ્సે & $\begin{array}{c}0 \\
n \\
0 \\
0 \\
+1 \\
n \\
n \\
0 \\
0\end{array}$ & $\mid$ & \begin{tabular}{c|}
0 \\
$\mu$ \\
0 \\
0 \\
+1 \\
+1 \\
\multirow{1}{0}{} \\
0 \\
0
\end{tabular} & 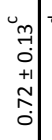 & 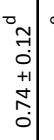 & | & 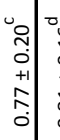 & 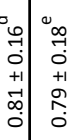 & $\mid$\begin{tabular}{c|}
0 \\
0 \\
0 \\
0 \\
+1 \\
0 \\
0 \\
0 \\
0
\end{tabular} & \begin{tabular}{c|c}
$\sigma_{0}$ & 0 \\
0 & 0 \\
0 & \\
+1 & 0 \\
$\Omega$ & \\
0 &
\end{tabular} & $\begin{array}{l}0 \\
7 \\
0 \\
+1 \\
\infty \\
0 \\
0\end{array}$ & \begin{tabular}{l|l} 
& 0 \\
-1 & 0 \\
0 & \\
+1 & \\
0 & \\
0 &
\end{tabular} & 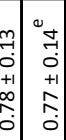 & $\mid$\begin{tabular}{c|}
0 \\
0 \\
0 \\
0 \\
+1 \\
0 \\
0 \\
0
\end{tabular} & \begin{tabular}{c|}
${ }_{0}$ \\
0 \\
0 \\
+1 \\
0 \\
0 \\
0
\end{tabular} & 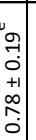 & \begin{tabular}{l|l} 
& \\
0 & \\
0 \\
+1 \\
+1 \\
0 \\
0 \\
0
\end{tabular} & \begin{tabular}{c|c} 
& \\
0 & \\
0 & \\
0 & \\
+1 & \\
$\Omega$ & \\
0 &
\end{tabular} & 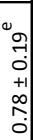 \\
\hline ఫ্ & $\begin{array}{c}0 \\
- \\
0 \\
0 \\
+1 \\
5 \\
0 \\
0\end{array}$ & $\mid$\begin{tabular}{c|}
0 \\
0 \\
0 \\
0 \\
$0+1$ \\
0 \\
0 \\
0 \\
0
\end{tabular} & 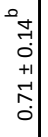 & \begin{tabular}{c|} 
\\
0 \\
0 \\
0 \\
+1 \\
0 \\
0 \\
0 \\
0
\end{tabular} & \begin{tabular}{l|l}
0 \\
7 \\
0 \\
+1 \\
0 \\
0 \\
0
\end{tabular} & $\begin{array}{c}0 \\
- \\
- \\
0 \\
+1 \\
+1 \\
\\
0 \\
0\end{array}$ & \begin{tabular}{c|c}
$\pi$ & \\
-1 & \\
0 & \\
+1 & \\
0 & \\
0 & \\
0 &
\end{tabular} & 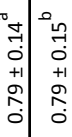 & \begin{tabular}{|c|}
0 \\
0 \\
0 \\
0 \\
+1 \\
0 \\
0 \\
0 \\
0
\end{tabular} & 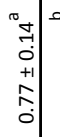 & 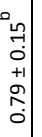 & \begin{tabular}{c|c} 
& 0 \\
0 & \\
0 & \\
+1 & \\
0 & \\
0 &
\end{tabular} & 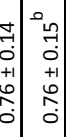 & $\begin{array}{c}0 \\
0 \\
7 \\
0 \\
+1 \\
0 \\
0 \\
0 \\
0\end{array}$ & \begin{tabular}{c|}
0 \\
- \\
0 \\
0 \\
+1 \\
\\
0 \\
0
\end{tabular} & 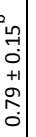 & \begin{tabular}{l|l} 
& \\
7 \\
0 \\
+1 \\
+1 \\
0 \\
0
\end{tabular} & 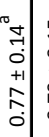 & \begin{tabular}{l}
$n$ \\
\multicolumn{1}{c}{} \\
0 \\
+1 \\
2 \\
0 \\
0
\end{tabular} \\
\hline ఫ్తి & 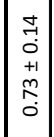 & $\mid$\begin{tabular}{c|c}
$\pi$ \\
0 \\
0 \\
0 \\
+1 \\
0 \\
0 \\
0
\end{tabular} & 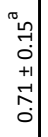 & $\begin{array}{l}\stackrel{+}{-} \\
\dot{0} \\
+1 \\
\stackrel{n}{n} \\
\dot{0}\end{array}$ & \begin{tabular}{l|} 
\\
7 \\
0 \\
+1 \\
+1 \\
0 \\
0
\end{tabular} & $\begin{array}{l}0 \\
m \\
0 \\
0 \\
+1 \\
n \\
0 \\
0\end{array}$ & 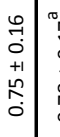 & 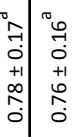 & $\begin{array}{l}m \\
m \\
0 \\
+1 \\
+1 \\
0 \\
0 \\
0\end{array}$ & 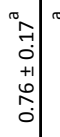 & 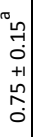 & \begin{tabular}{c|c}
0 & 0 \\
- & \\
0 \\
+1 \\
$n$ \\
$\hat{n}$ & \\
0 &
\end{tabular} & 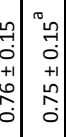 & $\begin{array}{c}m \\
n \\
0 \\
+1 \\
+1 \\
\hat{n} \\
0 \\
0\end{array}$ & \begin{tabular}{l|}
0 \\
7 \\
0 \\
+1 \\
0 \\
0 \\
0
\end{tabular} & 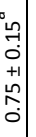 & 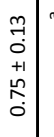 & \begin{tabular}{l}
0 \\
\multirow{2}{0}{} \\
0 \\
+1 \\
0 \\
0 \\
0 \\
0
\end{tabular} & 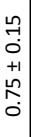 \\
\hline ઠें & $\begin{array}{c}{ }^{0} m \\
\stackrel{m}{0} \\
0 \\
+1 \\
n \\
0 \\
0\end{array}$ & 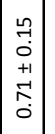 & 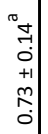 & 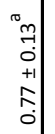 & $\begin{array}{c}m \\
\stackrel{1}{0} \\
0 \\
+1 \\
\hat{~} \\
0\end{array}$ & 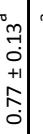 & 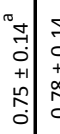 & 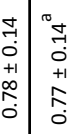 & \begin{tabular}{|c|}
$0^{n}$ \\
7 \\
0 \\
0 \\
+1 \\
$\hat{1}$ \\
0 \\
0
\end{tabular} & 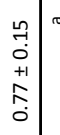 & \begin{tabular}{l}
0 \\
\multirow{2}{*}{} \\
0 \\
+1 \\
+1 \\
$\hat{0}$ \\
0
\end{tabular} & 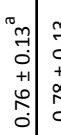 & \begin{tabular}{c|c}
$n$ & 0 \\
0 & 0 \\
0 \\
+1 \\
0 \\
0 & +1 \\
0 & +1 \\
0 & 0
\end{tabular} & \begin{tabular}{|c|}
${ }^{0}$ \\
7 \\
0 \\
0 \\
+1 \\
$\hat{1}$ \\
0 \\
0
\end{tabular} & 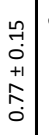 & 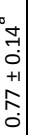 & 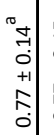 & 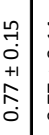 & 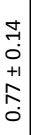 \\
\hline ळें & 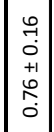 & $\left|\begin{array}{l}0 \\
0 \\
0 \\
+1 \\
+1 \\
0 \\
0\end{array}\right|$ & 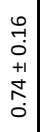 & \begin{tabular}{c|c}
$n$ \\
$a$ \\
0 \\
+1 \\
0 \\
$\infty$ \\
0 \\
0
\end{tabular} & $\begin{array}{c}n \\
\stackrel{1}{0} \\
0 \\
+1 \\
0 \\
\infty \\
0 \\
0\end{array}$ & 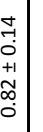 & 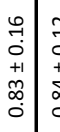 & 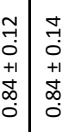 & \begin{tabular}{|c|} 
\\
0 \\
0 \\
0 \\
+1 \\
$\infty$ \\
$\infty$ \\
0 \\
0
\end{tabular} & 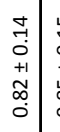 & 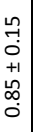 & 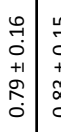 & 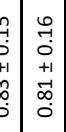 & \begin{tabular}{|c|}
$n$ \\
0 \\
0 \\
+1 \\
$\infty$ \\
$\infty$ \\
0 \\
0 \\
\end{tabular} & 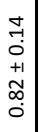 & $\begin{array}{c}n \\
0 \\
0 \\
+1 \\
0 \\
0 \\
0 \\
0\end{array}$ & \begin{tabular}{l}
$n$ \\
\multirow{2}{*}{} \\
0 \\
+1 \\
$\infty$ \\
$\infty$ \\
0 \\
0
\end{tabular} & 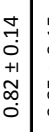 & 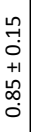 \\
\hline$=$ & F & of & 8 & 寸 & $f$ & ৪। & 7 & $\begin{array}{lll}8 & 8\end{array}$ & $|7|$ & \& & 8 & 7 & 88 & F & f & 8 & F & f & \& \\
\hline $\begin{array}{l}\frac{2}{3} \\
\frac{2}{0}\end{array}$ & $\overline{\widetilde{\varkappa}}$ & $\begin{array}{l}\overline{0} \\
\stackrel{0}{0} \\
0 \\
0\end{array}$ & $\begin{array}{l}\bar{c} \\
\stackrel{5}{\circ} \\
\stackrel{\circ}{\leftarrow}\end{array}$ & $\bar{\alpha} \frac{\bar{\alpha}}{\alpha}$ & 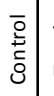 & $\begin{array}{l}\overrightarrow{\widetilde{v}} \\
\stackrel{\circ}{\circ}\end{array}$ & $\overline{\mathscr{\kappa}}$ & 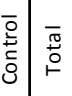 & $\overline{\propto \mu}$ & 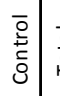 & $\begin{array}{l}\overline{\widetilde{\pi}} \\
\stackrel{\circ}{\circ}\end{array}$ & $\frac{\bar{\alpha}}{\propto}$ & $\begin{array}{l}\overline{\widetilde{\pi}} \\
\stackrel{\circ}{\circ}\end{array}$ & $\overline{\frac{\alpha}{\propto}}$ & $\begin{array}{l}\overline{0} \\
\stackrel{0}{0} \\
\text { d }\end{array}$ & 离 & $\overline{\widetilde{\varkappa}}$ & $\begin{array}{l}\overline{0} \\
\stackrel{0}{t} \\
\text { ¿ }\end{array}$ & $\begin{array}{l}\bar{\sigma} \\
\stackrel{0}{\circ} \\
\stackrel{\circ}{\circ}\end{array}$ \\
\hline $\begin{array}{l}\frac{0}{0} \\
\frac{0}{\frac{0}{5}} \\
\frac{5}{5}\end{array}$ & & $\bar{n}$ & & & 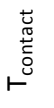 & & & 莒 & & 总 & & $\stackrel{\mathrm{L}}{\mathrm{c}}$ & 5 & & $\begin{array}{l}\frac{5}{\mathrm{t}_{0}} \\
\text { ज光 }\end{array}$ & & & 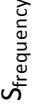 & \\
\hline$\frac{\frac{n}{n}}{\frac{n}{\pi}} \frac{5}{\frac{5}{\alpha}}$ & & & & & & & & & & 虫 & & & & & & & & & \\
\hline
\end{tabular}

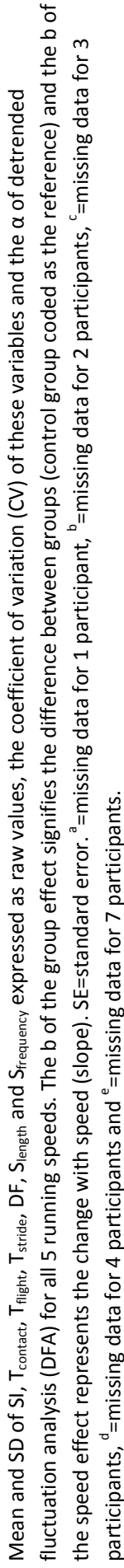




\section{Chapter 5}

\section{The Effect of Fatigue and Shoe Type on Running Biomechanics from Pressure Data.}

Robert Mann, Laurent Malisoux, Axel Urhausen, Andrew Statham, Kenneth Meijer and Daniel Theisen

Gait \& Posture, In press. 


\section{Abstract}

We aimed to observe differences in running style parameters and the stride-to-stride coefficient of variation (CV) and correlative patterns using detrended fluctuation analysis (DFA) between conventional and first-time minimalistic shoe use. We also aimed to study the effect of fatigue on these parameters. 26 recreational runners were tested using a pressure insole device on a treadmill whilst wearing conventional (CONV) and minimalistic (MIN) shoes. They then performed a prolonged running bout simulating a fatiguing training session, before being tested a second time in both shoe types. Average values of strike index (initial ground contact point on the footsole expressed as a percentage of total sole length) were not significantly different between CONV [25.7 $\pm 14.6 \%$ (unfatigued), $23.1 \pm 11.1 \%$ (fatigued)] and MIN [28.9 \pm $19.1 \%$ (unfatigued), $26.7 \pm 17.6 \%$ (fatigued)] ( $p=0.501$ ). The fatigued state also yielded a similar strike index compared to the unfatigued state $(p=0.661)$. An overall trend in decreased inter-stride correlative patterns of strike index was observed in MIN compared to CONV ( $p=0.075)$. No differences in contact time, flight time, stride time, duty factor, stride length and stride frequency were found between shoe types. A trend in reduced flight time $(p=0.078)$ and therefore increased duty factor $(p=0.053)$ was observed due to fatigue. We conclude that in a recreational runners, no meaningful, acute adaptation in running style occurs as a result of first-time MIN use. Similarly, runners were able to maintain their running style after a prolonged running bout.

\section{Key words}

Pressure insole, running style, foot strike pattern, detrended fluctuation analysis 


\section{Introduction}

Shoe type has been thought to affect the running style, and a handful of studies comparing minimalistic (MIN - low profile, flexible sole, reduced or zero drop, wide toe-box and no motion control or heavy cushioning) and conventional (CONV) running shoes have been published (Bonacci et al., 2013; Squadrone \& Gallozzi, 2009; Willson et al., 2014; Willy \& Davis, 2014). Popular belief is that MIN encourage a non-rearfoot strike (non-RFS) running pattern (Lieberman, 2012), thereby lowering vertical loading rates which have been associated with the occurrence of injuries (Zadpoor \& Nikooyan, 2011). However, Willy et al. (2014) observed higher vertical loading rates when MIN were used compared to CONV, and interestingly a more dorsiflexed foot at footstrike (Willy \& Davis, 2014). Similarly, a study comparing the ground reaction forces between racing flats and CONV found that loading rates and peak vertical impact force were significantly higher when male runners used racing flats (Logan et al., 2010). A shorter

stride length $\left(S_{\text {length }}\right)$ and higher stride frequency $\left(S_{\text {frequency }}\right)$ have been found with MIN compared to CONV (Bonacci et al., 2013). Squadrone \& Gallozzi (2009) found a significantly reduced contact time $\left(T_{\text {contact }}\right)$ and increased strike index (SI) with MIN (Squadrone \& Gallozzi, 2009). SI is a continuous measure of strike pattern expressing the initial contact point on the foot sole as a percentage of the total sole length, with $0 \%$ at the heel (Cavanagh \& Lafortune, 1980; Mann et al., 2014). In contrast to the abovementioned studies (Bonacci et al., 2013; Logan et al., 2010; Willy \& Davis, 2014), Squadrone \& Gallozzi (2009) tested habitually barefoot runners, a minority among modern runners. Indeed it has been observed that $88-94 \%$ of recreational, shod runners adopt a rearfoot strike (RFS) pattern (Kasmer et al., 2013; Larson et al., 2011). Therefore a consensus on the effect of shoe type on running style, especially foot strike pattern and temporal parameters, has not yet been reached.

The effect of physical fatigue on running style also remains elusive. Fatigue due to training and extended bouts of running has been theorised as a potential mechanism of injury (Christina et al., 2001; Clansey et al., 2012; Derrick et al., 2002; Gerlach et al., 2005). Researchers have looked into identifying biomechanical differences between measurements taken before and after a fatiguing running bout, yielding conflicting results for vertical loading rate (Christina et al., 2001; Gerlach et al., 2005), S Iength (Clansey et al., 2012; Willson \& Kernozek, 1999) and $\mathrm{S}_{\text {frequency }}$ (Morin et al., 2011; Willson \& Kernozek, 1999) for example. Willems et al. (2012) concluded that several plantar pressure patterns change as a result of a $20 \mathrm{~km}$ race and could contribute to the development of injuries (Willems et al., 2012), whereas Alfuth \& Rosenbaum (2011) found no differences in plantar pressure measurements before and after a $10 \mathrm{~km}$ run (Alfuth \& Rosenbaum, 2011). These conflicting findings could be due to the variations in protocols used to fatigue the runners. The importance of recreating typical training 
conditions (i.e. duration and intensity) has been highlighted and recommended as these are the conditions during which most injuries occur (Dierks et al., 2010).

Our main aim was to observe any differences in $\mathrm{SI}$ and spatiotemporal parameters between first-time MIN, and CONV use. A second aim was to identify any fatigue effect, induced by a prolonged running bout designed to mimic typical running activity, on running style parameters. Finally, we tested the interaction of the shoe type and fatigue and its influence on running style. We hypothesized that running in MIN would increase the SI whereas fatigue would decrease it.

\section{Methods}

\section{Participants}

A sample size calculation with a power of $80 \%$, a significance level set at $p=0.05$ and an expected SI mean difference based on minimal detectible change of 4.9\% (Mann et al., 2014) between shoe conditions yielded a required 20 participants for this study. Runners over the age of 18 , injury-free during the previous 12 months, running a minimum of twice a week on average and with an average session duration of $\geq 45$ minutes with CONV were included. Runners were contacted via leaflets at races, sport shops and public training locations as well as through direct contact with participants of previous cohort studies from our laboratory. Runners already familiar with MIN, unfamiliar with treadmill running, deemed unfit to undertake strenuous exercise (by way of a standardised cardiovascular screening questionnaire) or requiring orthopaedic insoles for running were excluded. Written informed consent was acquired; the study was approved by the National Research Ethics Committee of Luxembourg (CNER N: 201403/06).

\section{Protocol}

Participants declared their preferred running speed (PRS) defined as the speed they could maintain for a typical running session, and average session duration over the last 12 months. They provided details regarding past and current running shoe use. All testing was performed on a treadmill (Woodway, PPS70 Plus, Germany) in two different shoe types: MIN (0mm drop, $5 \mathrm{~mm}$ overall stack height, $158 \pm 15 \mathrm{~g}$ average shoe mass, very flexible) and CONV (10 mm drop, $26 \mathrm{~mm}$ heel stack height, $284 \pm 25 \mathrm{~g}$ average shoe mass). The order of shoe testing was randomised, and runners were equipped with the Runalyser (TNO, Eindhoven, The Netherlands), a pressure-sensitive insole device which is inserted into the shoe and designed to measure pressure 
location and temporal parameters (Mann et al., 2014). The pre-fatigue acquisition protocol started with a 5-minute warm-up at $85 \%$ of the PRS. Then treadmill speed was increased to the PRS and participants continued running for another 5 minutes. This resulted in 10 minutes of running, enough time to provoke short-term adaptation to shoe type (Delattre et al., 2013). Pressure data was acquired during the final 2 minutes at the PRS along with heart rate (HR) and rate of perceived exertion (RPE) using the visual analogue scale from 6 to 20 (Borg et al., 1987). After a 5-minute recovery period, the procedure was repeated with the other shoe type. After a 2minute break, participants completed a fatiguing running bout using their own, habitual running shoes. Duration was defined as $120 \%$ of a typical running session duration minus the 20 minute pre-fatigue acquisition period. If participants felt they could not complete the predefined duration, slight adjustments in speed were made according to the RPE and HR which were recorded every 5 minutes. We ensured that RPE remained $<17$ throughout. After completing the fatiguing running bout, the acquisition protocol for both shoe types was repeated (in the same order) with 2minute breaks for the participant to change shoes and install the Runalyser.

\section{Data analysis}

Data of both feet were averaged for all acquisitions, and $\mathrm{SI}$, contact time $\left(\mathrm{T}_{\text {contact }}\right)$, flight time $\left(T_{\text {flight }}\right)$, stride time $\left(T_{\text {stride }}\right)$, duty factor (DF, $\left.T_{\text {contact }} / T_{\text {stride }} * 100\right), S_{\text {length }}$ and $S_{\text {frequency }}$ were calculated using custom-made MATLAB (Mathworks Inc., USA) algorithms as previously described (Mann et al., 2014). Based on previously published cut-offs (Mann et al., 2014), runners were subdivided as RFS (SI<43.9\%) or non-RFS (SI>43.9\%) runners using their pre-fatigue, CONV data. Using the full 2-minute data acquisitions, coefficient of variation (CV) of each parameter was calculated providing information on the stride variability. Detrended fluctuation analysis (DFA) was performed on all parameters, to detect any presence of stride-to-stride correlative patterns within each time series (Jordan et al., 2006; Peng et al., 1993). This technique calculates a scaling exponent value known as $\alpha$, which can be interpreted as follows: $\alpha=0.5$ represents white noise or the absence of any correlation, $\alpha>0.5$ signifies that long-range correlations are present (as $\alpha$ increases, so does the strength of the correlation), meaning that a given stride is correlated with one or more previous strides. Finally, an $\alpha<0.5$ signifies the presence of anti-correlations, meaning that a shorter stride is more likely to be followed by a longer one, for example. 


\section{Statistics}

Linear mixed models with "shoe type" and "fatigue" as fixed effects and "subject" as random slopes and intercepts were used to test all variables measured with the unstructured term applied. The statistical software package SPSS for Windows version 20 was used. Statistical significance was accepted at $p<0.05$.

\section{Results}

27 runners were tested, and data for one participant who was unable to complete the fatiguing running bout due to pain in the lower extremity was discarded. Table 5.1 provides a description of the 26 runners retained for the analysis. Four runners (15.4\%) were identified as non-RFS runners (no significant differences in demographics were observed between non-RFS and RFS runners). The average running duration between acquisitions of the same shoe type was $73.7 \pm 13.1$ minutes, and the average HR at the end of the fatiguing protocol was $164 \pm 15 \mathrm{bpm}$, representing $91 \pm 8 \%$ of the overall maximal HR estimated for each individual as 220-age. Participants reported a mean final RPE score of $14.0 \pm 1.5$ (intensity="hard").

Table 5.1. Descriptives and training characteristics of the 26 participants.

\begin{tabular}{ll}
\hline \hline RFS runners & $\mathrm{n}=22(84.6 \%)$ \\
Sex (male) & $14(63.6 \%)$ \\
Age $(\mathbf{y})$ & $40 \pm 8$ \\
Height (m) & $1.75 \pm 0.08$ \\
Weight (kg) & $70 \pm 10$ \\
BMI (kg/m2) & $22.9 \pm 2.0$ \\
Running experience (years) & $9.8 \pm 7.8$ \\
Average number of sessions/week & $3.3 \pm 1.1$ \\
Average session duration (min) & $63.2 \pm 13.2$ \\
Preferred running speed (km/h) & $10.7 \pm 1.3$ \\
Total mileage last 12 months $(\mathbf{k m})$ & $1352 \pm 758$ \\
Months run last 12 months & $11.8 \pm 0.6$ \\
\hline \hline
\end{tabular}

RFS: rearfoot strike; BMI: Body mass index; Values are mean \pm SD.

Although overall average values of SI were lower for CONV [25.7 $\pm 14.6 \%$ (unfatigued) and $23.1 \pm 11.1 \%$ (fatigued)] than for MIN [28.9 $\pm 19.1 \%$ (unfatigued) and $26.7 \pm 17.6 \%$ (fatigued)], these differences were not significant $(p=0.501)$ (figure $5.1 \mathrm{~A})$. The dotted line in figure 5.1A delineates the cut-off value for SI between a RFS and non-RFS running pattern, with data points below the dotted line representing a RFS. No significant differences due to fatigue state were observed $(p=0.661)$. Similarly, no shoe 
effect $(p=0.374)$ or fatigue effect $(p=0.305)$ was found for the CV of SI (figure 5.1B). DFA of SI displayed an overall trend towards a reduced $\alpha(p=0.075)$ in CONV, which was primarily due to the RFS group ( $p=0.051$ ); no fatigue effect was observed for the $\alpha$ of SI ( $p=0.841$ ) (figure $5.1 C$ ).

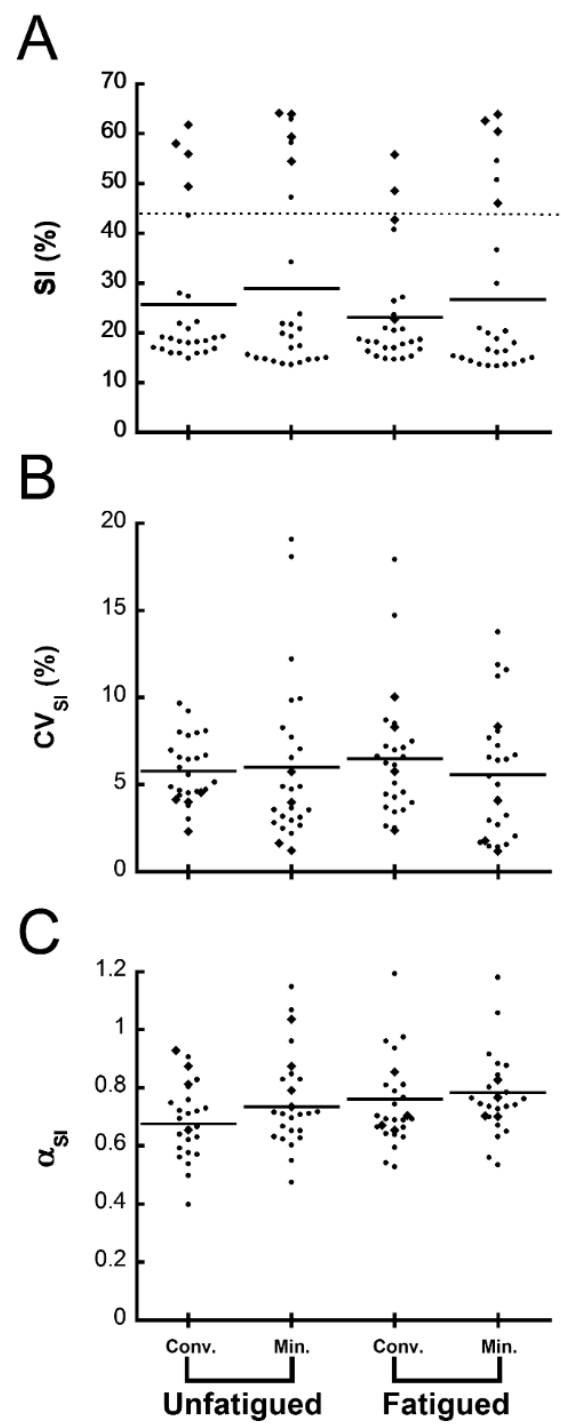

Figure 5.1. Dispersion of strike index as measured using the Runalyser (A), the coefficient of variation of strike index (B) and detrended fluctuation analysis of strike index (C) for each of the four running conditions. The dotted line represents the cut-off between a rearfoot and a non-rearfoot strike running pattern. $\bullet=$ habitually rearfoot strike runners, $\bullet$ habitually non-rearfoot strike runners based on unfatigued, conventional shoe acquisition. Horizontal lines represent the means. 
We observed an overall trend for a higher DF in the fatigued condition $(p=0.053)$, which was due to the trend present in the RFS group ( $p=0.052$ ) (figure 5.2D). Similarly, a trend in reduced $T_{\text {flight }}$ with fatigue was also visible overall $(p=0.078)$ and in particular for the RFS group ( $p=0.053$ ) (figure $5.2 B$ ). None of the other parameters displayed any significant differences or trends for shoe type or fatigue effect (figure 5.2). This was also the case for the CV and the $\alpha$ of all these parameters, as well as for the shoe type*fatigue interactions. The data for all parameters tested in all conditions is available as supplementary data.

A

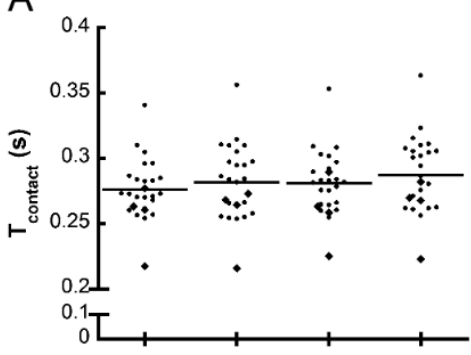

C

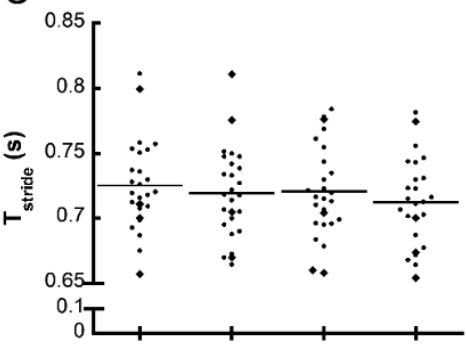

$E$

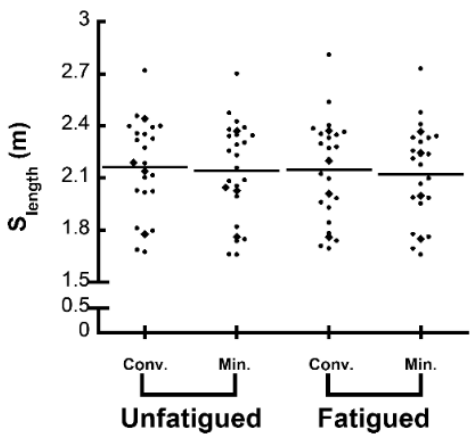

$\mathrm{B}$

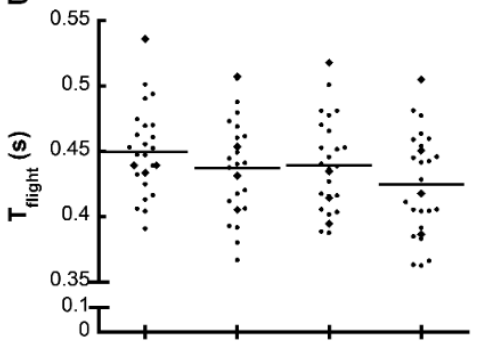

D

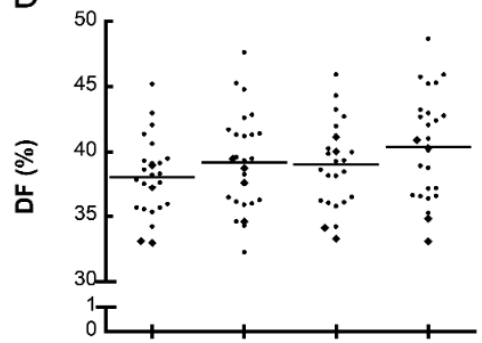

$\mathrm{F}$

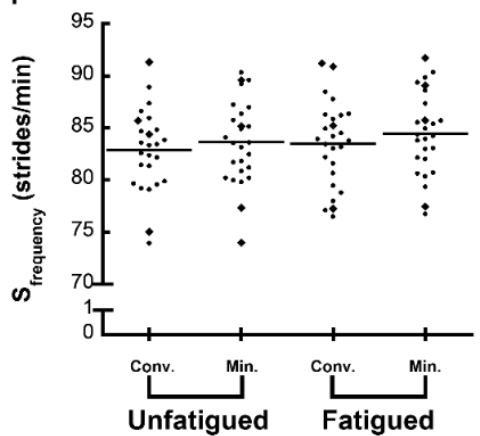

Figure 5.2. Spatiotemporal parameters as measured using the Runalyser in the four running conditions. $\bullet=$ habitually rearfoot strike runners, $\bullet$ habitually non-rearfoot strike runners based on unfatigued, conventional shoe acquisition. Horizontal lines represent the means. 


\section{Discussion}

Our main aim was to observe differences in $\mathrm{SI}$ and spatiotemporal parameters between running with CONV, and first-time running with MIN. Overall, we did not find any significant differences between shoe types and between the unfatigued and fatigued state. Therefore, except for a tendency towards a reduced $\alpha$ of SI when using CONV, we could not confirm our hypothesis within the conditions of this experiment. Only three habitual RFS runners changed to a non-RFS pattern when running in MIN in the unfatigued condition. The overall increase of $3.4 \% \mathrm{SI}$ did not meet the minimal detectible change expected. Despite the MIN in this study having only a $5 \mathrm{~mm}$ stack height, this aspect alone did not incur an overall significant short-term change in running strike pattern. Our results agree with two recent studies also finding no difference in SI between shoe types (Bergstra et al., 2014; McCallion et al., 2014). Yet both observed a reduced $\mathrm{T}_{\text {contact }}$ for the MIN condition, which was not the case in our study. Similarly, we observed that changing the shoe type was not enough to provoke a significant acute change in $S_{\text {length }}$ and $S_{\text {frequency. }}$. Willy et al. (2014) also found no differences in step length and frequency between MIN and CONV (Willy \& Davis, 2014), and neither did Willson et al, (2014) for step length and $T_{\text {contact }}$ (Willson et al., 2014). McCallion et al. (2014) did observe a shorter $\mathrm{T}_{\text {stride, a shorter }} \mathrm{T}_{\text {contact }}$ and a higher $\mathrm{S}_{\text {frequency }}$ in the MIN condition in 14 competitive runners at $13.0 \pm 1.0$ and $16.1 \pm 1.3 \mathrm{~km} / \mathrm{h}$ (McCallion et al., 2014). However, they did not observe systematic differences for both speeds, and the clinical relevance of the differences they observed is difficult to determine. Their subjects underwent a 4-minute familiarisation trial with all shoe types on a previous occasion, were more competitive, ran faster and most habitually used a midfoot strike running pattern. In all, those runners were perhaps more predisposed to adapt $T_{\text {stride, }} T_{\text {contact }}$ and $S_{\text {frequency }}$ according to shoe type than our runners. $T_{\text {flight }}$ and $\mathrm{T}_{\text {stride }}$ were not statistically different between the two shoe types in the present study. Another reason for differences in findings between studies could be related to the varying types of MIN used. There is no consensus on a definition of minimalism, and care must be taken when comparing results of studies using different brands and models of minimalistic shoes (Bonacci et al., 2013). So far the Nike Free 3.0 (17mm heel stack height, 4mm drop) (Bonacci et al., 2013; Willy \& Davis, 2014), Merrell Pace Glove (9.5mm overall stack height, 0mm drop) (Bergstra et al., 2014) or the Vibram 5 Fingers Bikila ( $3 \mathrm{~mm}$ rubber sole, 0mm drop) (McCallion et al., 2014; Squadrone \& Gallozzi, 2009; Willson et al., 2014) for example have been tested. Our study used a minimalistic shoe comparable to the latter model.

Stride variability (CV) and stride-to-stride correlative patterns (DFA) of spatiotemporal parameters were also analysed. Other than the observed trend in $\alpha$ of $\mathrm{SI}$, it seems that first-time running in MIN does not have a short-term effect on the variability or long- 
range correlations of strike pattern and spatiotemporal parameters. A truly lower $\alpha$ of SI would indicate that CONV induces a more random strike pattern; i.e. strides are less correlated with each other than when running in MIN, especially for habitual RFS runners. In such a case, CONV could provide more possibility to change the strike pattern between strides, most likely due to the familiar sensation provided by the cushioning. MIN provided an unfamiliar feel for all of our participants mainly due to the absence of a thick midsole or crash-pad (often commented on by the runners), possibly invoking greater awareness of the foot-ground contact, leading to a more correlated strike pattern. However, this discussion is speculative since only trends were observed. Further analyses of long-range correlative patterns of SI are warranted, along with comparing groups of runners habitually using minimalistic and conventional running shoes.

Our second aim was to observe the effect of fatigue on running style. None of the parameters tested yielded significant changes. With an overall reduction of $2.4 \% \mathrm{SI}$ in the fatigued condition, this does not meet our minimal detectible change of $4.9 \%$ and therefore not a relevant difference. The four non-RFS runners maintained this running style using the MIN in the unfatigued and fatigued condition. Two runners reduced their SI to below the cut-off while using the CONV in the fatigued state. Of the 22 RFS runners, three adopted a non-RFS using MIN in the unfatigued state, and two maintained this style in the fatigued state. No universal adaptation to shoe type was identified therefore, and any change appears to be individual specific. Contrarily, Larson et al. (2011) observed increased RFS at the $32 \mathrm{~km}$ mark of a marathon, concluding that muscle fatigue induced a change in running style (Larson et al., 2011). The trend in increased DF was provoked by the trend in decreased $T_{\text {flight }}$ and unchanged $T_{\text {contact }}$ in the fatigued state. A significant reduction in $T_{\text {flight }}$ has been observed 3 hours after a 166km ultra-marathon (Morin et al., 2011). These authors hypothesized that the reduction in propulsive forces due to fatigue resulted in a 'smoother' run as $\mathrm{S}_{\text {frequency }}$ was also significantly increased and vertical oscillation of the spring-mass system significantly reduced. Although our fatiguing protocol does not compare, the same anatomical reasoning could apply to explain this trend. Another study found a prolonged $\mathrm{T}_{\text {contact }}$ of $2 \%$ after a $20 \mathrm{~km}$ run and assumed a shortened $\mathrm{T}_{\text {flight }}$ (Willems et al., 2012), however, clinically this finding was deemed of little importance. $\mathrm{T}_{\text {contact }}$ in the present study was increased by a comparable $1.8 \%$ as a result of fatigue. Alfuth \& Rosenbaum (2011) found no change in plantar sensitivity or loading after a $10 \mathrm{~km}$ run simulating moderately exhausting exertion with a max $H R$ of $173 \pm 13 \mathrm{bpm}$ and a mean RPE of $14.5 \pm 2.0$, similar to that of the present study.

A limitation was that we tested our subjects on a treadmill and not in their natural environment. The treadmill used had a good dampening system with rubber slats as the running surface, possibly yielding different results to other running surfaces. Some 
of our observations are based on trends in the data, and not significant findings. Inclusion of more runners in future studies could shed more light on the relevance of these findings. Although $15.4 \%$ non-RFS runners is consistent with the literature (Larson et al., 2011), no meaningful analyses on this subgroup of four could be conducted. Further, SI provides a reliable measure of the initial contact point on the foot sole with the ground, yet additional loading parameters such as peak vertical impact force and loading rate could provide more accurate information on the interaction of shoe type and loading mechanisms.

\section{Conclusion}

Overall, our findings demonstrate that regular, recreational runners do not display an intuitive and significant adaptation in running style when asked to run using CONV and MIN consecutively. This supports previous work suggesting that MIN do not in themselves provide enough stimuli to provoke any short-term adaptation in running style compared to running in CONV in first-time users. Further investigation of the trend in increased randomness of the strike pattern using CONV, and how this relates to injury is needed. Physical fatigue induced by a typical training intensity had no significant effect on the SI or spatiotemporal parameters at the preferred running speed, meaning recreational runners are able to maintain their running style throughout a fatiguing training session.

\section{Acknowledgments}

The present study was financially supported by the National Research Fund, Luxembourg (AFR Robert Mann: ref.1102562). Thanks go to Dr Marc Hoppenbrouwers of TNO, Eindhoven, The Netherlands for his technical support, and to the study participants for their valuable contribution. 


\section{References}

Alfuth, M., \& Rosenbaum, D. (2011). Long distance running and acute effects on plantar foot sensitivity and plantar foot loading. Neurosci Lett, 503(1), 58-62.

Bergstra, S. A., Kluitenberg, B., Dekker, R., Bredeweg, S. W., Postema, K., Van den Heuvel, E. R., ... Sobhani, S. (2014). Running with a minimalist shoe increases plantar pressure in the forefoot region of healthy female runners. J Sci Med Sport

Bonacci, J., Saunders, P. U., Hicks, A., Rantalainen, T., Vicenzino, B. G., \& Spratford, W. (2013). Running in a minimalist and lightweight shoe is not the same as running barefoot: a biomechanical study. $\mathrm{Br} J$ Sports Med, 47(6), 387-392.

Borg, G., Hassmen, P., \& Lagerstrom, M. (1987). Perceived exertion related to heart rate and blood lactate during arm and leg exercise. Eur J Appl Physiol Occup Physiol, 56(6), 679-685.

Cavanagh, P. R., \& Lafortune, M. A. (1980). Ground reaction forces in distance running. J Biomech, 13(5), 397-406.

Christina, K. A., White, S. C., \& Gilchrist, L. A. (2001). Effect of localized muscle fatigue on vertical ground reaction forces and ankle joint motion during running. Hum Mov Sci, 20(3), 257-276.

Clansey, A. C., Hanlon, M., Wallace, E. S., \& Lake, M. J. (2012). Effects of fatigue on running mechanics associated with tibial stress fracture risk. Med Sci Sports Exerc, 44(10), 1917-1923.

Delattre, N., Chambon, N., Berton, E., Gueguen, N., \& Rao, G. (2013). Effect of time during a running session with minimal footwear. Comput Methods Biomech Biomed Engin, 16 Suppl 1, 104-105.

Derrick, T. R., Dereu, D., \& McLean, S. P. (2002). Impacts and kinematic adjustments during an exhaustive run. Med Sci Sports Exerc, 34(6), 998-1002.

Dierks, T. A., Davis, I. S., \& Hamill, J. (2010). The effects of running in an exerted state on lower extremity kinematics and joint timing. J Biomech, 43(15), 2993-2998.

Gerlach, K. E., White, S. C., Burton, H. W., Dorn, J. M., Leddy, J. J., \& Horvath, P. J. (2005). Kinetic changes with fatigue and relationship to injury in female runners. Med Sci Sports Exerc, 37(4), 657-663.

Jordan, K., Challis, J. H., \& Newell, K. M. (2006). Long range correlations in the stride interval of running. Gait Posture, 24(1), 120-125.

Kasmer, M. E., Liu, X. C., Roberts, K. G., \& Valadao, J. M. (2013). Foot-strike pattern and performance in a marathon. Int J Sports Physiol Perform, 8(3), 286-292.

Larson, P., Higgins, E., Kaminski, J., Decker, T., Preble, J., Lyons, D., . . . Normile, A. (2011). Foot strike patterns of recreational and sub-elite runners in a long-distance road race. J Sports Sci, 29(15), 16651673.

Lieberman, D. E. (2012). What we can learn about running from barefoot running: an evolutionary medical perspective. Exerc Sport Sci Rev, 40(2), 63-72.

Logan, S., Hunter, I., JT, J. T. H., Feland, J. B., \& Parcell, A. C. (2010). Ground reaction force differences between running shoes, racing flats, and distance spikes in runners. J Sports Sci Med, 9(1), 147-153.

Mann, R., Malisoux, L., Brunner, R., Gette, P., Urhausen, A., Statham, A., . . . Theisen, D. (2014). Reliability and validity of pressure and temporal parameters recorded using a pressure-sensitive insole during running. Gait Posture, 39(1), 455-459.

McCallion, C., Donne, B., Fleming, N., \& Blanksby, B. (2014). Acute differences in foot strike and spatiotemporal variables for shod, barefoot or minimalist male runners. J Sports Sci Med, 13(2), 280286.

Morin, J. B., Tomazin, K., Edouard, P., \& Millet, G. Y. (2011). Changes in running mechanics and spring-mass behavior induced by a mountain ultra-marathon race. J Biomech, 44(6), 1104-1107.

Peng, C. K., Mietus, J., Hausdorff, J. M., Havlin, S., Stanley, H. E., \& Goldberger, A. L. (1993). Long-range anticorrelations and non-Gaussian behavior of the heartbeat. Phys Rev Lett, 70(9), 1343-1346.

Squadrone, R., \& Gallozzi, C. (2009). Biomechanical and physiological comparison of barefoot and two shod conditions in experienced barefoot runners. J Sports Med Phys Fitness, 49(1), 6-13.

Willems, T. M., De Ridder, R., \& Roosen, P. (2012). The effect of a long-distance run on plantar pressure distribution during running. Gait Posture, 35(3), 405-409.

Willson, J. D., Bjorhus, J. S., Williams, D. S., 3rd, Butler, R. J., Porcari, J. P., \& Kernozek, T. W. (2014). Shortterm changes in running mechanics and foot strike pattern after introduction to minimalistic footwear. $P M R, 6(1), 34-43$. 
Willson, J. D., \& Kernozek, T. W. (1999). Plantar loading and cadence alterations with fatigue. Med Sci Sports Exerc, 31(12), 1828-1833.

Willy, R. W., \& Davis, I. S. (2014). Kinematic and kinetic comparison of running in standard and minimalist shoes. Med Sci Sports Exerc, 46(2), 318-323.

Zadpoor, A. A., \& Nikooyan, A. A. (2011). The relationship between lower-extremity stress fractures and the ground reaction force: a systematic review. Clin Biomech (Bristol, Avon), 26(1), 23-28. 
Supplementary data 


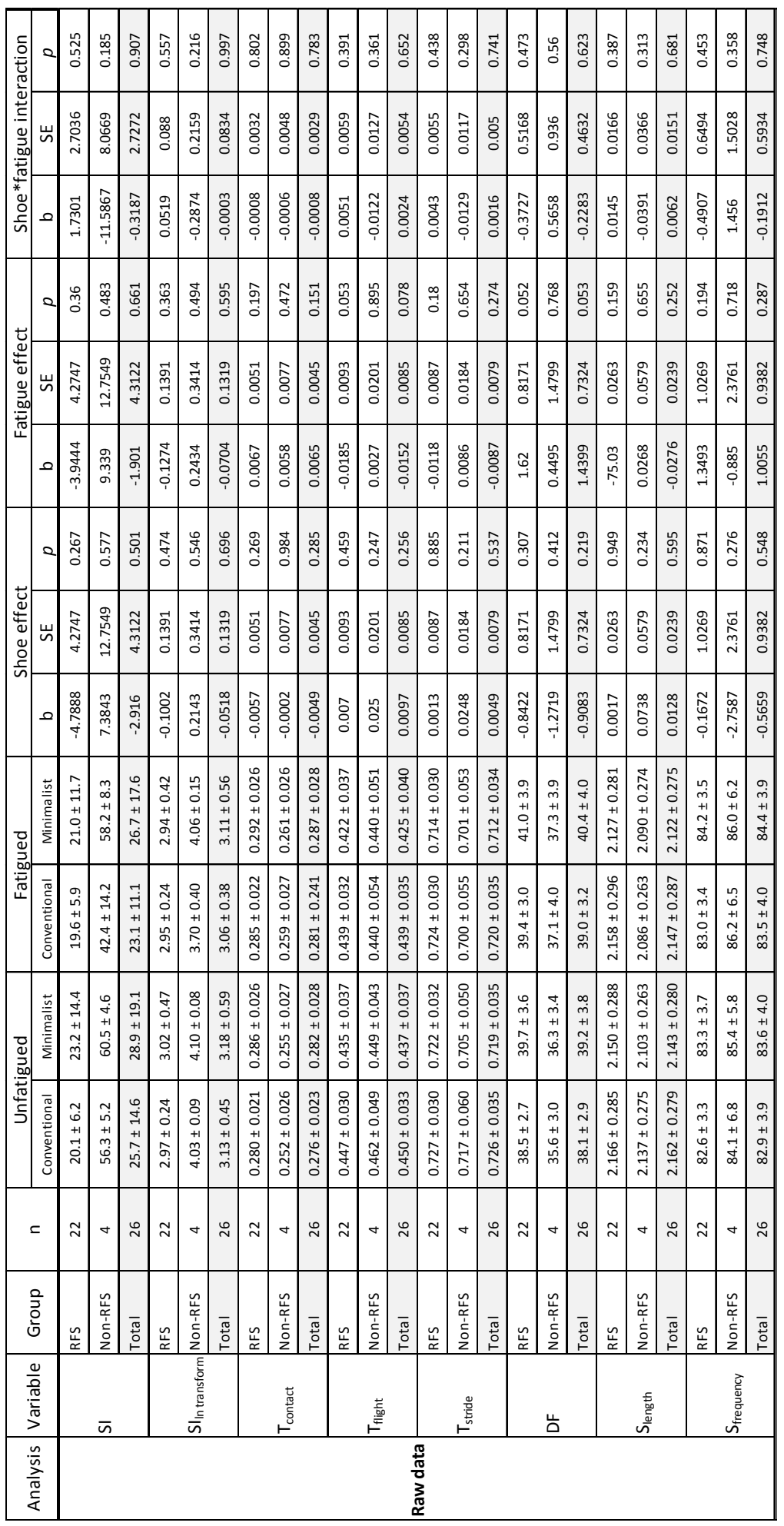




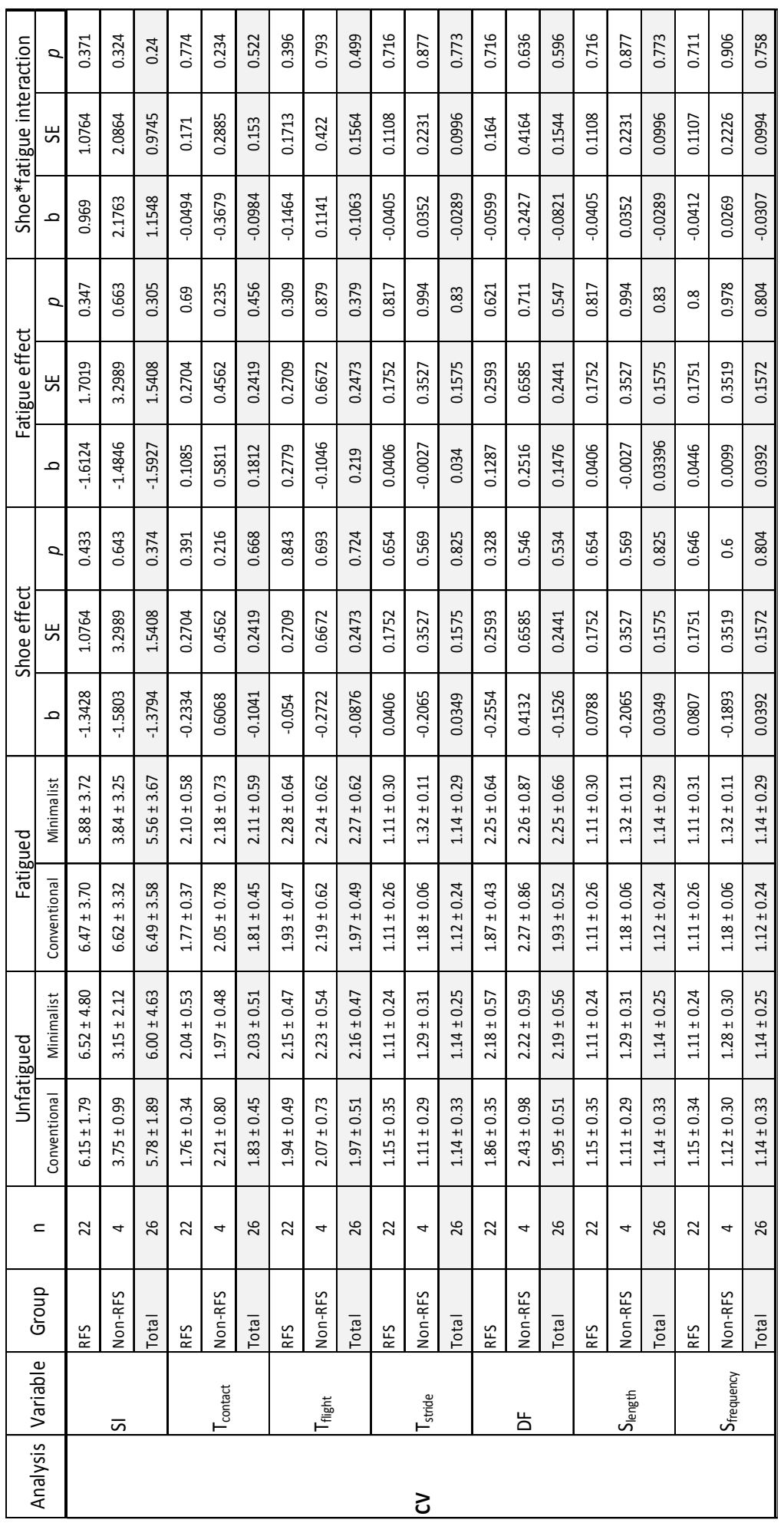




\begin{tabular}{|c|c|c|c|c|c|c|c|c|c|c|c|c|c|c|c|c|c|c|c|c|c|}
\hline .ำ & e & $\begin{array}{l}\text { 范 } \\
0\end{array}$ & 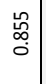 & $\begin{array}{l}\overrightarrow{\hat{~}} \\
\text { ठ }\end{array}$ & $\stackrel{\circ}{0}$ & 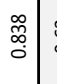 & $\begin{array}{l}\mathscr{0} \\
0 \\
\circ\end{array}$ & $\begin{array}{l}\infty \\
\text { o } \\
0\end{array}$ & 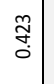 & $\begin{array}{c}\stackrel{\omega}{\infty} \\
\infty \\
0 \\
0\end{array}$ & 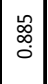 & $\begin{array}{l}9 \\
\frac{9}{2} \\
0\end{array}$ & 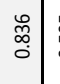 & 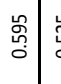 & 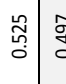 & 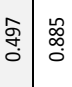 & $\begin{array}{l}b \\
\vdots \\
\dot{b}\end{array}$ & \begin{tabular}{|c|}
0 \\
$\infty$ \\
0 \\
0
\end{tabular} \mid & $\begin{array}{r}\infty \\
\infty \\
0 \\
0\end{array}$ & $\begin{array}{c}\text { ב̃ } \\
\text { O }\end{array}$ & $\mid \begin{array}{c}\infty \\
0 \\
0 \\
0 \\
0\end{array}$ \\
\hline \multirow{2}{*}{ 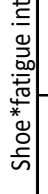 } & 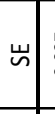 & $\begin{array}{l}\hat{o} \\
\stackrel{0}{0} \\
0\end{array}$ & \begin{tabular}{|l|} 
\\
0 \\
0 \\
0 \\
0
\end{tabular} & $\begin{array}{l}\stackrel{0}{0} \\
\substack{0 \\
0}\end{array}$ & 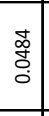 & $\begin{array}{l}\overrightarrow{\tilde{m}} \\
0 \\
0 \\
0\end{array}$ & 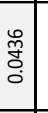 & $\begin{array}{l}m \\
\ddot{0} \\
0 \\
0\end{array}$ & \begin{tabular}{l|}
$\begin{array}{l}0 \\
\stackrel{0}{0} \\
0 \\
0\end{array}$ \\
\end{tabular} & $\begin{array}{l}\tilde{N} \\
\stackrel{0}{0} \\
0\end{array}$ & $\mid$\begin{tabular}{|c|}
$\tilde{\Xi}$ \\
$\delta$ \\
0 \\
0
\end{tabular} & $\begin{array}{l}0 \\
0 \\
0 \\
0 \\
0\end{array}$ & $\begin{array}{l}\text { 音 } \\
\text { o. } \\
0\end{array}$ & \begin{tabular}{l|l}
$\overrightarrow{0}$ & \\
0 &
\end{tabular} & 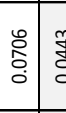 & 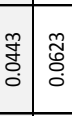 & 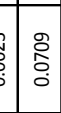 & $\begin{array}{l} \\
\text { 息 } \\
0\end{array}$ & $\begin{array}{l}\tilde{\Xi} \\
\dot{0} \\
\dot{0}\end{array}$ & 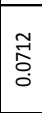 & $\begin{array}{l}\text { ơ } \\
\text { 菅 } \\
0\end{array}$ \\
\hline & 。 & $\begin{array}{l}\text { Fे } \\
\text { ठ․ }\end{array}$ & $\mid \begin{array}{l}\vec{y} \\
0 \\
0 \\
0\end{array}$ & 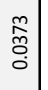 & 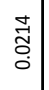 & $\begin{array}{l}\mathscr{0} \\
\stackrel{0}{0} \\
0\end{array}$ & $\begin{array}{l}ت \\
\tilde{D} \\
0\end{array}$ & $\begin{array}{l}0 \\
0 \\
0 \\
0 \\
i\end{array}$ & \begin{tabular}{l|}
0 \\
0 \\
$o$ \\
0 \\
0
\end{tabular} & $\begin{array}{l}\hat{0} \\
0 \\
0\end{array}$ & $\mid$\begin{tabular}{|l|}
$\overrightarrow{8}$ \\
0 \\
0 \\
0
\end{tabular} & $\begin{array}{l}\tilde{\tilde{z}} \\
\tilde{\delta} \\
0\end{array}$ & $\begin{array}{l}m \\
\tilde{a} \\
0 \\
0\end{array}$ & \begin{tabular}{l|l}
$\widetilde{\Xi}$ \\
$\tilde{\delta}$
\end{tabular} & 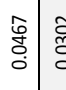 & 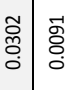 & 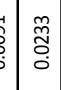 & $\mid \begin{array}{l}m \\
\vdots \\
0 \\
0\end{array}$ & $\begin{array}{l}\infty \\
0 \\
0 \\
0 \\
0\end{array}$ & 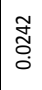 & 吉 \\
\hline \multirow{3}{*}{ 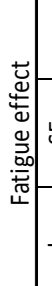 } & 2 & $\begin{array}{l}\stackrel{\leftrightarrow}{\circ} \\
\stackrel{\circ}{\circ}\end{array}$ & \begin{tabular}{|l|}
0 \\
$q$ \\
0 \\
0
\end{tabular} & 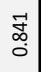 & $\mid$\begin{tabular}{l}
0 \\
\multirow{2}{*}{} \\
0 \\
0
\end{tabular} & $\begin{array}{c}0 \\
0 \\
0 \\
0\end{array}$ & 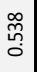 & \begin{tabular}{c|}
$\hat{o}$ \\
$\stackrel{0}{0}$ \\
0
\end{tabular} & \begin{tabular}{|l|}
$\mathbb{N}$ \\
0 \\
0
\end{tabular} & 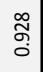 & \begin{tabular}{|l|}
$\overrightarrow{0}$ \\
0 \\
0
\end{tabular} & 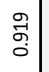 & ชิ & 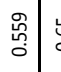 & $\stackrel{\leftrightarrow}{0}$ & 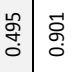 & \begin{tabular}{c|c}
0 \\
$\vdots$ \\
$\vdots$ \\
$\vdots$
\end{tabular} & ชิ & $\begin{array}{l}\text { ŏ } \\
\text { ọ }\end{array}$ & 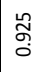 & 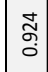 \\
\hline & 岕 & $\begin{array}{l}\stackrel{u}{0} \\
\stackrel{0}{0} \\
0 \\
0\end{array}$ & $\begin{array}{l}\overrightarrow{0} \\
\overrightarrow{0} \\
0\end{array}$ & $\begin{array}{l}\tilde{\tilde{N}} \\
\text { Oू. } \\
0\end{array}$ & \begin{tabular}{|l|}
$u$ \\
0 \\
0 \\
0 \\
0
\end{tabular} & 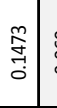 & $\begin{array}{l}: \\
: \\
0 \\
0\end{array}$ & $\begin{array}{l}0 \\
0 \\
0 \\
0 \\
0\end{array}$ & \begin{tabular}{|l|}
$\stackrel{2}{0}$ \\
ă \\
0
\end{tabular} & 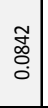 & $\begin{array}{l}\stackrel{\leftrightarrow}{0} \\
\stackrel{0}{0} \\
0\end{array}$ & $\begin{array}{l}\exists \\
0 \\
0\end{array}$ & $\begin{array}{l}\stackrel{0}{0} \\
0 \\
0\end{array}$ & $\begin{array}{l}0 \\
0 \\
0 \\
0\end{array}$ & 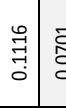 & 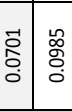 & $\begin{array}{l}\vdots \\
\vdots \\
\vdots \\
\vdots\end{array}$ & $\begin{array}{l}0 \\
0 \\
0 \\
0\end{array}$ & $\begin{array}{l}\mathbf{0} \\
o \\
0 \\
0 \\
0\end{array}$ & $\begin{array}{l}\underset{I}{ \pm} \\
\underset{0}{0}\end{array}$ & 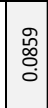 \\
\hline & مـ & 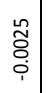 & 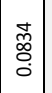 & \begin{tabular}{|l|}
0 \\
0 \\
0 \\
0
\end{tabular} & 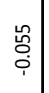 & 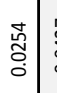 & $\begin{array}{l}\hat{F} \\
\text { ș } \\
\text { î }\end{array}$ & $\begin{array}{l}0 \\
0 \\
0 \\
0 \\
1\end{array}$ & \begin{tabular}{|l|}
0 \\
$\stackrel{8}{0}$ \\
0 \\
0 \\
$i$
\end{tabular} & $\begin{array}{l}\hat{\hat{o}} \\
0 \\
i \\
i\end{array}$ & 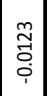 & $\begin{array}{l}\overrightarrow{7} \\
0 \\
0\end{array}$ & $\begin{array}{l}\mathscr{0} \\
\stackrel{0}{0} \\
\vdots \\
i\end{array}$ & 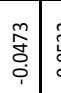 & 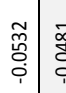 & \begin{tabular}{c|c}
$\overrightarrow{0}$ & $\tilde{z}$ \\
$\vdots$ \\
0 \\
0
\end{tabular} & $\begin{array}{l}\vec{y} \\
\vdots \\
0\end{array}$ & $\left|\begin{array}{l}0 \\
0 \\
0 \\
0 \\
i\end{array}\right|$ & $\begin{array}{l}\hat{a} \\
\dot{0} \\
i \\
i\end{array}$ & 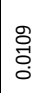 & $\begin{array}{l}\tilde{\alpha} \\
\stackrel{0}{0} \\
\stackrel{0}{1}\end{array}$ \\
\hline \multirow{3}{*}{\multicolumn{2}{|c|}{ s }} & $\begin{array}{l}\vec{H} \\
\stackrel{0}{0} \\
0\end{array}$ & $\begin{array}{c}\tilde{O} \\
\infty \\
0 \\
0\end{array}$ & $\begin{array}{l}n \\
\hat{0} \\
0 \\
0\end{array}$ & $\begin{array}{l}\text { Oू. } \\
\text { o. } \\
\end{array}$ & 色 & $\begin{array}{c}0 \\
0 \\
0 \\
0\end{array}$ & 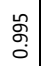 & \begin{tabular}{l|} 
\\
\\
0
\end{tabular} & 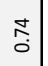 & $\begin{array}{c}\stackrel{d}{N} \\
0 \\
0\end{array}$ & $\begin{array}{l}\stackrel{\oplus}{0} \\
\stackrel{0}{0}\end{array}$ & $\begin{array}{l}\text { 令 } \\
\text { مุ }\end{array}$ & 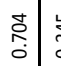 & 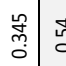 & 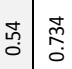 & $\begin{array}{l}\qquad \\
\vdots \\
\vdots \\
\vdots\end{array}$ & $\begin{array}{l}\text { శ్ } \\
\text { స్ }\end{array}$ & 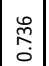 & $\stackrel{\infty}{\stackrel{0}{0}}$ & $\mid \begin{array}{l}\overrightarrow{0} \\
\hat{0} \\
0\end{array}$ \\
\hline & & $\begin{array}{l}\text { 崖 } \\
\stackrel{0}{0} \\
0\end{array}$ & $\mid \begin{array}{l}\overrightarrow{0} \\
0 \\
0\end{array}$ & $\begin{array}{l}\tilde{\tilde{N}} \\
\stackrel{\hat{\alpha}}{0} \\
0\end{array}$ & 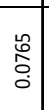 & 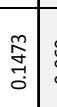 & $\begin{array}{l}0 \\
\ddot{0} \\
0 \\
0\end{array}$ & $\begin{array}{l}0 \\
\stackrel{0}{0} \\
0 \\
0 \\
0\end{array}$ & \begin{tabular}{|l|}
$\stackrel{0}{0}$ \\
$\stackrel{7}{7}$ \\
0
\end{tabular} & \begin{tabular}{l}
$\tilde{y}$ \\
\multirow{0}{0}{} \\
0 \\
0
\end{tabular} & \begin{tabular}{|l|} 
\\
0 \\
0 \\
0 \\
0 \\
0
\end{tabular} & \begin{tabular}{l}
\multirow{7}{*}{} \\
○े
\end{tabular} & $\begin{array}{l}0 \\
: \\
0 \\
0\end{array}$ & $\begin{array}{l}0 \\
0 \\
0 \\
0\end{array}$ & \begin{tabular}{l|l}
0 & $\bar{a}$ \\
\multirow{1}{0}{} & $\bar{c}$ \\
\end{tabular} & 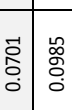 & 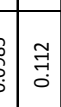 & $\mid$\begin{tabular}{l|}
0 \\
$\stackrel{0}{0}$ \\
0 \\
\end{tabular} & \begin{tabular}{|l|} 
\\
0 \\
0 \\
0 \\
0 \\
0
\end{tabular} & 志 & $\begin{array}{l}\text { Oू } \\
\text { o. } \\
0 \\
0\end{array}$ \\
\hline & & $\begin{array}{c}\tilde{0} \\
\stackrel{7}{1} \\
0\end{array}$ & \begin{tabular}{|l|}
0 \\
$\tilde{a}$ \\
0 \\
0
\end{tabular} & $\begin{array}{l}0 \\
0 \\
0 \\
0 \\
\end{array}$ & $\begin{array}{l}0 \\
0 \\
0 \\
i \\
1\end{array}$ & $\begin{array}{l}\stackrel{0}{2} \\
0 \\
0 \\
0\end{array}$ & $\begin{array}{l}0 \\
\overrightarrow{0} \\
0 \\
0\end{array}$ & $\begin{array}{l}\hat{o} \\
0 \\
i \\
1\end{array}$ & 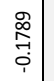 & $\begin{array}{l}\overrightarrow{0} \\
\stackrel{0}{0} \\
\dot{i}\end{array}$ & 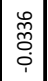 & $\begin{array}{l}: \\
\stackrel{0}{0} \\
\stackrel{1}{0} \\
0\end{array}$ & \begin{tabular}{l} 
yे \\
\multirow{3}{0}{} \\
$i$ \\
$i$
\end{tabular} & \begin{tabular}{l|l}
$\infty$ \\
0 \\
0 \\
0
\end{tabular} & 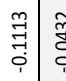 & 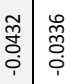 & 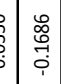 & 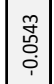 & 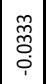 & $\begin{array}{l}0 \\
0 \\
\text { c. } \\
\text { i. }\end{array}$ & 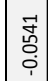 \\
\hline \multirow[b]{2}{*}{ 蓸 } & 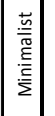 & $\begin{array}{l}n \\
\stackrel{2}{0} \\
0 \\
+1 \\
\infty \\
0 \\
0\end{array}$ & 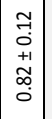 & $\mid \begin{array}{l}0 \\
⿱ \\
0 \\
+1 \\
0 \\
0 \\
0 \\
0\end{array}$ & 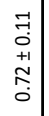 & $\begin{array}{l}\vec{t} \\
0 \\
+1 \\
+1 \\
0 \\
0 \\
0\end{array}$ & $\begin{array}{l}m \\
0 \\
0 \\
+1 \\
\\
0 \\
0\end{array}$ & $\begin{array}{l}2 \\
0 \\
0 \\
+1 \\
+1 \\
0 \\
0\end{array}$ & \begin{tabular}{|l|}
$\infty$ \\
0 \\
0 \\
+1 \\
0 \\
0 \\
0 \\
0
\end{tabular} & $\begin{array}{l}0 \\
0 \\
0 \\
+1 \\
\infty \\
0 \\
0\end{array}$ & $\mid \begin{array}{l}0 \\
0 \\
0 \\
+1 \\
\infty \\
0 \\
0 \\
0\end{array}$ & $\begin{array}{l}m \\
0 \\
0 \\
+1 \\
\vdots \\
0 \\
0\end{array}$ & $\begin{array}{c}f \\
0 \\
+ \\
+1 \\
\infty \\
0 \\
0\end{array}$ & \begin{tabular}{l|l}
$m$ & \\
0 & \\
+1 & \\
0 & \\
0 & \\
0 &
\end{tabular} & \begin{tabular}{c|c}
7 & \multicolumn{1}{|c}{} \\
0 & 0 \\
+1 & + \\
0 & + \\
0 & 0 \\
0 & 0
\end{tabular} & \begin{tabular}{l|l}
0 & 0 \\
0 & 0 \\
0 & 0 \\
+1 & +1 \\
0 & +1 \\
0 & 0 \\
0
\end{tabular} & 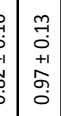 & \begin{tabular}{|c|}
$f$ \\
0 \\
0 \\
++1 \\
0 \\
0 \\
0 \\
0
\end{tabular} & $\mid \begin{array}{c}0 \\
0 \\
0 \\
+1 \\
0 \\
0 \\
0\end{array}$ & $\begin{array}{c}m \\
\tilde{0} \\
0 \\
+1 \\
\hat{\sigma} \\
0 \\
0\end{array}$ & $\mid \begin{array}{c}f \\
0 \\
0 \\
+1 \\
+1 \\
0 \\
0 \\
0\end{array}$ \\
\hline & 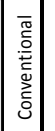 & \begin{tabular}{l}
0 \\
\multicolumn{1}{c}{} \\
0 \\
+1 \\
+1 \\
0 \\
0
\end{tabular} & $\begin{array}{l}m \\
0 \\
0 \\
+1 \\
0 \\
0 \\
0 \\
0\end{array}$ & $\begin{array}{l}0 \\
0 \\
0 \\
+1 \\
0 \\
0 \\
0\end{array}$ & \begin{tabular}{l}
0 \\
\multirow{1}{0}{} \\
0 \\
+1 \\
0 \\
0 \\
0
\end{tabular} & 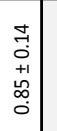 & 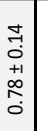 & $\begin{array}{c}m \\
m \\
0 \\
+1 \\
0 \\
0 \\
0 \\
0\end{array}$ & $\begin{array}{l} \\
\\
0 \\
+1 \\
0 \\
o \\
0\end{array}$ & 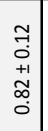 & \begin{tabular}{|c|}
$m$ \\
$\stackrel{1}{0}$ \\
0 \\
+1 \\
0 \\
0 \\
0 \\
\end{tabular} & $\begin{array}{c}7 \\
7 \\
0 \\
+1 \\
0 \\
\infty \\
0 \\
0\end{array}$ & $\begin{array}{c}m \\
\stackrel{0}{0} \\
0 \\
+1 \\
\dot{0} \\
0 \\
0\end{array}$ & \begin{tabular}{l|l}
\multirow{2}{*}{} & \\
0 & \\
+1 & \\
\multirow{2}{*}{} & \\
0 &
\end{tabular} & 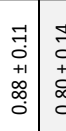 & 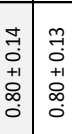 & 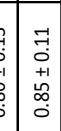 & $\mid \begin{array}{c}m \\
0 \\
0 \\
+1 \\
+0 \\
0 \\
0 \\
0\end{array}$ & $\mid \begin{array}{c}m \\
0 \\
0 \\
+1 \\
0 \\
0 \\
0\end{array}$ & 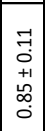 & $\begin{array}{c}m \\
- \\
0 \\
+1 \\
0 \\
0 \\
0\end{array}$ \\
\hline \multirow[b]{2}{*}{ 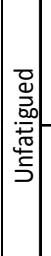 } & 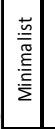 & $\begin{array}{l}0 \\
0 \\
0 \\
+1 \\
+ \\
0 \\
0\end{array}$ & 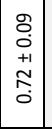 & 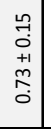 & 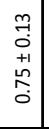 & $\begin{array}{l}0 \\
0 \\
0 \\
+1 \\
0 \\
0 \\
0 \\
0\end{array}$ & $\begin{array}{l}m \\
0 \\
0 \\
+1 \\
i \\
0 \\
0\end{array}$ & 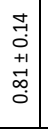 & $\mid$\begin{tabular}{l|}
\multicolumn{2}{c}{} \\
0 \\
+1 \\
+1 \\
0 \\
0 \\
\end{tabular} & 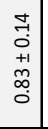 & 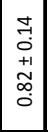 & $\begin{array}{l}\stackrel{2}{0} \\
0 \\
+1 \\
m \\
o \\
0\end{array}$ & 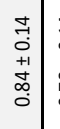 & \begin{tabular}{l|l}
\multirow{2}{*}{} & \\
0 & \\
+1 & \\
$\infty$ & \\
0 & \\
0 &
\end{tabular} & \begin{tabular}{c|c}
0 & \multicolumn{1}{c}{} \\
0 & 1 \\
0 & \\
+1 & + \\
0 & + \\
0 & 0 \\
0 & 0
\end{tabular} & 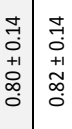 & 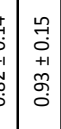 & \begin{tabular}{|c|}
0 \\
0 \\
0 \\
+1 \\
0 \\
0 \\
0 \\
0
\end{tabular} & $\begin{array}{c}\vec{t} \\
0 \\
+ \\
+1 \\
\infty \\
0 \\
0 \\
0\end{array}$ & $\mid$\begin{tabular}{|c|}
$n$ \\
0 \\
0 \\
+1 \\
0 \\
0 \\
0 \\
0
\end{tabular} & $\mid \begin{array}{l}0 \\
0 \\
0 \\
0+1 \\
+0 \\
0 \\
0 \\
0\end{array}$ \\
\hline & 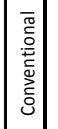 & $\begin{array}{l}7 \\
0 \\
0 \\
+1 \\
0 \\
0 \\
0\end{array}$ & \begin{tabular}{|c|}
0 \\
0 \\
0 \\
+1 \\
$\stackrel{1}{2}$ \\
0 \\
0
\end{tabular} & $\mid \begin{array}{l}7 \\
0 \\
+1 \\
+1 \\
0 \\
0 \\
0 \\
0\end{array}$ & 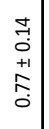 & 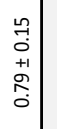 & 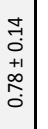 & $\begin{array}{l}0 \\
0 \\
0 \\
+1 \\
0 \\
0 \\
0\end{array}$ & 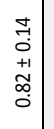 & $\begin{array}{l}7 \\
0 \\
+1 \\
+1 \\
0 \\
0\end{array}$ & $\mid$\begin{tabular}{|c|}
$\infty$ \\
0 \\
0 \\
+1 \\
0 \\
$\hat{0}$ \\
0 \\
0
\end{tabular} & 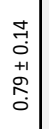 & $\begin{array}{l}\hat{a} \\
\vdots \\
+1 \\
o \\
\hat{0}\end{array}$ & \begin{tabular}{l|l}
7 & \\
0 \\
+1 \\
$\infty$ \\
0 \\
0
\end{tabular} & \begin{tabular}{c|c}
$m$ & \multicolumn{2}{c}{} \\
0 & 0 \\
+1 & + \\
$\infty$ & + \\
0 & 0 \\
0 & 0
\end{tabular} & \begin{tabular}{c|c}
0 & $\infty$ \\
0 & 0 \\
0 & 1 \\
0 & +1 \\
2 & 0 \\
0 & 0
\end{tabular} & 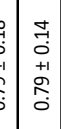 & $\mid \begin{array}{l}\hat{7} \\
0 \\
+1 \\
0 \\
0 \\
0 \\
0\end{array}$ & $\mid$\begin{tabular}{|c|}
0 \\
0 \\
0 \\
+1 \\
0 \\
0 \\
0
\end{tabular} & $\mid$\begin{tabular}{c|}
0 \\
0 \\
0 \\
+1 \\
0 \\
0 \\
0 \\
0
\end{tabular} & $\begin{array}{l}\text { ㄱ. } \\
0 \\
+1 \\
\text { +1 } \\
\text { ô } \\
0\end{array}$ \\
\hline \multicolumn{2}{|c|}{$=$} & $\approx$ & $\sigma$ & $\stackrel{\sim}{ }$ & $\approx$ & $\sigma$ & $\stackrel{\sim}{2}$ & $\approx$ & + & $\stackrel{\sim}{N}$ & $\approx$ & $\sigma$ & $\stackrel{\sim}{2}$ & $\approx$ & $\nabla$ & $\approx$ & $\begin{array}{l}v \\
v\end{array}$ & $\stackrel{\sim}{2}$ & $\approx$ & $\nabla$ & $\stackrel{N}{2}$ \\
\hline \multicolumn{2}{|c|}{$\begin{array}{l}\text { בे } \\
\text { 임 }\end{array}$} & 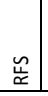 & 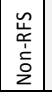 & \begin{tabular}{|l|}
$\overline{5}$ \\
$\stackrel{9}{\circ}$ \\
\end{tabular} & \begin{tabular}{|c|}
$\stackrel{\tilde{c}}{\alpha}$ \\
\end{tabular} & 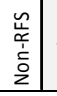 & 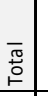 & 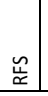 & 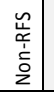 & 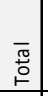 & \begin{tabular}{|l|}
$\stackrel{4}{\alpha}$ \\
\end{tabular} & 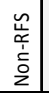 & 覀 & $\underset{\mu}{\mu}$ & 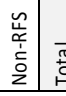 & 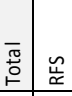 & 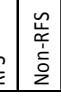 & $\overline{\text { s. }}$ & 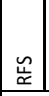 & & 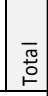 \\
\hline \multicolumn{2}{|c|}{$\begin{array}{l}\frac{0}{2} \\
\frac{0}{0} \\
\frac{0}{50} \\
>\end{array}$} & \multicolumn{3}{|c|}{ দি } & \multicolumn{3}{|c|}{ 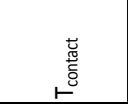 } & \multicolumn{3}{|c|}{ 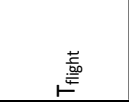 } & \multicolumn{3}{|c|}{ 曾 } & & \multicolumn{3}{|c|}{ 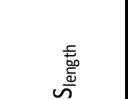 } & \multicolumn{3}{|c|}{ 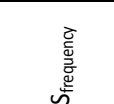 } \\
\hline & & & & & & & & & & & & & & & & & & & & & \\
\hline
\end{tabular}





\section{Chapter 6}

\section{Can Parallel Use of Different Running Shoes Decrease Running related Injury Risk?}

Laurent Malisoux, Joseph Ramesh, Robert Mann, Romain Seil, Axel Urhausen and Daniel Theisen

Scan J Med Sci Sports, 2015, 25(1): 110-5. 


\begin{abstract}
The aim of this study was to determine if runners who use concomitantly different pairs of running shoes are at a lower risk of running-related injury (RRI). Recreational runners $(n=264)$ participated in this 22-week prospective follow-up and reported all information about their running session characteristics, other sport participation and injuries on a dedicated internet platform. A RRI was defined as a physical pain or complaint located at the lower limbs or lower back region, sustained during or as a result of running practice and impeding planned running activity for at least 1 day. One third of the participants $(n=87)$ experienced at least one RRI during the observation period. The adjusted Cox regression analysis revealed that the parallel use of more than one pair of running shoes was a protective factor $(\mathrm{HR}=0.614 ; 95 \% \mathrm{Cl}=0.389-0.969)$, while previous injury was a risk factor $(\mathrm{HR}=1.722 ; 95 \% \mathrm{Cl}=1.114-2.661)$. Additionally, increased mean session distance $(\mathrm{km} ; \mathrm{HR}=0.795 ; 95 \% \mathrm{Cl}=0.725-0.872)$ and increased weekly volume of other sports (h.week-1; $\mathrm{HR}=0.848 ; 95 \% \mathrm{Cl}=0.732-0.982$ ) were associated with lower RRI risk. Multiple shoe use and participation in other sports are strategies potentially leading to a variation of the load applied to the musculoskeletal system. They could be advised to recreational runners to prevent RRI.
\end{abstract}

\title{
Keywords:
}

Recreational runners, risk factors, injury incidence, survival analysis, cohort study 


\section{Introduction}

Running is characterised by the repetition of a large number of almost identical movements with very few variations. Consequently, most of the running-related injuries (RRI) are cumulative micro-trauma injuries (progressive in nature), and thus, could be classified as overuse injuries (Hreljac, 2004). The latter occur when repetitive stress is applied to a muscle, tendon or bone resulting in micro-traumatic damage followed by insufficient time to heal or repair (Hreljac, 2004). Various studies have estimated that $27 \%$ to $70 \%$ of recreational and competitive runners sustain overuse injuries during one year of practice (Ferber et al., 2009). Different strategies could be used to prevent overloading and to vary the stress applied to the body. For example, it has been reported that non-injured runners participated significantly more often in other sports in comparison with injured runners (Jacobs \& Berson, 1986). However, contradictory results have also been found (Satterthwaite et al., 1999), and this point needs further study (van Gent et al., 2007; van Mechelen, 1992).

A number of reports have shown that shoe characteristics influence the magnitude and the type of stresses applied to the musculoskeletal system (Bonacci et al., 2013; Kong et al., 2009; Lieberman et al., 2010; Rethnam \& Makwana, 2011; Wakeling et al., 2002). For example, it has been recently demonstrated that running with flat-midsole footwear for 3 months result in a $30 \%$ lower shock magnitude at the heel (Giandolini et al., 2013). Other authors have shown that the characteristics of cushioned running shoes induce an adaptation of running style (Perl et al., 2012; Wiegerinck et al., 2009). It has also previously been demonstrated that slight modifications in shoe mechanics as a result of shoe usage leads to kinematic changes. As a consequence of shoe degradation, stance time was increased and the ankle displayed lower maximum dorsiflexion and greater plantar flexion at toe-off (Kong et al., 2009). Midsole hardness was also shown to induce changes in lower-extremity muscle activity (Wakeling et al., 2002). Since these studies demonstrated that shoe characteristics impact on running pattern, a regular change of running shoes might cause variation of repetitive external loads which, according to the overuse injury mechanism, could decrease its incidence. Few studies have investigated the relationship between shoe use and RRI risk (van Gent et al., 2007), yielding inconsistent results. To date, no information regarding the effect of alternation between several pairs of running shoes on RRI risk is available. Therefore, the purpose of the current study was to establish the relationship between parallel use of different running shoes and RRI incidence. It was hypothesized that runners using concomitantly more than one pair of shoes would be at a lower risk of sustaining a RRI. A secondary hypothesis was that the practice of other sports would be a protective factor as this also allows a variation of the type of stress applied to the body. 


\section{Methods}

\section{Participants and study design}

This prospective 22-week follow-up study targeted all types of amateur runners. The advertisement for recruitment of runners was done through the local media and the website of the ING Marathon Luxembourg. Healthy participants above 18 years old with any level of fitness were eligible to take part in the study, without any obligation to participate in the race. All participants received a full description of the study objectives and protocol, and provided signed informed consent for participation at the moment of their registration for the study on an online sports diary (TIPPS - Training and Injury Prevention Platform for Sport). A total of 455 participants created their account on the website during the recruitment phase. They were asked to familiarize themselves with this online tool in December 2011 while the data collection period lasted throughout the following 5 months. This sample size was estimated sufficient to answer our main hypothesis considering the following assumptions: given a desired power of 0.8 and an $\alpha$-level of 0.05 , to detect a significant difference for injury incidence between participants using more than one pair of shoes and those using only one, based on expected injury rate of $37 \%$ over the 5 -month follow-up period (van Gent et al., 2007) and a hazard ratio of 0.62 , the total number required is 360 runners. The background information of the participants was collected at the time of registration, while running experience (years of regular practice) and regular running practice over the last 12 months (number of months with at least one session a week) were recorded via electronic questionnaires during the follow-up. Additionally, participants were asked to upload information regarding previous injury to the lower back or lower limbs preventing them from normal running activity and sustained during the 12 months preceding the follow-up in the TIPPS. Participants also received explanations about the main study requirements: (1) to train on average at least once a week, (2) to upload training data pertaining to running and all other sports practice at least once a week, and (3) to systematically report any injury sustained during the follow-up period. The study protocol and online procedures had previously been approved by the National Ethics Committee for Research (ref.201111/10).

\section{Recording of sport participation and injury information}

The TIPPS is a specially designed internet-based electronic database, which allows for uploading, reviewing and managing of information related to training and sports injuries.(Malisoux et al., 2013; Theisen et al., 2013) All participants had access to the TIPPS on the internet via a personal username and password. The researchers had 
access to each participant's contact details and could follow information on sport participation and injuries in real time. Data were rendered anonymous during the extraction process before the statistical analyses. Throughout the follow-up, participants were instructed to upload all running or other sporting activities undertaken onto their TIPPS account. Required information included the type of activity, context, duration, subjectively perceived intensity, distance, shoe pair used, running surface (hard or soft) and whether the participant had experienced any pain during the session forcing him/her to reduce practice volume or intensity, or to interrupt the practice. Session intensity was determined using the Borg's rating of perceived exertion (RPE) scale, a purely subjective 10 point scale.(Foster, 1998) Multiple shoe users were identified as those who reported a minimum of 2 different pairs of running shoes (different brand, model or version) in the system and who alternated a minimum of 2 times between them over the observation period. Indeed, some participants had to replace their old pair of shoes and were characterised by a unique change of shoe pair.

All adverse events preventing participants from normal running activity were reported by the participants via a dedicated questionnaire on their TIPPS account. A new injury could be declared either via the sport session interface (see above) or a dedicated injury declaration page. A RRI was defined as a physical pain or complaint located at the lower limbs or lower back region, sustained during or as a result of running practice and impeding planned running activity for at least 1 day (time-loss definition).(Bovens et al., 1989; Buist et al., 2010) These RRIs were classified according to the latest consensus on sports injury surveillance studies.(Fuller et al., 2007; Fuller et al., 2006; Fuller et al., 2008) Once an injury was registered, the system considered the injury on-going, and generated an automatic email to ask participants to close their injury file by specifying the exact day of return to sport.

\section{Data quality control}

Individual e-mail reminders were sent to the participants who had not provided the system with any data for the previous week. Personal phone calls were made if the participants did not react to the e-mail reminders and if the reported information in either the training log or on the injury form was found to be inconsistent. Injury data was systematically checked by one of the investigators for completeness and coherence. Participants who did not complete their entire running calendar with weekly information were contacted by one of the investigator to ensure that a RRI was not the reason for non-compliance or dropping out. 
The study group characteristics were compared using Student $t$-tests for independent samples and Chi squared test after checking the data for normal distribution. RRI incidence was calculated as the number of RRIs per 1000 hours of exposure to running activity. The period of interest was defined as the period from the beginning of the follow-up until the first RRI (event), the end of the observation period or the moment of drop out. A participant was considered as dropping out of the study when no data was uploaded in the system for more than 2 weeks despite the automatic reminder sent by the system and a phone call from the research team. A Cox proportional hazard regression analysis was used to identify injury risk factors amongst participants' characteristics and sport participation characteristics over the period of interest. Exposure volume to running activities (hours) during the period of interest was used as the outcome variable. First, unadjusted analyses were performed, entering each variable separately into the Cox regression model. For the final adjusted model (Forward Likelihood Ratio method), all variables with a p-value below 0.250 were introduced in the model.(Buist et al., 2010) Additionally, previous regular running practice and previous injury were introduced in a first block (enter method) to control for these factors. Forward LR method was chosen because of the low number of events ( 87 RRIs) observed during the period of interest and the high number of potential predictors $(n=10)$ identified with the unadjusted model. Results are presented as mean \pm SD. Significance was accepted for $p<0.05$.

\section{Results}

Of the 455 participants who created an account in the TIPPS and registered to the study, 154 did not take part in the study as they did not upload any sporting activities during the observation period. Additionally, 37 participants recorded less than 2 running sessions in total and were excluded. Therefore, a total of 264 amateur runners were finally included in the analyses. The characteristics of the single shoe users $(n=116)$ and the multiple shoe users $(n=148)$, as well as their sport participation pattern are presented in table 6.1. As expected, multiple shoe users wore a higher number of different pair of shoes during the observation period when compared to single shoe users ( $3.6 \pm 1.6$ vs. $1.3 \pm 0.5$ pair of shoes, $p<0.001$ ). The proportion of usage of the predominant pair of shoes was lower in the multiple shoe users group $(58 \pm 19 \%$ vs. $91 \pm 17 \%, p<0.001)$. Multiple shoe users were more regular in their running training over the 12 months prior to the study $(p=0.001)$, more experienced in half-marathon $(p<0.001)$ and competitions $(p<0.001)$. Furthermore, they had a higher volume of other 
sports practice $(p=0.045)$, and a greater running training load regarding frequency $(p<0.001)$, distance $(p<0.001)$ and duration $(p<0.001)$ during the observation period (see table 6.1).

Table 6.1. Participants' characteristics and sport participation pattern $(n=264)$

\begin{tabular}{|c|c|c|c|c|}
\hline Characteristics & Unit/Qualifier & $\begin{array}{l}\text { Single Shoe } \\
\text { Users }(N=116)\end{array}$ & $\begin{array}{l}\text { Multiple Shoe } \\
\text { Users ( } N=148)\end{array}$ & p-value \\
\hline \multicolumn{5}{|l|}{ Participants' characteristics: } \\
\hline Age & Years & $40.5 \pm 9.8$ & $44.2 \pm 8.8$ & 0.002 \\
\hline \multirow[t]{2}{*}{ Sex } & Male & $80(69.0 \%)$ & 115 (77.7\%) & 0.122 \\
\hline & Female & $36(31.0 \%)$ & $33(22.3 \%)$ & \\
\hline BMI & $\mathrm{kg} \cdot \mathrm{m}^{-1}$ & $23.0 \pm 2.6$ & $22.9 \pm 2.4$ & 0.717 \\
\hline \multirow[t]{2}{*}{ a Previous Injury } & Yes & $53(45.7 \%)$ & 67 (45.3\%) & 0.608 \\
\hline & No & $52(44.8 \%)$ & 77 (52.0\%) & \\
\hline b Running experience & Years & $6.6 \pm 8.9$ & $7.3 \pm 9.8$ & 0.561 \\
\hline c Regularity (last 12 months) & Months (1-12) & $9.4 \pm 3.8$ & $10.8 \pm 3.0$ & 0.001 \\
\hline \multirow[t]{2}{*}{ d Half-Marathon (last 12 months) } & Yes & $61(52.6 \%)$ & $120(81.1 \%)$ & $<0.001$ \\
\hline & No & $38(32.8 \%)$ & $22(14.9 \%)$ & \\
\hline \multicolumn{5}{|l|}{ Sport participation pattern: } \\
\hline Mean number of shoe pairs & Unit & $1.3 \pm 0.5$ & $3.6 \pm 1.6$ & $<0.001$ \\
\hline Use of main shoe pair & $\%$ & $91 \pm 17 \%$ & $58 \pm 19 \%$ & $<0.001$ \\
\hline Volume of other sports & h. week $^{-1}$ & $1.20 \pm 1.51$ & $1.69 \pm 2.43$ & 0.045 \\
\hline Mean session frequency & sessions.week ${ }^{-1}$ & $1.94 \pm 1.06$ & $2.82 \pm 1.18$ & $<0.001$ \\
\hline Mean session distance & $\mathrm{km}$ & $9.8 \pm 3.2$ & $11.7 \pm 3.0$ & $<0.001$ \\
\hline Mean session duration & minutes & $58.6 \pm 15.9$ & $69.7 \pm 17.5$ & $<0.001$ \\
\hline Mean session intensity & Borg CR10 scale - a.u. & $3.82 \pm 1.02$ & $4.04 \pm 0.93$ & 0.072 \\
\hline Mean running speed & $\mathrm{km} \cdot \mathrm{h}^{-1}$ & $10.1 \pm 1.5$ & $10.2 \pm 1.4$ & 0.477 \\
\hline Running on hard surface & $\%$ of total sessions & $56.8 \pm 34.6$ & $61.1 \pm 28.8$ & 0.282 \\
\hline Competitions & $\%$ of total volume & $4.9 \pm 8.5$ & $9.8 \pm 11.4$ & $<0.001$ \\
\hline
\end{tabular}

${ }^{a} 15$ missing data; ${ }^{b} 17$ missing data; ${ }^{c} 16$ missing data; ${ }^{d} 23$ missing data; a.u., arbitrary unit.

Of the 264 participants included in the analyses, 87 (33\%) experienced at least one RRI during the 5-month follow-up period. The overall incidence was $7.64 \mathrm{RRI} / 1000$ hours of running during the period of interest. The latter ranged from 1 week (for a few participants who sustained a RRI during the first week of follow-up) to 22 weeks for those who were not injured and remained compliant over the whole observation period (mean: 15.5 \pm 7.4 weeks). Table 6.2 presents the characteristics of the first RRI reported by the participants. More than $2 / 3$ of these RRIs affected muscles and tendons $(67.8 \%)$ and $2 / 3$ of all RRIs were progressive in nature, while about $36.8 \%$ of 
all RRIs required more than 1 week before a full recovery and return to a normal training program.

Table 6.2. Characteristics of reported running-related injuries $(n=87)$.

\begin{tabular}{|c|c|c|}
\hline & $\begin{array}{l}\text { RRI } \\
\text { n (\%) }\end{array}$ & $\begin{array}{l}\text { Incidence } \\
\text { RRI/1000h }\end{array}$ \\
\hline \multicolumn{3}{|l|}{ Injury location } \\
\hline Lower back region / Pelvis & $9(10.3)$ & 0.79 \\
\hline Hip/groin & $6(6.9)$ & 0.53 \\
\hline Thigh & $16(18.4)$ & 1.41 \\
\hline Knee & $17(19.5)$ & 1.49 \\
\hline Lower leg & $17(19.5)$ & 1.49 \\
\hline Ankle & $14(16.1)$ & 1.23 \\
\hline Foot & $7(8.0)$ & 0.61 \\
\hline Toe & $1(1.1)$ & 0.09 \\
\hline \multicolumn{3}{|l|}{ Injury type } \\
\hline Muscle and tendon & $59(67.8)$ & 5.18 \\
\hline Capsules and ligaments & $20(23.0)$ & 1.76 \\
\hline Contusion & $3(3.4)$ & 0.26 \\
\hline Other injury / Unknown & $5(5.7)$ & 0.44 \\
\hline \multicolumn{3}{|l|}{ Injury severity } \\
\hline Slight (0-3 days) & $38(43.7)$ & 3.34 \\
\hline Minor (4-7 days) & $17(19.5)$ & 1.49 \\
\hline Moderate (8-28 days) & $18(20.7)$ & 1.58 \\
\hline Major (>28 days) & $14(16.1)$ & 1.23 \\
\hline \multicolumn{3}{|l|}{ Recurrence } \\
\hline Yes & $31(35.6)$ & 2.72 \\
\hline \multicolumn{3}{|l|}{ Injury category } \\
\hline Contact acute & $2(2.3)$ & 0.35 \\
\hline Non-contact acute & $29(33.3)$ & 2.46 \\
\hline Progressive & $56(64.4)$ & 4.83 \\
\hline
\end{tabular}

Among the participants' baseline characteristics, previous injury, regularity of running practice over the past 12 months and participation in a half-marathon over the last 12 months were independently associated with RRI (Table 6.3). Additionally, some aspects related to sport participation measured during the follow-up were or tended to be associated with RRI occurrence: mean session distance, mean session duration, mean session intensity, mean session frequency, proportion of competition, average volume of other sports practiced and, in line with our expectation, multiple shoe use. The adjusted Cox proportional hazard regression analysis revealed that parallel use of more than one pair of shoes is a protective factor $(p=0.036)$. Among personal characteristics, previous injury $(p=0.014)$ was a significant risk factor, but none of the variables related to running experience and short-term regularity of practice were 
significantly identified as protective factors. Nevertheless, sport participation pattern had an impact on RRI occurrence, since mean session distance was a significant protective factor $(p<0.001)$, as well as weekly volume of other sports $(p=0.028)$.

Table 6.3. Unadjusted and adjusted Cox regression models for variables tested ( $n=241 / 264$ ).

\begin{tabular}{|c|c|c|c|c|c|}
\hline \multirow{2}{*}{ Indicator } & \multirow{2}{*}{ Unit/Qualifier } & \multicolumn{2}{|c|}{ Unadjusted model } & \multicolumn{2}{|c|}{ Adjusted model } \\
\hline & & HR & p-value & HR & $95 \% \mathrm{Cl}$ \\
\hline \multicolumn{6}{|l|}{ Participants' characteristics: } \\
\hline Age & Years & 0.991 & 0.428 & & \\
\hline Sex & Male is ref. & 0.842 & 0.510 & & \\
\hline BMI & $1 \mathrm{~kg} \cdot \mathrm{m}^{-1}$ increase & 1.034 & 0.441 & & \\
\hline a Previous injury & No (prev. inj.) is ref. & 1.528 & $0.050^{e f}$ & 1.722 & $1.114-2.661$ \\
\hline b Running Experience & Years & 0.998 & 0.860 & & \\
\hline c Regularity (past year) & Months (1-12) & 0.945 & $0.049^{\text {ef }}$ & - & - \\
\hline d Half-Marathon (past year) & No is ref. & 0.436 & $0.001^{\mathrm{e}}$ & - & - \\
\hline \multicolumn{6}{|l|}{ Sport participation pattern: } \\
\hline Multiple shoe use & Ref is "No" & 0.446 & $<0.001^{\mathrm{e}}$ & 0.614 & $0.389-0.969$ \\
\hline Volume of other sports & h. week ${ }^{-1}$ & 0.869 & $0.046^{\mathrm{e}}$ & 0.848 & $0.732-0.982$ \\
\hline Mean session frequency & sessions.week ${ }^{-1}$ & 0.707 & $0.002^{\mathrm{e}}$ & - & - \\
\hline Mean session distance & $\mathrm{km}$ & 0.805 & $<0.001^{\mathrm{e}}$ & 0.795 & $0.725-0.872$ \\
\hline Mean session duration & minutes & 0.963 & $<0.001^{\mathrm{e}}$ & - & - \\
\hline Mean session intensity & Borg CR10 scale - a.u. & 0.873 & $0.248^{\mathrm{e}}$ & - & - \\
\hline Mean running speed & $\mathrm{km} \cdot \mathrm{h}^{-1}$ & 0.947 & 0.481 & & \\
\hline Running on hard surface & $\%$ of total sessions & 0.997 & 0.482 & & \\
\hline Competitions & $\%$ of total volume & 0.973 & $0.038^{e}$ & - & - \\
\hline
\end{tabular}

\section{Discussion}

To the authors' knowledge, this prospective follow-up is the first investigation on the relationship between concomitant use of different running shoes and RRI risk. As hypothesized, runners reporting the use of different pairs of running shoes during the observation period had a $39 \%$ lower risk of RRI compared to runners using only one pair of shoes. Since multiple shoe users wore their predominant pair of shoes for no more than $58 \%$ of their running sessions on average, it could be argued that the relationship between a multiple shoe use strategy and the lower injury risk arises from the alternation in the forces applied to the body. Running is a repetitive movement that subjects the musculoskeletal system to two different types of forces: external impact forces and active forces. External impact forces are influenced by a number of 
variables including the material properties of the damping elements such as soft tissue, shoes, and the surface of contact.(Hreljac, 2004) On the other hand, active forces are mainly determined by the movement of the runner during foot contact. Although RRIs are generally thought to be connected to impact forces, there is evidence suggesting that active forces also play a significant role in some overuse injuries.(Messier et al., 1991) A number of studies have shown that running shoe characteristics influence external impact forces and kinematics of runners. Firstly, plantar pressure measures in runners using new and old running shoes showed that newer shoes have higher peak pressures than older shoes, suggesting a higher risk of injury to the foot and ankle when running shoes are used for shorter periods.(Rethnam \& Makwana, 2011) Thus, the authors recommended breaking into new running shoes slowly, using them for mild physical activity. Conversely, a biomechanical study comparing the effect of shoe cushioning on kinetics and kinematics of new and worn shoes concluded that worn shoes resulted in an increased stance time and kinematic adaptations by the runner as shoe cushioning decreased. (Kong et al., 2009) Thus, runners adapt their patterns to maintain constant external loads when shoe cushioning capacity declines. Another study showed that shoe midsole hardness influences lower extremity kinematics during running.(Nigg et al., 2012) Results from a study measuring lower extremity muscle activity while running with two different pairs of shoes characterised by different material hardness of the insole showed that the intensity of EMG and muscle fibre type recruitment significantly differed between the two pairs.(Wakeling et al., 2002) This suggests that muscle activity, fibre type recruitment and active forces can be altered with different shoe materials. Taken together, the aforementioned studies suggest that the concomitant use of different pairs of running shoes will provide alternation in the running pattern and vary external and active forces on the lower legs during running activity. Whether the reduced RRI risk can be ascribed to alternation of different shoe characteristics, such as midsole densities, structures or geometries cannot be determined from these results and warrants future research.

The concomitant participation in other sporting activities next to running training was also found to be protective against $R R I(H R=0.85)$. It has been previously speculated that runners who spend more time in others sports decrease their risk of overuse injuries, since they use different muscle groups. (Jacobs \& Berson, 1986) In youth sport, it has been shown that athletes who engage in a variety of sports have fewer injuries and play sports longer than those who specialize before puberty.(Brenner, 2007) Our results suggest that similar principles may also apply to recreational adult runners. Multiple shoe use and participation in other sporting activities are strategies leading to a variation of external and internal loads applied to the musculoskeletal system that could have a beneficial effect on RRIs. Although speculative, it could be that any 
training paradigm which limits excess repetitions will decrease the risk of RRI, especially overuse injuries which typically result from highly repetitive activities.

Previous injury was a significant predictor for $\mathrm{RRI}(\mathrm{HR}=1.72)$, as already reported by others. (Bredeweg et al., 2010; Macera et al., 1989; Marti et al., 1988; van Mechelen, 1992) Previous injury is one of the most frequently identified risk factor. This means that people who expect to start or to resume a running training program after having been injured are at a higher risk and should be a target for preventive measures. Additionally, a greater mean session distance was found here to be a protective factor $(H R=0.80)$. This observation is in line with a previous study showing that longdistance/marathon runners were characterized by a lower injury incidence than middle-distance runners.(Lysholm \& Wiklander, 1987) It could be argued that individuals running longer distances exercise at a lower mean intensity. Since training speed was significantly associated with an increased risk of running injuries (Jacobs \& Berson, 1986), recreational runners aiming to practice longer distances could be exposed to a lower injury risk because of a lower intensity and/or running speed. Many studies focused on weekly running distance and found it to be a significant risk factor, even when controlling for volume of exposure.(van Gent et al., 2007; van Mechelen, 1992) On the other hand, a significant relationship between running frequency and running injury was put forward in some studies.(Jacobs \& Berson, 1986; Macera et al., 1989; Walter et al., 1989) Since weekly running distance and running frequency are closely related, it could be speculated that the increased RRI risk associated with weekly running distance is a consequence of an increase of running frequency rather than mean session distance. This needs to be confirmed by future studies. Other participants' characteristics and sport participation characteristics were not associated with the risk of sustaining a RRI in the adjusted Cox regression model (see table 6.3).

Previous studies have reported incidences between 2.5 and 38 RRIs/1000h of running.(Nielsen et al., 2012) The overall RRI incidence found in the present study $(7.64 / 1000 \mathrm{~h})$ is in line with those reported in the literature, and lies in the lower third of the range. This could be explained by the characteristics of our study participants. Indeed, most of the runners followed here were experienced (mean: 7.0 \pm 9.4 years) and had practiced running regularly over the preceding 12 months (mean: 10.2 \pm 3.4 months of regular running), such characteristics being usually associated with lower injury incidence.(Macera, 1992; Macera et al., 1989; Marti et al., 1988; van Mechelen, 1992)

The main limitation of this study is the duration of the observation period ( 22 weeks). The end of the study was announced at the date of a regional Marathon race, with the 
event being used as a vector of communication for the recruitment, and that we anticipated having a lot of drop outs and rest period in the week following the race. This rather short observation period limited the number of expected injuries for a given number of participants. Additionally, some of the participants $(n=56)$ dropped out of the study for other reasons than sustaining a RRI before the end of the observation period. One of the investigators systematically contacted these participants to ensure that no RRI was overlooked (see methods). Even if they were maintained in the survival analysis, the total volume of exposure was affected by their shortened period of interest. As a consequence, considering the injury incidence, the number of events $(n=87)$ and the injury rate $(33 \%)$ recorded during the study were lower than the values expected and considered for the sample size calculation (133 events, $37 \%$ ). Therefore, the present results should be confirmed by a study of a larger scale, a longer duration or by a randomized control trial.

\section{Perspective}

Running is one of the most popular leisure sports activities. However, annual runningrelated injury (RRI) incidence has recently been reported between $19 \%$ and $79 \%$.(van Gent et al., 2007) The identification of specific risk factors has received growing interest since running continues to increase in popularity. Few epidemiological studies have focused on the impact of running shoes on injury incidence.(Theisen et al., 2013) While some studies have shown the influence of shoe characteristics on running pattern, (Bonacci et al., 2013; Kong et al., 2009; Lieberman et al., 2010; Rethnam \& Makwana, 2011; Wakeling et al., 2002) the causal relationship between running pattern and RRI has not been established. This prospective cohort study showed that runners using concomitantly more than one pair of shoes had a lower risk of RRI. A possible explanation would be that the alternation of running shoes induces a variation in the type of physical load applied to the musculoskeletal system. Furthermore, a decreased risk was observed in runners who practice concomitantly other sports. These results open the door to a large field of research on training scheduling and variation of contents with the aim to decrease the occurrence of preventable RRIs. Furthermore, a large number of questions still remain unanswered concerning running shoe use and injury prevention.

\section{Acknowledgments}

The present study was financially supported by a grant from the National Research Fund awarded to Laurent Malisoux (AFR ref.1189878). 


\section{References}

Bonacci, J., Saunders, P. U., Hicks, A., Rantalainen, T., Vicenzino, B. G., \& Spratford, W. (2013). Running in a minimalist and lightweight shoe is not the same as running barefoot: a biomechanical study. $\mathrm{Br} J$ Sports Med, 47(6), 387-392.

Bovens, A. M., Janssen, G. M., Vermeer, H. G., Hoeberigs, J. H., Janssen, M. P., \& Verstappen, F. T. (1989). Occurrence of running injuries in adults following a supervised training program. Int J Sports Med, 10 Suppl 3, S186-190.

Bredeweg, S. W., Zijlstra, S., \& Buist, I. (2010). The GRONORUN 2 study: effectiveness of a preconditioning program on preventing running related injuries in novice runners. The design of a randomized controlled trial. BMC Musculoskelet Disord, 11, 196.

Brenner, J. S. (2007). Overuse injuries, overtraining, and burnout in child and adolescent athletes. Pediatrics, 119(6), 1242-1245.

Buist, I., Bredeweg, S. W., Bessem, B., van Mechelen, W., Lemmink, K. A., \& Diercks, R. L. (2010). Incidence and risk factors of running-related injuries during preparation for a 4-mile recreational running event. Br J Sports Med, 44(8), 598-604.

Ferber, R., Hreljac, A., \& Kendall, K. D. (2009). Suspected Mechanisms in the Cause of Overuse Running Injuries: A Clinical Review. Sports Health: A Multidisciplinary Approach, 1(3), 242-246.

Foster, C. (1998). Monitoring training in athletes with reference to overtraining syndrome. Med Sci Sports Exerc, 30(7), 1164-1168.

Fuller, C. W., Bahr, R., Dick, R. W., \& Meeuwisse, W. H. (2007). A framework for recording recurrences, reinjuries, and exacerbations in injury surveillance. Clin J Sport Med, 17(3), 197-200.

Fuller, C. W., Ekstrand, J., Junge, A., Andersen, T. E., Bahr, R., Dvorak, J., . . . Meeuwisse, W. H. (2006). Consensus statement on injury definitions and data collection procedures in studies of football (soccer) injuries. Br J Sports Med, 40(3), 193-201.

Fuller, C. W., Laborde, F., Leather, R. J., \& Molloy, M. G. (2008). International Rugby Board Rugby World Cup 2007 injury surveillance study. Br J Sports Med, 42(6), 452-459.

Giandolini, M., Horvais, N., Farges, Y., Samozino, P., \& Morin, J. B. (2013). Impact reduction through longterm intervention in recreational runners: midfoot strike pattern versus low-drop/low-heel height footwear. Eur J Appl Physiol, 113(8), 2077-2090.

Hreljac, A. (2004). Impact and overuse injuries in runners. Med Sci Sports Exerc, 36(5), 845-849.

Jacobs, S. J., \& Berson, B. L. (1986). Injuries to runners: a study of entrants to a 10,000 meter race. Am J Sports Med, 14(2), 151-155.

Kong, P. W., Candelaria, N. G., \& Smith, D. R. (2009). Running in new and worn shoes: a comparison of three types of cushioning footwear. Br J Sports Med, 43(10), 745-749.

Lieberman, D. E., Venkadesan, M., Werbel, W. A., Daoud, A. I., D'Andrea, S., Davis, I. S., . . . Pitsiladis, Y. (2010). Foot strike patterns and collision forces in habitually barefoot versus shod runners. Nature, $463,531-536$.

Lysholm, J., \& Wiklander, J. (1987). Injuries in runners. Am J Sports Med, 15(2), 168-171.

Macera, C. A. (1992). Lower extremity injuries in runners. Advances in prediction. Sports Med, 13(1), 50-57.

Macera, C. A., Pate, R. R., Powell, K. E., Jackson, K. L., Kendrick, J. S., \& Craven, T. E. (1989). Predicting lowerextremity injuries among habitual runners. Arch Intern Med, 149(11), 2565-2568.

Malisoux, L., Frisch, A., Urhausen, A., Seil, R., \& Theisen, D. (2013). Monitoring of sport participation and injury risk in young athletes. J Sci Med Sport, doi:10.1016/j.jsams.2013.1001.1008.

Marti, B., Vader, J. P., Minder, C. E., \& Abelin, T. (1988). On the epidemiology of running injuries. The 1984 Bern Grand-Prix study. Am J Sports Med, 16(3), 285-294.

Messier, S. P., Davis, S. E., Curl, W. W., Lowery, R. B., \& Pack, R. J. (1991). Etiologic factors associated with patellofemoral pain in runners. Med Sci Sports Exerc, 23(9), 1008-1015.

Nielsen, R. O., Buist, I., Sorensen, H., Lind, M., \& Rasmussen, S. (2012). Training errors and running related injuries: a systematic review. Int J Sports Phys Ther, $7(1), 58-75$.

Nigg, B. M., Baltich, J., Maurer, C., \& Federolf, P. (2012). Shoe midsole hardness, sex and age effects on lower extremity kinematics during running. J Biomech, 45(9), 1692-1697.

Perl, D. P., Daoud, A. I., \& Lieberman, D. E. (2012). Effects of footwear and strike type on running economy. Med Sci Sports Exerc, 44(7), 1335-1343. 
Rethnam, U., \& Makwana, N. (2011). Are old running shoes detrimental to your feet? A pedobarographic study. BMC Res Notes, 4, 307.

Satterthwaite, P., Norton, R., Larmer, P., \& Robinson, E. (1999). Risk factors for injuries and other health problems sustained in a marathon. Br J Sports Med, 33(1), 22-26.

Theisen, D., Malisoux, L., Genin, J., Delattre, N., Seil, R., \& Urhausen, A. (2013). Influence of midsole hardness of standard cushioned shoes on running-related injury risk: a double-blind randomised controlled trial. Br J Sports Med, doi:10.1136/bjsports-2013-092613.

van Gent, R. N., Siem, D., van Middelkoop, M., van Os, A. G., Bierma-Zeinstra, S. M., \& Koes, B. W. (2007). Incidence and determinants of lower extremity running injuries in long distance runners: a systematic review. Br J Sports Med, 41(8), 469-480; discussion 480.

van Mechelen, W. (1992). Running injuries. A review of the epidemiological literature. Sports Med, 14(5), 320-335.

Wakeling, J. M., Pascual, S. A., \& Nigg, B. M. (2002). Altering muscle activity in the lower extremities by running with different shoes. Med Sci Sports Exerc, 34(9), 1529-1532.

Walter, S. D., Hart, L. E., McIntosh, J. M., \& Sutton, J. R. (1989). The Ontario cohort study of running-related injuries. Arch Intern Med, 149(11), 2561-2564.

Wiegerinck, J. I., Boyd, J., Yoder, J. C., Abbey, A. N., Nunley, J. A., \& Queen, R. M. (2009). Differences in plantar loading between training shoes and racing flats at a self-selected running speed. Gait Posture, 29(3), 514-519. 
Chapter 7

General discussion 
For decades, RRIs have been a growing concern to coaches, clinicians, researchers and runners themselves, and the existing research on identifying risk factors and providing evidence-based preventative measures does not provide any conclusive findings. Results on risk factor identification have rarely been reproduced, largely due to differences in study population and RRI definition, poor sample sizes, varying methodology and measurement protocols, and a lack in large-scale prospective cohort studies of sufficient follow-up length. This thesis addresses these methodological issues by introducing a new measurement tool, the Runalyser, and a series of studies designed to work towards improved understanding of the link between biomechanical factors and RRI. The retrospective study (chapter 4 ) and the prospective study (chapter 6) both include comparatively large sample sizes ( $n=90$ and $n=264$, respectively). Inclusion criteria were also very strict to ensure homogeneity of the study populations, and to limit the amount of confounding. As a result, recruiting enough runners who fulfilled these criteria was not an easy task. We also ensured a strict standardisation of protocols to ensure that all participants were subjected to the same conditions. The aims of this thesis were 1 ) to establish the reliability of a newly-developed pressuresensitive insole device, the Runalyser, 2) to apply the Runalyser in research settings to observe associations of running style and previous RRI, 3) to observe the effect of running speed, shoe type and fatigue on running style using the Runalyser, and finally 4) to determine the association between using concomitantly different running shoes and RRI incidence by way of a large-scale, prospective cohort study. In the introduction, seven hypotheses were put forward, each of which will now be addressed with reference to the findings of the studies presented.

\section{Hypothesis testing}

\section{We hypothesised that the Runalyser would be a valid and reliable tool when measuring strike index and spatiotemporal parameters (chapter 2).}

The parameters tested were those relating to the location of the centre of pressure. This is because parameters relating to magnitudes of pressure were found not to be reliable due to the composition of the insoles, as highlighted in chapter 3 . After creating an algorithm to accurately detect the moment and location of foot contact on the insole, the Runalyser was capable of distinguishing between RFS, MFS, and FFS runners (chapter 2$)$. We found a good correlation $\left(R^{2}=0.89\right)$ between the SI measured with the Runalyser and the footstrike angle using 3D motion analysis. Footstrike pattern has been suggested by many to be an important factor in RRI research (Kulmala et al., 2013; Shih et al., 2013) as well as in running economy research 
(Ogueta-Alday et al., 2014). We put forward the SI as a continuous measure for the analysis of running strike pattern, as opposed to arbitrarily subdividing into the three classifications as previously suggested (Cavanagh \& Lafortune, 1980). A continuous scale is easier to interpret when providing real-time feedback, when aiming to gradually change the footstrike pattern for example. Gait retraining has previously been successfully carried out, but has been limited to treadmill running in a laboratory (Crowell \& Davis, 2011; Diebal et al., 2012). Should gait retraining prove a viable option for injury prevention or pain reduction, providing runners with a tool to facilitate this in their natural running environment could be a solution to understanding how to treat and prevent RRIs outside of the laboratory. Further, $\mathrm{T}_{\text {contact, }}, \mathrm{T}_{\text {flight, }}, \mathrm{T}_{\text {stride }}$ and DF also depend on the identification of a foot contact event as well as a toe-off event. Similarly, receiving instant feedback on these temporal parameters is also useful, as we have shown that there are differences in these parameters between footstrike patterns (chapter 2). Indeed, providing live feedback on temporal parameters could be additional, useful information when coaching runners to reduce their $T_{\text {contact }}$ and $S_{\text {length }}$ (characteristic of a FFS) for example. However, the efficiency of providing such feedback in training and clinical settings remains to be demonstrated.

\section{We hypothesised that the Runalyser would be able to provide an estimate of vertical loading rate, based on a comparison of data acquired using an instrumented treadmill (chapter 3).}

In chapter 3, we pushed the Runalyser to its limits by testing the correlation of VLR outputs of the Runalyser (a.u./ms) with that of an instrumented treadmill (N/ms) during habitual, FFS and RFS running. The results of this study are conclusive, in that the Runalyser, at its current stage of development, is not able to estimate VLR accurately during running. The reliance of capacitance-based sensors on a foam layering between conductive surfaces means that the hysteresis effect creates a time lag, which varies according to the state of the foam. An alternative to capacitancebased sensors is resistive-based, which do not need a viscoelastic material (Rosenbaum \& Becker, 1997), meaning the time lag is reduced. The attention magnitudes and rates of loading have received in RRI research, and the evidence put forward that VLR is associated with stress fractures (Zadpoor \& Nikooyan, 2011) would suggest that advancements in insole technology to incorporate such measures is warranted. Indeed, several researchers have demonstrated successful estimation of ground reaction forces with insoles (Barnett et al., 2000; Dixon, 2008; Fong et al., 2008; Forner Cordero et al., 2004), yet data on the VLR measured by insoles has not yet been reported. 
We hypothesised a decrease in strike index and contact time and stride time, and an increase in flight time, stride length and frequency with increasing running speed based on previous observations (chapter 4).

The hypothesis that SI would decrease with increasing running speed stems from the underlying mechanism runners use to increase their running speed. This is achieved by either increasing the $S_{\text {length, }}$ the $S_{\text {frequency }}$ or both. Increasing the $S_{\text {length }}$ signifies a footground contact which is further in front of the centre of mass. Extending the knee, yet maintaining the same amount of ankle flexion would encourage a more pronounced heelstrike in RFS runners. With this theory in mind, a preliminary study on the effect of running speed on SI and spatiotemporal parameters using the Runalyser on 38 participants was conducted. Besides a slight reduction in $\mathrm{SI}$ at $3 \mathrm{~m} / \mathrm{s}$, SI did not significantly change with increasing running speed [22.7-22.6\%; $b=2.079, \mathrm{SE}=0.544$, $95 \% \mathrm{Cl}=1.245,3.471, \mathrm{p}=0.904$ ] (figure 7.1). However, this preliminary study required participants to run at absolute running speeds. It is for this reason that we determined the preferred running speed of each individual in chapter 4, allowing for a comparison of relative running speeds, and ensuring that the conditions are similar from a typical training perspective. Increases in relative running speed did indeed induce an overall significant decrease in $\mathrm{SI}$, confirming our hypothesis. A possible explanation for this difference in SI behaviour between absolute and relative running speed increase could relate to the varying intensities between participants. Absolute speeds requires that all participants run at the same speeds, but some may find these speeds comfortable, whereas others may be not be used to the predefined speeds. This problem was overcome in chapter 4 by using the preferred running speed for all runner as a reference. Further, the average maximum speed run by the participants in chapter 4 was $3.5 \mathrm{~m} / \mathrm{s}$, therefore slower than in the preliminary study. Another study observed a significant increase in SI with running speeds ranging from 3.2 to $6.2 \mathrm{~m} / \mathrm{s}$ (Breine et al., 2014). These speeds are overall much higher than the ones in our studies on recreational runners. An increase in SI found by Breine et al. (2014) could be explained by a portion of their runners switching to a sprinting gait at such high speeds. Sprinting has been characterised as a FFS pattern (Novacheck, 1998) which would incur a higher SI. The relative training speeds in chapter 4 were too slow to provoke a sprinting gait, yet a significant increase in $\mathrm{S}_{\text {length }}$ was found. 


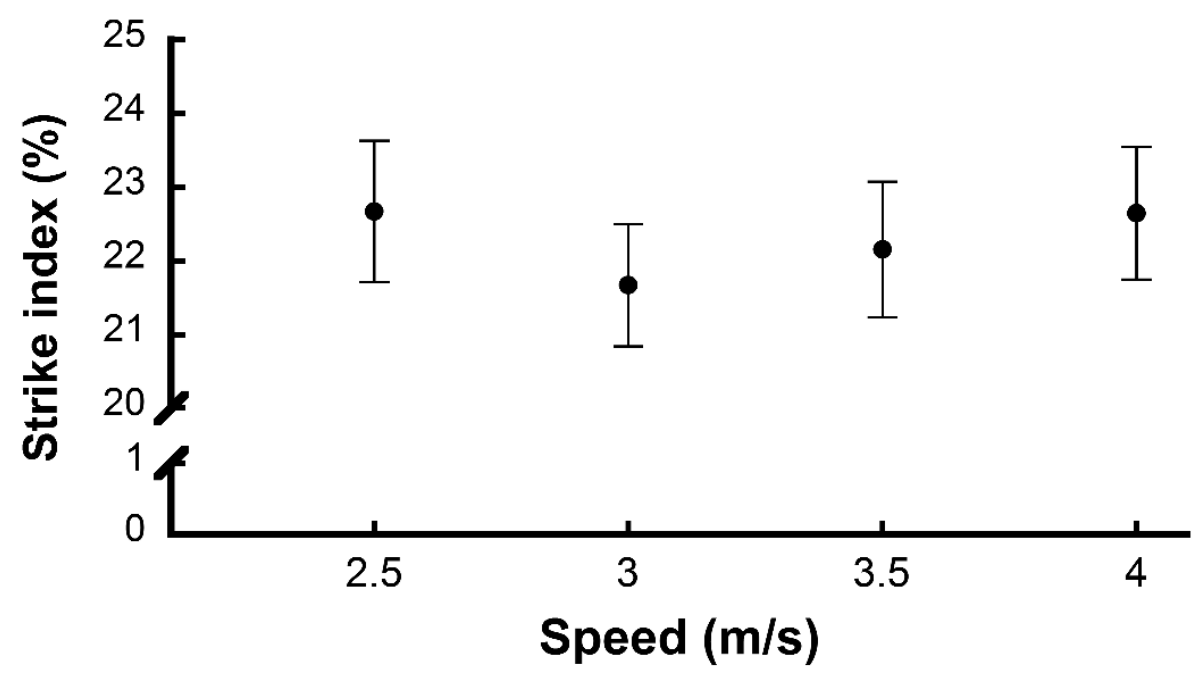

Figure 7.1. Preliminary data on adaptations in SI with increasing running speed. Data points represent the mean of 38 participants, and the error bars represent the standard error.

With regards to spatiotemporal parameters, the results of 90 runners presented in chapter 4 confirm those previously found (Padulo et al., 2012) and in our preliminary study (figure 7.2). Our preliminary data revealed an increase in running speed to significantly increase $S_{\text {length }}, S_{\text {frequency }}$ and reduce $T_{\text {flight }}$. We confirmed these results in chapter 4 , with the exception of $\mathrm{T}_{\text {flight }}$ which actually increased. Increasing $\mathrm{S}_{\text {length }}$ can lead to overstriding, which has been associated with higher breaking forces and has been suggested as a possible risk factor of injury (Lohman et al., 2011).

The hypothesis that $S_{\text {length }}$ increased with increasing running speed was confirmed. Although a significant increase in $\mathrm{S}_{\text {frequency }}$ was also observed, the percentage increase was much smaller. The notion of overstriding has been touched upon (Lieberman, 2012; Lohman et al., 2011; Shih et al., 2013) but no concrete definition has been coined. Future prospective studies should focus on quantifying overstriding, and study its relationship with RRI, taking into account the mechanism of increasing running speed as presented above. Although we did not measure lower limb accelerations, the significant decrease of all temporal parameters would suggest that lower limb accelerations increased as $S_{\text {length }}$ increased. 
A

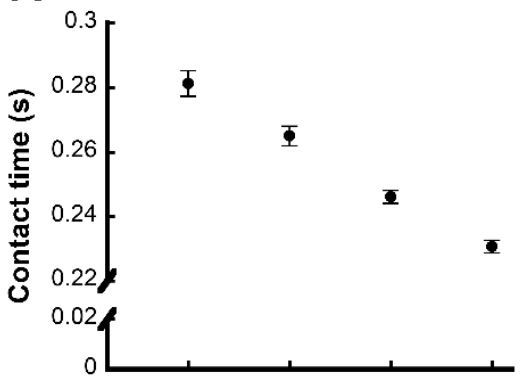

C

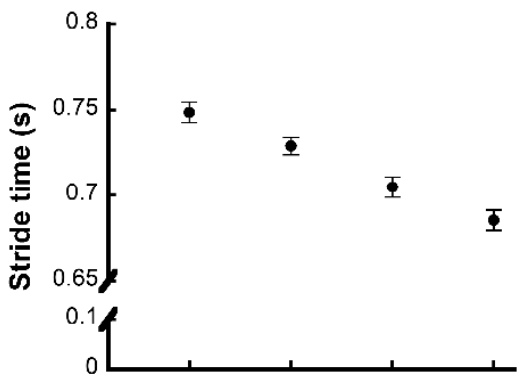

E

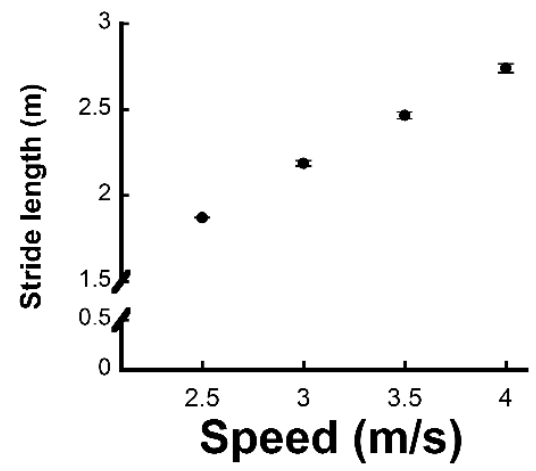

B

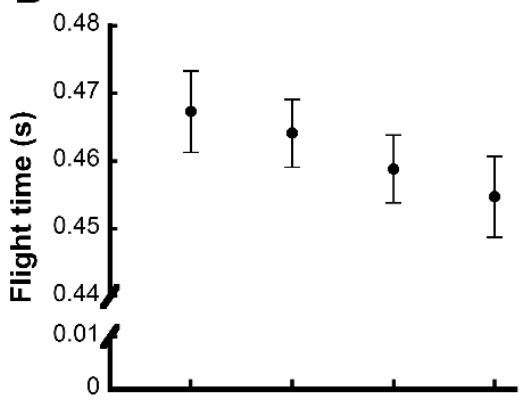

D

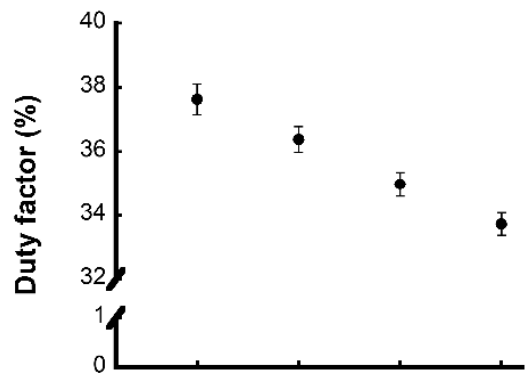

$\mathbf{F}$

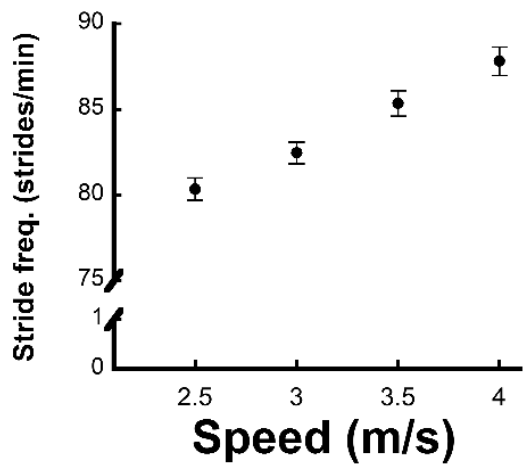

Figure 7.2. Preliminary data on changes in spatiotemporal parameters with increased running speed. Data points represent the mean of 38 participants, and the error bars represent the standard error.

We hypothesised that strike index and spatiotemporal parameters will be different between previously injured and non-injured runners (chapter 4).

This hypothesis was not confirmed. Indeed very little difference was observed in all parameters measured between previously injured and non-injured runners (chapter 4). Previous study on the running strike pattern has revealed FFS runners to display lower 
patellofemoral contact forces, patellofemoral stress and frontal plane moment compared to RFS runners (Kulmala et al., 2013). Another study reported greater contractual force of the plantar flexors and greater peak ankle joint forces in FFS runners, concluding an elevated injury risk of these structures for runners wishing to transition from a RFS to a FFS (Rooney \& Derrick, 2013). Similarly, Almonroeder et al. (2013) found an 11\% increase in Achilles tendon impulse in FFS runners, also suggesting caution when adopting such a running style (Almonroeder et al., 2013). RRI was not the main outcome in any of these studies, meaning any conclusions are highly speculative. Our study (chapter 4) attempted to identify associations of spatiotemporal parameters and previous RRI. The fact that we did not find any could be explained by the retrospective design of the study on the one hand, and the global definition of RRI included on the other. Previously injured runners may have adapted their running style since their injury, to adopt a less injurious running style. As mentioned above, different running styles solicit different anatomical structures, meaning that different types of overuse RRIs are possible, depending on the running style. To investigate the relationship between $\mathrm{SI}$ and spatiotemporal parameters with RRI further, large-scale studies with sufficient RRI events to allow for robust statistical analyses and even stratification by RRI type should be conducted. They should be of prospective design with sufficient follow-up duration to enable a large number of RRI events.

\section{We hypothesised that first-time use of minimalistic running shoes will increase the strike index and decrease the stride length (chapter 5).}

We found that overall, runners did not change their running style when using minimalistic footwear for the first time (chapter 5). Similarly, a previous study reported no differences in $\mathrm{S}_{\text {length, }}$ step rate and foot inclination at footstrike (Willy \& Davis, 2014). However, the minimalistic shoes in our study provided considerably less cushioning, and was expected to result in a more barefoot-like running style i.e. a non-RFS as was found in another study comparing first-time barefoot running with shod running (Cheung \& Rainbow, 2014). Possibly the sensation of having some form of protection, no matter how thin between the foot and the running surface may still have enabled runners to continue using their familiar RFS pattern without too much discomfort. It is unclear whether effects of long-term minimalistic shoe use without instruction would be visible. Additionally, the natural dampening mechanism of the treadmill may also have contributed to the majority of runners maintaining a RFS with minimalistic running shoes. Although treadmill running allows for analysis of multiple steps in the laboratory, future study on the effect of minimalistic shoes on running style should aim to be conducted in the natural running environment. Additionally, the participants in this study received no instruction on how to run using minimalistic running shoes. They 
simply adopted the running style which came naturally to them. Contrarily, a study specifically aiming to reduce impacts and VLR with instructed barefoot running (using real-time feedback on force parameters) $92 \%$ of the runners adopting a RFS before the intervention, and only $2 \%$ during the intervention (Samaan et al., 2014). Educating runners on different footstrike patterns, providing them with more options to adapt to different running conditions could be an effective way of 1) ensuring a safer transitioning period when changing running style and 2) provide more general variability in their habitual running strike pattern.

\section{We hypothesised greater variability and more randomness in the running pattern of non-injured runners (chapter 4), when using a minimalistic running shoe for the first time, and after a prolonged running bout (chapter 5).}

The recurring theme of variability in running has been present throughout this thesis. Stride-to-stride variability (CV) and correlative patterns (DFA) were calculated in chapters 4 and 5 . Indeed, a significantly more random SI was observed in the noninjured group of the retrospective cohort study presented (chapter 4). This suggests an association between having a more random strike pattern and not having had a RRI during the previous 12 months. Only one other study looked at differences in correlative patterns of $\mathrm{T}_{\text {stride }}$ between previously injured and non-injured runners, and found an association between a more random $\mathrm{T}_{\text {stride }}$ and having had a RRI, although they did not specify the time period during which these injuries had occurred (Meardon et al., 2011). In any case, to be able to determine a causal relationship between running style variability and correlative patters, and RRI, prospective analysis of these relationships should be undertaken. The study presented in chapter 4 has confirmed an association in need of further study.

Running in minimalistic shoes for the first time was expected to induce more randomness in the running style than in conventional running shoes, as the latter is what our study population was most used to using (chapter 5 ). The opposite was found in our study, and we hypothesise that this could relate to the conventional running shoe providing overall more cushioning, allowing for variation in strike pattern without providing any discomfort. An unfamiliar minimalistic shoe with hardly any cushioning may have encouraged runners to select one particular strike pattern providing the most comfort, and not deviating from this strike pattern during the protocol. In most cases, this strike pattern remained a RFS, and creating awareness of other running styles, perhaps more suited to long-term, minimalistic running, may induce more randomness. Indeed, when relating minimalistic running with RRI, symptoms have been found to develop within a month (Salzler et al., 2012). We and others have 
shown, that without instruction, a natural adaptation in strike pattern with minimalistic shoe use does not occur in the short term in most cases.

Due to neuromuscular processes becoming less efficient with prolonged running, we expected runners to display more variability and less correlation in their stride-tostride strike pattern after a prolonged running session. This has received little attention in the literature. Miller et al. (2008) compared variability of kinematic variables in illiotibial band syndrome runners and controls during a fatiguing protocol designed to last no longer than 20 minutes (Miller et al., 2008). Based on 10 seconds of data at the start, middle and end of the run, they found less variability in thigh ad/abduction and foot in/eversion in injured runners, yet did not report on overall effects of fatigue on variability. We found no effect of prolonged running on variability or correlative patterns of SI. We specifically aimed to recreate typical training conditions for our participants, and we therefore conclude that our cohort was capable of maintaining neuromuscular control of their strike pattern on a treadmill.

\section{We hypothesised a lower running-related injury incidence among runners alternating between multiple pairs of running shoes during a 22 week follow-up period (chapter} 6).

It has often been stated throughout this thesis, that prospective study is necessary to better understand the relationship between specific contributing, biomechanical risk factors and RRI. The results of a prospective study presented in chapter 6 showed that using multiple pairs of running shoes concomitantly presented a reduced risk of RRI compared to runners who used one single pair of running shoes. We speculated that continuous variation in structural loading due to different sensory feedback from different shoes was the reason for this. Similarly, a review by Tonoli et al. (2010) found that cross-country runners displayed the lowest RRI incidences compared with marathon, competitive, recreational and novice runners (Tonoli, 2010). Regular running on uneven terrain could mean that these runners are more adept to altering their strike pattern with each step according to the conditions. These runners therefore constantly adapt their foot placement strategy, soliciting muscles differently and never exposing one particular structure to repeated overload. Other studies have shown that differences in ground reaction forces, temporal parameters and plantar loading can be induced by different types of footwear (Logan et al., 2010; McCallion et al., 2014; Wiegerinck et al., 2009; Willson et al., 2014), further supporting the theory that alternating between shoes has a protective effect on sustaining RRIs. Finally, we also found regular practice of other sports to be associated with a reduced RRI risk (chapter 6). Much in the same way that shoes change the mechanics of running, 
performing different movement patterns altogether will load anatomical structures differently. This again, induces the variability of structural loading on yet another level.

\section{Limitations}

It is important to note that the Runalyser used in the presented studies was at the prototype stage of development. Although we confirmed its reliability and validity when measuring $\mathrm{SI}$ and spatiotemporal parameters, the material was subject to degradation due to continuous use during the 4-year thesis period. This meant that insoles were replaced when the output signal displayed artefacts. However, the Runalyser is not the only insole-based measurement device subject to sensor malfunction (Woodburn \& Helliwell, 1996). Indeed, this appears to have been a common problem in research using pressure insoles, and more robust solutions are warranted. Insoles are identical in surface area and sensor placement (for each of the three available sizes). Therefore, SI and spatiotemporal parameters could be reliably measured throughout this period. The limited number of insole sizes available could have caused ill-fitting within the running shoes. The current author was present for all data acquisitions and personally inserted the insoles into the running shoes on all occasions. The largest possible insole was chosen on all occasions to ensure the entire plantar area of the shoe was covered, without bending of the sensors. Further, prolonged running causes the temperature in the shoe to rise, a factor which has been reported to affect measurement output (Razak et al., 2012). However, in all the experiments presented in this thesis, the Runalyser insole was never in the shoe for longer than 20 minutes at sub-maximal running intensity. Further improvement of the Runalyser is in progress, with the aim of reducing its current limitations and providing more shoe sizes. In particular the addition of a sensor at the $2^{\text {nd }}$ to $5^{\text {th }}$ phalanges would improve the accuracy of the Runalyser further (as mentioned in the limitations of chapter 2).

We must acknowledge studies which have shown differences in running mechanics between treadmill and overground running (Cronin \& Finni, 2013; Fellin et al., 2010; Hong et al., 2012; Kluitenberg et al., 2012; Kong et al., 2012; Riley et al., 2008). The experiments in this thesis were all conducted using a treadmill, as the Runalyser was not at a stage of development allowing for outdoor acquisition. Reduced maximum plantar pressure and force have been found between running on concrete and on a treadmill (Hong et al., 2012), as well as reduced peak propulsive anterior and peak medial ground reaction forces on a treadmill compared to a laboratory runway (Riley et al., 2008). No differences in temporal parameters have been reported (Cronin \& Finni, 2013; Kluitenberg et al., 2012). One study even reported no differences in 
vertical ground reaction forces between the two running conditions (Kluitenberg et al., 2012), concluding the treadmill to have the added benefit of multiple step acquisition in a laboratory setting. One study found that runners perceive themselves to be running faster than they actually are on a treadmill compared to overground running (Kong et al., 2012). They hypothesised that this was due to the "absence of backward optic flow" as a result of running on the spot on a treadmill. Despite this, when we determined the preferred running speed on a treadmill (chapter 4 ) in 90 runners, we found no difference between this determined speed and their self-reported, preferred running speed during habitual training. In all, using the treadmill for our studies was necessary to be able to acquire sufficient consecutive steps, yet it is suspected that the natural dampening may have influenced the running style in first-time minimalistic shoe use (chapter 5).

The study presented in chapter 6 did not include the Runalyser. The conclusion that simultaneous use of multiple pairs of running shoes induces adaptations in musculoskeletal loading, thus generally reducing the repetitive stress to anatomical structures remains speculative. Providing a runner with a Runalyser to be used for all his/her running sessions and keeping track of which shoes are used for which session would greatly aid in testing this hypothesis. Currently, such a study design is not possible, as the Runalyser has not yet reached a development stage allowing for multiple systems to be produced and distributed. With the help of the work carried out and the findings presented in this thesis, such developments are foreseen for the near future.

\section{Future Perspectives}

We are not at a stage where we can confidently answer the question: "Why does one runner sustain a RRI, while another runner with a similar profile does not?" (Hreljac, 2005). As has been stipulated on numerous occasions throughout this thesis, RRIs are multifactorial, and that although the underlying mechanism is simply a misbalance between stress and recovery of susceptible anatomical structures, a multitude of contributing factors must be taken into account. It is therefore necessary to measure training characteristics, biomechanical parameters, as well as anthropometry and environmental aspects of each individual runner and their running activities. Widespread screening for biomechanical factors has not been done until now (Hreljac, 2005), as large-scale investment and resources are required. Current methods and protocols incorporating biomechanical measurements are time-consuming and complex, and require specialist know-how. Longitudinal, epidemiological studies dependent on self-report by the participants have reported between 28 and $47 \%$ 
dropout rates (Buist et al., 2010; Hein et al., 2014). However, with fast-pace development of social media applications and activity monitors, researchers should now be looking to exploit these technologies, and incorporate them into large-scale prospective cohort studies, with continuous measurement of running biomechanics, as well as parameters already considered in epidemiological studies. With such systems automatically uploading data to online databases, the limitations of self-report and recall bias previously reported (Chorley et al., 2002) can be circumvented. Additionally, the Runalyser could be used as a large-scale RRI profile screening tool. Anonymous uploading of training and biomechanical variables onto online platforms along with information on RRI incidence could provide the running community with a source of much needed knowledge on RRI preventative methods. It has been pointed out that educating the runner to identify warning signs of RRI and be able to react to them is paramount (Hreljac, 2005). A device capable of accurately measuring training and biomechanical characteristics, providing this information as real-time feedback and comparing it to norms found among large numbers of injury-free runners would seem an elegant strategy to reduce the risk of RRI development. Indeed, more serious runners training for a race, or novice runners with little experience and not attuned to "listening to the language of their body" (Taunton et al., 2003) are at an increased risk of surpassing the injury threshold as outlined in the introduction. It could be hypothesised that while cardiovascular improvements due to running activity occur within a short space of time with adequate training, the musculoskeletal system however, requires much longer to adapt to the ensuing increase in training loads. It is not uncommon that these runners do "too much, too soon" (Bredeweg, Kluitenberg, et al., 2012; Bredeweg, Zijlstra, et al., 2012). Such runners would undoubtedly benefit from a tool capable of identifying the training boundaries based on specific demographic and biomechanical characteristics of the individual. The ultimate aim is to ensure that runners can achieve their maximum training potential while keeping stresses applied to the musculoskeletal system as a result of this running practice at a healthy and sustainable level.

A more immediate issue regarding the Runalyser which has not been addressed in this thesis, is its ability to measure the centre of pressure trajectory. Indeed, large differences in centre of pressure trajectory have been observed between RFS and FFS running patterns (Breine et al., 2014; Kernozek et al., 2014), which are also observed in the Runalyser output. Additionally, previous research has shown promise in using the initial contact point on the foot in the mediolateral direction as an estimate of foot function (De Cock et al., 2008). This method has featured in various prospective studies reporting significant associations between the position of the initial contact point in the mediolateral direction and a more laterally oriented centre of pressure with RRI (Ghani Zadeh Hesar et al., 2009; Thijs et al., 2007; Van Ginckel et al., 2009; Willems et 
al., 2006). However, as a pressure platform was used in these studies, limited numbers of steps were recorded and participants had to run barefoot. A validation study of the next generation Runalyser to test whether centre of pressure trajectory correlates with rearfoot in/eversion angle would provide further research value to the device. This would add an indication of pronation and pronation rate to the list of parameters measureable using the Runalyser. Pronation, along with VLR were highlighted as potential risk factors of RRI in the introduction.

\section{Conclusion}

Repetitive stress is the fundamental reason for the development of RRIs, it is therefore of paramount importance to measure the biomechanics throughout habitual running activity to gain insight into the contributing biomechanical mechanisms of RRI. Further developing biomechanical measurement tools such as the Runalyser to facilitate widespread distribution to and analysis of recreational runners in situations where RRIs most naturally occur should be the current focus. Essentially, with all the laboratorybased testing which has been performed until now, research has provided many hypotheses on potential biomechanical risk factors, and how variability at various levels could influence RRI risk. This thesis highlights the importance of measuring multiple, consecutive steps, to gain insight on variability and correlative patterns of running style parameters, which we showed to be associated with RRI. We must now look to test these associations and hypotheses by bringing the research out into the field. Continuous measure of biomechanical variables will provide much needed information on not only which variables are related to RRI, but perhaps even more importantly, how changes in these variables relate to the development of RRI symptoms over time. A number of hypotheses to be tested in this manner have been put forward. Such research designs will ensure that running for health improvement, performance or pleasure can remain an enjoyable, and become a less injurious physical activity. 


\section{References}

Almonroeder, T., Willson, J. D., \& Kernozek, T. W. (2013). The effect of foot strike pattern on achilles tendon load during running. Ann Biomed Eng, 41(8), 1758-1766.

Barnett, S., Cunningham, J. L., \& West, S. (2000). A comparison of vertical force and temporal parameters produced by an in-shoe pressure measuring system and a force platform. Clin Biomech (Bristol, Avon), 15(10), 781-785.

Bredeweg, S. W., Kluitenberg, B., Bessem, B., \& Buist, I. (2012). Differences in kinetic variables between injured and noninjured novice runners: A prospective cohort study. J Sci Med Sport

Bredeweg, S. W., Zijlstra, S., Bessem, B., \& Buist, I. (2012). The effectiveness of a preconditioning programme on preventing running-related injuries in novice runners: a randomised controlled trial. $\mathrm{Br} J$ Sports Med

Breine, B., Malcolm, P., Frederick, E. C., \& De Clercq, D. (2014). Relationship between running speed and initial foot contact patterns. Med Sci Sports Exerc, 46(8), 1595-1603.

Buist, I., Bredeweg, S. W., Bessem, B., van Mechelen, W., Lemmink, K. A., \& Diercks, R. L. (2010). Incidence and risk factors of running-related injuries during preparation for a 4-mile recreational running event. Br J Sports Med, 44(8), 598-604.

Cavanagh, P. R., \& Lafortune, M. A. (1980). Ground reaction forces in distance running. J Biomech, 13(5), 397-406.

Cheung, R. T., \& Rainbow, M. J. (2014). Landing pattern and vertical loading rates during first attempt of barefoot running in habitual shod runners. Hum Mov Sci, 34, 120-127.

Chorley, J. N., Cianca, J. C., Divine, J. G., \& Hew, T. D. (2002). Baseline injury risk factors for runners starting a marathon training program. Clin J Sport Med, 12(1), 18-23.

Cronin, N. J., \& Finni, T. (2013). Treadmill versus overground and barefoot versus shod comparisons of triceps surae fascicle behaviour in human walking and running. Gait Posture, 38(3), 528-533.

Crowell, H. P., \& Davis, I. S. (2011). Gait retraining to reduce lower extremity loading in runners. Clin Biomech (Bristol, Avon), 26(1), 78-83.

De Cock, A., Vanrenterghem, J., Willems, T., Witvrouw, E., \& De Clercq, D. (2008). The trajectory of the centre of pressure during barefoot running as a potential measure for foot function. Gait Posture, 27(4), 669-675.

Diebal, A. R., Gregory, R., Alitz, C., \& Gerber, J. P. (2012). Forefoot running improves pain and disability associated with chronic exertional compartment syndrome. Am J Sports Med, 40(5), 1060-1067.

Dixon, S. J. (2008). Use of pressure insoles to compare in-shoe loading for modern running shoes. Ergonomics, 51(10), 1503-1514.

Fellin, R. E., Rose, W. C., Royer, T. D., \& Davis, I. S. (2010). Comparison of methods for kinematic identification of footstrike and toe-off during overground and treadmill running. J Sci Med Sport, 13(6), 646-650.

Fong, D. T., Chan, Y. Y., Hong, Y., Yung, P. S., Fung, K. Y., \& Chan, K. M. (2008). Estimating the complete ground reaction forces with pressure insoles in walking. J Biomech, 41(11), 2597-2601.

Forner Cordero, A., Koopman, H. J. F. M., \& van der Helm, F. C. T. (2004). Use of pressure insoles to calculate the complete ground reaction forces. Journal of Biomechanics, 37(9), 1427-1432.

Ghani Zadeh Hesar, N., Van Ginckel, A., Cools, A., Peersman, W., Roosen, P., De Clercq, D., \& Witvrouw, E. (2009). A prospective study on gait-related intrinsic risk factors for lower leg overuse injuries. $\mathrm{Br} J$ Sports Med, 43(13), 1057-1061.

Hein, T., Janssen, P., Wagner-Fritz, U., Haupt, G., \& Grau, S. (2014). Prospective analysis of intrinsic and extrinsic risk factors on the development of Achilles tendon pain in runners. Scand J Med Sci Sports, 24(3), e201-e212.

Hong, Y., Wang, L., Li, J. X., \& Zhou, J. H. (2012). Comparison of plantar loads during treadmill and overground running. J Sci Med Sport, 15(6), 554-560.

Hreljac, A. (2005). Etiology, prevention, and early intervention of overuse injuries in runners: a biomechanical perspective. Phys Med Rehabil Clin N Am, 16(3), 651-667, vi.

Kernozek, T. W., Meardon, S., \& Vannatta, C. N. (2014). In-Shoe Loading in Rearfoot and Non-Rearfoot Strikers during Running Using Minimalist Footwear. Int J Sports Med, 35(13), 1112-1117. 
Kluitenberg, B., Bredeweg, S. W., Zijlstra, S., Zijlstra, W., \& Buist, I. (2012). Comparison of vertical ground reaction forces during overground and treadmill running. A validation study. BMC Musculoskelet Disord, 13, 235.

Kong, P. W., Koh, T. M., Tan, W. C., \& Wang, Y. S. (2012). Unmatched perception of speed when running overground and on a treadmill. Gait Posture, 36(1), 46-48.

Kulmala, J. P., Avela, J., Pasanen, K., \& Parkkari, J. (2013). Forefoot strikers exhibit lower running-induced knee loading than rearfoot strikers. Med Sci Sports Exerc, 45(12), 2306-2313.

Lieberman, D. E. (2012). What we can learn about running from barefoot running: an evolutionary medical perspective. Exerc Sport Sci Rev, 40(2), 63-72.

Logan, S., Hunter, I., JT, J. T. H., Feland, J. B., \& Parcell, A. C. (2010). Ground reaction force differences between running shoes, racing flats, and distance spikes in runners. J Sports Sci Med, 9(1), 147-153.

Lohman, E. B., 3rd, Balan Sackiriyas, K. S., \& Swen, R. W. (2011). A comparison of the spatiotemporal parameters, kinematics, and biomechanics between shod, unshod, and minimally supported running as compared to walking. Phys Ther Sport, 12(4), 151-163.

McCallion, C., Donne, B., Fleming, N., \& Blanksby, B. (2014). Acute differences in foot strike and spatiotemporal variables for shod, barefoot or minimalist male runners. J Sports Sci Med, 13(2), 280286.

Meardon, S. A., Hamill, J., \& Derrick, T. R. (2011). Running injury and stride time variability over a prolonged run. Gait Posture, 33(1), 36-40.

Miller, R. H., Meardon, S. A., Derrick, T. R., \& Gillette, J. C. (2008). Continuous relative phase variability during an exhaustive run in runners with a history of iliotibial band syndrome. J Appl Biomech, 24(3), 262-270.

Novacheck, T. F. (1998). The biomechanics of running. Gait Posture, 7(1), 77-95.

Ogueta-Alday, A., Rodriguez-Marroyo, J. A., \& Garcia-Lopez, J. (2014). Rearfoot striking runners are more economical than midfoot strikers. Med Sci Sports Exerc, 46(3), 580-585.

Padulo, J., Annino, G., Migliaccio, G. M., D'Ottavio, S., \& Tihanyi, J. (2012). Kinematics of running at different slopes and speeds. J Strength Cond Res, 26(5), 1331-1339.

Razak, A. H., Zayegh, A., Begg, R. K., \& Wahab, Y. (2012). Foot plantar pressure measurement system: a review. Sensors (Basel), 12(7), 9884-9912.

Riley, P. O., Dicharry, J., Franz, J., Della Croce, U., Wilder, R. P., \& Kerrigan, D. C. (2008). A kinematics and kinetic comparison of overground and treadmill running. Med Sci Sports Exerc, 40(6), 1093-1100.

Rooney, B. D., \& Derrick, T. R. (2013). Joint contact loading in forefoot and rearfoot strike patterns during running. J Biomech, 46(13), 2201-2206.

Rosenbaum, D., \& Becker, H. P. (1997). Plantar pressure distribution measurements. Technical background and clinical applications. Foot and Ankle Surgery, 3(1), 1-14.

Salzler, M. J., Bluman, E. M., Noonan, S., Chiodo, C. P., \& de Asla, R. J. (2012). Injuries observed in minimalist runners. Foot Ankle Int, 33(4), 262-266.

Samaan, C. D., Rainbow, M. J., \& Davis, I. S. (2014). Reduction in ground reaction force variables with instructed barefoot running. Journal of Sport and Health Science, 3(2), 143-151.

Shih, Y., Lin, K. L., \& Shiang, T. Y. (2013). Is the foot striking pattern more important than barefoot or shod conditions in running? Gait Posture, 38(3), 490-494.

Taunton, J. E., Ryan, M. B., Clement, D. B., McKenzie, D. C., Lloyd-Smith, D. R., \& Zumbo, B. D. (2003). A prospective study of running injuries: the Vancouver Sun Run "In Training" clinics. Br J Sports Med, $37(3), 239-244$

Thijs, Y., Van Tiggelen, D., Roosen, P., De Clercq, D., \& Witvrouw, E. (2007). A prospective study on gaitrelated intrinsic risk factors for patellofemoral pain. Clin J Sport Med, 17(6), 437-445.

Tonoli, C., Cumps, E., Aerts, I., Verhagen, E., Meeusen, R. (2010). Incidence, Risk Factors and Prevention of Running Related Injuries in Long-distance Running: a Systematical Review. Sport \& Geneeskunde(5), 12-18.

Van Ginckel, A., Thijs, Y., Hesar, N. G., Mahieu, N., De Clercq, D., Roosen, P., \& Witvrouw, E. (2009). Intrinsic gait-related risk factors for Achilles tendinopathy in novice runners: a prospective study. Gait Posture, 29(3), 387-391.

Wiegerinck, J. I., Boyd, J., Yoder, J. C., Abbey, A. N., Nunley, J. A., \& Queen, R. M. (2009). Differences in plantar loading between training shoes and racing flats at a self-selected running speed. Gait Posture, 29(3), 514-519. 
Willems, T. M., De Clercq, D., Delbaere, K., Vanderstraeten, G., De Cock, A., \& Witvrouw, E. (2006). A prospective study of gait related risk factors for exercise-related lower leg pain. Gait Posture, 23(1), 91-98.

Willson, J. D., Bjorhus, J. S., Williams, D. S., 3rd, Butler, R. J., Porcari, J. P., \& Kernozek, T. W. (2014). Shortterm changes in running mechanics and foot strike pattern after introduction to minimalistic footwear. $P M R, 6(1), 34-43$.

Willy, R. W., \& Davis, I. S. (2014). Kinematic and kinetic comparison of running in standard and minimalist shoes. Med Sci Sports Exerc, 46(2), 318-323.

Woodburn, J., \& Helliwell, P. S. (1996). Observations on the F-Scan in-shoe pressure measuring system. Clin Biomech (Bristol, Avon), 11(5), 301-304.

Zadpoor, A. A., \& Nikooyan, A. A. (2011). The relationship between lower-extremity stress fractures and the ground reaction force: a systematic review. Clin Biomech (Bristol, Avon), 26(1), 23-28. 
Summary 
The popularity of running as a recreational activity has escalated over the last few decades, and with it the number of running-related injuries (RRIs). These injuries are most often of an overuse nature commonly affecting the back and lower limbs. Interest in biomechanical analyses and the relation between biomechanical variables and injury occurrence has grown among researchers. How biomechanics and epidemiology can be combined to better understand RRI risk factors is a new concept and introduced as part of this thesis. Most commonly used biomechanical measurement techniques to date are force platforms and 3D motion analysis systems to measure the kinetics and kinematics, respectively. Ground reaction force, vertical loading rate, rearfoot eversion, pronation and pronation velocity are examples of parameters recorded at the foot which are measured regularly in biomechanics of running research. Pressure measurement devices have also featured in biomechanical studies on running, providing data on the plantar pressure magnitudes and locations. This thesis puts forward a pressure-sensitive insole device, the Runalyser, as a research tool capable of measuring strike index (SI - the point of contact on the foot sole with the ground expressed as a percentage of total sole length) and temporal parameters.

Chapter $\mathbf{2}$ explains the methodology used and the analyses performed to validate the Runalyser against gold standards. 3D motion analysis was used to compare the SI to the foot strike angle during running using a rearfoot, midfoot and forefoot strike pattern. We found a strong, linear correlation between $\mathrm{SI}$ and foot strike angle. This enabled the classification of footstrike pattern based on the $\mathrm{SI}$, by defining $\mathrm{SI}$ at $0^{\circ}$ contact angle as a midfoot strike pattern, greater values signifying a forefoot strike and lower values a rearfoot strike. Synchronising the Runalyser data with that of an instrumented treadmill allowed for the comparison of spatiotemporal parameters obtained from both devices. Using Bland-Altman plots, we observed high agreement for contact time, flight time, stride time and duty factor, confirming the validity of the Runalyser when measuring these parameters. Additionally we found a high intra-class correlation for test-retest reliability of the Runalyser output. The Runalyser was therefore deemed a suitable research tool for the ensuing studies on running biomechanics.

As the vertical loading rate had received a lot of recent attention in the scientific literature on potential RRI risk factors, we wanted to determine whether or not the Runalyser could reliably measure this parameter. The study presented in chapter 3 compared simultaneously recorded Runalyser data with ground reaction force data acquired while subjects ran on an instrumented treadmill. Subjects ran using their habitual running style, a forefoot and a rearfoot strike running style. The vertical loading rate was calculated for the data sets of both measurement devices and a regression analysis demonstrated no particular correlation between these devices. Furthermore, we could not confirm that the Runalyser is capable of detecting the same 
changes in vertical loading rate as the instrumented treadmill when different foot strike patterns are used. This is most likely due to the positioning and activation of specific sensors. We concluded that the Runalyser is not a reliable tool to measure vertical loading rate in its current state, and that significant changes to the hardware would be necessary. The hysteresis effect of the foam layering of the insole caused a time lag in the data which most likely led to this large disparity between the two devices. The data acquired using the instrumented treadmill confirmed findings of previous studies that a forefoot strike pattern generates lower vertical loading rates than a rearfoot strike pattern.

Having established the advantages and limitations of the Runalyser compared to more traditional measurement systems, the next aim was to apply the device to research on RRI. We compared SI and spatiotemporal parameters between a group of previously injured runners $(n=44)$ and a control group $(n=46)$, as explained in chapter 4 . All runners ran at $80,90,100,110$ and $120 \%$ of their typical running speed on a treadmill. As the Runalyser is capable of continuous measurement, two minutes of data were analysed for each of the five speeds. Coefficient of variation and detrended fluctuation analysis were performed on an average of 161 strides for each speed, to measure the stride variability and inter-stride correlative patterns of all variables, respectively. Detrended fluctuation analysis calculates a value known as $\alpha$, which provides an indication of how correlated or how random the stride variables are within a time series. For SI, contact time, flight time, stride time, duty factor, stride length and stride frequency, no significant differences between groups were found. This was also the case for the stride variability of all parameters. The $\alpha$ of SI showed that runners without previous injury displayed a more random strike pattern. The $\alpha$ of all other parameters was not significantly different between groups. We also observed changes of the above-mentioned parameters as running speed changed. SI, contact time, stride time and duty factor decreased with increasing running speed, whereas flight time, stride length and stride frequency increased. Variability decreased for $\mathrm{SI}$, contact time, stride time and duty factor, while contact time, stride time, duty factor, stride length and stride frequency became more random as running speed increased. This study revealed that $\mathrm{SI}$ is reduced with increasing running speed and strike pattern is more random among previously uninjured runners.

Having tested the effect of running speed and previous injury on running style parameters, we proceeded to use the Runalyser to test the effect of other conditions on these parameters. Chapter $\mathbf{5}$ describes a study with the aim of determining the effect of shoe type and fatigue due to prolonged running on these parameters. Running in conventional shoes was compared to running in minimalistic shoes in 26 subjects before and after a prolonged running bout on a treadmill. Again, variability and correlative patterns were calculated and also compared between conditions. We 
concluded that in this population of recreational runners, under the specific test conditions of this experiment, no shoe effect or fatigue effect was present. Although a trend in more correlation between strides was observed for the conventional running shoe, a larger sample size and natural running environment are suggested to identify more distinct findings.

The final study presented in chapter 6 of this PhD thesis primarily addressed the epidemiological aspect of the project by asking the primary question: can parallel use of different running shoes decrease RRI risk? This large-scale prospective cohort study followed 264 recreational runners for 22 weeks, gathering data on all their training performed, injuries sustained and running shoes used. A third of the cohort sustained a RRI, and an adjusted Cox regression analysis showed that using more than one pair of running shoes in parallel was protective against sustaining an injury. Previous injury was found to be a risk factor, whereas increased mean session distance and increased weekly volume of other sports were associated with lower injury risk. A tool such as the Runalyser could aid in monitoring these risk factors.

Chapter 7 addresses the main findings of this thesis which relate to variation in load distribution and how this could potentially limit the risk of sustaining an overuse injury during running. As we saw in chapter 4, more random strike patterns may be protective of running injuries. Regularly rotating out running shoes and regular participation in other sporting activities could also reduce the risk of injury. These are mechanisms allowing for a regular variation in forces applied to specific structures of the lower limbs, dissipating the accumulated forces, thereby possibly reducing overload of specific structures. This thesis has put forward novel tools and analysis techniques to further our understanding of biomechanical risk factors of running injuries. We suggest the integration of such a tool as the Runalyser and analysis techniques such as detrended fluctuation analysis into large-scale prospective followup studies and randomised controlled trials, so as to begin to identify causal relationships with injury. 
Samenvatting 
De populariteit van hardlopen als een recreatieve bezigheid is de laatste decennia enorm gegroeid, en daarmee ook het aantal hardloopgerelateerde blessures (RRI's). Deze blessures komen voort uit overbelasting en betreffen meestal de rug en de onderste ledematen. $\mathrm{Er}$ is een toenemende interesse in biomechanische analyses en het verband tussen biomechanische variabelen en het ontstaan van blessures. De combinatie van biomechanica en epidemiologie om de RRI-risicofactoren beter te begrijpen, is relatief nieuw en wordt in dit proefschrift beschreven. De meest gangbare biomechanische meetinstrumenten tot op heden zijn krachtplatformen en 3Dbewegingsanalysesystemen om respectievelijk kracht en lichaamsbeweging te meten. Grondreactiekracht, vertical loading rate (snelheidsopbouw van verticale grondreactiekracht), hielstand bij landing en (snelheid van) pronatie tijdens de standfase zijn voorbeelden van aan de voet geregistreerde biomechanische parameters die relevant zijn voor de analyse van de belasting, en regelmatig in het biomechanische hardlooponderzoek bestudeerd worden. In biomechanisch onderzoek naar hardlopen worden tevens drukmeetinstrumenten gebruikt, die gegevens verschaffen over de omvang en locatie van de druk op de voetzool. In dit proefschrift wordt een drukgevoelige binnenzool, de zogenaamde 'Runalyser' geïntroduceerd, waarmee de strike index (SI - het eerste contactpunt op de voetzool met de ondergrond uitgedrukt als een percentage van de totale zoollengte) en tijd-specifieke parameters gemeten kunnen worden.

In hoofdstuk 2 worden de gebruikte methodologie uiteengezet en de uitgevoerde analyses om de Runalyser te valideren ten opzichten van de gouden standaard. Zodoende hebben wij 3D-bewegingsanalyse gebruikt om de SI te vergelijken met de helling van de voethoek ten opzichte van de grond (de zogenaamde voetinclinatiehoek) op het moment van landing tijdens het hardlopen met gebruikmaking van hak-, midvoet en voorvoetlandingspatronen. Het resultaat was een sterke, lineaire correlatie tussen SI en voet-inclinatiehoek. Dit maakte een classificatie van landingspatronen gebaseerd op de SI mogelijk, door de SI van 0 graden als midvoetlanding te beschouwen, waarbij hogere waarden een voorvoetlanding en lagere waarden een haklanding aanduiden. Door synchronisatie van de gegevens van de Runalyser met die van een loopband uitgerust met krachtplatformen kunnen de specifieke spatio-temporele parameters van beide apparaten met elkaar vergeleken worden. Er werd een grote mate van overeenstemming gevonden in contacttijd, zweeftijd en schredetijd, waaruit geconcludeerd werd dat de Runalyser een valide instrument is voor het registreren van deze parameters. Eveneens werd een hoge intra-class correlatie aangaande de test- en her-testbetrouwbaarheid van de Runalyser output vastgesteld. Zodoende veronderstelden we dat de Runalyser een geschikt onderzoeksinstrument is bij onze vervolgstudies aangaande biomechanicaonderzoek bij hardlopen. 
Recentelijk heeft de wetenschappelijke literatuur de vertical loading rate veelvuldig aangewezen als een potentiele RRI-risicofactor. Zodoende wilden wij vaststellen of de Runalyser deze parameter ook op betrouwbare wijze kon meten. In het onderzoek dat in hoofdstuk 3 wordt beschreven, worden tegelijkertijd geregistreerde Runalysergegevens vergeleken met grondreactiekrachtdata verkregen tijdens het lopen op een loopband uitgerust met krachtplatformen. De proefpersonen werd gevraagd om op het voor hen normale looppatroon te gaan hardlopen, dus met de voor hen gebruikelijke loopstijl, en eveneens met hak- of voorvoetlanding. De vertical loading rate werd berekend middels beide meetinstrumenten. Een regressieanalyse rapporteerde geen significante correlatie tussen beide instrumenten. Bovendien konden wij niet bevestigen dat de Runalyser in staat is dezelfde veranderingen in vertical loading rate te registreren als de geïnstrumenteerde loopband, in het geval van verschillende landingspatronen. Dit is hoogstwaarschijnlijk te wijten aan de plaatsing en het activeren van specifieke sensoren in de Runalyser. Onze conclusie was dat de Runalyser geen betrouwbaar instrument is om vertical loading rate in zijn huidige toestand te meten, en dat belangrijke aanpassingen aan de hardware noodzakelijk zullen zijn om te zorgen dat de validiteit van de Runalyser zal toenemen. De demping van de binnenzool zoals gebruikt in de Runalyser, veroorzaakte een tijdsvertraging in de gegevens die hoogstwaarschijnlijk het gebrek aan correlatie tussen de twee instrumenten veroorzaakte. Via gegevens verkregen bij het gebruik van de geïnstrumenteerde loopband werden de bevindingen van voorgaande onderzoeken bevestigd dat een voorvoetlanding een lagere vertical loading rate vertoont dan een haklanding.

$\mathrm{Na}$ de voordelen en beperkingen vastgesteld te hebben van de Runalyser in vergelijking met de meer traditionele meetsystemen, was het volgende doel om het apparaat op onderzoek naar RRI toe te passen. Wij vergeleken SI en spatio-temporele parameters tussen een groep hardlopers met een blessuregeschiedenis $(n=44)$ en een controlegroep zonder blessuregeschiedenis $(n=46)$, zoals uiteengezet in hoofdstuk 4. Alle hardlopers liepen op 80, 90, 100, 110 en 120\% van hun typische loopsnelheid op een loopband. Aangezien de Runalyser continu kan meten, werden twee minuten aan gegevens geanalyseerd voor ieder van de vijf snelheden. Teneinde de variabiliteit van schreden en de correlatiepatronen binnen de schrede van alle variabelen te kunnen bepalen hebben we de variabiliteitscoëfficiënt berekend en detrended fluctuation analysis uitgevoerd over een gemiddelde van 161 passen voor iedere snelheid. Deze analyse resulteert in een gegeven waarde $\alpha$, die aangeeft hoe gecorreleerd of hoe willekeurig de schrede variabelen zijn binnen een tijdserie. Voor de variabelen SI, contacttijd, zweeftijd, schredetijd, schredelengte en schredefrequentie werden geen significante verschillen tussen de groepen vastgesteld. Dit was ook het geval voor de schredevariabiliteit van alle parameters. Op basis van de detrended fluction analysis 
data voor de SI kon worden vastgesteld dat hardlopers zonder blessuregeschiedenis een meer willekeurig looppatroon vertonen. De $\alpha$ van alle andere parameters was niet significant verschillend tussen de groepen. Er was ook een significant effect van loopsnelheid op de gemeten parameters. SI, contacttijd en schredetijd namen af met een toenemende loopsnelheid, terwijl zweeftijd, schredelengte en schredefrequentie toenamen. De variabiliteit verminderde voor SI, contacttijd en schredetijd, terwijl contacttijd, schredetijd, schredelengte en schredefrequentie meer willekeurig werden bij een toenemende loopsnelheid. Deze studie toont aan dat de SI afneemt (dat het contactpunt in de richting van de hiel verplaatst) naarmate de loopsnelheid toeneemt en dat het looppatroon meer variabiliteit vertoont bij hardlopers zonder blessuregeschiedenis.

$\mathrm{Na}$ het effect van loopsnelheid en eerdere blessures getoetst te hebben op loopstijlparameters, werd de Runalyser gebruikt om het effect van andere omstandigheden op deze parameters te testen. Hoofdstuk 5 beschrijft een onderzoek dat tot doel heeft het effect van schoentype en vermoeidheid te bepalen op loopstijlparameters tijdens duurlopen. Er werd een vergelijk gemaakt tussen hardlopen op conventionele schoenen en hardlopen op minimalistische schoenen bij 26 personen vóór en na een lange hardloopsessie op de loopband. Wederom werden de variabiliteit en correlatie berekend en vergeleken tussen de genoemde omstandigheden. De conclusie was dat bij deze specifieke groep recreatieve hardlopers, en tijdens de specifieke testomstandigheden van dit experiment, schoentype noch vermoeidheid tijdens de duurloop enig effect leek te hebben. Er werd een tendens waargenomen naar een grotere correlatie tussen de schreden bij de conventionele hardloopschoen. Het lijkt derhalve zinvol om het experiment te herhalen met een grotere doelgroep en in een meer natuurlijke loopomgeving.

Het onderzoek dat gepresenteerd wordt in hoofdstuk 6 van dit proefschrift richt zich voornamelijk op het epidemiologische aspect van het project door het stellen van de primaire vraag: kan een parallel gebruik van verschillende hardloopschoenen het RRIrisico verminderen? Bij dit omvangrijke prospective cohort-onderzoek werden 264 recreatieve hardlopers 22 weken lang gevolgd, waarbij gegevens werden vergaard met betrekking tot al hun trainingstijd en vorm, alle opgelopen blessures en de gebruikte hardloopschoenen. Een derde van het cohort liep een RRI op. Een aangepaste Cox regressieanalyse toonde aan dat het gebruik van meer dan één paar hardloopschoenen bescherming bood tegen het oplopen van een blessure. Een eerder opgelopen blessure bleek een risicofactor, terwijl een toegenomen gemiddelde afstand per trainingssessie en een toegenomen omvang (weekvolume) van het beoefenen van andere sporten dan hardlopen correleren met een lager blessurerisico. Een meetsysteem zoals de Runalyser kan helpen bij het monitoren van deze risicofactoren. 
Hoofdstuk 7 richt zich op de hoofdbevindingen van dit proefschrift, die betrekking hebben op variatie in gewichtsverdeling en in hoeverre dit mogelijkerwijze het risico van het oplopen van een door overbelasting ontstane blessure bij hardlopen kan verminderen. Zoals uiteengezet in hoofdstuk 4, kunnen meer willekeurige looppatronen het risico op hardloopblessures verkleinen. Het regelmatig wisselen van hardloopschoenen en het regelmatig beoefenen van andere sportactiviteiten kunnen eveneens het risico van blessures doen afnemen. Op deze wijze kan een regelmatige afwisseling aan krachten ontstaan waardoor de specifieke structuren van de lagere ledematen minder worden belast en het risico op overbelasting kan worden beperkt. In dit proefschrift worden nieuwe instrumenten en analysetechnieken neergelegd om ons begrip van biomechanische risicofactoren bij hardloopblessures te vergroten. $\mathrm{Om}$ de eerste stappen te kunnen zetten naar het identificeren van mogelijke causale relaties tussen looppatronen en blessures stellen we voor om een combinatie van de Runalyser met analysetechnieken zoals detrended fluctuation analysis toe te passen in grootschalige randomised control trials. 

Valorisation 
This thesis validated a pressure-sensitive insole device designed to measure spatiotemporal parameters during running. A subsequent case-control study to identify associations of biomechanical risk factors with running-related injury was performed, followed by an observational study to assess running style in varying running conditions. The device used throughout the thesis was at the prototype stage of development. Strike index, centre of pressure trajectory and temporal parameters were calculated from the raw data. The outcome of these studies has enhanced our understanding of the device's potential and its limitations, highlighting areas for further development. A spinoff company to commercialise the pressure-sensitive insole device was created at the end of 2014, and is currently developing the next generation prototype, with a view to finalising a marketable product by the end of 2015. Future versions of the Runalyser should be able to measure the absolute amplitudes and impulses of pressure and force. Being able to reliably measure these parameters continuously and in the natural environment of the runner will be of great interest to researchers and clinicians alike. The work carried out in this thesis, and relating to the advances in understanding of the technological capabilities of the device, are a result of the excellent collaboration between Maastricht University, the Luxembourg Institute of Health and TNO Eindhoven.

\section{1) Social and economic relevance of research results}

This thesis put forward several new aspects of running analysis among recreational runners. The first stage of the work carried out ensured that the pressure insole used could reliably measure strike index and spatiotemporal parameters independently and no matter what type of running style the runner uses. This required extensive testing of many different running styles to develop an analysis algorithm capable of providing accurate results in all conditions. At a population level, the accurate measurement of such parameters is of great interest, especially to the recreational long distance runner. It is estimated that $50 \%$ of runners sustain an injury related to running annually, incurring huge medical and social welfare costs. Until now, no system has been developed which is capable of continuous monitoring of training parameters as well as biomechanics of running. Although the Runalyser is still at a development stage, future versions of the device will be able to gather such data in the runner's natural environment. Making this device commercially available will stimulate economic growth through creating job opportunities in research and development in various countries. Providing recreational runners, who in general are very susceptible to overuse injuries, with a means of monitoring their training and biomechanics with a view to prevent injury, could save governments vast spendings in medical treatment and social welfare costs. Additionally, preventing overuse injuries will ensure reduced 
dropout rates of people participating in regular physical activity and help to improve overall quality of life of the general population.

\section{2) Target groups who find interest in the research results}

Running as a recreational sport and physical activity has boomed during the last 40 years. It has become a sporting activity adopted by both the young and old, the active and previously inactive, the experienced and novice. This is a result of the recognition of the health benefits of regular cardiovascular training. However, increases in participation numbers also led to a parallel increase in injury numbers. Since the 1970 s, researchers have tried to identify the risk factors associated running injuries, and tried to shed some light on ways of reducing this risk. Until now, no conclusive evidence of identifiable risk factors has emerged, particularly within biomechanical analyses of running. Several reasons are behind this slow progress in running injury prevention. One is that biomechanical analyses are time consuming and require a large amount of resources to perform. Expensive force plates and motion analysis systems are the main instrument types employed until now, which need to be carefully installed, calibrated and operated by experienced and skilled lab technicians in a laboratory setting. Preparing the runner for testing can be laborious and often requires more than one tester. Once everything is prepared, there is no guarantee that the runner can perform habitual running, as the laboratory setting is different to the habitual running environment, where injuries most often occur. The constraints related to laboratory testing of biomechanical parameters have meant that studies until now have been limited to low numbers of test subjects (often not exceeding 20 subjects) and rarely incorporate a prospective follow-up. Associations of biomechanical variables with injury are often speculative therefore, and true relationships are yet to be determined. A tool which is valid and reliable, readily available, easy to use and with the capacity to record and store large quantities of data would be a huge advantage in running injury prevention research. Such a tool could be distributed among hundreds of runners and can be used in each runner's habitual running environment, providing researchers with representative data and a direct link to training and biomechanical progressions in the build-up to injury occurrence. Findings emerging from such studies would contribute to, and further our current understanding of, biomechanical risk factors of running injuries. Such information would be very useful to sports doctors and medical professionals within the field of running. A system specially developed to collate data from injured runners, identify risky behaviour or risky biomechanical patterns and provide timely warnings and training alternatives would be of great use to such physicians. This also goes for physiotherapists and coaches wishing to keep track of their patients and athletes. Indeed, both performance and health status can be 
monitored and data can be available to all parties instantly via the internet and social media applications. Finally, the leisure time and top end athletes alike can benefit greatly from such a device. Not only through their entourage making use of the device and associated applications, but through real-time feedback on their running style, pace, impact distributions and magnitudes etc., athletes can adapt their training and running pattern to maximise their performance and reduce the risk of sustaining an overuse injury.

3) Into which concrete products, services, processes, activities or commercial activities will your results be translated and shaped?

The Sports Medicine Research Laboratory of the Luxembourg Institute of Health began a collaboration with TNO Eindhoven, The Netherlands in 2011, within the framework of this $\mathrm{PhD}$ project. At the time there was already talk of taking the Runalyser prototype to the next stage of development. After three years of research on running using the Runalyser, a start-up company was founded and a next generation prototype has been under development since December 2014. The results of this thesis have contributed to the knowledge and understanding of the capabilities and requirements of a pressure insole device for the commercial market. The variables tested in the studies presented in the thesis currently feature in the next generation prototype. Further, through extensive testing of hundreds of runners over the years, we were able to compile lists of features to be improved upon, as well as suggestions for future design and materials to be employed in the production. Concretely, the marketable product will consist of a pair of pressure-sensitive insoles, a pair of microprocessors to be attached to each running shoe, a wrist watch for real-time feedback and data storage and a software application.

4) Innovative aspects of the research and Runalyser

This thesis has attempted to put forward a pressure-based device for plantar measurements as a reliable means of quantifying the foot strike pattern by way of the strike index. In addition, reliable algorithms for temporal parameter measurements as well as strike index measurement have been developed and submitted to the Benelux Office for Intellectual Property to be date-stamped as proof of creation as an i-Depot. Although this does not offer legal protection, it does guarantee proof of conception on a given date, by a given party. This is a product of the work carried out within the framework of the PhD project, and is the property of the Sports Medicine Research Laboratory of the Luxembourg Institute of Health. 
The device allowed for continuous measurement of multiple, consecutive steps during running, which is often not the case in biomechanical studies. Generally the use of force plates mounted in a laboratory-based runway limit the measurement of consecutive steps. The development of instrumented treadmills (with force measurement integrated) have facilitated this, however it is a very expensive solution. A portable pressure-sensitive insole device is a much cheaper solution, and overcomes many measurement restraints associated with treadmills and laboratory-based testing. This advantage allowed our research to apply an analysis method new to running and unique to injury prevention research. However, when it comes to overuse injuries, it is exactly this long-term observation of possible risk factors which is necessary, to observe whether changes (or lack thereof) in certain parameters can be associated with injury development. This thesis provides a comprehensive methodology to combine the use of pressure insoles and detrended fluctuation analysis to better understand the fluctuations in running style and how this may relate to injury occurrence. This analysis was originally used to assess correlative patterns of the heartbeat, has recently been applied in running analysis. It is still a new concept in running, and chapter 4 of this thesis is the second study to compare stride-to-stride correlative patterns between previously injured and uninjured runners.

5) Implementation and commercialisation planning

A spinoff company was founded in December 2014, by one of the developers of the original prototype. Since then, the project has gained momentum and is entering into the first test stage of the new prototype. This stage is heavily research-oriented, with a view to distribute multiple devices to a cohort of runners, to begin the long awaited research into biomechanics, prospective follow-up and injury monitoring. The device will again be validated (as several changes to the hardware and software have been made since the last validation study), ensuring its suitability for a scientific, medical and consumer market. By the end of 2015, sales of the device will be open to the general public, and the company will start generating revenue, and look to invest in continued improvements of the product. Such improvements will largely be due to the findings of the validation and prospective studies on injury risk factor identification. The end product is envisaged to incorporate techniques developed, and findings observed as a result of the research presented in this thesis. 

Acknowledgements 
It all started while I was doing my Masters placement at the Sports Medicine Research Laboratory of the Luxembourg Institute of Health. My placement was coming to an end, and I had to think of exciting things to do afterwards, and a talk with Dan one day all of a sudden presented the very real possibility that I could stay on in the lab as a PhD student. After submitting a research proposal to the Fond National de la Recherche (FNR) of Luxembourg and it being accepted, I began working on the project in early 2011. Indeed, without this funding I would not have been able to do a PhD, and I extend a warm thank you to the FNR for providing the financial means for this research.

Along the way, I was fortunate enough to collaborate with, and enlist the help of many excellent scientists and professionals, without whom this work would not have been possible. I would like to start by thanking my scientific supervisor, Professor Daniel Theisen, for bravely taking me on as a PhD student in his lab. Dan, I have learnt a tremendous amount of new skills and truly value everything you have taught me over the years. I can only hope future PhD students can benefit as much as I have from your knowledge and mentoring. E ganz grousse Merci fir d'Encadrement, fir d'Erfahrung an fir deng Frëndschaft. Ech wënschen dir weider vill Erfolleg am Labo, an hoffen mir kréien d'Geleeënheet fir an der Zukunft erëm eng Kéier zesummen ze schaffen.

I am also very grateful to Dr Kenneth Meijer for agreeing to be my academic supervisor and supporting me from across borders. I knew we were onto a good thing when Dan and I left your office after the very first time the two of you met, and he turns to me and says. "I feel like I've known that guy all my life." Your experience and input were a tremendous asset to the project and my development as a researcher. I thoroughly enjoyed our collaboration, and hope our paths cross in the future. Heel hartelijk bedankt voor jouw ondersteuning en waardevolle bijdrage door de jaren heen. Ik heb Jouw professionele en vriendelijke eigenschappen zeer gewaardeerd.

As the project became increasingly challenging, it was a great help to have Dr Laurent Malisoux join my supervisory team. I was lucky enough to share an office with him during the final years of the project. Laurent, I really appreciate the time you took for our discussions and the carefully calculated advice and guidance you provided. C'était un plaisir de partager un bureau avec toi, merci pour ta bonne humeur (sauf lorsque ton ordi ne fonctionnait pas) et les nombreux bons moments passés ensemble. Surtout, merci pour tes excellentes contributions scientifiques, pour ton amitié et pour le chocolat!

It's fair to say that without the foresight and resourcefulness of Dr Andy Statham, this particular PhD project would never have taken place. After hearing about the Sports Medicine Research Laboratory and its research activities he was very keen to collaborate, providing us with the Runalyser which he and his colleagues at TNO developed. Andy, you were an inspiration to me at Loughborough, and have continued 
to inspire me throughout my PhD. I am immensely grateful for your enthusiasm, your technical support, your knowledgeable contributions, and most of all, for your friendship, and I look forward to what the future holds!

A warm thank you to my official promoter, Professor Matthijs Hesselink, whose involvement became invaluable towards the final stages of my PhD period. Matthijs, heel erg bedankt voor jouw hulp met de administratie, het organiseren van mijn verdediging en jouw input bij het schrijven van mijn these.

Ich bedanke mich ganz herzlich bei Professor Axel Urhausen, der von Anfang an, an meinem Projekt beteiligt war, und bei mehreren Studien als "Principal medical doctor" mitgewirkt hat. Danke auch für die lehrreichen Diskussionen über Methodologie und klinische Bedeutung. Ebenfalls herzlichen Dank an Benno, Jackie, Pia und Edith aus der Ergometrie Abteilung in der Clinique d'Eich. Ihr wart immer sehr hilfsbereit und es hat mich sehr gefreut, meine Tests bei euch durchführen zu können.

Roman und Paul, es hat super Spaß gemacht mit euch beiden zu arbeiten, sowohl unten im Labor, als auch bei der Programmierung und dem Besprechen von Algorithmen. Ich habe sehr viel von euch gelernt, vielen Dank für die wertvolle Unterstützung. Thierry, merci pour ton aide au labo, pour ton enthousiasme et ton énergie. C'était un plaisir de travailler avec toi. Caroline, ton professionnalisme m'a toujours impressionné et inspiré. Merci pour ton soutient, pour les expériences et ton amitié. Je voudrais également remercier Hélène, Cyrille, Alexis, Anne, Amelie et Eric pour le support moral, pour leur aide avec mes tests au labo et pour une ambiance géniale au bureau! Finalement un grand merci à Joachim pour ton aide au début de ma thèse et surtout pour les explications approfondies en biomécaniques.

Dr Marc Hoppenbrouwers van TNO, heel erg bedankt voor jouw toelichtingen en technische ondersteuning. Ook Dr Nicolien Van Giffen, voor jouw tijd en professioneel advies, hartelijk dank. Dr Christian Nührenbörger, danke für den klinische Beitrag, die methodologische Besprechungen und das Zuschicken von Patienten. An och nach e ganz grousse Merci un den Jeannot an den Charlie vum Service Technique an der Eecher Klinik. Är onersetzlech Fähegkeeten an Hëllefsbereetschaft an den kriteschen Momenter hunn ech einfach genial fonnt an dir hutt mir immense vill weider gehollef. Villmools Merci!

A big "thank you" to the participants of all the studies conducted within this PhD project. Without their enthusiasm and effort I would not have had any data to present. And finally, a great deal of moral support was very welcome throughout, and I would like to thank my parents and my brother for their enduring acceptance and motivation, Dominique for challenging me, for believing in me, and for helping me through tough times, and especially Daniela for her unfaltering encouragement, her undying enthusiasm, and most importantly, for getting me through to the finish line. 

About the author 
Robert Mann was born in the Grand Duchy of Luxembourg on the 20th of June 1985. In 2003 he received his European Baccalaureate along with the Sports Prize from the European School of Luxembourg. This spurred him on to study Sport Science with Management at Loughborough University. After having successfully completed his bachelor degree, Robert worked as a personal trainer for two years, where he obtained invaluable experience in working directly with individuals to achieve their health and fitness-related goals. During this time he came to appreciate the importance of physical well-being on a population level, and decided to further his education in this area. In 2010 he obtained a Master's degree in Sport and Physical Activity Interventions from Maastricht University. His six-month placement was spent at the Sports Medicine Research Laboratory of the Luxembourg Institute of Health, where he was directly involved with an epidemiological research project on trainingrelated risk factors with regards to running injuries. A good collaboration between the Sports Medicine Research Laboratory, the department of Human Movement Sciences of Maastricht University and TNO Eindhoven resulted in an opportunity to apply for a research grant from the National Research Fund of Luxembourg, which was awarded to him in early 2011. Throughout the PhD project on biomechanical analyses of running and running-related injury risk factor identification, Robert attended and presented his work at several national and international congresses, such as the International Society of Biomechanics Congress, the European College of Sport Science Congress and the IOC World Conference on Prevention of Injury and IIIness in Sport. The research projects carried out within this PhD project have all been published in highranking, peer-reviewed journals within the field of biomechanics and sports medicine. In parallel to his research activities, Robert has continued to compete at an international level as a member of the Luxembourg National Badminton Team. Over the years he has represented Luxembourg at several international tournaments, and although it has not always been easy to combine high volumes of training with the demands required for successfully completing a $\mathrm{PhD}$, he is very content with his past achievements, and keen to set new objectives. Armed with his newly acquired research and project management skills, Robert is looking forward to a fruitful career in sport and physical activity promotion. 


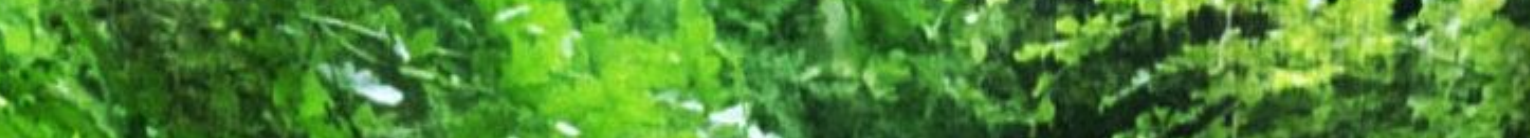

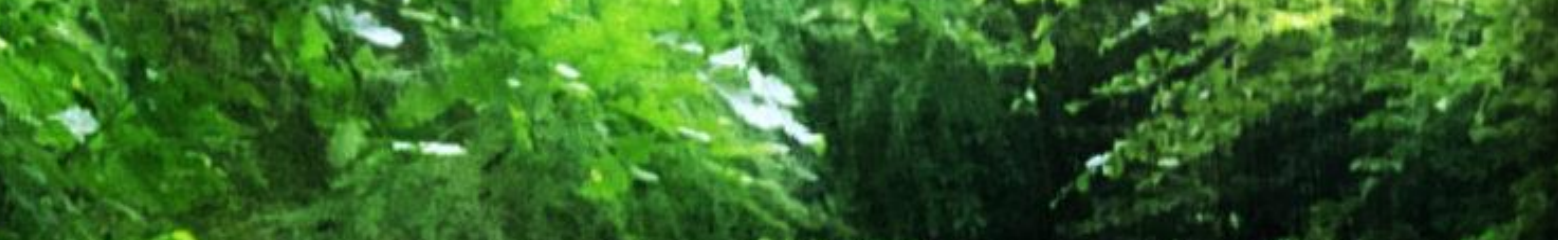

$\$ 3$

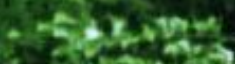

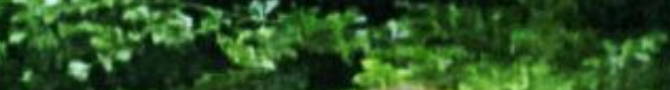

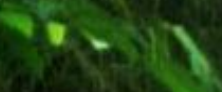

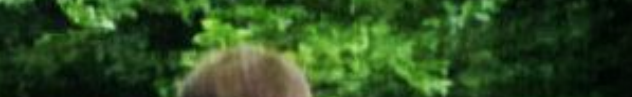

$\sin \times 1: 5$

Wh, 1,12

Cox des

Bx nom i:

Bxich 3.

(3) 51 .

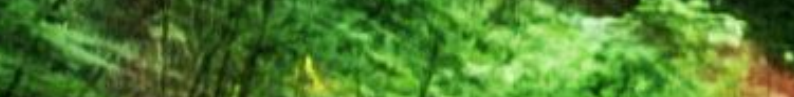

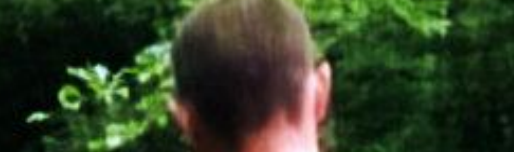

(x)

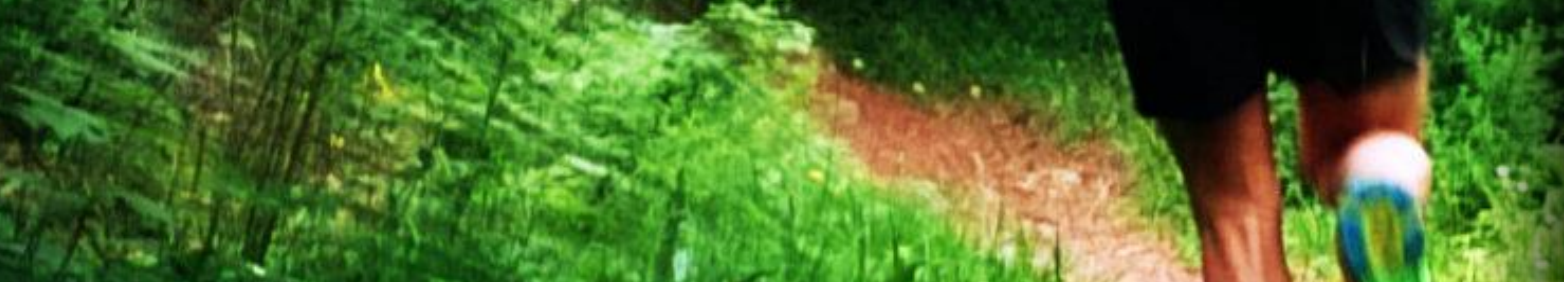

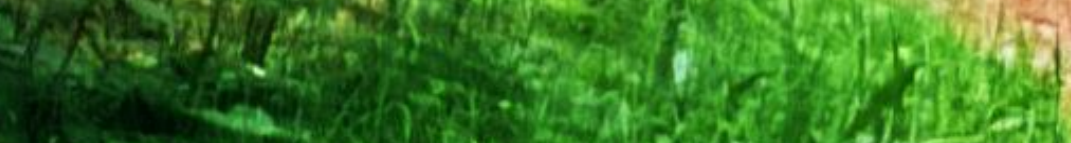

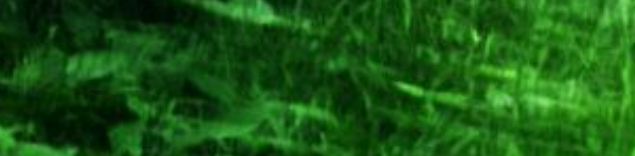
athent.

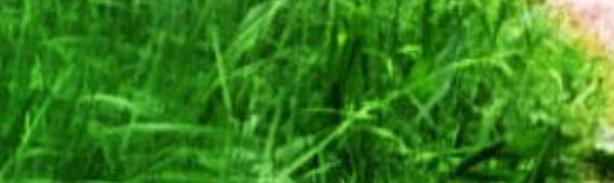

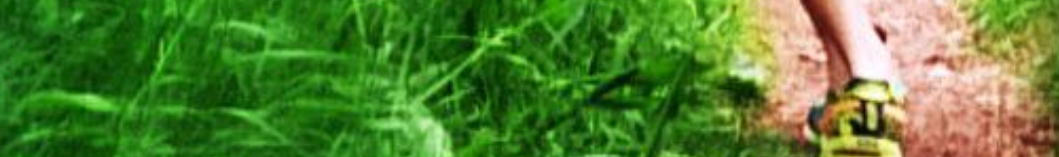

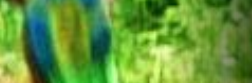

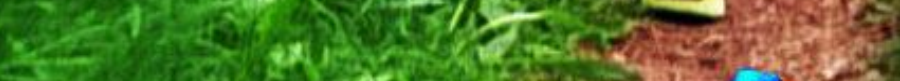
W. W. 